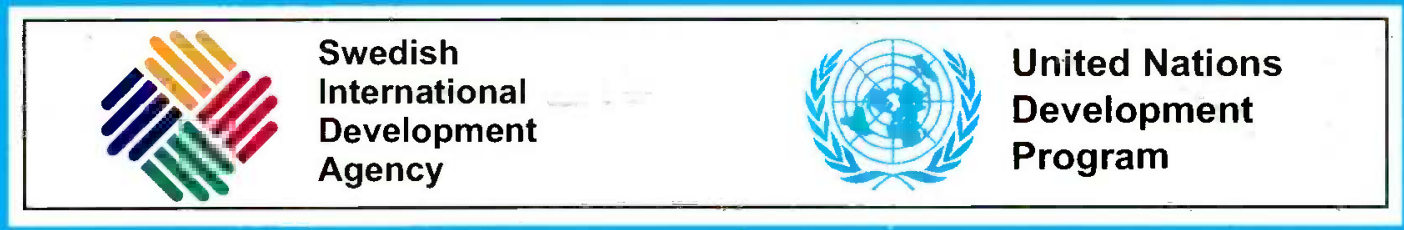

Food and Agriculture Organization of the United Nations

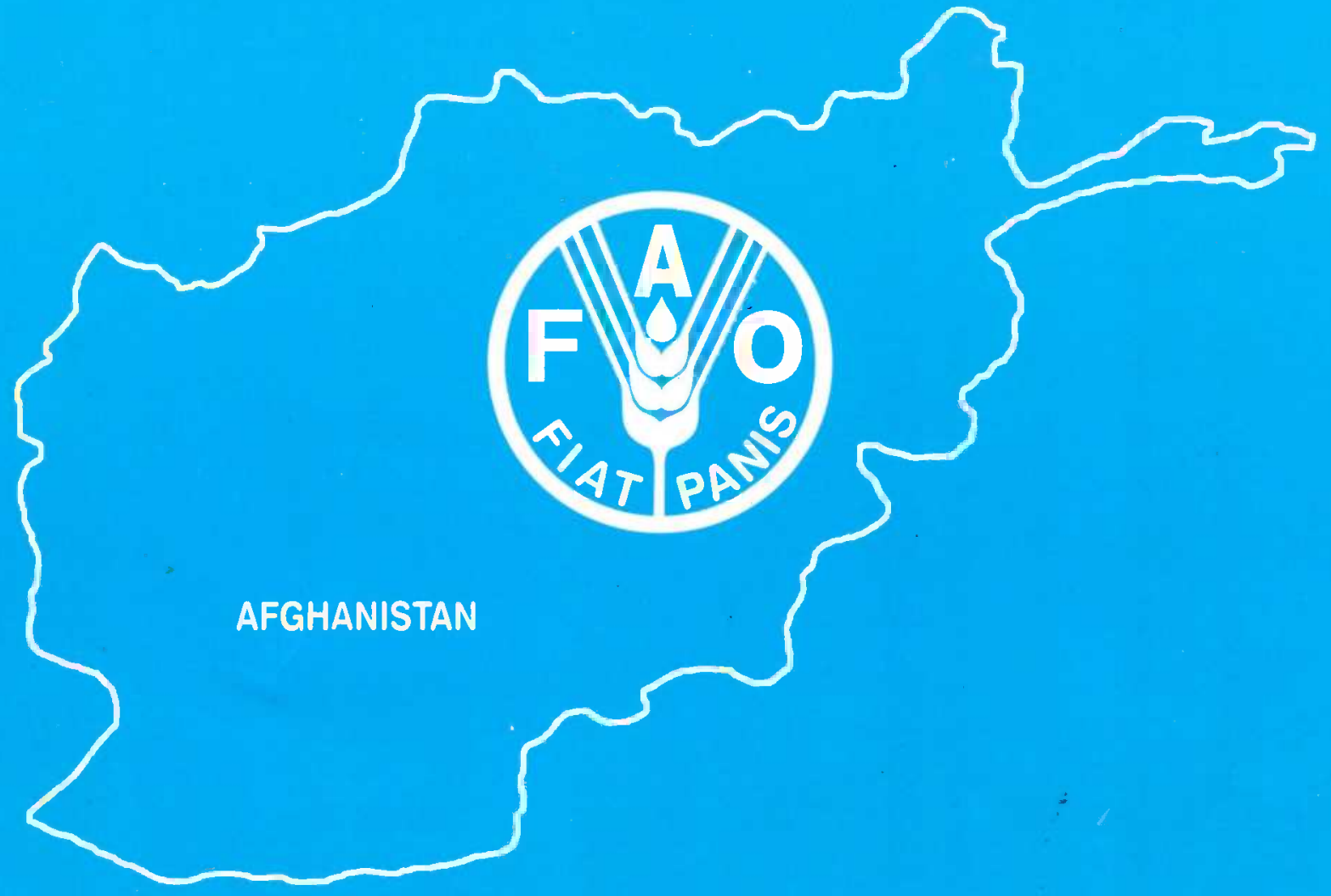

Technical Report on Cereals and Food Legumes

Crop Varieties Selection in Afghanistan

December 1999

By: Dr. N. Wassimi, STA 


\section{DISCLAIMER}

The designations in the presentation of the materials in this publication do not imply the expression of any opinion on the part of FAO or UNDP. The opinions expressed in this technical report are those of the author's alone and do not imply any opinion whatsoever on the part of FAO or UNDP 

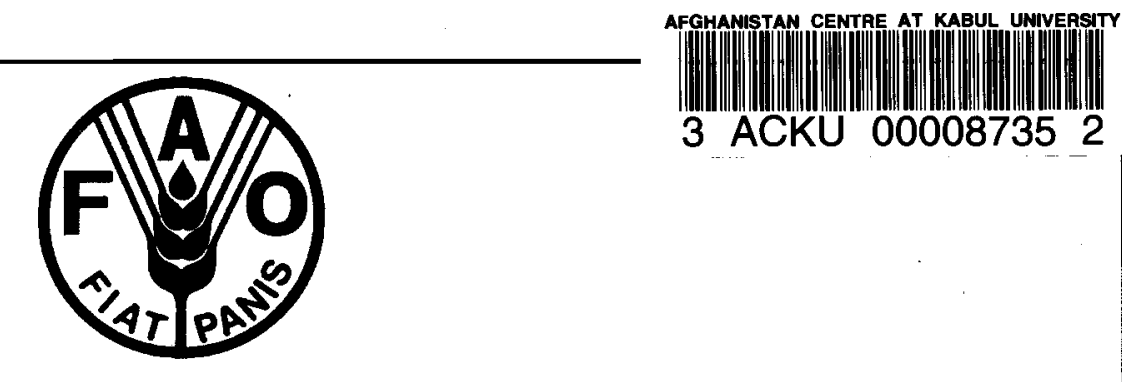

Food and Agriculture Organization of the United Nations

\title{
Second Technical Report on Cereals and Food Legumes Varietal Selection in Afghanistan 1998-1999.
}

\section{By}

\author{
N. Wassimi, Ph. D
}

Senior Technical Adviser (Crop Improvement)

AFG/94/A02 (UNO/AFG/001/DPS)

December 1999 


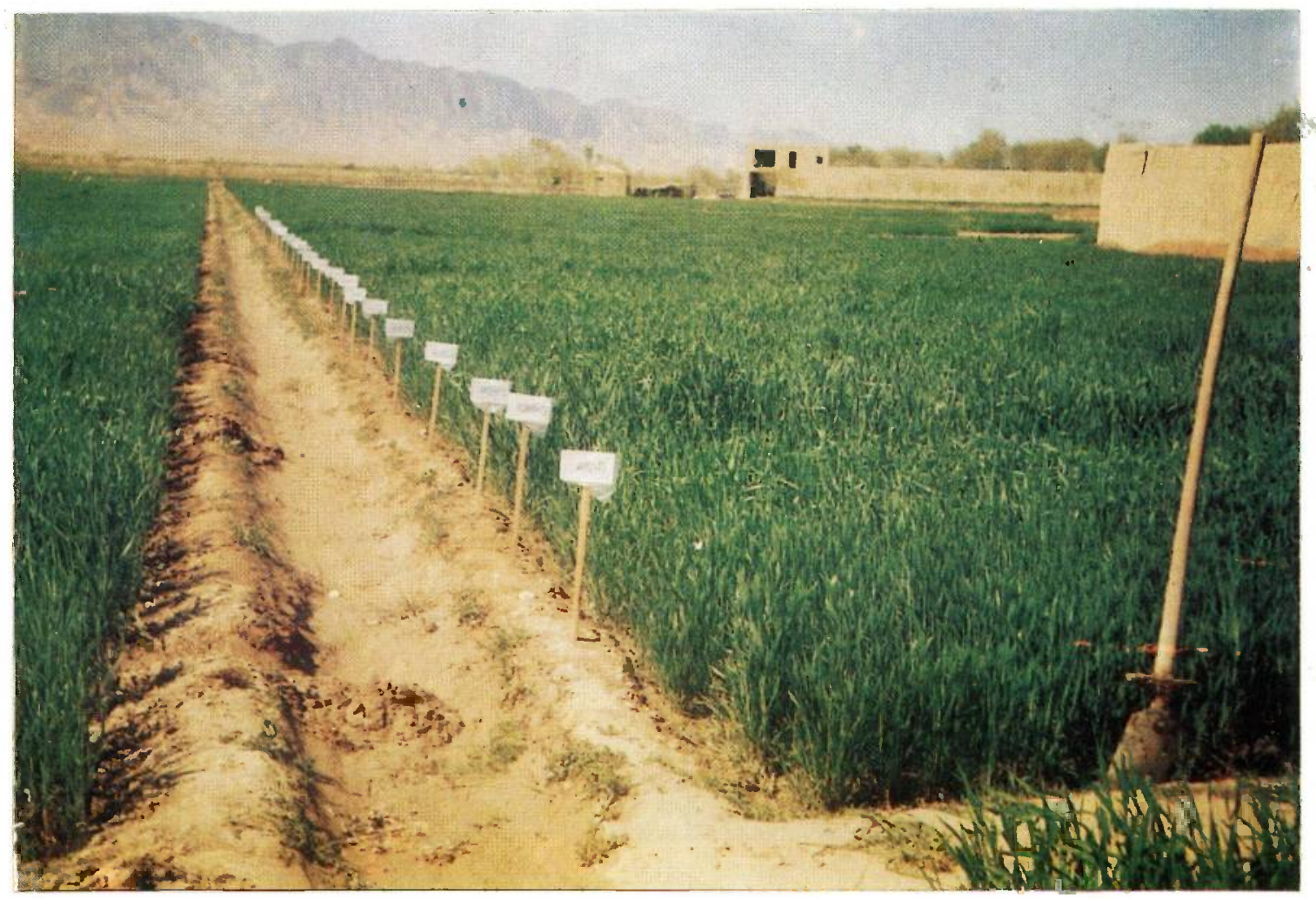

Wheat Varieties Selection Trials in Mazar-i-Sharif, Afghanistan

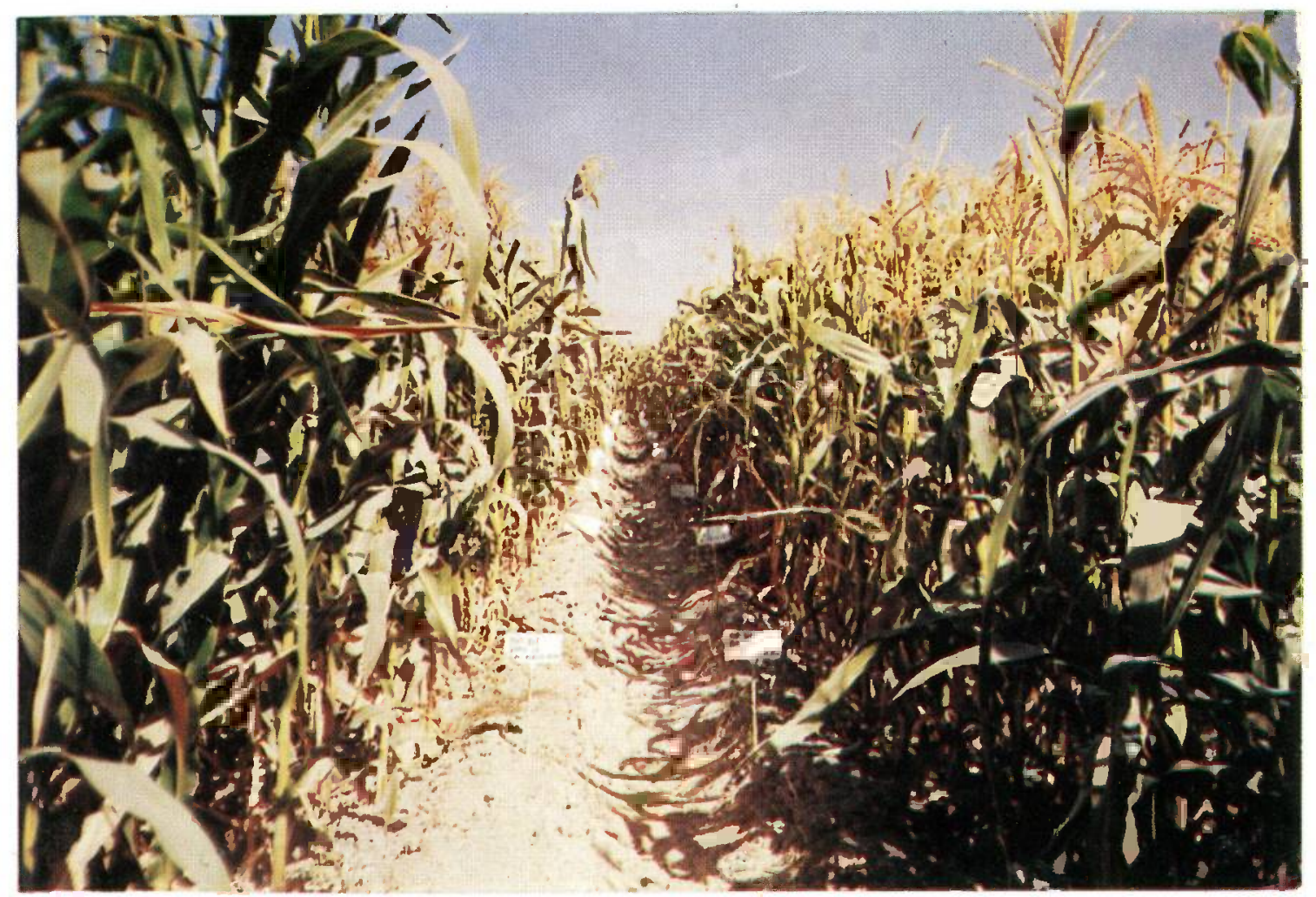

Maize Varieties Selection Trials in Kandahar, Afghanistan 


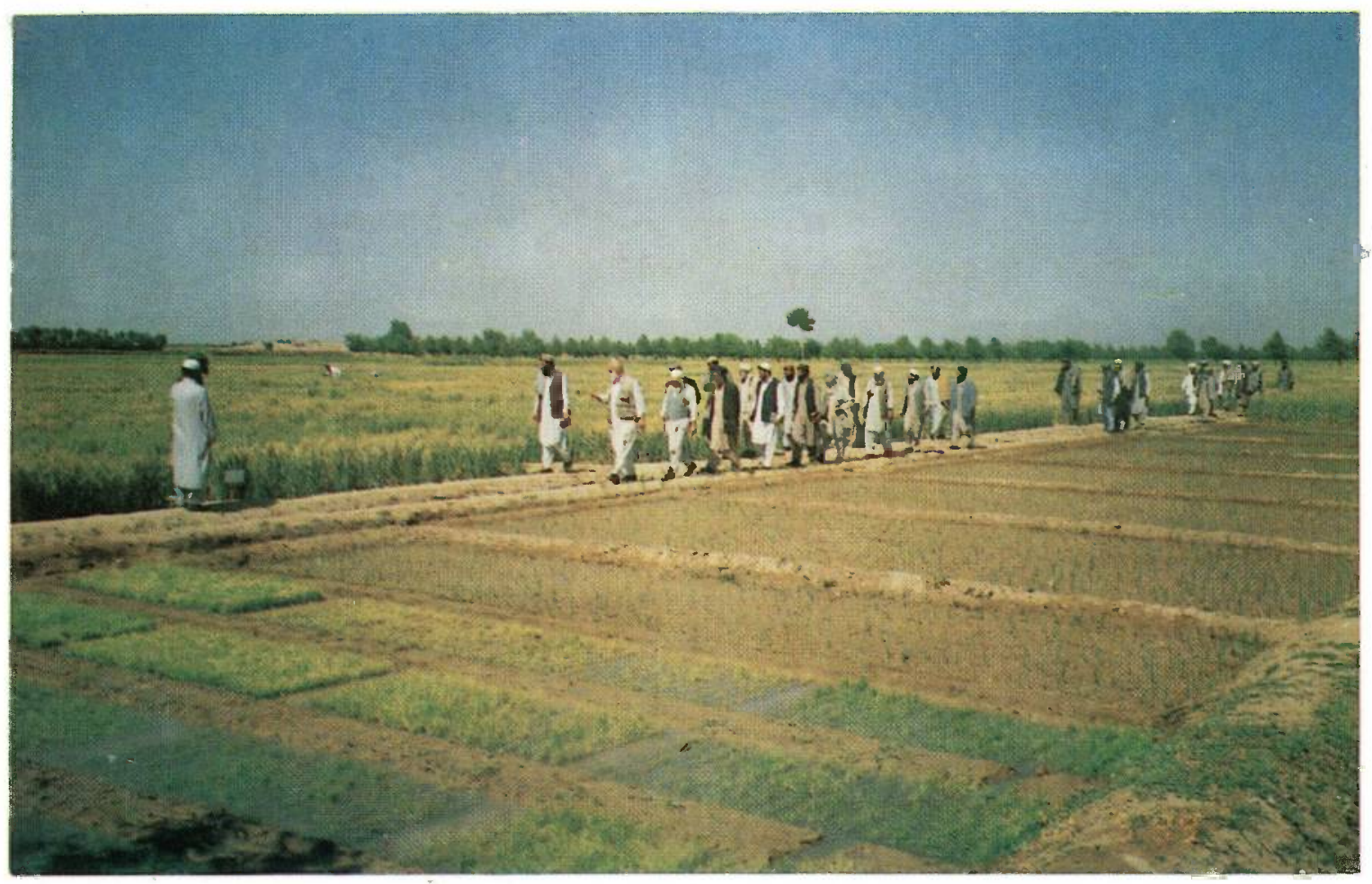

Farmers Field Visit to Wheat Varieties Selection Trials in Herat Afghanistan

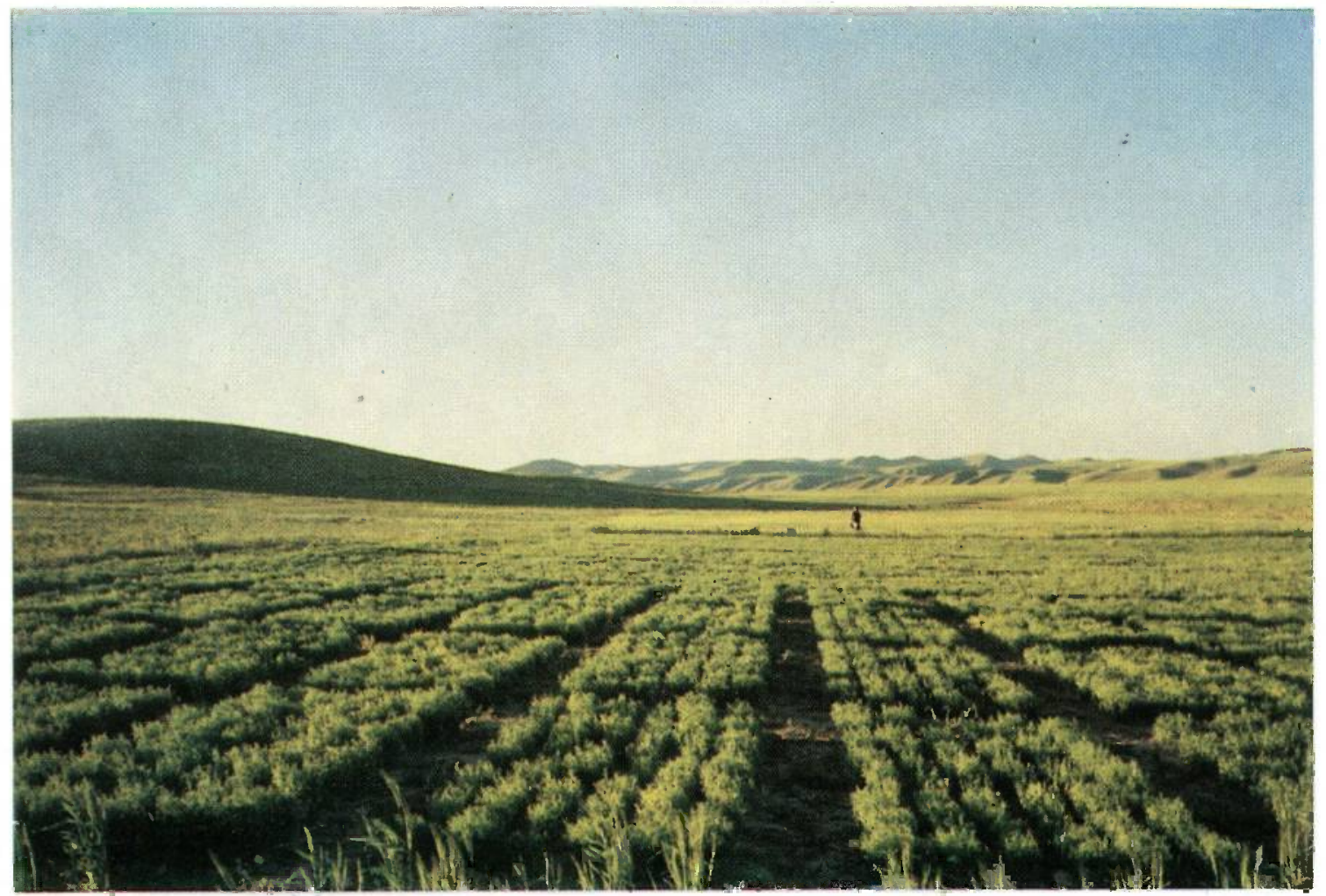

Rainfed Food Legumes and Wheat Varieties Trials in Herat, Afghanistan 


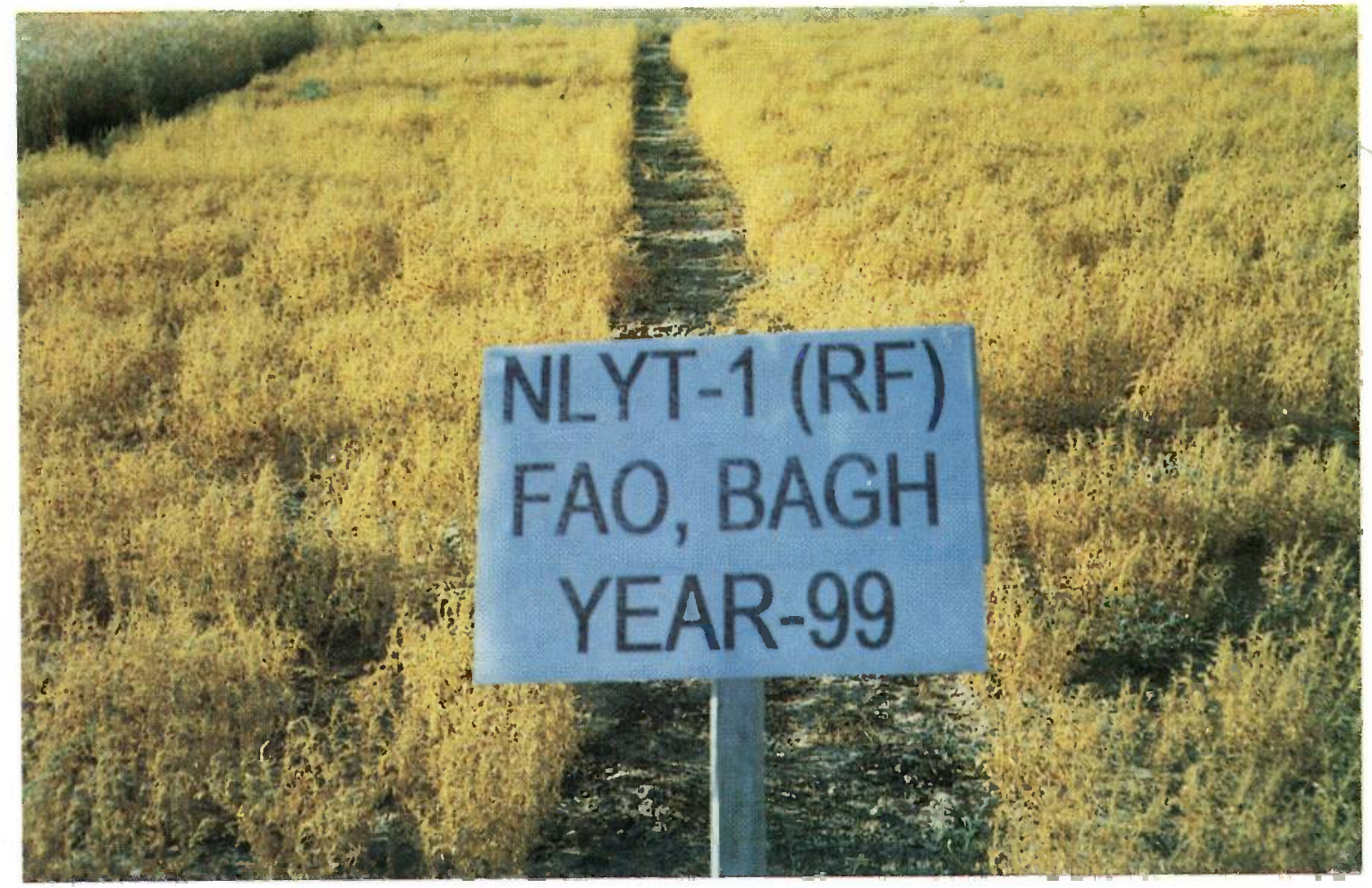

Rainfed Lentil Varieties Selection Trials in Baghlan, Afglanistan

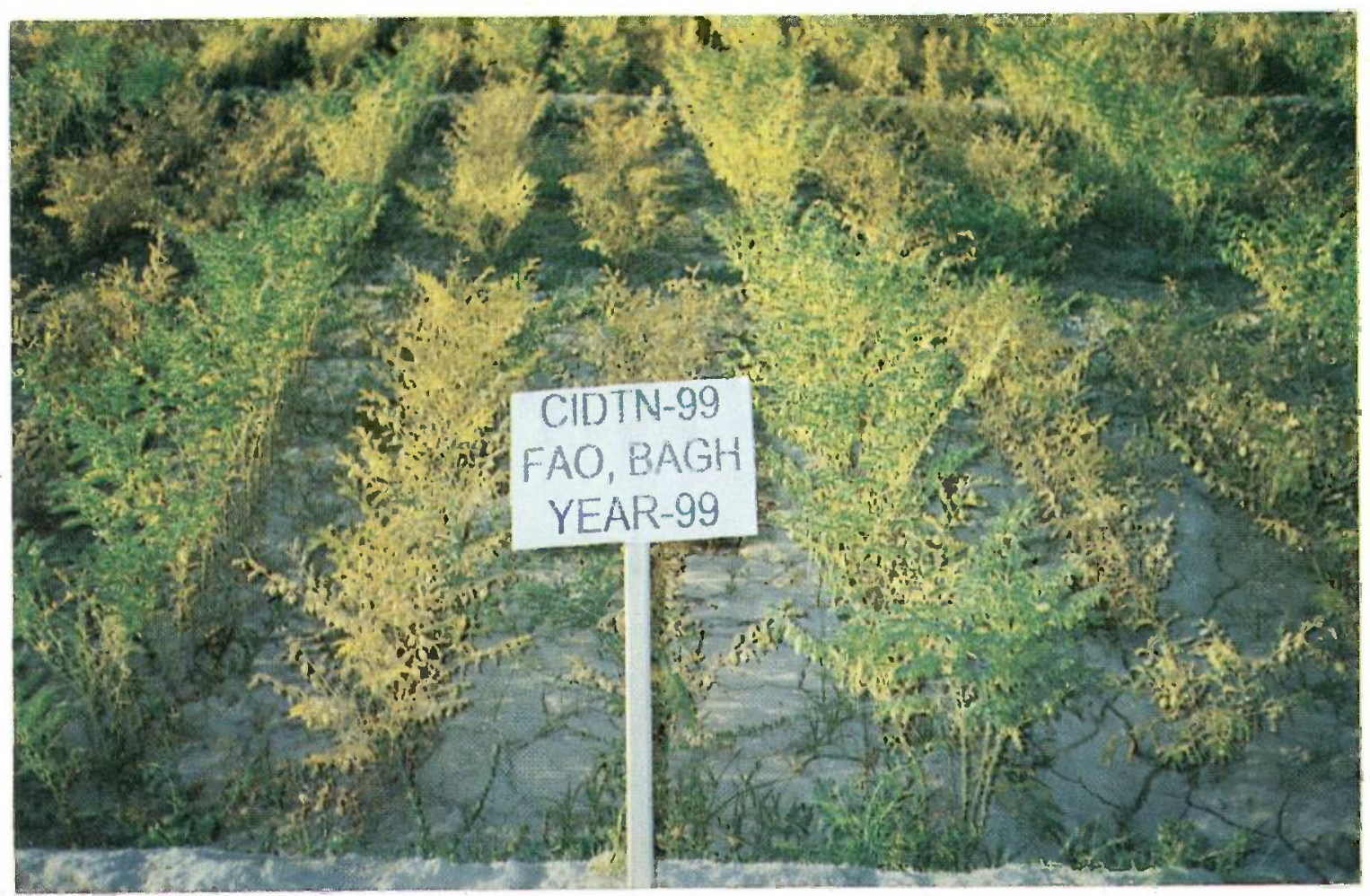

Chickpea Cold Tolerance Nursery in Baghlan, Afghanistan 


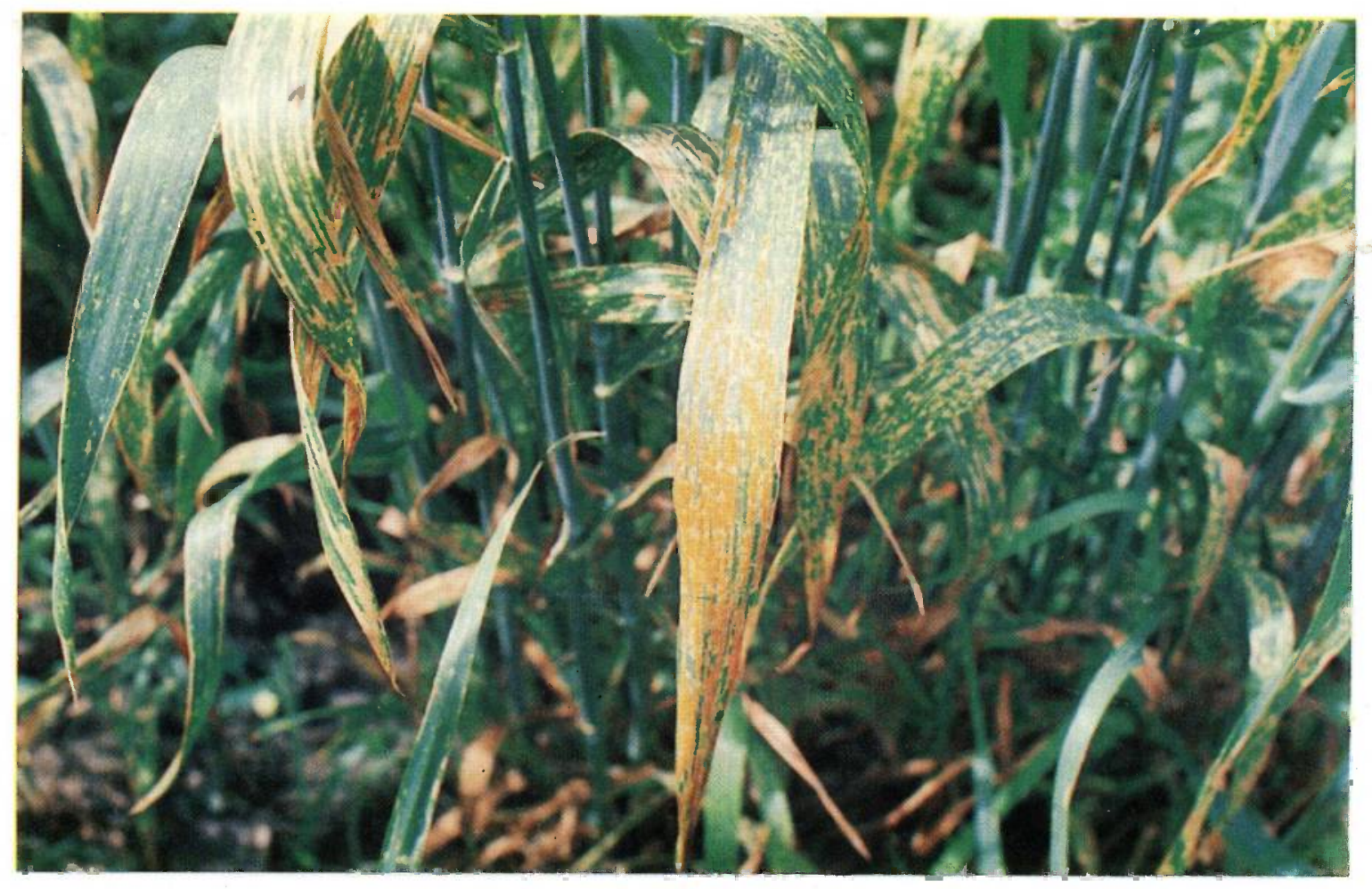

Stripe rust on Wheat Varictics in Nangarhar, Afghanistan

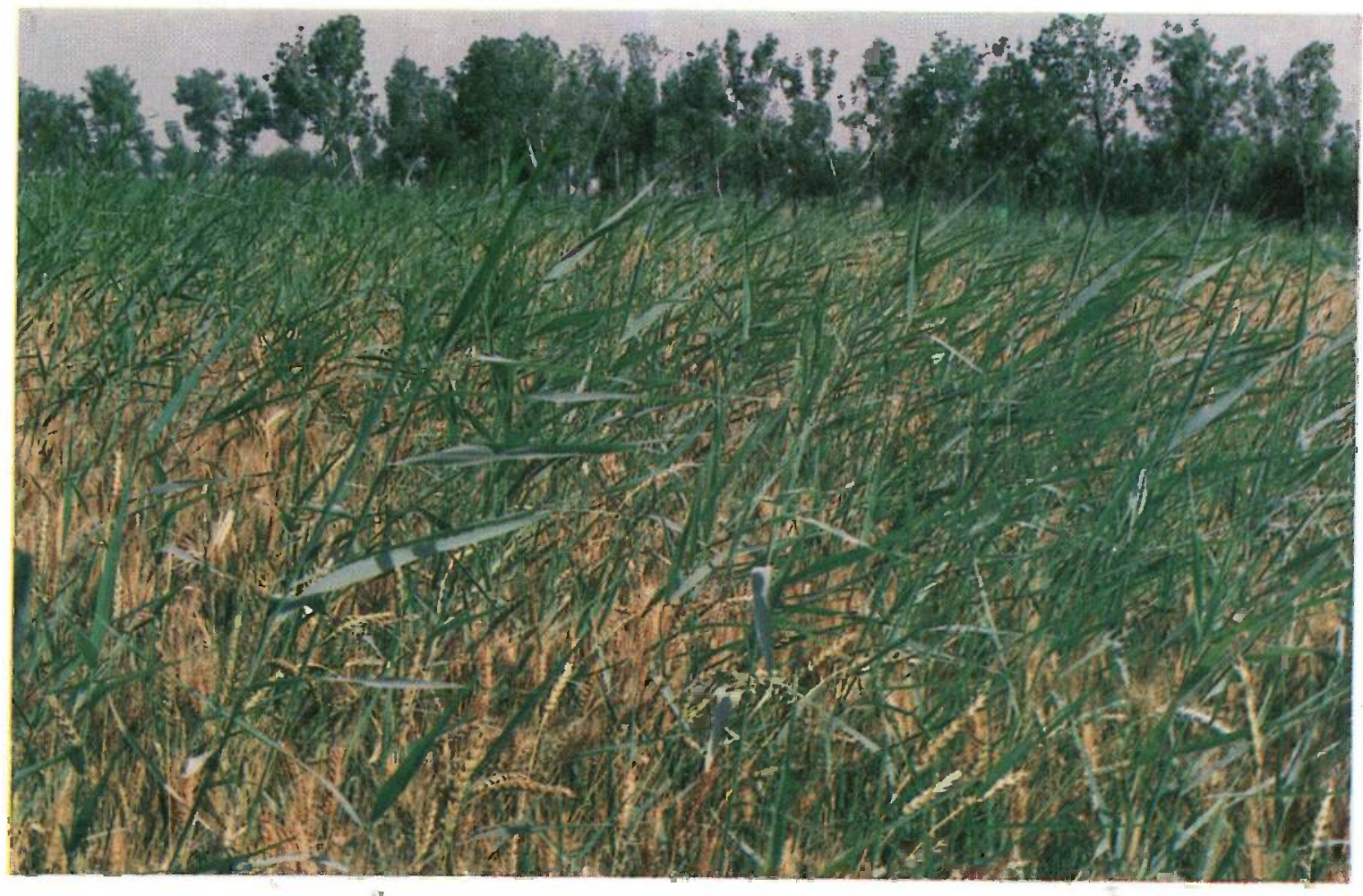

Weed Problem in Wheat in Herat, Afghanistan 
Acknowledgement 1

Preamble 2

Executive Summary 3

Wheat Varieties Selection Research 5

1. Material and Method 5

2. Results and Discussion 5

3. Wheat data 1997-98 5

4. Wheat data 1998-99 10

$\begin{array}{ll}\text { Wheat Agronomy } & 16\end{array}$

$\begin{array}{ll}\text { Fertilizer Experiments } & 16\end{array}$

Dates of Planting 19

Seed Rates $\quad 21$

Water Use efficiency $\quad 22$

Annex 1 Wheat data 1997-98 (Tables 1 to 36) 23

Annex 2 Wheat data 1998-99 (Tables 1 to 30) 61

Rice Varieties Selection Research 92

Introduction $\quad 92$

Materials and Methods $\quad: \quad 92$

Results and Discussion (1998) 93

1. Long Grain Rice 93

2. Short Grain Rice 95

Results and Discussion (1999) 96

1. Long Grain Rice 96

2. Short Grain Rice $\quad 97$

Agronomy Trials 1998 and $1999 \quad 98$

1. Dates of Planting 98

2. Fertilizer Experiment 99

Conclusion and Recommendation $\quad 99$ 
Annex 3 Rice data 1998 (Tables 1 to 4) 100

Annex 4 Rice data 1999 (Tables 1 to 6). 105

$\begin{array}{ll}\text { Barley Varieties Selection Research } & 112\end{array}$

$\begin{array}{ll}\text { Introduction } & 112\end{array}$

$\begin{array}{ll}\text { Methods and Materials } & 112\end{array}$

$\begin{array}{ll}\text { Results and Discussion } & 113\end{array}$

$\begin{array}{ll}\text { Recommendation } & 115\end{array}$

Annex 5 Barley data 1997-98 and 1998-99 (Tables 1 to 8) 116

Food Legumes Varieties Selection Research 125

$\begin{array}{ll}\text { Introduction } & 125\end{array}$

$\begin{array}{ll}\text { Materials and Methods } & 125\end{array}$

$\begin{array}{ll}\text { Results and Discussions } & 126\end{array}$

$\begin{array}{ll}\text { 1. Bean } 1998 & 126\end{array}$

2. Chickpea $1998 \quad 127$

$\begin{array}{lr}\text { 3. Pea } 1998 & 128\end{array}$

$\begin{array}{lr}\text { 4. Lentil } 1998 & 128\end{array}$

$\begin{array}{ll}\text { 5. Bean } 1999 & 130\end{array}$

6. Chickpea $1999+131$

$\begin{array}{ll}\text { 7. Pea } 1999 & 132\end{array}$

8. Lentil 1999

Annex 6 Food Legumes 1998 (Tables 1 to 19) 133

Annex 7 Food Legumes 1999 (Tables 1 to 10) 153

$\begin{array}{ll}\text { Maize } & 164\end{array}$

$\begin{array}{ll}\text { Achievements } & 167\end{array}$

$\begin{array}{lr}\text { Project Staff } & 175\end{array}$ 


\section{ACKNOWLEDGMENT}

The author wishes to express his gratitude to SIDA and UNDP Afghanistan for their financial support without which this work would not been possible. Sincere appreciation is extended to all technical and administrative staff of RAPR/FAO, FAO head quarter for their support to the activities of crop improvement project AFG/94/A02 ( UNO / AFG/ $001 /$ DPS ) to conduct varietal screening for major staple food crops in order to identify and recommend high yielding. stress tolerant genotypes to farmers in Alghanistan. Special thanks to Mr. H. C. Brink. program manager. $\Lambda F G / 96 / 004$ for his support, guidance and helpful suggestions.

I would like to take this opportunity to thank the staff of crop improvement project in six agroecological zones in the country. They have worked very hard under most difficult climatic and security conditions and have produced data that is in par with international agriculture research stations. Their hard word and dedication is highly appreciated. The continuous help of administrative staff of FAO crops program in Islamabad. Peshawar and inside Afghanistan is highly appreciated. Special thanks to Mr. Ashraf Qaderi for his help in the design of cover pages.

I am grateful to the staff of DACAAR, MADERA. Afghanaid and Solidarity Afghanistan for their cooperation in conducting research in their areas of activities inside Afghanistan. Their findings have strengthen our research results and recommendations.

Special thanks to the leadership and scientists of International Research Institute such as CIMMYT. ICARDA, IRRI, CIAT and NARC of Pakistan for their cooperation in sharing germplasm with the FAO crops for screening and selection in Afghanistan. The research results have been shared with these organizations regularly.

N. Wassimi, Ph.D.

Senior Technical Adviser ( Crop Improvement) 


\section{Preamble}

Afghanistan a primarily agrarian economy and about 85 percent of the population is employed in agriculture. As a consequence of more than two decades of conflict and political turmoil. food security in the country has been put at serious risk. Food security is directly related to increased crop productivity at farm level. The basic aim of all concerned, even in the absence of an operational national government, is to achieve and maintain its pre-conflict level of self-sufficiency particularly in terms of basic food production in the shortest possible time and in terms of both quantity and quality.

For the achievement of the above objective, SIDA. UNDP and FAO have worked collectively to assist Afghan farmers to raise the level of staple food crops production. SIDA and UNDP recognize the multiplicity of factors that impinge upon increased food production and the need for a concerted effort to address the problems created by semi destruction of variety improvement. seed multiplication and farming systems. The main components of sustainable food production in Afghanistan is the production and distribution of high yielding, stress tolerant varieties, fertilizers, water use efficiency, water management, and extension services.

The systematic varietal screening, crop varieties release and early generation seed production activities under taken by the project $\mathrm{AFG} / 94 / \mathrm{A} 02$ (UNO/AFG/001/DPS) that was financed by SIDA from 1996 to the end of 1999 has been very successful. The crop improvement project has conducted varietal screening and agronomic trials in six agro-climatic zones (North, North Eastern, North Western, South, East Central and Eastern) has succeeded in the introduction and release of ten new varieties of wheat (Triticum aestivum), three of rice (Oryza sativa), two of barley (Hordeum vulgare), four of bean (Phaseolus vulgaris), and two of chickpea (Cicer arietimum). Varietal screening work has been conducted on lentil (Lens culinaris), beans (Phaseolus vulgaris), Mung bean (Vigna mungo) and pea (Pisum sativum). Good data has been gathered on the dates of planting and fertilizer requirement and its economic gain on wheat and rice. In every country of the world this type of work has been conducted by specialized team of scientist in each of these crops. FAO crops project for Afghanistan is proud to say that we have done this work with one STA and a few dedicated Afghan scientists. This team has conducted $\mathbf{5 9 0}$ trials on a total of eight crops using $\mathbf{5 8 2 9}$ lines. In addition to research. this project has produced and distributed 159 MT early generation seed of these crops to farmers in 23 provinces. The research results of this project are at par with those of International Research Institutes. The research finding of this project for 1996 and 1997 were published in a technical report in December 1998. This report describes the research activities of crop improvement project for 1998 and 1999. I hope the research data presented in this report will be of interest to the readers.

Hans C. Brink

Program Manager AFG/96/004 


\section{EXECUTIVE SUMMARY}

The enhanced crop productivity project AFG/94/A02 (UNO/AFG/001/DPS) started its activities under direct FAO crops implementation in 1996 with the financial support from the people of Sweden through SIDA and UNDP. The objectives of this project were to screen, identify, recommend improved high yielding, disease and stress tolerant varieties of cereal and food legumes crops and to produce early generation (breeder nucleus and pre-basic) class seed of the newly recommended genotypes for further multiplication and distribution to farmers in Afghanistan. The varietal screening activities were conducted in Balkh, Takhar, Herat, Kandahar, Ghazni, Baghlan, Kunduz, Laghman, Bamyan, Badakhshan and Nangrahar provinces of Afghanistan representing diverse agro-climatic conditions. This report summarizes the data obtained by the project in 1997-98 and 1998--99 crop seasons. In addition to these two years data of FAO crops, the results of research activities carried by Danish Committee for Aid to Afghan Refugees (DACAAR), Mission d'Aide au Development des Economies Rurales Afghanistan (MADERA), and Solidarity Afghanistan has been included as well to get an even broader view of the performance of genotypes tested in the country. The findings are summarized as follows:

Wheat: From 1996 to $1999-2000$ crop season the project has conducted 382 trials on wheat and have tested 3881 genotypes in six zone and 15 provinces. From the research of 1998 and 1999 on facultative wheat, three new varieties Herat-99. Mazar-99 and Amu-99 have been released and recommended to farmers in the country for irrigated production. Data has shown that these genotypes are out yielding the previously introduced wheat variety Pirsabak-85 by $9 \%$ to $30 \%$ and remain resistant to the prevailing races of stripe rusts in Afghanistan. The economic impact of these yield increases are USD 216-360 per hectare and would significantly contribute to food security and poverty alleviation. If $60 \%$ of the irrigated land was sown with these varieties there would be an extra 1.95 million Mt. Food grain produced annually. This extra wheat has a value of USD 351 million and could sustain an extra ten million people. For rainfed wheat the two varieties Dayma-96 and Ghori-96 exceed in yield the national average and if multiplied and distributed properly, it has the potential to contribute an additional $900,000 \mathrm{MT}$ to national production ( able to sustain an extra 5 million people ) worth an extra USD 162 millions to farmers in Afghanistan.

\section{Early Generation Seed Production:}

In 1997-98 crop season, the project produced 32.4 MT of early generation seed of seven new varieties of wheat and in the fall of 1998 a further 36.3 MT of eleven top yielding wheat varieties was produced in six zones. In 1998-99 crop season the project produced 84 MT of foundation seed of selected improved varieties. This seed was distributed to NGOs and farmers for further increase. From the start of the project to the end of 1999 , a total of 125 MT early generation has been produced and distributed to farmers.

\section{Agronomy Trial on Wheat:}

Fertilizer : A series of trials on sowing time and rate of fertilizer were conducted on wheat using new varieties. The data revealed that the highest mean yield and economic gains were recorded for high level of nitrogen ( $115 \mathrm{Kg} / \mathrm{ha}$ ) in combination with $46 \mathrm{Kg} / \mathrm{ha}$ and $92 \mathrm{Kg} / \mathrm{ha}$ of phosphorus. On average the yield increases due to fertilizer application range from $59 \%$ to $86 \%$. 
Dates of Planting: There is great genotypic variation in response to planting time in wheat. The data showed that for wheat in low elevation ( Balkh. Herat. Kandahar, Kunar. Laghman, Nangrahar) provinces the optimum date of planting for facultative wheat is mid-November. Delaying planting by fortnightly interval from the end of November to mid- January resulted in vield reduction of 17.20 and $40 \mathrm{~kg} / \mathrm{ha}$ per day. At higher altitudes, for example in (ihazni, Banyan. Kabul. and Badakhshan provinces, the optimum sowing date is mid-October to the end of November. Delaying atter November resulted in yield losses of $258 \mathrm{Kg} / \mathrm{ha}$ per day. From the $98 \mathrm{NWYT1}$ data it can be concluded that on the average there is a $17 \mathrm{~kg} / \mathrm{ha} /$ day yield loss due to one month late planting. This is an unnecessary yield loss that can lead to $663000 \mathrm{MT}$ production loss in the country. This amount of wheat will feed 5.1 million Afghans for one year.

Rice: Rice is an important crop in North East. North. North West and Eastern part of the country. From the 192 rice lines tested in the rice growing areas of the country in 63 trials, three new rice varieties Swat-2 ( $6790 \mathrm{Kg} / \mathrm{ha}$ ). Afghan-98 ( $6127 \mathrm{Kg} / \mathrm{ha}$ ) and Baghlan-98 ( $5354 \mathrm{Kg} / \mathrm{ha}$ ) have been released and recommended for production in Afghanistan. In the duration of this project 17 MT early generation seed of these varieties have been produced and distributed to farmers in Nangarhar. Baghlan. Takhar, Kunduz, Balkh, and Herat provinces. In long grain rice variety yield trial conducted from 1994 to 1999. Afghan-98 is the top yielding and has produced $1.5 \mathrm{Mt}$./ha more yield than Basmati-385 (the current long grain ) rice variety in Afghanistan.

Barley: The overall means of the 3 years from 9 locations and 17 national barley yield trials were combined. The data showed that the varieties Hewad 98, Watan 98 and IIRAN/UNA 80// LIGNEE are the top yielding varieties. These genotypes are resistant to yellow rust and leaf rusts. They produced as an average 24.23 and $21 \%$ higher yield than the local variety $(3320 \mathrm{~kg} / \mathrm{ha})$. The barley varieties Watan 98 and Hewad 98 are adapted well in the barley growing areas of the country and are recommended for release and multiplication.

Food legumes: The project has screened germplasm of beans, chickpea and lentils for adaptability and yield in the country. Data summary showed that kidney bean line 5229. UI ( Salamati-99) with bush growth habit. Arapaho ( Bari-99), a pinto climbing type. Co 1760 ( Arzo-99) great northern type with bush growth habit and variety Viva( Barakat-99), red kidney bean with bush type growth habit are the top yielding varieties. Their yield is $56 \%, 50 \%, 41 \%$ and $75 \%$ higher than the local beans. These lines are considered for multiplication and distribution.

In chickpea two lines (FLIP 93-53 and FL.IP-93-58) have been identified as top yielding and cold tolerant and ascochyta blight resistant. These lines are released as new varieties and their seed is distributed to farmers in Tahkar. Baghlan. Balkh and Herat provinces for early generation seed production. The name Madad-99 is given to FL.IP 93-53 and Sehat-99 is assigned to FL.IP 93-58 Their yields are 12\% and 15\% higher than the local varieties in 1998 and 1999.

In lentils wo lines (78S 26002 and FLIP 92-15L) are high yielding and have been recommended for multiplication in I lerat. Balkh and Takhar provinces. Their vielding ability is $53 \%$ and $37 \%$ higher than the local variety.

Crop varieties selection in food legumes needs to continue in the area of disease resistance. cold and drought tolerance, and agronomic package development.

The project has succeeded in selecting valuable germplasm in wheat, rice, maize, barley and food legumes. This germplasm has been selected for both favorable and stress environments. It is extremely important for food security and poverty alleviation in all parts of $\wedge$ fghanistan. 


\section{Wheat Varieties Selection Research}

\section{Introduction}

Wheat is an important staple food crop in Afghanistan. It is also a very important crop world wide. The per capita wheat consumption of Afghanistan is $180 \mathrm{~kg}$ per annum. Wheat is grown under both irrigated and rainfed conditions. Irrigated wheat provide $77 \%$ of total wheat production of the country. The national average wheat yield in Afghanistan is $1.66 \mathrm{Kg} / \mathrm{ha}$ which is very low compared to the potential of improvement possible. It is therefore very important that high yielding, disease and stress tolerant varieties are developed for food self sufficiency and sustainable food production. This work on variety screening and foundation seed production was funded by SIDA through UNDP since 1996. A technical report on cereals and food legumes variety performance covering 1996 and 1997 was published in 1998. In this report data of 1998 and 1999 is presented.

\section{Wheat Variety screening}

\section{Material and Methods:}

In 1997-98 and 1998-99 wheat growing seasons, 545 lines of wheat were selected and planted in different trials in six agro-climatic zones in the country. The selections criterion was based on the yield performance, disease reaction, cold tolerance and grain color of these lines. In addition to this, a number of yield trials and observation nurseries were received from CIMMYT, ICARDA and NARC for specific adaptation (cold, heat, drought and diseases). The selected lines were placed in trials consisting of 10 or 15 lines arranged in a randomized complete block design (RCBD) with four replications. There were six rows five meter long in each plot. The row spacing was $25 \mathrm{~cm}$. The four central rows with four meter length were harvested for yield determination. The trials in the East Central zone cooler areas (Ghazni and Wardak) were planted in October and those for the warmer areas were planted 15 November and 15 December. All agronomic practices were uniformly applied to the plots according to design and plan. The data was statistically analyzed using MSTAT statistical package.

\section{Results and Discussion}

Wheat data (1997-98): The data of 10 bread wheat genotypes tested in seven locations in a national wheat yield trial (97NWYT1) is presented in (Table 1, Annex 1). In Nangarhar province, highly significant differences were observed in the yield of the lines. The top yielding lines are no. 3,6 with a mean yield of $5116 \mathrm{~kg} / \mathrm{ha}$. Lines 2,4 and 10 are significantly lower yielding than the rest. The yield differences of the remaining lines are not significant. The data shows that line 2 is the lowest yielding in Nangarhar province, it seems that this line is better adapted to cooler areas than to warmer areas such as Nangarhar, Kandahar and Kunduz provinces (Table 1, Annex 1). The yield advantage of the top yielding lines ( 3 and 6) over Pirsabak-85 is 35\%. These lines have given 19\% higher yield than the nursery mean ( $4312 \mathrm{~kg} / \mathrm{ha}$ ).

In Kandahar province the yield differences of entries 2, 7 and 8 were significantly different from the rest of the entries but, not from each other. Similarly the top yielding line (7) out yielded Pirsabak- 85 by $14 \%$ and the nursery mean ( $5007 \mathrm{~kg} / \mathrm{ha}$ ) by $20 \%$. In Laghman province highly significant yield differences were observed among the entries. The top yielding tines are no. 1, 6 and 7 . These lines have out yielded Pirsabak-85 by more than $70 \%$ and the nursery mean by 14 to 19\%،(Annex 1, Table 1).

In Herat province the yield difference of the top ranking line no. 7 and the lowest ranking line no. 
3 is significant but with the rest of them it is not significant. In Balkh province significant differences are observed between lines. The yield of the best line (6) is significantly higher than the yield of lines 1, 3, 4 and 9.

In Kunduz province, no significant yield differences are observed between lines 3,6, 7, and 8 . The yield differences of line number 1,2,5,9, and 10 are also not significantly different from each other. Line number 6 is significantly higher yielding than these lines.

In Ghazni province the top yielding line is number $4(8356 \mathrm{~kg} / \mathrm{ha})$. This yield is not significantly different from the yield of lines number 1 and 2, but significantly higher than the rest of the lines. In Kunar province line number 6 is top yielding $(5560 \mathrm{~kg} / \mathrm{ha})$. This line is significantly higher yielding than lines 9 and 10 but it is not significantly higher yielding from the rest of the lines.

From the seven locations average yield (kg/ha) it is clear that entries number 6 (Pasteur), 1 (Roshan-96), and 2 (Gul-96) are the three top yielding lines. These lines have out yielded Pirsabak- 85 by $21 \%, 20 \%$ and $16 \%$ respectively. Similarly, the mean yield of these lines is $9 \%$, $8 \%$ and $4 \%$ higher than the nursery mean over seven locations $(4914 \mathrm{~kg} / \mathrm{ha})$. These lines have exhibited desirable reaction to the prevailing races of both leaf and stripe rusts (Annex 1, Table 2). Based on disease response and yielding ability, lines 1,2,3,5,6, and 9 are selected for further testing in 1998-99.

Yield data of 10 bread wheat lines tested in (97NWYT2) over seven locations is summarized in (Table 3, Annex 1 ) and their response to leaf and stripe rust is presented in (Table 4, Annex 1 ). The entries tested in these trials were selected based on yield, disease resistance and cold tolerance traits from the 1996-97 trials.

In Nangarhar lines 8,9 and 1 are in the same significance group and are significantly higher yielding than the rest of the lines and the nursery mean $(3421 \mathrm{~kg} / \mathrm{ha})$. In Kandahar lines 1, 6 and 9 are in the same group and have yielded significantly better than the rest of the lines. The yield of these lines is $13 \%$ to $27 \%$ higher than the nursery mean $(4542 \mathrm{~kg} / \mathrm{ha})$. In Kunar lines 3,5 and 6 are in the same yield group and are significantly higher yielding than the rest of the lines and are 8 to $20 \%$ higher yielding than the nursery mean $(2750 \mathrm{~kg} / \mathrm{ha})$.

In Balkh entries 1, 3, 4, 7, 8 and 9 are in same significance range and have yielded significantly higher than the rest of the entries. Their yield advantage over nursery mean $(5583 \mathrm{~kg} / \mathrm{ha})$ range from 51 to $732 \mathrm{~kg} / \mathrm{ha}$. In Kunduz entries 3, 4, 5, 7, 8 and 9 are in the same group and have yielded significantly higher than the rest of the lines. These lines have out yielded the nursery mean ( 2888 $\mathrm{kg} / \mathrm{ha}$ ) by 8 to $16 \%$.

In Herat lines 1, 3, 4, 5, 7 and 10 are in the same yield group with significant yield advantage over other lines and from $78 \mathrm{~kg}$ to $525 \mathrm{~kg}$ higher than the nursery mean $(5350 \mathrm{~kg} / \mathrm{ha})$. In Ghazni lines 2 , 3 and 10 are significantly higher yielding than the rest of the lines and have out yielded the nursery mean by 15 to $27 \%$.

From the overall mean yield data it is clear that entry $7,3,8,5$ and 9 are top yielding and are in the same yield ranking in 7 locations. Their mean yields are 4482, 4445, 4416, 4398 and 4344 $\mathrm{kg} /$ ha respectively These entries produced an average yield of more than four tons per hectare and have been selected for 1998-99 trials. The rust response of lines 7 and 9 have been the most desirable of these lines (Annex 1, Table 4). In selection, greater emphasis was placed and yielding ability, cold tolerance and disease resistance.

On farm water management, water use efficiency and the quantity and seasonal distribution of precipitation is a limiting factor in wheat production in Afghanistan. Half of the arable of the country is classified as rain fed. DAI in 1993 reported that the greatest percentage of rain fed land is in Northern zone' $(75 \%)$, in North Eastern zone (67\%), in North Western zone $(50 \%)$ and in Southern zone (13\%). Bringing this land under irrigation requires large investments and long time. The project is developing wheat varieties that are adapted to water stress conditions.

In 1997-98 crop season, the project tested 15 bread wheat lines under water stress conditions in (97NWYT3RF) trial in Herat, Balkh and Wardak provinces. The same trial was tested under irrigated conditions in Nangarhar, Kandahar and Balkh provinces (Annex 1, Table 5). 
In the rain fed environment of Herat province, lines 2, 4, 6, 7,8, 10 and 12 are in the same significance group and are higher yielding than the nursery mean $(1886 \mathrm{~kg} / \mathrm{ha})$ by 3 to $20 \%$. This yield performance under rain fed condition is high for the country. This is due timely planting and adequate precipitation that occurred in 1997-98 crop season as a result of the adequate rain effect. In Balkh province lines 3-10, 12 and 13 are in the same significant yield range (Annex 1, Table 5). In this location the 5 top yielding lines $(3,8,12,10,6)$ yielded 9 to $31 \%$ above the nursery mean of $(915 \mathrm{~kg} / \mathrm{ha})$. In Wardak lines 4, 5, 7, 12,13 and 15 are in the same group for yield. The first 5 ranked lines have produced 10 to $38 \%$ higher yield than the nursery mean $(483 \mathrm{~kg} / \mathrm{ha})$ and is the lowest of the three environments. Under the water stress condition, lines $(3,6,8,10$ and 12) have yielded 6 to $17 \%$ higher than the nursery mean over three locations $(1090 \mathrm{~kg} / \mathrm{ha})$.

Under irrigated condition in (Nangarhar, Kandahar and Balkh) Annex 1, Table 5, the first 5 ranking lines are $(1,7,9,12$ and 14) with mean yield ranging from $4901 \mathrm{~kg} / \mathrm{ha}$ to $5160 \mathrm{~kg} / \mathrm{ha}$ exceeding the nursery mean (4764 kg/ha) by 3 to $8 \%$ (Annex 1, Table 5 ).

The overall mean yield data revealed that line number $1,7,9,12$ and 14 have performed very well under both rain fed and irrigated conditions. It is interesting to note that line number 12 has given top yield under both conditions. This line also exhibited desirable stripe and leaf rust response (Annex 1, Table 6). It shows that this lines is stable performer under both conditions and should be considered as a candidate for release if its performance over years is also stable in the 1998-99 trials. Based on yield and disease response, nine lines $(1-5,7,8,10,12)$ have been selected for further evaluation in 1998-99 crop season.

Mean yield, overall mean yield and ranks of 15 bread wheat lines tested in six locations in (97AWYT1) are summarized in (Annex 1, Table 7). The lines included in test were selected based on their yield potential and reaction to rust diseases. In Nangarhar entries 2-6, 11 and 12 are in the same yield group and have significantly higher yielding than the rest of the entries. The mean yield difference of these lines is 7 to $20 \%$ higher than the nursery mean of $(4520 \mathrm{~kg} / \mathrm{ha})$. In Kandahar lines 2-5, 11 and 13 are in same yield group and are significantly higher yielding. Their yield is 8 to $25 \%$ higher than the nursery mean of (4435 kg/ha). In Herat entries $1,5,7,8$ and 15 are in same yield group with significantly higher yields. These entries have yielded 6 to $14 \%$ higher than the nursery mean $(5571 \mathrm{~kg} / \mathrm{ha})$. In Balkh entries $1,5,6,11$ and 12 are in the same level of significance group and have yielded 4 to 18 higher yield than the nursery mean (3961 $\mathrm{kg} / \mathrm{ha}$ ). In Takhar the significantly higher yielding top five entries are $1,3,12,14$ and 15. These lines have produced from 4 to $20 \%$ higher yield than the nursery mean $(2913 \mathrm{~kg} / \mathrm{ha})$. In Ghazni entries $1,3,12,14$ and 15 are significantly higher yielding than the rest of the entries. Their mean yield is 13 to $23 \%$ higher than the nursery mean $(6084 \mathrm{~kg} / \mathrm{ha})$. From the overall mean yield, entries 1, 3, 5, 11 and 12 are the five top yielding entries. These entries have yielded 3 to $13 \%$ higher than the overall mean yield $(4580 \mathrm{~kg} / \mathrm{ha})$. In 1996-97 trial these entries were also top yielding and produced yields that were higher than the nursery mean (Annex 2, Table 28). Their leaf and stripe rust response is also very good except for entry 11 which is moderately susceptible in Ghazni. For leaf rust the entries 1, 11 and 12 exhibited susceptible reaction in Takhar.(Annex 1, Table 8). These entries are selected for trials in 1998-99 crop season

The yield and rust data of 15 bread wheat lines tested in (97AWYT2) is summarized in (Annex 1, Tables 9 and 10). It shows that in Nangarhar the yields of entries 1, 5, 7-9 and 15 are significantly higher than the yields of the remaining lines. These lines have produced grain yield 12 to $25 \%$ higher than the nursery mean (4426 kg/ha). In Kandahar entries 3, 4, 7, 9, 10 and 15 produced significantly higher yields and are in the same group of significance. These lines have also out yielded the nursery mean ( $4778 \mathrm{~kg} / \mathrm{ha}$ ) by 9 to $17 \%$. In Herat lines $1-4$ and, $6-11$ are in same yield group and are significantly higher yielding than the rest of the lines. These lines have produced 7 to $15 \%$ higher yield than the nursery mean $(5172 \mathrm{~kg} / \mathrm{ha})$. In Balkh the five top yielding lines are $2,6,8,13$ and 14 . They are significantly higher yielding than line $I$ and their mean yield is 4 to 7 $\%$ higher than the nursery mean $(5546 \mathrm{~kg} / \mathrm{ha})$. In Ghazni the six top yielding lines are 1, 4, 6, 7, 13 and 14. These have significantly out yielded other entries and have produced mean yield of 5 to 24 
$\%$ higher than the nursery mean $(4651 \mathrm{~kg} / \mathrm{ha})$. The five locations mean yield of these entries showed that entry 4-7 and 9 have exceeded the nursery mean by 4 to $11 \%$. The stripe rust response of these lines in the test sites ranges from 0 to MR (Annex 1, Table 10) but, for leaf rust entry 4 and 9 had 20S and 40S reaction respectively in Ghazni. Entries 1 and 5-8 are selected for 1998-99 trials.

The mean yield, overall mean yield and rank of ten bread wheat lines tested in four locations in 97AWYT3 are summarized in (Annex 1, Table 11). In Nangarhar the yield of entry $I$ is significantly higher than the rest of the lines. The top five high yielding lines $(1,2,4,5$ and 10$)$ have yielded 9 to $46 \%$ higher than the nursery mean of $3683 \mathrm{~kg} / \mathrm{ha}$. In Balkh entries $(1-4,7,9$, and 10 ) are high yielding and there is not significantly differences between their mean yields. These lines produced significantly outyielded the rest of the entries. Their mean yield is 8 to $15 \%$ higher than the nursery mean of $5261 \mathrm{~kg} / \mathrm{ha}$. In Herat entries 9, I, 4, 5, and 8 are the top yielding ones and have produced 3 to $16 \%$ higher yields than the nursery mean of $5108 \mathrm{~kg} / \mathrm{ha}$. In Ghazni entries I, 6-8 and 10 are significantly high yielding ones and have yielded $1-23 \%$ higher than the nursery mean of $5353 \mathrm{~kg} / \mathrm{ha}$. The overall mean yield of this trial in four locations shows that entries $1,4,5$ 7 and 9 are the top yielding ones and have yielded 1 to $15 \%$ higher than the overall mean yield of $4876 \mathrm{~kg} / \mathrm{ha}$. The leaf and stripe rust response of these lines summarized in (Annex 1, Table 12) shows that entry 1 and 5 have consistently exhibited resistance reaction to the prevailing races of these two rust fungi and are therefore selected for inclusion in 1998-99 trials.

Mean yield, overall mean yield and rank of 15 bread wheat lines tested in (97PWYT1) are summarized in (Annex 1. Table 13). In Balkh entry 12 significantly out yielded all other entries. Entries $5,6,8$ and 15 are the top yielding ones. The yield differences of the top performing lines are 1 to $24 \%$ from the nursery mean of $5092 \mathrm{~kg} / \mathrm{ha}$. In Takhar entries $1,8,12,14$ and 15 are in the first significant yield group. Their yield increase over nursery mean $(3334 \mathrm{~kg} / \mathrm{ha})$ is 8 to $26 \%$. In Ghaxni entry 5 and 9 are in one yield group and entries 4,10 , and 13 are in the second yield group. These are the top five yielding lines and have out yield the nursery mean $(7486 \mathrm{~kg} / \mathrm{ha})$ by 5 to $23 \%$. In Nangarhar entries 3, 4, 10, 11 and 13 are significantly high yielding and have performed 13 to $29 \%$ higher than the nursery mean of $3684 \mathrm{~kg} / \mathrm{ha}$. In Kandahar entries $3,4,11$, 13 , and 15 are significantly higher yielding. These lines have produced 11 to $18 \%$ higher yields than the nursery mean of $4103 \mathrm{~kg} / \mathrm{ha}$. In Herat entries $4,7,9,12$ and 15 are the five top yielding ones with yield advantage of 7 to $22 \%$ over the nursery mean of $4875 \mathrm{~kg} / \mathrm{ha}$. The overall mean yield showed that entries $4,5,9,10$ and 13 are the top performers and have produced 3 to $7 \%$ better yield than the overall mean yield of $4739 \mathrm{~kg} / \mathrm{ha}$. Based on the yield and disease response (Annex 1, Table 14), entries 1, 3, 10,11, and 13 are selected and included in the 1998-99 trial.

Mean yield, overall mean yield, yield rank, leaf and stripe rust response of 15 bread wheat lines tested in (97PWYT2) are summarized in (Annex 1, Tables 15 and 16). In Nangarhar entries 4, 5 , 8,13 and 14 are the first five significantly high yielding ones with yield advantage of 11 to $50 \%$ over the nursery mean of $2740 \mathrm{~kg} / \mathrm{ha}$. In Kandahar entries 2, 3, 12, 14 and 15 are significantly higher yielding than the rest of the lines. These lines are 6 to $23 \%$ higher yielding than the nursery mean of $3332 \mathrm{~kg} / \mathrm{ha}$. In Balkh entries $5,7,8,12$ and 14 are the top five performers. These lines have produced 3 to $18 \%$ higher yields than the nursery mean of ( $4464 \mathrm{~kg} / \mathrm{ha})$. In Takhar emtries 2-4 and. 15 are significantly higher yielding ones. Entry 1 is the fifth highest yielding lines. The yield increase of these five lines over the nursery mean $(2924 \mathrm{~kg} / \mathrm{ha})$ ranges from 3 to $44 \%$. In Ghazni lines 2-4, 10 and 14 are top yielding ones. These lines have produced 7 to $17 \%$ higher yields than the nursery mean of $6752 \mathrm{~kg} / \mathrm{ha}$. The five locations overall mean yield of this trial is $4042 \mathrm{~kg} / \mathrm{ha}$ and the top five entries $3,4,10,14$ and 15 have produced 4 to $14 \%$ higher yields. Based on both yield and rust reaction entries 3, 8, 9, and 13 were selected for 1998-99 trials.

Mean yield, overall mean yield, yield rank and rust response of 15 bread wheat lines tested in (97PWYT3) are summarized in (Annex 1, Tables 17 and 18). In Ghazni entry 1-is highest yielding $(9417 \mathrm{~kg} / \mathrm{ha})$ followed by entry $6(7983 \mathrm{~kg} / \mathrm{ha})$, entry $7(7933 \mathrm{~kg} / \mathrm{ha})$, entry $9(7833$ $\mathrm{kg} / \mathrm{ha})$ and entry $12 .(8033 \mathrm{~kg} / \mathrm{ha})$. The yield increase of these lines over the nursery mean $(7331$ 
$\mathrm{kg} / \mathrm{ha}$ ) ranges from 7 to $28 \%$. In Takhar entries $2,4,7,10$ and 15 are in the top five yielding group. These lines have out yielded the nursery mean of $(2707 \mathrm{~kg} / \mathrm{ha})$ by 17 to $53 \%$. The two location mean showed that entries $1,4,7,10$ and 15 are the top five yielding ones. These lines have produced yields in the range of 8 to $14 \%$ higher than the overall mean yield of $5019 \mathrm{~kg} / \mathrm{ha}$. Based on yield performance and rust reaction entries 1, 4, 6, 7, 10, and 11 are selected for 1998-99 trials

A 10 lines trial (97PWYT4) was prepared for Herat in 1997, the yield and rust reaction of these lines are presented in (Annex 1, Tables 19 and 20). The five top yielding lines are 1, 3, 4, 8 and 9. These lines have produced 9 to $19 \%$ higher yields than the nursery mean of $4761 \mathrm{~kg} / \mathrm{ha}$. Based on yield and rust reaction line 2, 8 and 9 are selected for 1998-99 trials.

In 1997-98 crop season, the project was requested by NGOs to identify early maturing spring wheat varieties for cooler areas of the country. With this in mind ten lines were selected and tested in 97SWYT 1 in Balkh, Kandahar and Takhar provinces. The grain yield and disease response of these lines are presented in (Annex 1, Tables 21 and 22). In Balkh entries 4, 6 and 8-10 are significantly higher yielding. These lines have out yielded the nursery mean (3298 kg/ha) by 9 to $24 \%$. In Kandahar entry 2 and 10 are the highest yielding ones. In Takhar entries 1, 6-8 and 10 are top yielding. These lines have produced 4 to $18 \%$ higher yields than the nursery mean of 2991 $\mathrm{kg} / \mathrm{ha}$. From the overall mean yield it shows that entries 2, 6, 8-10 are top performers and have exceeded the over all mean yield (3338 kg/ha) by 2 to $26 \%$. Entries 1, 5, 7 and 8 are selected for 1998-99 trial.

In 1997-98 crop season one facultative and winter wheat trial (4FAWWYT) consisting of 25 lines was sent to the project from CIMMYT wheat program in Turkey. This trial was planted in Nangarhar, Herat and Khost. The yield data is presented in (Annex 1, Table 23). In Nangarhar the yield of the entries were low because of the warmer climate. In Herat and in Khost the yields are high. Based on yield performance and disease (stripe and leaf rust) reaction, entries 2, 4, 6, 10, 12 , 20,21 and 25 were selected for 1998-99 trials.

A trial for semi-arid conditions (5SAWYT) consisting of 50 lines was tested in Takhar, Herat and Khost. The yield data of these 50 entries is summarized in (Annex 1, Table 24). In selection of entries greater weight was given to disease reaction with due consideration to yield per unit area. Entries 3, 6, 9, 12, 15, 18, 21, 24, 25, 39, 40, 42 and 50 were selected for further evaluation. The selected lines includes the top yielding lines that have out yielded the nursery mean $(3396 \mathrm{~kg} / \mathrm{ha})$ by 12 to $28 \%$. The coefficient of variation of the trial was satisfactory ( 10.36 to $16.84 \%$ ) and site mean yield ranged from $1930 \mathrm{~kg} / \mathrm{ha}$ to $4859 \mathrm{~kg} / \mathrm{ha}$.

In 1997-98, four sets of elite selection wheat yield (18ESWYT) from CIMMYT were evaluated in four locations in (Nangarhar, Kandahar, Herat and Khost) provinces of Afghanistan. The testing sites represented diverse environments in the country. The highest yielding site was Herat (6260 $\mathrm{kg} / \mathrm{ha}$ ) and lowest yielding site was Khost (3112 kg/ha). Based on overall mean yield and disease response (leaf and stripe rusts), entries 3, 8, 12, 14, 22, 23, 35, 41 and 50 are selected for 1998-99 trial (Annex 1, Table 25).

During the previous seasons durum wheat yield trials and nurseries from CIMMYT were evaluated for yield and diseases in Afghanistan. Ten lines were selected and tested in (97DWYT1) in six zones in the country. Summary of mean yield and rusts reactions are presented in (Annex 1, Tables 26 and 27). In Nangarhar entries 1, 4, 8 and 10 are in the same significant yield group. These four are the top yielding and have out yielded the nursery mean of $4207 \mathrm{~kg} / \mathrm{ha}$ by 2 to $15 \%$. In Kandahar the five top yielding entries are 2, 3, and 5-7. These lines are in same significant yield group and have produced 1 to $19 \%$ higher grain yield than the nursery mean of $3996 \mathrm{~kg} / \mathrm{ha}$. In Herat entries 2,3,6 and 7 are in the same yield group and have significantly out yielded other lines. These lines have out yielded the nursery mean $(4946 \mathrm{~kg} / \mathrm{ha})$ by 3 to $15 \%$. In Balkh entries 1, 2, 4, 5, 7, 8, and 10 are in the same yield group and are significantly higher yielding than entries 3,6 and 9. The yield of the top lines is 3 to $15 \%$ higher than the nursery mean of $4860 \mathrm{~kg} / \mathrm{hai}$ In Kunduz the four top yielding entries are 2,6,9 and 10 . These entries have 
out yielded the nursery mean (3144 kg/ha) by 1 to $14 \%$. In Ghazni the lines 4,5 and 7 have significantly out yielded all other entries. These entries have shown greater cold tolerance than the rest and their mean yield is 50 to $77 \%$ higher than the nursery mean of $3069 \mathrm{~kg} / \mathrm{ha}$. The grain yield of these lines across six zones revealed that entries 2-5, and 7 are the highest yielding ones and have exceeded the nursery mean yield by 1 to $9 \%$. Based on their yield and disease response (Annex 1, Table 27) entries 2, 3,6 and 9 are selected for further observation.

The project has also received a durum wheat yield trial (98HAAYT) from CIMMYT for 1998 and it was planted in Herat under rainfed conditions. The highest yielding line was line 23 followed by no. $5,8,9$, and 18 . These lines have out yielded the nursery mean $(1082 \mathrm{~kg} / \mathrm{ha})$ by $8-13 \%$. (Annex 1, Table 30). These lines have also been selected and are included in the trial for 1998-99 crop season. The leaf and stripe rust reaction of these lines have ranged from immunity to resistance. Similarly one trial of 12 wheat lines for rainfed areas (NUWYTRF) was received from NARC, Pakistan for evaluation in Afghanistan. This trial was planted in Herat under rainfed conditions. The data is summarized in (Annex 1, Table 29). The data shows that entries 2, 4 and 7-9 are the top yielding ones with grain yields advantages of 5 to $15 \%$ over the nursery mean of $1824 \mathrm{~kg} / \mathrm{ha}$. These yields are impressive because of early planting and well distribution of rain during the growing season.

In addition to these yield trials, observation nurseries and specific yield trials have been received from CIMMYT and ICARDA. These were 4th Facultative and Winter Wheat Yield Trial, 18th Elite Selection Wheat Yield Trial, 5th Semi Arid Wheat Yield Trial, 98 Elite Yield Trial, 30th International Bread Wheat Screening Nursery, 15th Semi Arid Wheat Screening Nursery and 7th Facultative and Winter Wheat Observation Nursery. High yielding and disease resistant lines have been selected from this material and are included in the 1998-99 trials.

Wheat data (1998-99): The National wheat yield trial (98NWYT1) included the top performing 15 lines and/or varieties that were selected from the 1997-98 trials. This trial was planted in two dates (one month apart) in five locations and the yield data is summarized in (Table 1, Annex 2). In Nangarhar province significant differences among entries were observed in both sowing dates. The entries that performed well in 1997-98 trials have shown similar performance in 1998-99 growing season. The yield of entries $(1,7,10-13)$ is not significantly different from each other at $5 \%$ level of significance in the early sowing but is significantly different than the rest of the lines. In late sowing the yields of entries $(4,5,8-10,12-15)$ are not significantly different from each other but significantly different from the rest of the lines. Mean yield loss due to delaying planting in Nangarhar is $11 \mathrm{~kg} / \mathrm{ha} /$ day.

In Kandahar the yields of entries (7, 9, 13-15) are significantly different from other entries while their mean yields are not significantly different from each other. In the late sowing the mean yield of all entries are not significantly different from each other. Mean yield loss due to delaying planting in Kandahar is $13 \mathrm{~kg} / \mathrm{ha} /$ day (Table 1, Annex 2).

In Herat in the normal sowing time, the mean yield of entries $(1,7)$ are significantly different from the rest of the entries while there is no significant difference among their yields. In the late sowing, entries $(1,2,4-7,9,13,14)$ did not show significant yield differences among them but are significantly higher yielding than the remaining entries. Delayed planting has resulted in yield loss of $28 \mathrm{~kg} / \mathrm{ha} /$ day (Table 1, Annex 2).

In Balkh the yields of entries in the trial in both dates were desirable. It indicates that the optimum sowing months are November and December. However, delayed planted has resulted in yield reduction. The mean yield loss due to one month late planting was $7 \mathrm{~kg} / \mathrm{ha}$ /day (Table 1 , Annex 2).

Ghazni is the high yielding location for both dates. The entries $(1,2,4,5,7,9,10$, and 13) produced significantly higher mean yields than the rest of the entries in the first date. The yield differences among these lines were not statistically significant (Table 1, Annex 2). In the second date entries 2, 6, 7, 10, and 13 are significantly higher yielding than the rest. In Ghazni the yield losses of $32 \mathrm{~kg} / \mathrm{ha} /$ day were observed due to late sowing. 
Mean yield over locations for the first sowing date showed entries $(1,5,7,11,13$ and 15) ranked in the top 6 rank. These are the entries that are suitable for early sowing and have out yielded the grand mean $(5778 \mathrm{~kg} / \mathrm{ha})$ by 89 to $633 \mathrm{~kg} / \mathrm{ha}$. The top yield was produced by Bloyka $(6411 \mathrm{~kg} / \mathrm{ha})$ followed by wheat variety Roshan-96 $(6321 \mathrm{~kg} / \mathrm{a})$ and the lowest yield was produced by wheat line PBW $154(5186 \mathrm{~kg} / \mathrm{ha})$. In the second date, the entries $(1,6,7,10,13$ and 14) ranked in the top 6 and produced grain yields of 137 to $259 \mathrm{~kg} / \mathrm{ha}$ more than the grand mean of $5271 \mathrm{~kg} / \mathrm{ha}$. The overall mean yield shows that entries $7,1,5,13,10$, and 15 ranked in the top 6 yielding entries across major agro-ecological zones. The mean yield differences among entries in each date showed genetic variability among genotypes in response to sowing dates. Entry l (Roshan-96), 6 (Bloyka) and 13 (KAUZ*2 / OPATA // KAUZ ranked in the top three entries that produced high yields indicated yield stability over longer sowing dates. The yield difference between two dates showed that entry 6 (ULC/PVN//INA/3/ONC), entry 14 (PBWI54) across locations have produced higher yield in the second sowing date (Table 1, Annex 2). These entries should be carefully studied in farmer's field demonstration trial of sowing dates in all six zones. From this data it can be concluded that on the average there is a $17 \mathrm{~kg} / \mathrm{ha} /$ day yield loss due to one month late planting. This is an unnecessary yield loss that can lead to $663000 \mathrm{MT}$ production loss in the country. This amount of wheat will feed 5.1 million Afghans for one year.

The genotypic differences among wheat lines in response to different planting times is well demonstrated by (Table 21, Annex 2). In cooperation with the Nation Agriculture Research Council of Pakistan, the National Uniform Wheat Yield Trial (NUWYT) was planted in two dates in Nangarhar in 1998-99. The yield loss between dates ranges from $12 \mathrm{~kg} / \mathrm{ha}$ for Inqalab-91 to $1325 \mathrm{~kg} / \mathrm{ha}$ for Roshan-96. There were lines that exhibited yield increase of $90 \mathrm{~kg} / \mathrm{ha}$ to 1181 $\mathrm{kg} / \mathrm{ha}$ in the second sowing date. This again confirms the genotypic differences among lines. For the two dates and 20 genotypes on the average $9 \mathrm{~kg} / \mathrm{ha} /$ day loss was recorded.

The $98 \mathrm{NWYTl}$ was also planted in Farah, Laghman, Kunar, Nangarhar (Shewa), and Khost in November and in Wardak (Jelraz) in October 1998. The overall mean yield data shows that the top 6 yielding entries are Roshan-96 (5986 kg/ha), Bloyka $(5715 \mathrm{~kg} / \mathrm{ha})$, PBWl $54(5165 \mathrm{~kg} / \mathrm{ha})$, Pasteur (5137 kg/ha), Kauz (5060 kg/ha) and KAUZ*2/ OPATA // KAUZ (5045 Kg/ha) respectively (Table 2, Annex 2). It is interesting to note that in Jelraz, the three top yielding wheat entries are Bloyka (6687 kg/ha), Roshan-96 (6375 kg/ha) and Gul-96 (4812 kg/ha). Based on yield, disease resistance and grain color entries 1, 4-7, 9, 10, and 13 have been selected for further evaluation in 1999-2000 crop season.

For cooler regions of the country winter wheat varieties are desirable. To this date no winter wheat variety has been released for Afghanistan. From 1997-1998 wheat trials, 15 top yielding facultative wheat lines with high degree of cold tolerance were selected and put in (98NWYT2) trial were planted in four locations (Nangarhar, Balkh, Herat, Nooristan). In Nangarhar the trial was planted in Agam district that has relatively cooler winter. Due to security problems this trial was not planted in Takhar. The data from four locations is summarized in (Table 3, Annex 2). Ten entries from this trial were tested in Ghazni and Wardak (Jelraz) in 1998-99 crop season and the data is presented in (Table 4, Annex 2).

In Nangarhar there are significant difference among entries for mean yield. The data shows that entry 3 and 5 are the highest yielding followed by entries 1,2,6, and 15 (Table 3, Annex 2). The yields of these entries are ranging from $6514 \mathrm{~kg} / \mathrm{ha}$ to $5632 \mathrm{~kg} / \mathrm{ha}$. The lowest yielding line is 11 with a yield of $4339 \mathrm{~kg} / \mathrm{ha}$ which is also a very good yield.

In Balkh all lines performed very well and those lines that were top yielding in Nangarhar are also top yielding in Balkh. Entries 3-8, 10, 12, 14 and 15 are in the highest yielding with no significant difference in their mean yield but, they are significantly different from other entries. The mean yield of these entries ranged from the highest of $6952 \mathrm{~kg} / \mathrm{ha}$ to lowest of $5052 \mathrm{~kg} / \mathrm{ha}$ (Table 3 , Annex 2). In Herat entries $(1,6,9,10,13$, and 15) ranked in the top six high yielding genotypes with no significant difference in their yields (Table 3, Annex 2). The yield range of these entries is 5881 to $5321 \mathrm{~kg} / \mathrm{ha}$ producing 167 to $727 \mathrm{~kg} / \mathrm{ha}$ higher yield than the site mean $(5154 \mathrm{~kg} / \mathrm{ha})$. In 
Nooristan the trial was conducted by MADERA. The six top yielding entries are $(1,5,6,12-14)$ ranging in yield from $3756 \mathrm{~kg} / \mathrm{ha}$ to $4337 \mathrm{~kg} / \mathrm{ha}$ exceeding the nursery mean (3573 kg/ha) by 183 to $764 \mathrm{~kg} / \mathrm{ha}$. The highest yield was given by wheat variety Pamir-94. The overall mean yield data showed that entry $(1,3,5,6,9$ and 12) are the six highest yielding lines exceeding the overall nursery mean $(5116 \mathrm{~kg} / \mathrm{ha})$ by 127 to $489 \mathrm{~kg} / \mathrm{ha}$. Considering the four locations the highest yielding site is Balkh and the lowest yielding site is Nooristan (Table 3 Annex 2). Entries 1, 5, 7 , and 14) are selected for 1999-2000 yield trials. The data of the ten lines of this trial that were tested in Ghazni and Jalrez is summarized in Table 4, Annex 2. All entries performed very well in Ghazni. The highest yield was given by entry $2(8906 \mathrm{~kg} / \mathrm{ha})$ followed by Pamir-94 ( $8375 \mathrm{~kg} / \mathrm{ha})$ and Rana-96 $(8250 \mathrm{~kg} / \mathrm{ha})$. The yields of these entries are not significantly different from each other. In Jalrez because of security problems, difficulties were encountered in the management of the trial, but those entries that produced highest yields in Ghazni have also ranked in the top 5 yielding entries (Table 4, Annex 2).

For rainfed wheat production 10 highest yielding lines were selected form the 1997-98 wheat trials and tested in (98NRWYT3) in Balkh, Herat, and Baghlan provinces. In Balkh entries (6-8) produced the highest yields with no significant difference in their yields (Table 5, Annex 2). In Herat entries (2-4, 7 and 8 ) produced the highest yields with no significant difference in their mean yield. In Baghlan entries (3, 5, 8, and 9 ) produced the highest yields with no significant difference in their mean yield (Table 5 , Annex 2 ). From the overall mean yield data it shows that entries ( 3 and 8 ) have yielded 13 and $10 \%$ higher than the country mean yield $(846 \mathrm{~kg} / \mathrm{ha})$ for rainfed conditions. Entries 3, 4, 5 and 7 have been selected for inclusion in the 1999-2000 wheat yield trial under rainfed conditions.

The present situation in Afghanistan necessitates the identification of wheat varieties with wide adaptability. For this purpose ten top yielding lines from 1997-98 yield trials were selected and tested in five locations in (98NWYT4) in the country. Mean yield and ranks of these lines are summarized in (Table 6, Annex 2). In Nangarhar the trial was conducted in Agam district and it shows that the yields of entries $(1,3,5,9$ and 10) ranked in the top five ranging from $6158 \mathrm{~kg} / \mathrm{ha}$ to $6828 \mathrm{~kg} / \mathrm{ha}$ and exceeding the site mean yield ( $6063 \mathrm{~kg} / \mathrm{ha})$ by $95 \mathrm{~kg}$ to $765 \mathrm{~kg} / \mathrm{ha}$. The yields of these entries are not significantly different from each other. In Balkh, the wheat variety Roshan-96 produced significantly higher yield $(8341 \mathrm{~kg} / \mathrm{ha}$ ) than the rest of the entries (Table 6 , Annex 2). The mean yield of the remaining entries came in a separate category of significance. Entries (2, 3 , 7 and 9 ) are among the top five highest yielding entries in this location. In Kandahar the mean yields of entries (1,3 5-9) are not significantly different from each other and the top five yielding lines are included in these entries. Their yields ranged from $5026 \mathrm{~kg} / \mathrm{ha}$ to $5530 \mathrm{~kg} / \mathrm{ha}$. In Ghazni the mean yield of entries (2-5, 7, 8 and 10) are not significantly different from each other. The top five yielding entries in this location yielded $4812 \mathrm{~kg}$ to $5781 \mathrm{~kg} / \mathrm{ha}$ with the site mean yield of $4800 \mathrm{~kg} / \mathrm{ha}$. In Herat entries $(1,4,5,9$ and 10) are the top five highest yielding ones with yield range of $5415 \mathrm{~kg}$ to $6094 \mathrm{~kg} / \mathrm{ha}$ and the site mean yield of $5315 \mathrm{~kg} / \mathrm{ha}$ (Table 6 , Annex 2). The overall mean yield data across locations revealed that Roshan-96 ranked first $(6105 \mathrm{~kg} / \mathrm{ha})$ over five location and followed by entry 9 (KAUZ *2 /OPATA // KAUZ) with a mean yield of 5802 $\mathrm{kg} / \mathrm{ha}$ are the entries with wide adaptability and ranked high in four out of five locations. Roshan96 is a wheat variety released by the project and has ranked 2nd in the 1997-98 yield trials. Entry 9 (KAUZ *2 /OPATA // KAUZ) has also performed very well in the 1997-98 trials. Gul-96 with a high degree of cold tolerance ranked 3rd highest yielding wheat variety: This is very encouraging for the project because these entries are included in the 1999-2000 trials and their multiplication is initiated.

Ten wheat lines select from 1997-98 preliminary wheat yield trial were tested in (98AWYT1). The trial was conducted in five locations and is summarized in (Table 7, Annex 2). In Nangarhar the mean yields of entries (1-5, 7 and 10) are not significantly different from each other. The five top yielding, lines are $(1,3,5,7$ and 10$)$, these entries exceed the site mean yield $(5003 \mathrm{~kg} / \mathrm{ha})$ by $329 \mathrm{~kg}$ to $498 \mathrm{~kg} / \mathrm{ha}$. In Kandahar the performance of these varieties was the same as in Nangarhar 
but the yields of these lines were higher in Kandahar. The site mean yield was $5709 \mathrm{~kg} / \mathrm{ha}$ and the five highest yielding lines exceeded the site mean yield by $354 \mathrm{~kg}$ to $747 \mathrm{~kg} / \mathrm{ha}$. Similar performance was recorded in both Balkh and Ghazni. In Balkh the five top yielding entries exceed the site mean yield ( $6364 \mathrm{~kg} / \mathrm{ha}$ ) by 53 to $507 \mathrm{~kg} / \mathrm{ha}$ and in Ghazni the five top yielding lines exceeded the site mean yield $(6946 \mathrm{~kg} / \mathrm{ha})$ by 4 to $835 \mathrm{~kg} / \mathrm{ha}$. In Kunduz the situation was different but entries (1,4 and 6-10) are in same category of significance. This has been the lowest yielding site in 1998-99 with the site mean yield of $4105 \mathrm{~kg} / \mathrm{ha}$. The five top yielding lines exceeded the site mean yield by $201 \mathrm{~kg}$ to $595 \mathrm{~kg} / \mathrm{ha}$ (Table 7, Annex 2). The overall mean yield of these lines showed that entries (1,3-5 and 10) have produced highest yields and have exceed the country mean yield (5626 kg/ha) by $196 \mathrm{~kg}$ to $238 \mathrm{~kg} / \mathrm{ha}$. Entries 1, 3, 6, and 8 have been selected for 1999-2000 yield trials.

The data of 15 bread wheat lines tested in (98AWYT2) is summarized in (Table 8, Annex 2). This trial was conducted in Nangarhar and Ghazni provinces. In Nangarhar the mean yield of entries ( 1 , $2,5,12-14)$ are not significantly different from each other but are significantly higher from the rest of the entries. The five highest yielding entries are 1,2,12-14 and these lines exceed the site mean yield of $4756 \mathrm{~kg} / \mathrm{ha}$ by $395 \mathrm{~kg}$ to $973 \mathrm{~kg} / \mathrm{ha}$ which is equal to $8 \%$ to $20 \%$ yield increase. In Ghazni the yield of entry 1 and 2 are not significantly different from each other but are highest in this site. The top five highest yielding entries are $(1,2,8,11$ and 15). These entries exceed the nursery mean by $193 \mathrm{~kg}$ to $987 \mathrm{~kg} / \mathrm{ha}$ corresponding to $3 \%$ to $14 \%$ yield increase. Data from both sites shows that entries 1, 2, 13-15 are the highest yielding and these ones out yielded the overall mean yield ( $5969 \mathrm{~kg} / \mathrm{ha}$ ) by 4 to $16 \%$. Entries 1, 2, and 8 have been selected for 1999-2000 yield trials.

The mean yield data of ten bread wheat lines tested in (98AWYT3) in five locations is summarized in (Table 9, Annex 2). In Nangarhar the mean yield of entries 3 and 4 is significantly less than the rest of the entries. The five highest yielding lines are (2,6,7,9 and 10). The mean yield of the highest yielding entry is $6.7 \%$ higher than the nursery mean $(5025 \mathrm{~kg} / \mathrm{ha})$. In Kandahar entries 9 and 1 are the highest yielding ones with mean yield of 7219 and $7084 \mathrm{~kg} / \mathrm{ha}$ respectively. Most of the entries are high yielding in this location as shown by nursery mean yield $(6072 \mathrm{~kg} / \mathrm{ha})$. The 5 highest yielding entries $(1,5,6,9,10)$ have shown yield increase of $3 \%$ to 19 $\%$ over the nursery mean. In Balkh entry 6 is significantly lower yielding than the rest of entries. The mean yield differences among the remaining entries are not significant (Table 9, Annex 2). The mean yield of the 5 highest yielding lines $(3,5,7,9$ and 10$)$ exceeded the nursery mean yield $(5642 \mathrm{~kg} / \mathrm{ha}$ ) by $5.6 \%$ to $8 \%$. In Herat entries 2 and 8 are significantly lower yielding than the rest (Table 9, Annex 2). The mean yield differences among the remaining entries are not significant. The mean yields of the 5 highest yielding entries $(1,5,7,9,10)$ exceed the nursery mean $(5424 \mathrm{~kg} / \mathrm{ha}$ ) by $92 \mathrm{~kg}$ to $469 \mathrm{~kg} / \mathrm{ha}$. In khost the trial received hail damaged at harvest time which resulted in considerable yields reduction, therefore the mean yields are much lower than other locations. Entries $(1,7,10)$ are significantly higher yielding than the rest. The mean yields of the five highest yielding entries $(1,3,6,7,10)$ are $12 \%$ to $39 \%$ higher than the nursery mean yield (1987 kg/ha). From the overall mean yield data it shows that entries 1 (Bacanora T88), 7 ( STAR//KAUZ/STAR), 9 ( Kariega) and 10 ( Kauz) are consistently higher yielding across locations and have registered yield increase of $5 \%$ to $10 \%$ over the mean yield across locations (4830 kg/ha) indicating the wide adaptability and yield stability. Based on yield and rust reaction entries 1 and 5 were selected for further evaluation in 1999-2000.

For rainfed wheat production 15 lines were tested in (98ARWYT4) in four locations ( Baghlan, Balkh, Herat and Takhar). The mean yield data is presented in (Table 10, Annex 2 ). In Baghlan entries 4 and 5 recorded lowest yields. The mean yield differences among lines 1-3,10,12 and 13 are not significant. These entries produced significantly higher yields than the remaining entries. The mean yields 5 top entries ( 2,3,10,12 and 13) exceeded the nursery mean (1141 kg/ha ) by $41 \mathrm{~kg}$ to $170 \mathrm{~kg} / \mathrm{ha}$. In Balkh entries 2, 4, 5, 7 and 12 ranked in the top five high yielding ones. Their mean yields exceeded the nursery mean ( $673 \mathrm{~kg} / \mathrm{ha}$ ) by $8 \%$ to $26 \%$. In Herat entries ( 7,9 
,and 14 ) are significantly lower yielding than the rest. The mean yield differences among the remaining entries are not significantly. The mean yields of the top five yielding lines exceeded the nursery mean yield ( $1258 \mathrm{~kg} / \mathrm{ha}$ ) by $5 \%$ to $27 \%$. In Takhar the mean yield of entries $(1,10,12-$ 15) are significantly different from other entries. The mean yields of these lines exceeded the nursery mean ( $1222 \mathrm{~kg} / \mathrm{ha}$ ) by $6 \%$ to $19 \%$. The combined mean yield data shows that entries ( 2. 10, 12, 13 and 15) are the top yielding and exceeded the national average (1053 kg/ha) by $6 \%$ to $19 \%$. These entries are selected for 1999-2000 crop season.

The mean yield data of 10 bread wheat lines tested under irrigated condition in Kandahar and Herat in (98AWYT5) is presented in ( Table 11, Annex 2 ). In Kandahar the yield performance is very good as indicated by nursery mean ( $6024 \mathrm{~kg} / \mathrm{ha}$ ). The yields of entries 9 and 10 are significantly different from other lines. The five highest yielding lines exceeded the nursery mean by $17 \mathrm{~kg}$ to $791 \mathrm{~kg} / \mathrm{ha}$. In Herat the yields of lines 2 , and 10 are significantly different from other. The five highest yielding lines ( $2,4,5,7$ and 10 ) exceeded the nursery mean ( $5082 \mathrm{~kg} / \mathrm{ha}$ ) by 29 $\mathrm{kg}$ to $887 \mathrm{~kg} / \mathrm{ha}$. The combined mean yield data shows that lines $(2,4,7,9$ and 10$)$ are the highest yielding and their yields exceeded the grand mean yield ( $5553 \mathrm{~kg} / \mathrm{ha}$ ) by $2 \%$ to $9 \%$.

The data on 15 bread wheat lines selected in Herat in 1997-98 was tested in (98HAWYT1) during 1998-99 crops season. The summary of data is presented in (Table 12. Annex 2 ). The yield of line 15 ( Pamir-94) is significantly higher than the rest of the lines. The yields of lines (1, 4, 9. and 11 ) are not significantly different from each other. These top yielding lines ( $1,4,9,11$ and 15) out yielded the nursery mean ( $4816 \mathrm{~kg} / \mathrm{ha}$ ) by $5 \%$ to $29 \%$. Based on disease response and yield, lines 4 and 8 have been selected for 1999-2000 wheat yield trials.

The data on yield of 15 bread wheat lines tested in (98PWYT1) trial from five locations is summarized in (Table 13, Annex 2 ). The data from Nangarhar shows that lines (2,3,11-15) are the highest yielding lines. The yield differences among these lines are not significant, but their yields are significantly different from the rest of the lines. The top five yielding lines are $(3,11-$ 13, and 15 ). Their yields ranged from $6820 \mathrm{~kg}$ to $7760 \mathrm{~kg} / \mathrm{ha}$. The yields of these lines exceeded the location mean yield ( $6448 \mathrm{~kg} / \mathrm{ha}$ ) by $6 \%$ to $20 \%$. All 15 lines have performed very well in this location. The lowest yield of $4552 \mathrm{~kg} / \mathrm{ha}$ was given by line 9 and the highest by entry II ( $7760 \mathrm{~kg} / \mathrm{ha}$ ). In Kandahar the highest yielding lines are (1-3, 5, 6, I1, and 13-15). The yields of these entries are not significantly different from each other, but significantly higher from the rest. The five highest yielding lines $(1,6,11,13,15)$ have yielded $7 \%$ to $15 \%$ higher than the nursery mean ( $6731 \mathrm{~kg} / \mathrm{ha}$ ). In Balkh province. entries $(4,6,10,13,15)$ are the highest yielding ones. The yields of these lines are not significantly different from each other but different from the rest at $5 \%$ level of significance. These entries have yielded $6 \%$ to $25 \%$ better than the nursery mean ( $4733 \mathrm{~kg} / \mathrm{ha})$. The data of this trial in Herat showed that entries $(2,3,5,11,15)$ are the top yielding with no significant difference among their yield but significantly higher from the rest. These entries have produce $3 \%$ to $16 \%$ higher yield than the site mean yield ( $4777 \mathrm{~kg} / \mathrm{ha}$ ). This trial was evaluated in Khost in cooperation with DACAAR. The data showed that the yields of entries 1-5, 7.8, and 11-14 are not significantly different from each other. These entries include the five highest yielding entries $(5,7,8,11,14$ ). These entries have produced $8 \%$ to $23 \%$ higher yield than the site mean yield ( $4506 \mathrm{~kg} / \mathrm{ha}$ ). The overall mean yield of these entries across five locations shows that the top yielding entries are 2. 5, 11, 13 and 15 ( Table 13, Annex 2 ). These entries on the average has produced from $4 \%$ to $10 \%$ higher yield than the national average of this trial ( $5439 \mathrm{~kg} / \mathrm{ha})$.

The yield data of 1,5 bread wheat lines tested in three locations in (98PWYT2 ) is summarized in (Table 14. Annex"2). In Nangarhar the lines 1,2, 4-7, 10-12, 14 and 15 gave the highest yield with no significance among these lines, but the yield differences of these lines are significant from the yields of remaining lines. The five top yielding lines yielded $0.5 \%$ to $11 \%$ higher yield than the site mean yield ( $6341 \mathrm{~kg} / \mathrm{ha}$ ). Balkh is the second highest yielding location for this trial. The highest yielding lines are $2,4-6,8,10,12$ and 13 . The yield differences of these lines are 
significantly different from the rest of the lines. These five top yielding lines have yielded $0.5 \%$ to $25 \%$ higher than the site mean yield $(4873 \mathrm{~kg} / \mathrm{ha})$. In Khost, there are no significant yield differences among the lines tested. The overall mean yield showed that lines 4-6, 10 and 12 have yielded $6 \%$ higher than the nursery mean yield ( $5216 \mathrm{~kg} / \mathrm{ha}$ ).

The mean yield ( $\mathrm{Kg} / \mathrm{ha}$ ) and rank of 10 bread wheat lines tested under irrigated condition (98PWYT3) in Ghazni and Herat is presented in (Table 15. Annex 2 ). The yield of these lines in Ghazni is higher than Herat but, lines 5, 7 and 9 are highest yielding in both locations. The overall mean yield of these lines shows that lines 3,5.7 and 9 are top yielding and have produced $5 \%$ to $17 \%$ higher yield than the nursery mean over two locations $(6174 \mathrm{Kg} / \mathrm{ha})$. Lines 5 and 9 are selected for 1999-2000 yield trials.

For 1998-99 crop season the project received wheat yield a trial (3EYT98-99IR) from CIMMYT/ Turkey for testing in Afghanistan. This trial consisted of 25 bread wheat lines and was planted in Ghazni. The data is summarized in Table 16, Annex 2. The yields of lines 9, 10,20,21, and 24 are significantly higher than the rest of the lines. Their mean yield is $8 \%$ to $17 \%$ higher than the nursery mean yield ( $7153 \mathrm{Kg} / \mathrm{ha}$ ). Lines $2,3,6,9,10,20-22$ and 24 have been selected for further evaluation in 1999-2000 crop season for higher elevation of Afghanistan.

In 1998-99 crop season the project received a trial from ICARDA ( WYT-TA-98-99) for screening in warmer areas of the country. This trial consisted of 24 bread wheat lines and was tested in Nangarhar and Kandahar and the data is presented in (Table 17, Annex 2 ). The performance of these lines was very good in these locations and compared well. The overall mean yield data shows that lines 6, 16-18, and 24 are the top yielding with a mean yield advantage of $4.5 \%$ to $6 \%$ over the nursery mean yield ( $5921 \mathrm{Kg} / \mathrm{ha}$ ). From this trial lines 11,17 and 18 are selected for further evaluation in 1999-2000 crop season.

Similarly in 1998-99 crop season the project received a trial ( 19ESWYT) from CIMMYT / Mexico consisting of 50 elite wheat lines for testing in Afghanistan. This trial was planted in two locations ( Nangarhar and Herat) representing both warmer and cooler areas of the country. The data is summarized in ( Table 18. Annex 2 ). In Nangarhar 36 lines yielded grain yield that were not significantly different from each other at $5 \%$ level of significance. The 5 highest yielding lines $(1,4,23,27,42)$ yielded $16 \%$ to $26 \%$ higher yield than the site mean yield ( $4435 \mathrm{Kg} / \mathrm{ha})$. The results of trial in Herat were similar to the results of Nangarhar. In this location the five highest yielding lines were $(4,21,24,26,36)$ and their yield advantage was $14 \%$ to $20 \%$ over the site mean yield ( $3008 \mathrm{Kg} / \mathrm{ha}$ ). The overall mean yield data showed that the five best yielding lines are $(1,4,13,23,42)$. These lines have produced yields that are $12 \%$ to $21 \%$ higher than the nursery mean yield ( $3722 \mathrm{Kg} / \mathrm{ha}$ ). Lines 3, 13, 16, 27 and 42 were selected for further evaluation in 1999-2000 crop season.

For the identification of promising wheat varieties for rainfed condition, the project received a trial ( 6SAWYT) consisting of 50 bread wheat lines. This trial was tested in rainfed conditions in Herat and Kunduz. The data of this trial is summarized in (Table 19, Annex 2 ). It showed that these lines producèd very good yield in Kunduz, and their performance in Herat was also very good. In Herat lines $(7,8,20,31,32$ ) are the top yielding with yields ranging from $1460 \mathrm{Kg} / \mathrm{ha}$ to $1975 \mathrm{Kg} / \mathrm{ha}$ which is $34 \%$ to $81 \%$ higher than the site mean yield of $109 \mathrm{l} \mathrm{Kg} / \mathrm{ha}$. In Kunduz lines $(3,4,8,9,21$ ) are the five highest lines with yields ranging from $4014 \mathrm{Kg} / \mathrm{ha}$ to $4540 \mathrm{Kg} / \mathrm{ha}$ which is $24 \%$ to $40 \%$ higher than the site mean yield of $3234 \mathrm{Kg} / \mathrm{ha}$. The combined data showed that lines 3, 4, 7-9 are the five highest yielding ones with yields ranging from $2607 \mathrm{Kg} / \mathrm{ha}$ t0 3128 $\mathrm{Kg} / \mathrm{ha}$. These yields are even better than the national average for local wheat varieties under irrigated conditions. These lines have performed equal to or $17 \%$ better than the nursery mean yield of $2679 \mathrm{Kg} / \mathrm{ha}$. For crop season 1999-2000 lines 7, 8, 12, 13 and 22 have been selected for multiple location testing.

The diverse agro-climatic conditions of Afghanistan necessitates to test wheat germplasm suitable for those conditions? For this purpose, the project tested 45 lines ( $5 \mathrm{FWWYT}$ ) from CIMMYT / 
Turkey in Ghazmi for the identification of winter wheat variety. The data showed that the yields of lines $(1,4,5,8,11-13,15,20,21,23-26,29,34,36,38-43$ and 45$)$ are not significantly different from each other at $5 \%$ level of significance ( Table 20, Annex 2 ). The five highest performing lines produced yields ranging from $6167 \mathrm{Kg} / \mathrm{ha}$ to $6967 \mathrm{Kg} / \mathrm{ha}$ representing $12 \%$ to $26 \%$ yield advantage over the site mean yield ( $5523 \mathrm{Kg} / \mathrm{ha}$ ). For the crop season 1999-2000 the lines ( 13 , $15,25,36,38-40$, and 43 have been selected for further testing.

The project continues to cooperate with the National Agriculture Research Council of Pakistan ( NARC) and in 1998-99 crop season one sowing date trial ( NUWYT) comprising of 20 lines was tested in Nangarhar planted in two dates one month apart. The results are summarized in ( Table 21 , Annex 2$)$. In the first sowing date the yields of entries $(2,5-8,10,11,13,16,18-20)$ are top . with no significant difference among these lines at $5 \%$ level of significance. In this sowing date the five top yielding lines were $(10,11,13,16$, and 20 ) with yields ranging from $4954 \mathrm{Kg} / \mathrm{ha}$ to $5354 \mathrm{Kg} / \mathrm{ha}$ representing a $6 \%$ to $14 \%$ yield increase over the nursery mean of $4685 \mathrm{Kg} / \mathrm{ha}$. In the second planting date generally the entries that were top yielding with no significant difference in their yield in the first sowing date performed the same in the second sowing date (Table 21, Annex 2 ) with very little change in the yield rank. In this date entries ( $1,2,5,14$ and 19$)$ are the five highest yielding ones with yields ranging from 4746 to $4800 \mathrm{Kg} / \mathrm{ha}$ and representing a $7.6 \%$ to $8.8 \%$ increase over the nursery mean yield ( $4411 \mathrm{Kg} / \mathrm{ha})$. In th is trial, six lines $(1,4,5,12$, 14,17 ) are suitable for latter planting while the remaining 14 lines are better for early planting. There are three lines ( $8,18,19$ ) that have genotypic plasticity regarding sowing dates. The overall mean yield showed that the five top yielding lines are $(2,10,11,16,19)$ with yields ranging from 4761 to $4866 \mathrm{Kg} / \mathrm{ha}$ representing a $5 \%$ to $7 \%$ yield advantage over the nursery mean ( $4548 \mathrm{Kg} / \mathrm{ha}$ ). On the average the yield loss due to late planting was $9 \mathrm{Kg} / \mathrm{ha} / \mathrm{day}$ in this trial.

The project has previously received durum wheat germplasm from CIMMYT and has selected ten lines that are good yielding. These lines have been tested in three locations in (98 NDWYT). The data is summarized in ( Table 22, Annex 2 ). The grain yield results of these lines are stable and similar in all three locations as indicated by site mean yields ranging from 4846 to $4943 \mathrm{Kg} / \mathrm{ha}$. The overall mean yield data shows that all 9 lines have produced $66 \%$ higher yields than the local ( $3065 \mathrm{Kg} / \mathrm{ha}$ ). Lines ( $3,4,7$ and 8 ) have out yielded the nursery mean yield ( $4886 \mathrm{Kg} / \mathrm{ha}$ ) by 5 $\%$ to $12 \%$.

\section{WHEAT AGRONOMY}

\section{Introduction}

Agronomy trials on dates of planting and rates of fertilizer were conducted in all six zones during 1997-98 and 1998-99 crop seasons in order to identify economical combinations of agronomic practices for profitable wheat production in the country. In Herat and Nangarhar the trials were conducted on research stations of the ministry of agriculture but, in the remaining 4 sites, research was conducted on farmers' field.

\section{Fertilizer Experiments}

In order for the wheat genotypes to produce yield according to its genetic potential, enough plant food, water and light must be available during growing season. Three rates of nitrogen in the form of urea ( 0,125 and $250 \mathrm{~kg} / \mathrm{ha}$ of urea) and three rates of phosphorus in the form of triple super phosphate $(0,100$ and $200 \mathrm{~kg} / \mathrm{ha}$ of TSP) in factorial combinations were tested in a randomized complete block design in four replications. The plot size was 6 rows 5 meter long with a row to 
row spacing of $25 \mathrm{~cm}$. For yield purposes four central rows, four meter long were harvested. The wheat varieties Roshan-96, Gul-96, Pamir-94 and Kauz were used for this trial. A seed rate of 100 $\mathrm{kg} / \mathrm{ha}$ was used in all locations. All other cultural practices were uniformly applied to the trial in all locations. The data was analyzed using MSTAT statistical package. Mean yield, yield ranking and economic gains for this trial are summarized in (Annex 1, Table 31 and Table 23, Annex 2). The experiment has been conducted and managed very well in all locations as shown by the low $\%$ C.V. Variation that is observed in the fertility and date of sowing trials has to be evaluated in light of the soil fertility status of the farmer's field because of considerable variability in farming practices. Economic gain due to fertilizer application is calculated by finding the yield differences from control times price of wheat minus cost of fertilizer for that treatment

During 1997-98 crop season in Nangarhar the grain yield data of fertilizer experiment showed that the highest yield (4581 kg/ha) and economic gain ( 1.5 million Afs) was achieved by treatment 6 $\left(\mathrm{N}_{1} \mathrm{P}_{2}\right)$. In this location, no significant differences were observed among the zero nitrogen level at all levels of phosphorus (Annex 1, Table 31). Similar trend was observed for the other two levels of nitrogen fertilizer. The yield differences between treatment combinations $\left(\mathrm{N}_{1} \mathrm{P}_{2}\right.$ and $\left(\mathrm{N}_{0} \mathrm{P}_{0}\right)$ were $2306 \mathrm{~kg} / \mathrm{ha}$ and between treatment combination $\left(\mathrm{N}_{2} \mathrm{P}_{2}\right)$ and $\left(\mathrm{N}_{0} \mathrm{P}_{0}\right)$ were $1413 \mathrm{~kg} / \mathrm{ha}$.

Results of 1998-99 crop season of this experiment in Nangarhar showed that the treatment combination $\left(\mathrm{N}_{2} \mathrm{P}_{1}\right)$ produced the highest yield $(6419 \mathrm{Kg} / \mathrm{ha})$ with an economic gain of (44.2 millions Afs.) followed by treatment combinations $N_{1} P_{0}(5551 \mathrm{Kg} / \mathrm{ha})$ and $\mathrm{N}_{2} \dot{\mathrm{P}}_{0}(5710 \mathrm{Kg} / \mathrm{ha}$. $)$. The data shows that wheat responded well to treatment combination of nitrogen with and without phosphorus and produced good yields with high profit. The yield differences among the $N_{1}$ treatment at all levels of phosphorus were not significantly different from each other but $\left(\mathrm{N}_{2} \mathrm{P}_{1}\right)$ produced the highest grain yield. The grain yield response to various doses of phosphorus in the absence of nitrogen was not significant. Treatments $5\left(\mathrm{~N}_{1} \mathrm{P}_{1}\right)$ and $9\left(\mathrm{~N}_{2} \mathrm{P}_{2}\right)$ have produced four metric tons extra yield in comparison to control treatment $\mathrm{N}_{0} \mathrm{P}_{0}$ ( Table 23 , Annex 2 ).

During 1997-98 crop season in Kandahar the highest yielding treatment combination was $\mathrm{N}_{2} \mathrm{P}_{2}$ $(6555 \mathrm{~kg} / \mathrm{ha})$. Highly significant yield differences were observed in the yields due to different rates of fertilizer. The difference in yield from no fertilizer and the highest yielding treatment combination $\mathrm{N}_{2} \mathrm{P}_{2}$ was $4396 \mathrm{~kg} / \mathrm{ha}$. In Herat the highest yield $(6034 \mathrm{~kg} / \mathrm{ha})$ was recorded for treatment combination $\left(\mathrm{N}_{2} \mathrm{P}_{1}\right)$ with no significant difference from $\left(\mathrm{N}_{2} \mathrm{P}_{2}\right)$ and $(\mathrm{N} 1 \mathrm{P} 2)$. No significant yield differences were observed for treatment combinations $\mathrm{N}_{0} \mathrm{P}_{1}, \mathrm{~N}_{0} \mathrm{P}_{2}$ and $\mathrm{N}_{1} \mathrm{P}_{0}$. Similarly no significant yield differences were observed between treatment combination $\mathrm{N}_{0} \mathrm{P}_{0}$ and $\mathrm{N}_{0} \mathrm{P}_{1}$. This could be explained due to the inherent fertility status of soil in the experimental site. The yield differences between $\mathrm{N}_{0} \mathrm{P}_{0}$ and $\mathrm{N}_{1} \mathrm{P}_{1}$ and $\mathrm{N}_{2} \mathrm{P}_{2}$ were 1513 and $1950 \mathrm{~kg} / \mathrm{ha}$. The 1998-99 crop season data showed ( Table 23, Annex 2 ). that the $57 \mathrm{Kg} / \mathrm{ha}$ and $115 \mathrm{Kg} / \mathrm{ha}$ nitrogen in combination with all levels of phosphorus produced good yields and economic gains but, the highest gains were achieved with treatment combination $\mathrm{N}_{1} \mathrm{P}_{2}(4527 \mathrm{Kg} / \mathrm{ha})$ and $\mathrm{N}_{2} \mathrm{P}_{2}(5067$ $\mathrm{Kg} / \mathrm{ha})$.

In Balkh the highest yields were recorded for $\mathrm{N}_{2} \mathrm{P}_{1}$ and $\mathrm{N}_{2} \mathrm{P}_{2}$ followed by $\mathrm{N}_{1} \mathrm{P}_{1}$ and. $\mathrm{N}_{1} \mathrm{P}_{2}$ during 1997-98 crop season. There is no significant differences between these treatments and these treatments are significantly higher than the rest. Treatments $\mathrm{N} 1 \mathrm{p} 1$ and $\mathrm{N} 2 \mathrm{P} 2$ produced 1753 and $2857 \mathrm{~kg} / \mathrm{ha}$ higher yields than no fertilizer treatment. The high yield of $3459 \mathrm{~kg} / \mathrm{ha}$ for control treatment is indicative of the good fertility status of the soil in farmer's field. It is worth mentioning that despite the high fertility status of the soil, application of both nitrogen and phosphorus fertilizer showed high economic gains. In 1998-99 crop season the yields are high in all treatment combinations. No significant yield differences are observed within nitrogen treatments at various levels of phosphorus. The $115 \mathrm{Kg} / \mathrm{ha}$ nitrogen treatment at all levels of phosphorus produced yields that are significantly higher than the other treatment combinations ( Table 23, Annex 2 ). The highest grain yield and economic gain was recorded for treatment 8 $\left(\mathrm{N}_{2} \mathrm{P}_{1}\right)$ followed by treatments 9 and $7\left(\mathrm{~N}_{2} \mathrm{P}_{2}\right.$ and $\left.\mathrm{N}_{2} \mathrm{P}_{0}\right)$.

In Laghman.during 1997-98 crop season, the highest yielding treatment combination are the high 
rates $(115 \mathrm{Kg} / \mathrm{ha})$ of nitrogen with or with out phosphorus fertilizer and followed by $(57 \mathrm{Kg} / \mathrm{ha})$ of nitrogen with or without phosphorus. The yield differences of nitrogen treatment with the low and high dose of phosphorus are significant in both cases. The lowest yielding treatment combinations are the zero level of nitrogen with or without phosphorus, and the yield differences between treatments are not significant (Annex 1, Table 31). The yield increase due to $N_{1} P_{1}$ and $\mathrm{N}_{2} \mathrm{P}_{2}$ treatments from control are $2280 \mathrm{~kg} / \mathrm{ha}$ and $4073 \mathrm{~kg} / \mathrm{ha}$ respectively. During 1998-99, crop season, the high rate of nitrogen ( $115 \mathrm{Kg} / \mathrm{ha}$ ) with medium level ( $46 \mathrm{Kg} / \mathrm{ha}$ ) and high level ( 92 $\mathrm{Kg} / \mathrm{ha}$ ) of phosphorus produced yields that are significantly higher than the rest of the treatment combinations ( Table 23. Annex 2 ). The medium level of nitrogen with all levels of phosphorus produced significantly higher yields than zero nitrogen in combination with all levels of phosphorus. The yield differences of zero nitrogen treatment at all doses of phosphorus are not significantly different from each other.

In Nooristan during 1997-98 crop season, no significant yield differences were observed in zero nitrogen treatment combination and produced the lowest yields (Annex 1, Table 31). Similarly, no significant yield differences were recorded for no phosphorus treatment in combination with either levels 1 and 2 of nitrogen. The yield differences due to $N_{1} P_{1}, N_{1} P_{2}, \dot{N}_{2} P_{1}$, and $N_{2} P_{2}$ are not significant from each other. The highest yields were recorded for these treatments. The yield increase due to $N_{1} P_{1}$ and $N_{2} P_{2}$ treatments from control are $901 \mathrm{~kg} / \mathrm{ha}$ and $1224 \mathrm{~kg} / \mathrm{ha}$ respectively. During the 1998-99 crop season the yields of zero nitrogen in combination with level 1 and 2 of phosphorus were significantly different from the control treatment ( Table 23, Annex 2 ). Similarly the yields of $57 \mathrm{Kg} / \mathrm{ha}$ and $115 \mathrm{Kg} / \mathrm{ha}$ of nitrogen in combination with level $1(46 \mathrm{Kg} / \mathrm{ha}$ ) and level 2 ( $92 \mathrm{Kg} / \mathrm{ha})$ of phosphorus are not significantly different from each other. The treatments $N_{1} P_{1}$ and $N_{2} P_{2}$ have produced $2361 \mathrm{Kg} / \mathrm{ha}$ and $3046 \mathrm{Kg} /$ ha higher grain yields than the control.

In Kunar the highest yielding treatment combination is $N_{2} P_{1}(6060 \mathrm{~kg} / \mathrm{ha})$, followed by $\mathrm{N}_{2} \mathrm{P}_{2}(5622$ $\mathrm{kg} / \mathrm{ha}$ ), but the yield differences between these treatment combination are not significant The yield differences between $N_{1} P_{1}$ and $N_{1} P_{2}$ are not significant. Similarly no significant yield differences were observed in no nitrogen treatment combination with or without phosphorus fertilizer. The yield increase due to $N_{1} P_{1}$ and $N_{2} P_{2}$ treatments are $1685 \mathrm{~kg} / \mathrm{ha}$ and $2322 \mathrm{~kg} / \mathrm{ha}$ respectively. The results of 1998-99 crop season are drastically different regarding response to phosphorus in the absence of nitrogen ( Table 23, Annex 2). In the absence of phosphorus the yields are significantly lower in both $57 \mathrm{Kg} / \mathrm{ha}$ and $115 \mathrm{Kg} / \mathrm{ha}$ of nitrogen treatments. The yields of these two treatments in combination with $46 \mathrm{Kg} / \mathrm{ha}$ and $92 \mathrm{Kg} / \mathrm{ha}$ of phosphorus are high, but the differences are not significant. The yield advantages due to $N_{1} P_{1}$ and $N_{2} P_{2}$ treatments over control treatment are 2137 $\mathrm{kg} / \mathrm{ha}$ and $1737 \mathrm{~kg} / \mathrm{ha}$ respectively, but the highest economic gain was recorded for treatments $\mathrm{N}_{1} \mathrm{P}_{2}$ and $\mathrm{N}_{2} \mathrm{P}_{1}$.

In Ghazni no significant yield differences were observed for nitrogen fertilizer in all combinations of phosphorus in the $1997-98$ experiment (Annex 1, Table 31). All of these treatment combinations produced significantly higher yields than the control treatment The yield of the control treatment is very good because of the high fertility status of the soil on farmer's field. The highest yield of $(6480 \mathrm{~kg} / \mathrm{ha})$ was recorded for treatment combination $N_{2} P_{2}$ followed by $N_{1} P_{0}$. During 1998-99 crop season no significant yield differences were observed at zero nitrogen treatment at all levels of phosphorus ( Table 23, Annex 2 ) but the yields were generally high due to good fertility status of the soil. However a $50 \%$ yield increase was recorded for $57 \mathrm{Kg} / \mathrm{ha}$ and $115 \mathrm{Kg} / \mathrm{ha}$ nitrogen in combination of $46 \mathrm{Kg} / \mathrm{ha}$ and $92 \mathrm{Kg} / \mathrm{ha}$ phosphorus. The highest grain yield and economic gain was recorded for $N_{2} P_{2}$. The yield increase due to treatments $N_{1} P_{1}$ and $N_{2} P_{2}$ over control was $2320 \mathrm{Kg} / \mathrm{ha}$ and $2960 \mathrm{Kg} / \mathrm{ha}$.

During 1997-98 crop season in Herat no significant yield differences were observed in zero nitrogen treatment at all levels of phosphorus ( Table 31, Annex 1 ) but the zero phosphorus treatment was significantly lower yielding than $46 \mathrm{Kg} / \mathrm{ha}$ and $92 \mathrm{Kg} / \mathrm{ha}$ phosphorus treatments at $57 \mathrm{Kg} / \mathrm{ha}$ and $115 \mathrm{Kg} / \mathrm{ha}$ nitrogen treatments. The yield differences between $\mathrm{N}_{1} \mathrm{P}_{1}$ and $\mathrm{N}_{1} \mathrm{P}_{2}$ are not 
significant. Similarly results are recorded for treatment combinations $\mathrm{N}_{2} \mathrm{P}_{1}$ and $\mathrm{N}_{2} \mathrm{P}_{2}$. The yield increase due to treatments $N_{1} P_{1}$ and $N_{2} P_{2}$ over control is $1513 \mathrm{Kg} / \mathrm{ha}$ and $1950 \mathrm{Kg} / \mathrm{ha}$. In 1998-99 experiment zero phosphorus treatment gave the lowest grain yield as whole compared to $46 \mathrm{Kg} / \mathrm{ha}$ and $92 \mathrm{Kg} / \mathrm{ha}$ phosphorus at all levels of nitrogen treatments (Table 23, Annex 2 ).

The two years, eight locations data for mean yield showed that the no nitrogen treatment combination gave the lowest yield. The highest overall mean yield was for the high level of nitrogen in combination with medium (46 Kg/ha) or high level $(92 \mathrm{Kg} / \mathrm{ha}$ ) of phosphorus (Table 31, Annex 1 and Table 23, Annex 2). On the average, the yield increase due to $N_{1} P_{1}$ and $N_{2} P_{2}$ treatments over control are $59 \%$ and $86 \%$ in 1997-98, but in 1998-99 this yield increase is $86 \%$ and $122 \%$. Each fertilizer effect analysis of variance for yield over locations in 1997-98 crop season showed highly significant nitrogen effect (Annex 1, Table 36). The phosphorus effect was significant in Balkh, Kandahar, Herat, Laghman and Nooristan. The interaction effect was non significant in all other locations except Laghman and Kunar. In 1998-99, the nitrogen effect was highly significant and the phosphorus effect was highly significant in Kandahar, Herat, Laghman, Kunar, and Nooristan. The nitrogen by phosphorus interaction was significant in Kunar and highly significant in Herat and Laghman provinces (Table 32, Annex 2). In a separate test using local and improved variety of wheat with three levels of fertilizer was used in Herat and Ghazni provinces. It was shown that improved variety of wheat has given higher yields than local under both low and adequate fertility regimes ( Table 24 , Annex 2). In Ghazni the yield of improved wheat variety ( Pamir-94 ) under no fertilizer was $894 \mathrm{Kg} / \mathrm{ha}$ higher than the local wheat variety (Ghund Wagai) and under adequate fertility regime, the improved wheat variety $2162 \mathrm{Kg} / \mathrm{ha}$ or $30 \%$ higher yield in this trial. Comparing the response of both improved and local wheat to different regimes of fertilizer, a $20 \%$ yield advantage was recorded for adequate level of fertilizer. Similar responses were recorded in two locations in Herat province where a local wheat variety "Kalak" was compared with Takhar-96 and Maxipak wheat variety was compared with wheat variety Gul-96. The effects of weed control and fertilizer application on the grain yield of wheat is demonstrated by an experiment in 1998-99 crop season conducted in Nangarhar and Ghazni using improved and local wheat cultivars ( Tables $28 \& 29$, Annex 2 ). On the average weed control increased yield by $1127 \mathrm{Kg} / \mathrm{ha}$, fertilizer alone increased yield by $3247 \mathrm{Kg} / \mathrm{ha}$ and weed control plus fertilizer increased the mean yield by $3400 \mathrm{Kg}$ /ha in Nangarhar ( Table 28, Annex 2 ). In Ghazni these effects are from $142 \mathrm{Kg} / \mathrm{ha}$ to $2625 \mathrm{Kg} / \mathrm{ha}$ ( Table 29, Annex 2 ).

\section{Dates of Planting}

Considerable yield losses can be avoided if farmers plant the wheat crop at the optimum time of sowing in order for the crop to take full advantages of the accumulated degree days. The seeding dates of wheat differs depending on the location and climatic conditions of the zone. This kind of research is necessary for new wheat varieties because some of the genotypes have genotypic plasticity and are less sensitive to different seeding dates than others.

An experiment was design to test different seeding dates on wheat varieties Roshan-96, Gul-96 and Kauz (Bakhtawar-92 or Ghaznavi). Seven planting dates at 15 days interval starting 15 October, 1997 to 15 January 1998 were tested in a randomized complete block with four replications in Nangarhar, Kandahar, Herat, Laghman, and Kunar provinces of Afghanistan. The wheat variety Roshan-96 was used in Nangarhar, Gul-96 was used in Kandahar and Herat while wheat variety Kauz was tested in Laghman and Kunar. The plot size was 6 rows, five meter long with row to row spacing of $25 \mathrm{~cm}$. An area of $4 \mathrm{~m}^{2}$ was harvested for yield determination. The yield in grams per unit area was converted into $\mathrm{kg} / \mathrm{ha}$ and the mean yield data is summarized in (Annex l, Table 32). Yield loss in $\mathrm{kg}$ per hectare is calculated for each location by dividing the yield difference (between the highest yielding date and the lowest yielding date) by the number of days in this interval. This same experiment was repeated in 1998-99 crop season and the data is summàrized in ( Table: 25 . Annex 2 ). Due to cyclic weather changes, variation in the two years 
data was observed. This type of changes and variations in weather compels the researchers to conduct experiments over long period.

In Nangarhar the wheat variety Roshan-96 gave the highest yield $(7694 \mathrm{~kg} / \mathrm{ha})$ when planted on October 30, 1997. The next highest yield was recorded for October 15 date of planting. The yield difference in these two dates are not significant. The $3 \mathrm{rd}$ and 4 th high yields were recorded for the November planting. As the planting of wheat was delayed, considerable yield reduction (35-121 $\mathrm{kg} / \mathrm{ha} /$ day) is noticed. On the average $78 \mathrm{~kg} / \mathrm{ha}$ /day yield loss is recorded in Nangarhar (Annex 1, Table 32). The results of 1998-99 experiment in Nangarhar showed that the wheat variety Roshan96 produced the highest grain yield in the December 15 sowing followed by December 30 and November 15-30 planting with no significant differences in their yields (Table 25, Annex 2 ). The yield loss of $66 \mathrm{Kg} / \mathrm{ha}$ per day was recorded between.the lowest yielding date ( 15 October 1998 ) and 15 December 1998.

The seeding date trial on wheat variety Gul-96 in Kandahar revealed that October 30, 1997 planting produced the highest yield of $(4580 \mathrm{~kg} / \mathrm{ha})$. The optimum planting time for Gul-96 in Kandahar is beginning of November. A yield loss of $43 \mathrm{~kg} / \mathrm{ha}$ /day was observed for this variety in Kandahar (Annex 1, Table 32). This facultative wheat variety has cold tolerance and is selected for cooler areas of the country, but has the ability to give reasonable yield in areas of mild winter temperatures.

The same variety was used in this trial in Herat and the highest yield $(7837 \mathrm{~kg} / \mathrm{ha})$ was recorded for the October 15, 1997 planting. The yield differences of this variety in Herat were statistically not significantly different from each other in the first four seeding dates (Annex 1, Table 32). The lowest yield of (1919 kg/ha) were recorded for the January 15, 1998 sowing time. Comparing the highest and lowest yielding dates, $64 \mathrm{~kg} / \mathrm{ha} /$ day yield loss is calculated for this location. During 1998-99, this trial was carried out using wheat variety Roshan-96 in seven dates. The top yields were recorded for the November and December planting. The October 30, 1998 sowing produced the higher yield ( $7316 \mathrm{Kg} / \mathrm{ha}$ ) compared to November $15(6216 \mathrm{Kg} / \mathrm{ha})$ and up to December 15 . The mean yield loss was $56 \mathrm{Kg} / \mathrm{ha} /$ day ( Table 25, Annex 2 ).

The wheat variety Kauz was used Laghman for this trial. No significant yield differences were observed in the first three dates of planting ( 15 October to 15 November), but the highest yield of $5525 \mathrm{~kg} / \mathrm{ha}$ was recorded for the 15 November sowing date. The yield loss in this location was 32 $\mathrm{kg} / \mathrm{ha} /$ day. This variety in Kunar province gave the highest yield $(6390 \mathrm{~kg} / \mathrm{ha})$ in the 15 October planting with progressive yield reduction in latter dates. The yield differences in the 2 nd to 6 th sowing are not significantly different from each other. The yield loss of $45 \mathrm{~kg} / \mathrm{ha} / \mathrm{day}$ was recorded for this location when planting was delay from 15 October 1997 to 15 January 1998 ((Annex 1, Table 32). In 1998-99 in Laghman this trial was conducted on the same wheat variety. The 15 October to 15 November dates produced the top yields. The mean yield loss was 38 $\mathrm{Kg} /$ ha/day ( Table 25, Annex 2). This trial was repeated in Kunar by MADERA using the same wheat variety but the first sowing date was 16 September and the last one was 15 December. The highest yield was recorded for 31 October planting followed by 1 and 16 October 1998. No significant yield differences were observed in the yields of October 1 to November 15, 1998 planting ( Table 26, Annex 2 ). The very early planting (16 September) and the very late planting ( 15 December) both gave lower yields compared to 31 October planting and the yield loss was 54 to $48 \mathrm{Kg} / \mathrm{ha} /$ day.

The same wheat variety was used for the date of planting trial in Mazar-i-Sharif in 1997. The first seeding date was December 1, 1997 and the last one was March 1, 1998 (Annex 1, Table 33). The mid December and end of December sowing date gave the highest yields of $7331 \mathrm{~kg} / \mathrm{ha}$ and 6530 $\mathrm{kg} / \mathrm{ha}$ respectively. The lowest yield was recorded for the end of February planting. The yield is high for this variety and the reason for this has been the sufficient rain through winter 1997 and 
spring 1998. The data confirms that the optimum date of wheat planting is the month of December and as planting is delayed, on the average $31 \mathrm{~kg} / \mathrm{ha} /$ day reduction in yield is shown. $\mathrm{n} 1998-99$ crop season in Mazar-e-Sharif this trial was planted in seven dates 15 October 1998 to 15 January 1999 using wheat variety Roshan-96 and the highest yield was recorded for the 15 November planting followed by 30 November 1998 with no significant differences in their yields ( Table 25 . Annex 2 ). The yield loss recorded in this location was $81 \mathrm{Kg} / \mathrm{ha} /$ day.

In Ghazni two wheat varieties were used for this trial, Kauz and Pamir-94. Kauz is not suitable variety for cooler areas of the country and considerable winter kill occurs when the temperatures are very low as is commonly recorded in East Central zone of the country. Similarly when the wheat crop is not at the suitable growth stage as it inters winter, heavy winter kill is seen in the fields. The wheat variety Pamir-94 was selected for production in this zone and is more winter hardy than wheat variety Kauz. This characteristic is reflected very well in the yield data in different seeding dates (Annex 1, Table 34). The winter of 1997 was very cold and December planting could not be implemented. For both varieties the end of November sowing gave the highest yields but the difference in yield at the highest date was $1142 \mathrm{~kg} / \mathrm{ha}$. This shows that variability in the cold tolerance of different genotypes of wheat. Wheat varieties bred and selected in warmer areas will be winter killed in areas of cold winter temperatures. This experiment was repeated in this location in 1998-99 crop season using wheat variety Gul-96 but six planting dates were used instead of 7 . The first sowing date was 30 October 1998 and the last one was 15 January 1999. The best yield was obtained from the October 30 planting followed by the November 15 th seeding. The lowest yield was recorded for the 15 December 1998 planting ( ( Table 25. Annex 2). The yield difference between the highest and lowest yield ivas 120 $\mathrm{Kg} / \mathrm{ha} / \mathrm{day}$.

There is substantial genotypic variation of wheat in response to date of sowing as shown through an experiment in cooperation with the National Agriculture Research Council (NARC) of Pakistan. The project received two set of National Uniform Wheat Yield Trial (NUWY') to be planted in two dates in Afghanistan. The first set was planted in Nangarhar in November and the second set was planted in December 1997.

The trial consisted of 20 different wheat genotypes from research station in four provinces of Pakistan. Grain yield and rust reactions on these lines are summarized in (Annex 1, Table 28). In the first date of seeding the five top yielding entries are 5, 7, 8, 12 and 15. These entries have yielded 10 to $22 \%$ higher than the nursery mean of $3626 \mathrm{~kg} / \mathrm{ha}$. In the second seeding date, the five top yielding lines are 5,8,9.12 and 14. These entries have out yielded the nursery mean $(2877 \mathrm{~kg} / \mathrm{ha}$ ) by 14 to $27 \%$. The data shows that entries 5.8 and 12 are top yielding in both dates and their yield reduction due to late planting is less than others. The five entries that were most affected by delayed planting are 3, 7, 10,17 and 19 with a yield reduction ranging from 1113 $\mathrm{kg} / \mathrm{ha}$ to $1391 \mathrm{~kg} / \mathrm{ha}$ or yield loss of 37 to $46 \mathrm{~kg} / \mathrm{ha}$ per day. On the nursery mean basis the delay in seeding date resulted in yield loss of $25 \mathrm{~kg} / \mathrm{ha} /$ day. This genotypic variation is clearly demonstrated once again by the 1998-99 experiment ( Table 21. Annex 2) of NUWYT consisting of 20 lines.

\section{Seed Rates:}

A seed rate experiment was conducted in Kunduz on two wheat varieties ( Takhar-96 and Roshan96 ) using ten seed rates starting at $87.5 \mathrm{Kg} / \mathrm{ha}$ to $245 \mathrm{Kg} / \mathrm{ha}$ ( Table 30 . Annex 2 ). For wheat variety Takhar -96 the highest yield was recorded for the $227.5 \mathrm{Kg} /$ ha seed rate followed by 157.5 $\mathrm{Kg} / \mathrm{ha}$ but these yield differences are not significant. There was no significant difference between the yields of $122.5 \mathrm{Kg} / \mathrm{ha}$ and $245 \mathrm{Kg}$ /ha seed rate. For wheat variety Roshan-96 no significant difference was noticed in the grain yield between $87.5 \mathrm{Kg} / \mathrm{ha}$ and $245 \mathrm{Kg} / \mathrm{ha}$ seed rate but the best yield was recorded for $210 \mathrm{Kg} / \mathrm{h}$ a seed rate. 


\section{Water Use Efficiency}

Water is one the limiting factors of wheat production in Afghanistan. Different quantities of water is needed from seed germination to grain filling stage of wheat plant. Any gain in amount or efficiency in use will lead into increase in attainable yield. In order to identify the most critical stage when water must be applied to get good yield. A trial was designed with 16 treatment combinations (Annex 1, Table 35) in four replications arranged in RCBD. These treatment combinations represent situation from rainfed to 4 irrigation. The wheat varieties used in this trial were Kauz in Nangarhar, Pamir-94 in Balkh and Ghazni and Gul-96 in Herat. The 1997-98 wheat crop season in Afghanistan was favorable for wheat production and there was sufficient rainfall throughout the season resulting in very high yields even under no irrigation. The facilities were not available control the treatment application. The results of the trial this year did not identify the most critical stage of irrigation for wheat.

This trial was repeated in 1998-99 crop season in four locations ( Nangarhar, Balkh, Herat, Ghazni ) on wheat variety Pamir-94 I Ghazni and Roshan-96 in the remaining three locations. The implementation of this type of experiment requires proper facilities where the amount and duration of water application can be controlled, but this type of facility is not at our disposal. The data shows that in Nangarhar the yields of treatment 1 is significantly less than treatments 2. 5 . and $8-16$ but no significant differences were observed in the yields of these treatments. Treatment 15 and 16 produced $25 \%$ higher yield ( Table 27. Annex 2 ). In Balkh no difference was observed between treatment 1 and treatments 2, 3, 5, 7-16. In Herat the situation was different and the yields of treatments $12-14$ and 16 were not significantly different from each other and these treatments produced the top yields. In Ghazni the yields of treatments 2, 14 and 16 were lower than the rest of the treatments. The overall mean yield data showed that treatment 8 produced the highest yield ( $5113 \mathrm{Kg} / \mathrm{ha}$ ) which is $25 \%$ higher than the treatment one. This reinforces the findings that irrigation at crown root initiation and milk stage is a must for good grain yield production. 


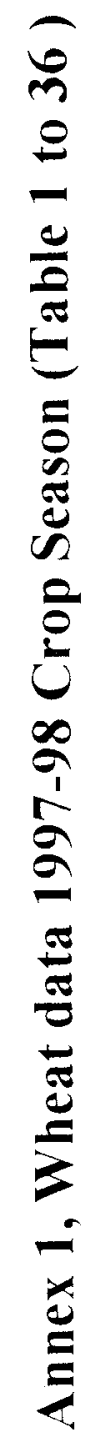



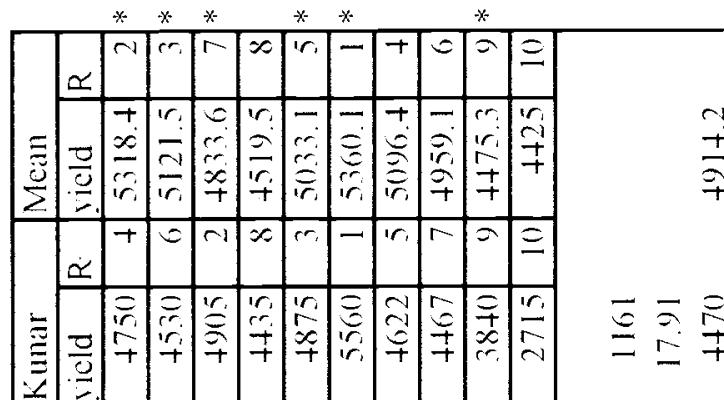

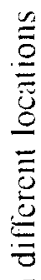

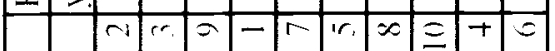

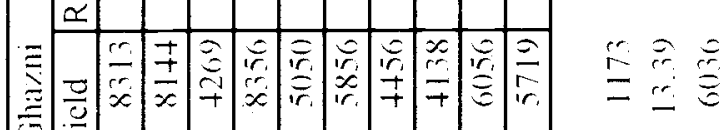

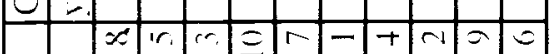

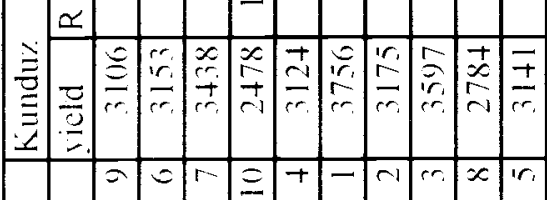

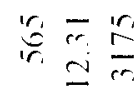

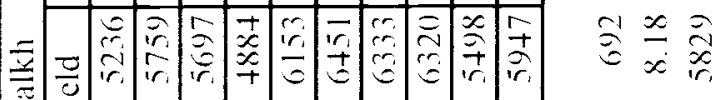

$\frac{\vec{C}}{\tilde{C}_{i}}$

承

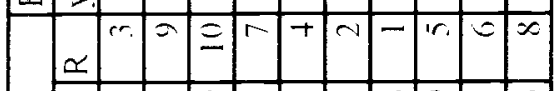

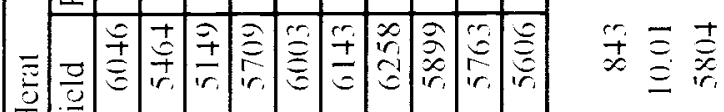

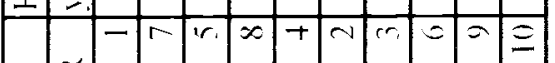

焉

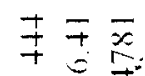

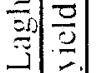

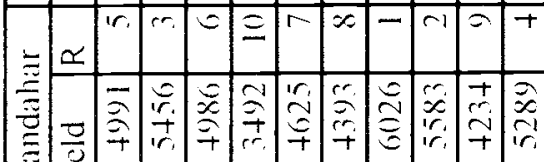

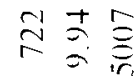

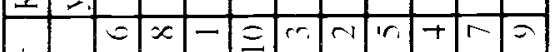

$\Xi \propto$

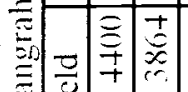

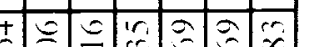

$\cong \cong \frac{N}{\Xi}$

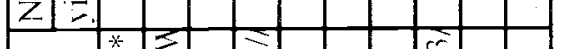

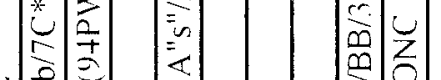

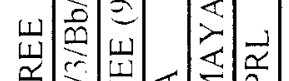

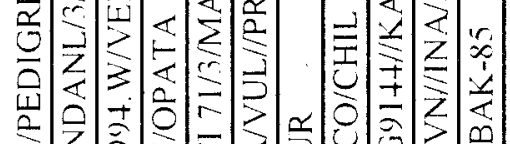

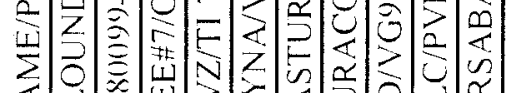

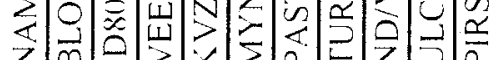

乙

z 


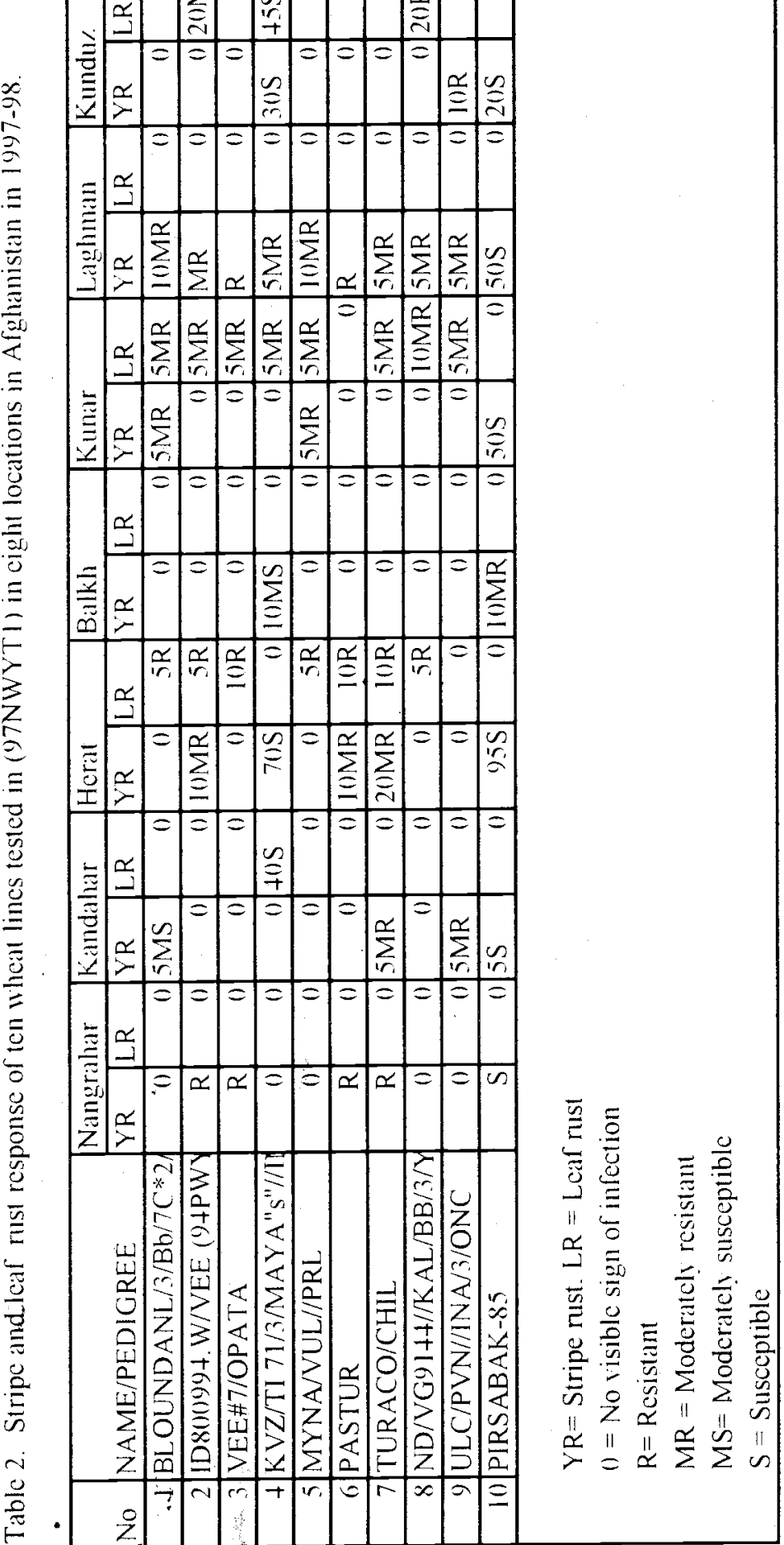




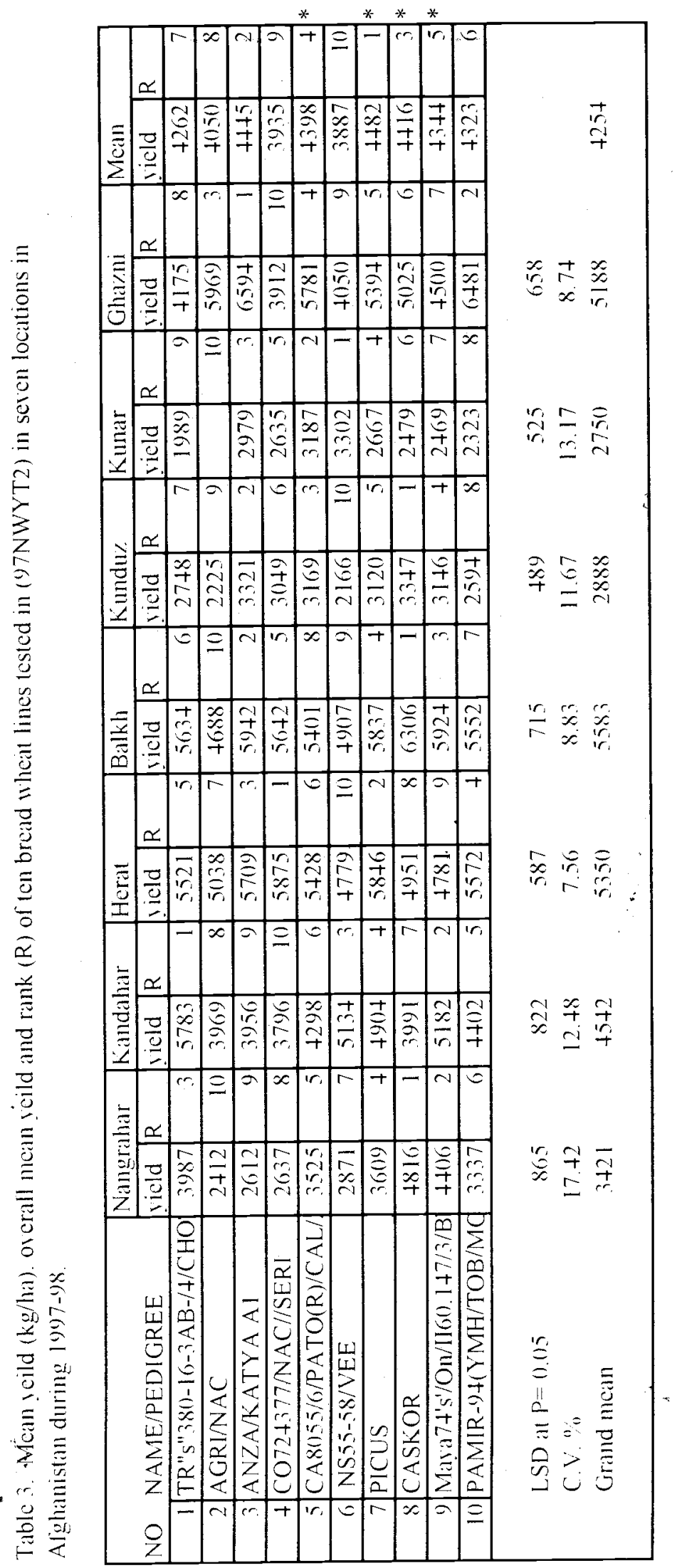


(3)
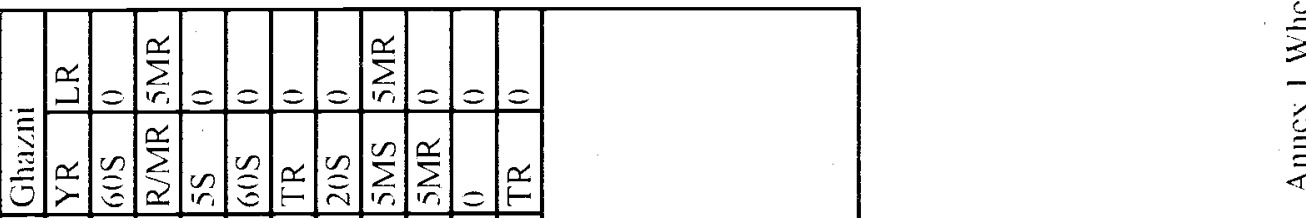

言

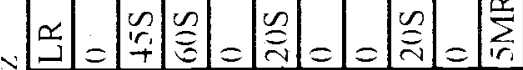

咅品

$\cong$

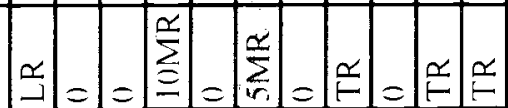

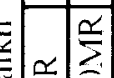

$r=0=0=0=0=$

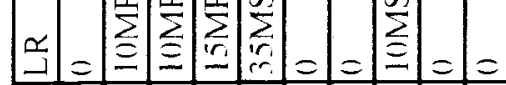

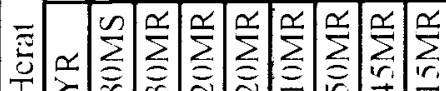

$=0$

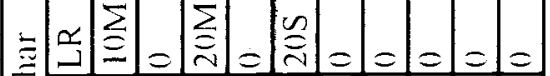

(1)

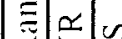

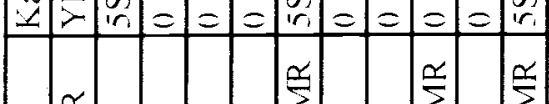

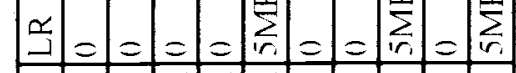

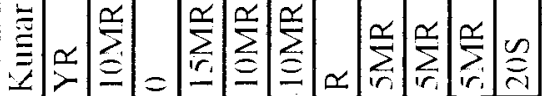

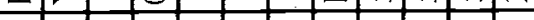

$\Xi \widetilde{x}$

$\approx==x=\Sigma=x=\alpha$

$\stackrel{\infty}{\Xi}$

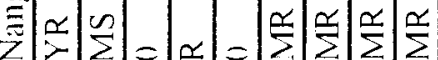

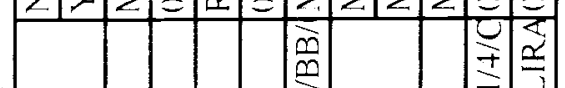

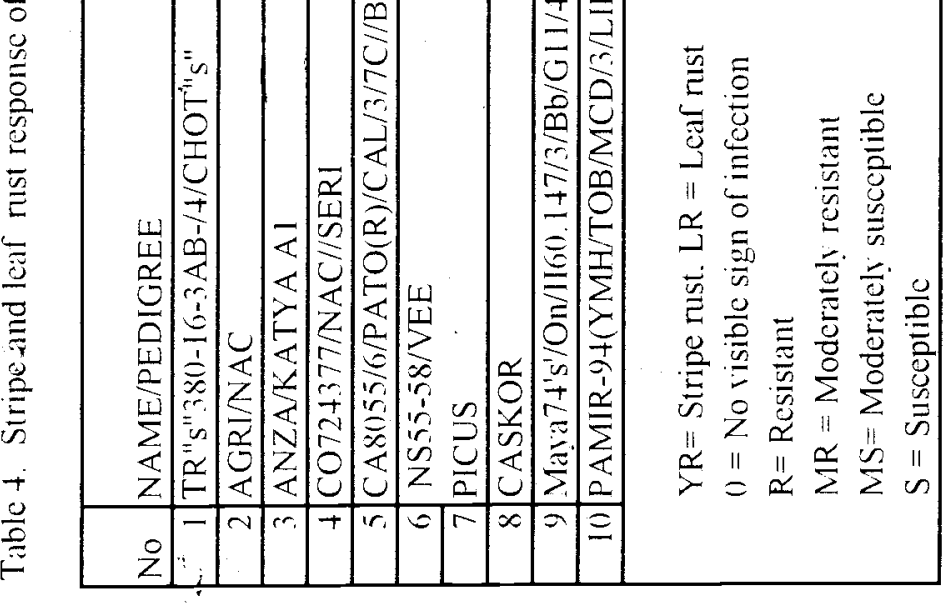




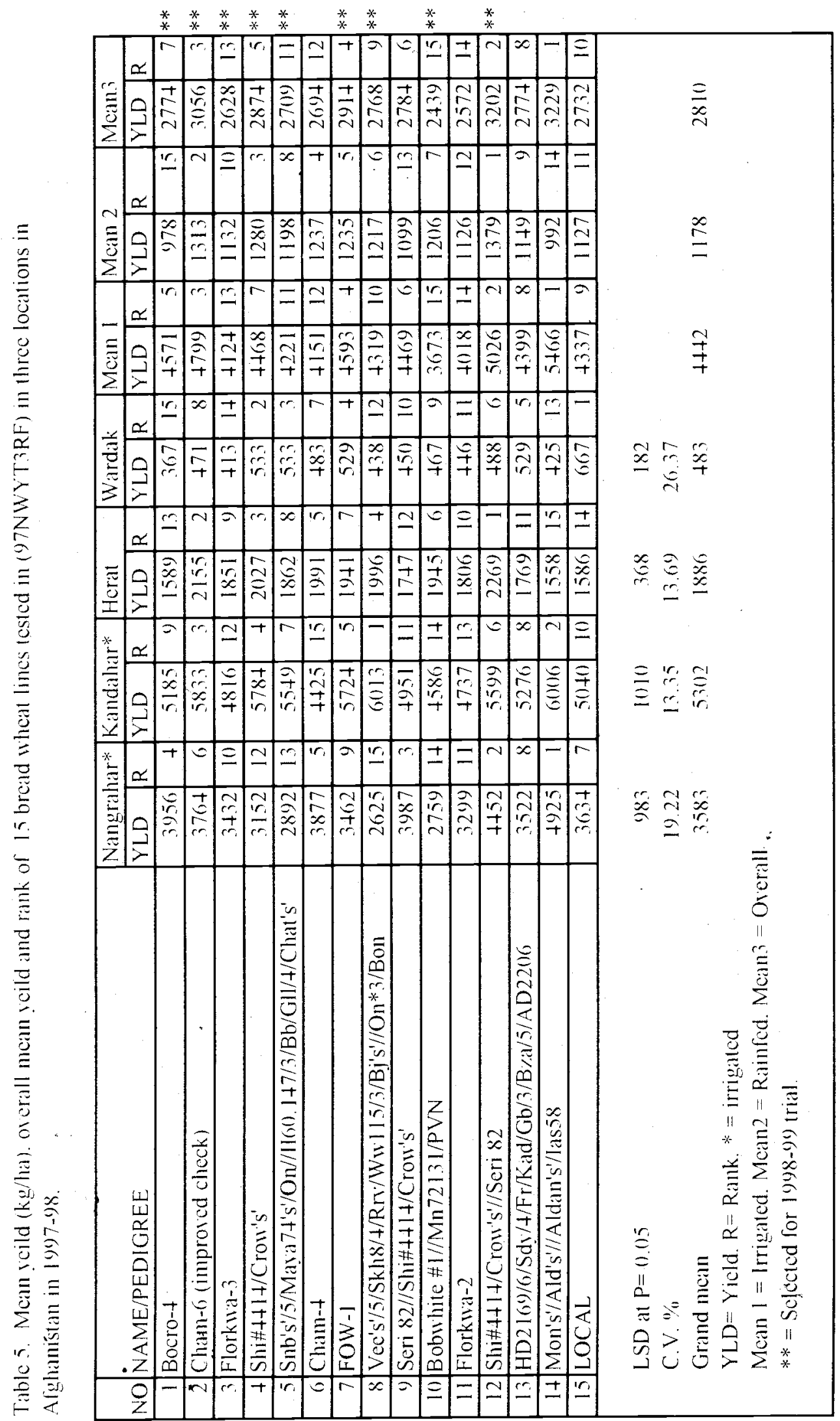




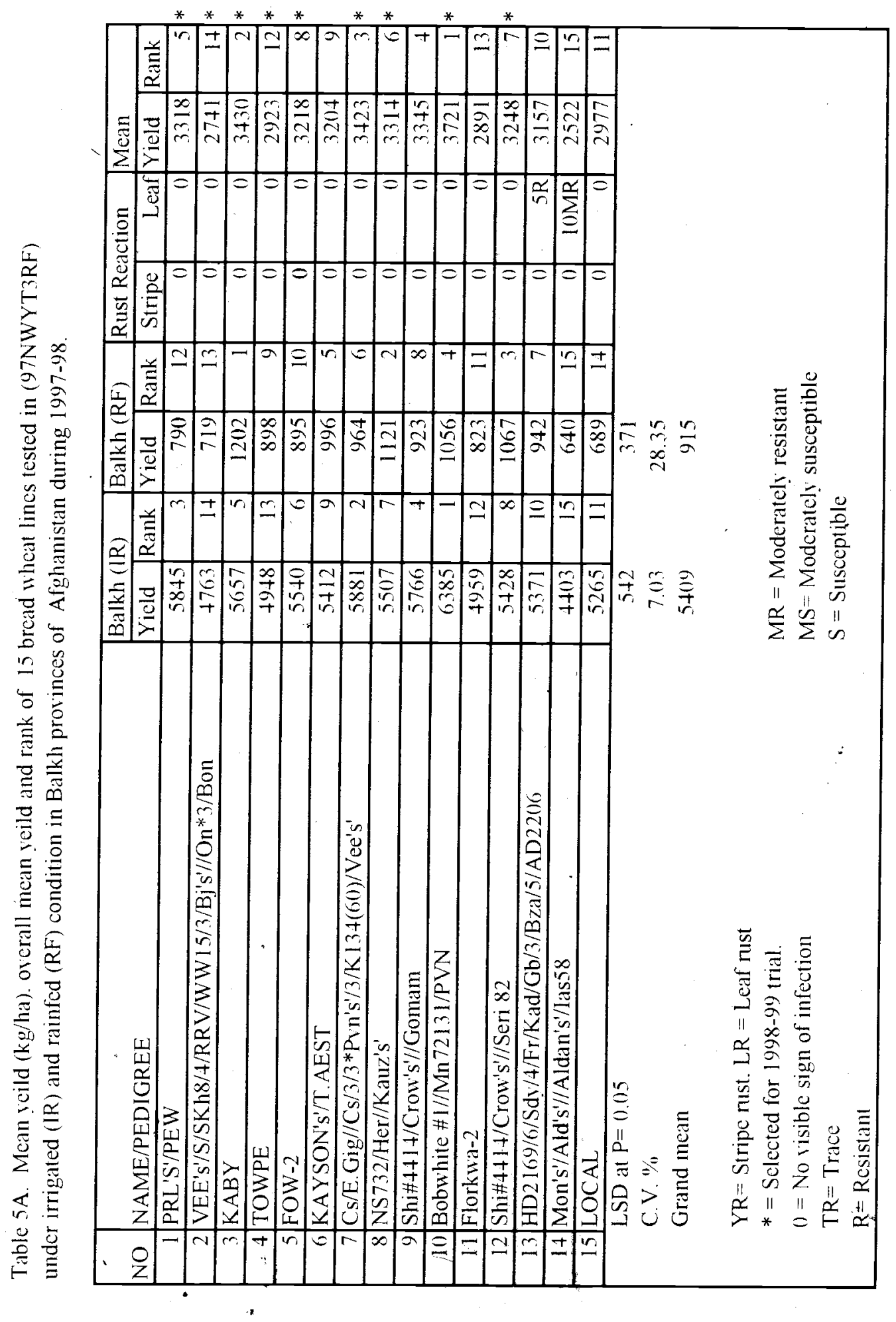




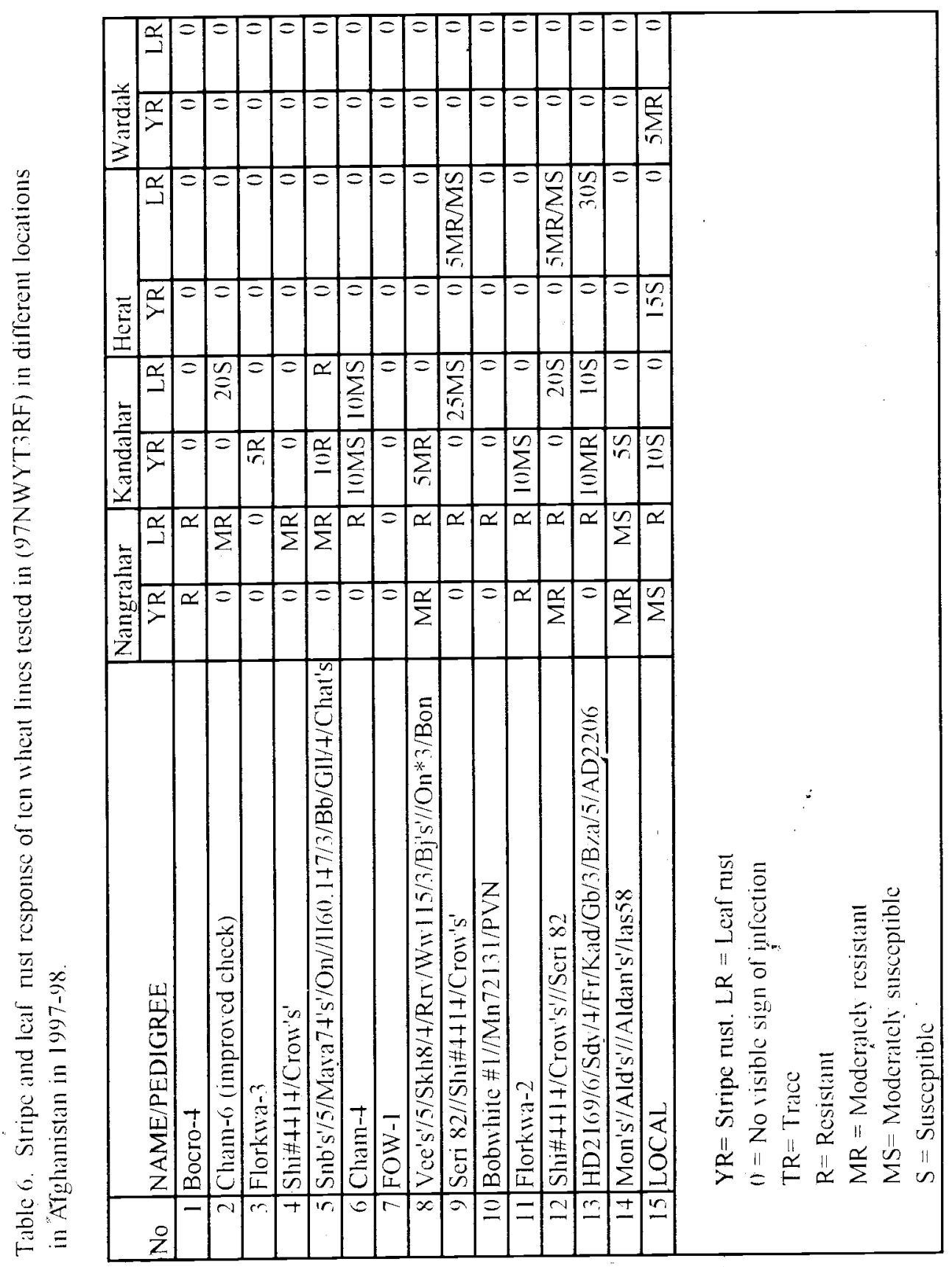




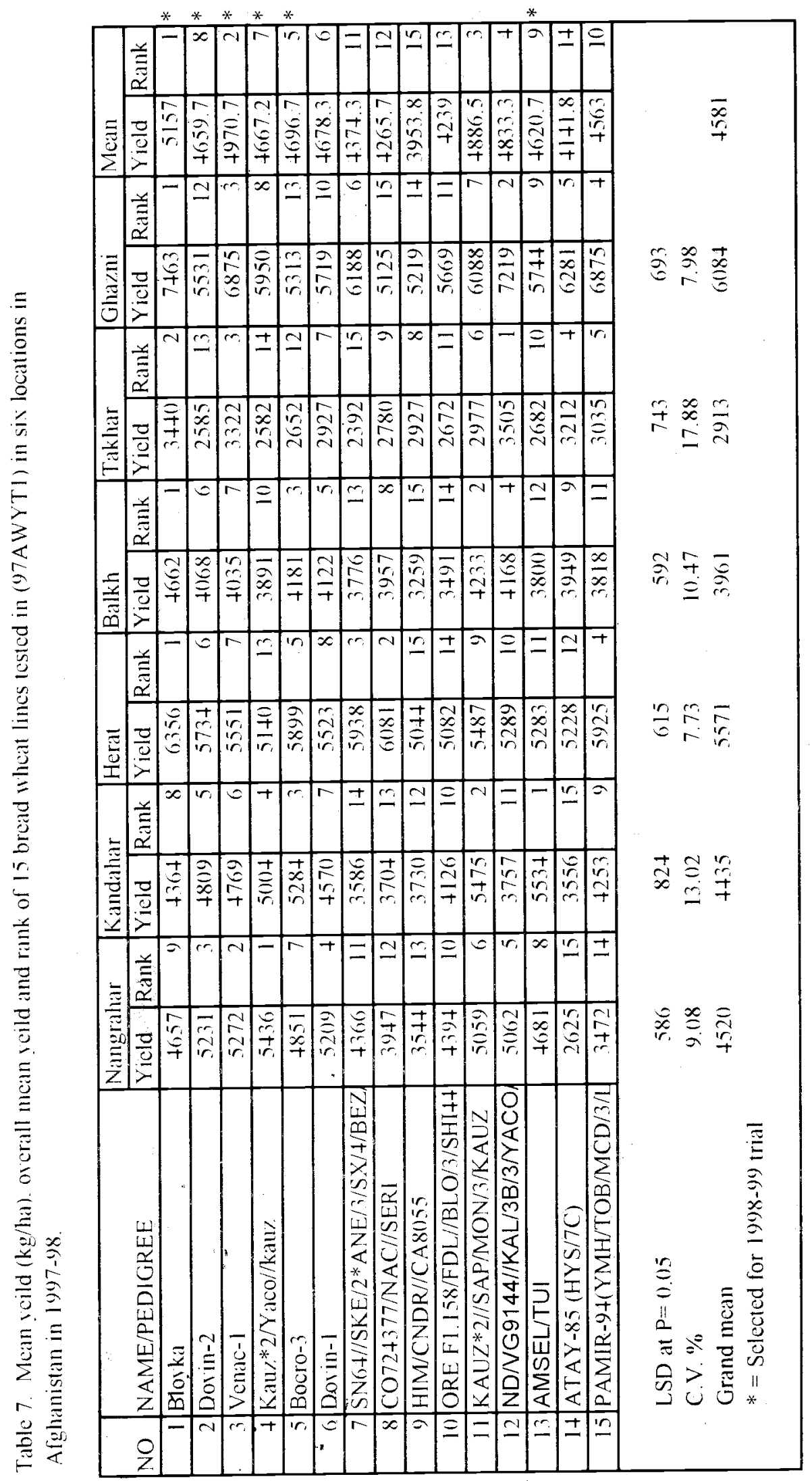




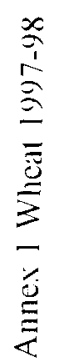

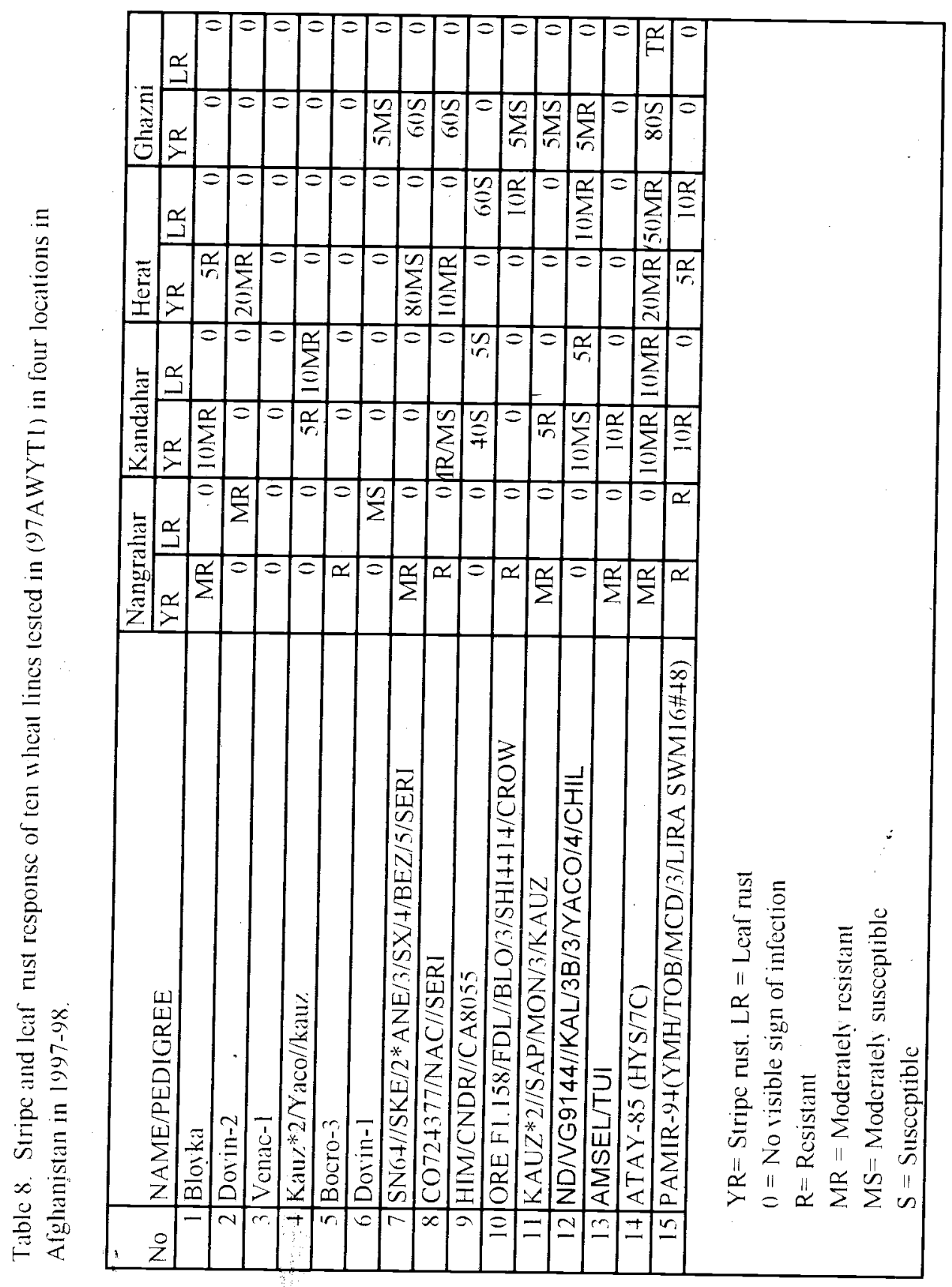




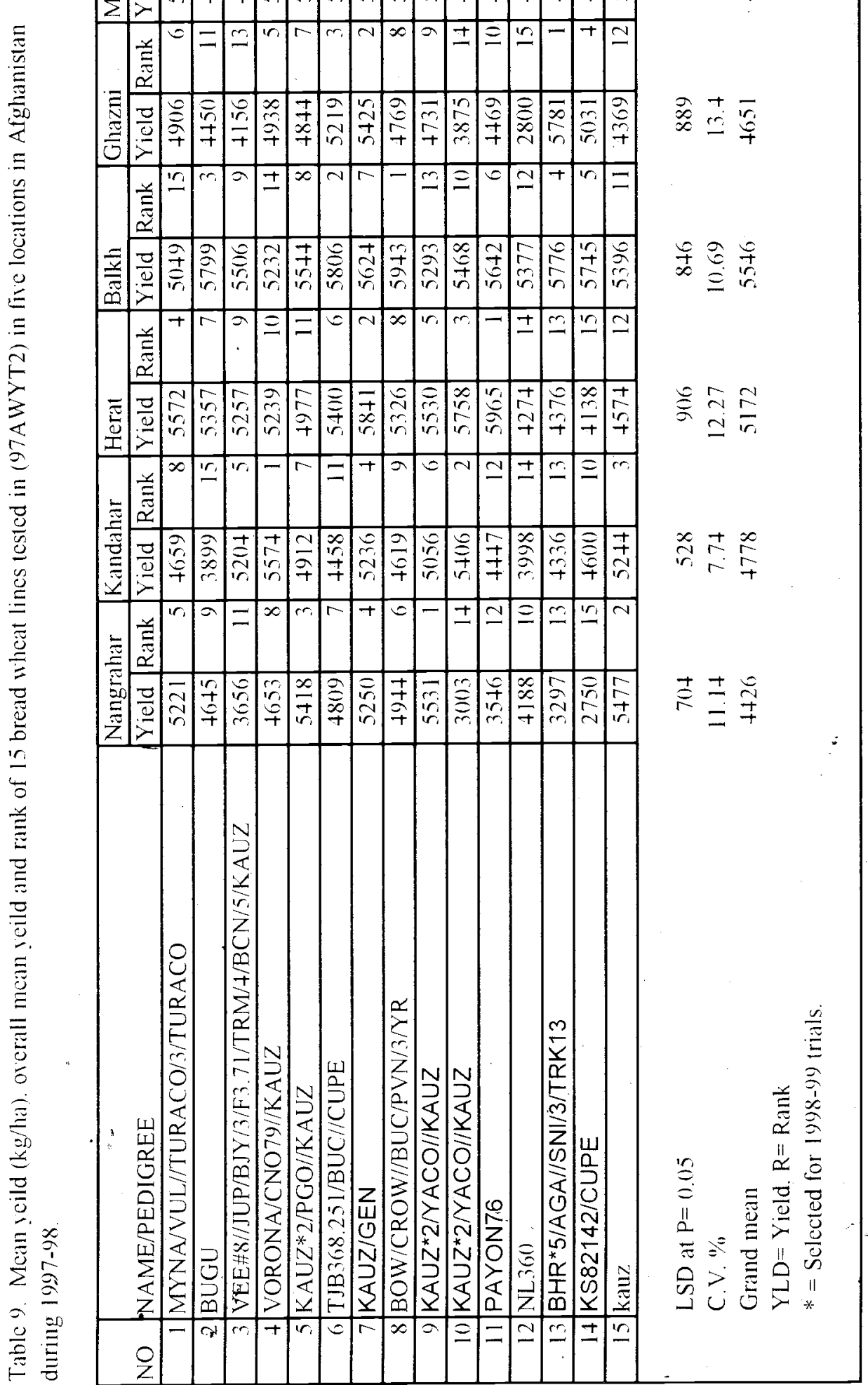




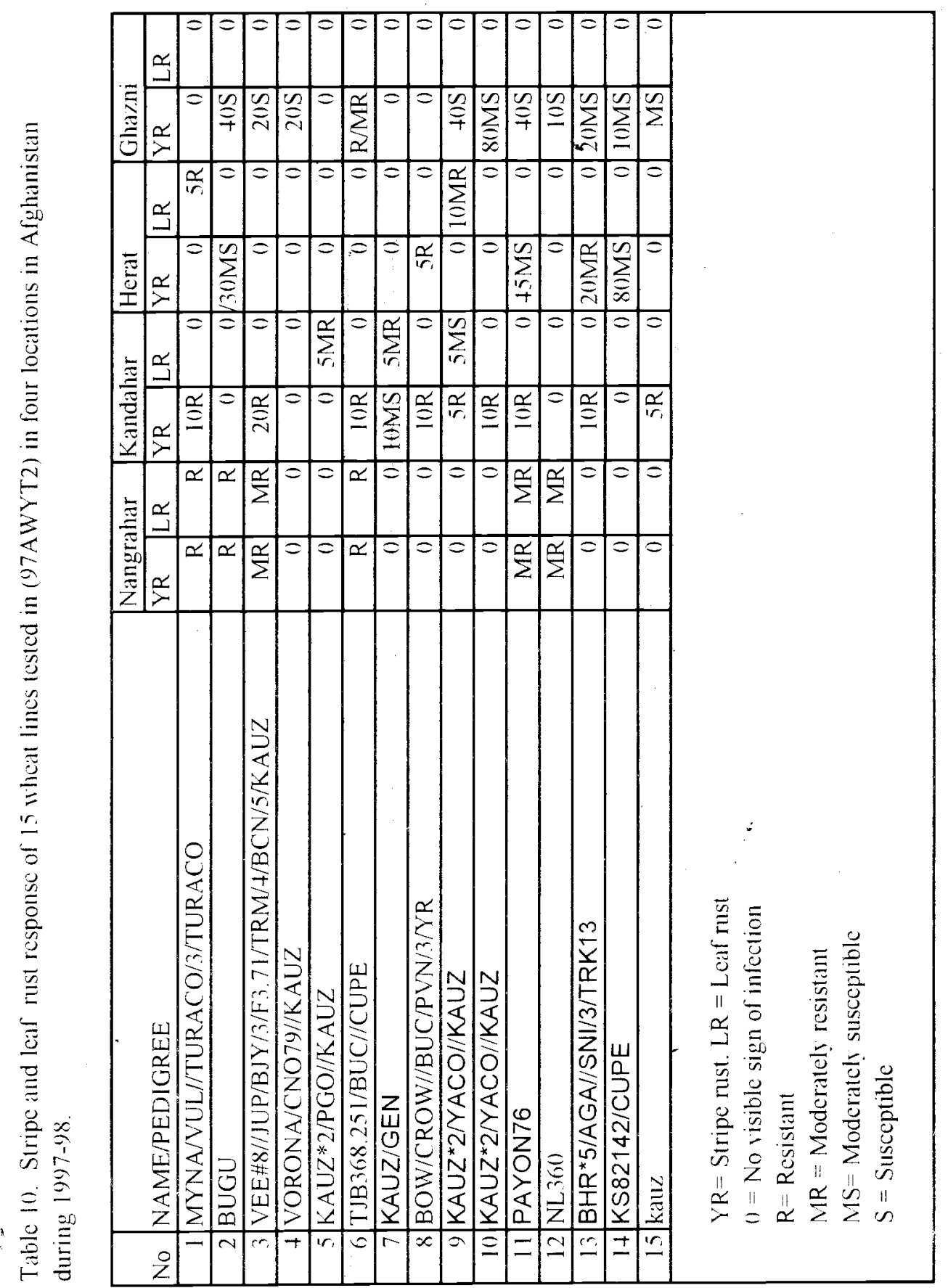




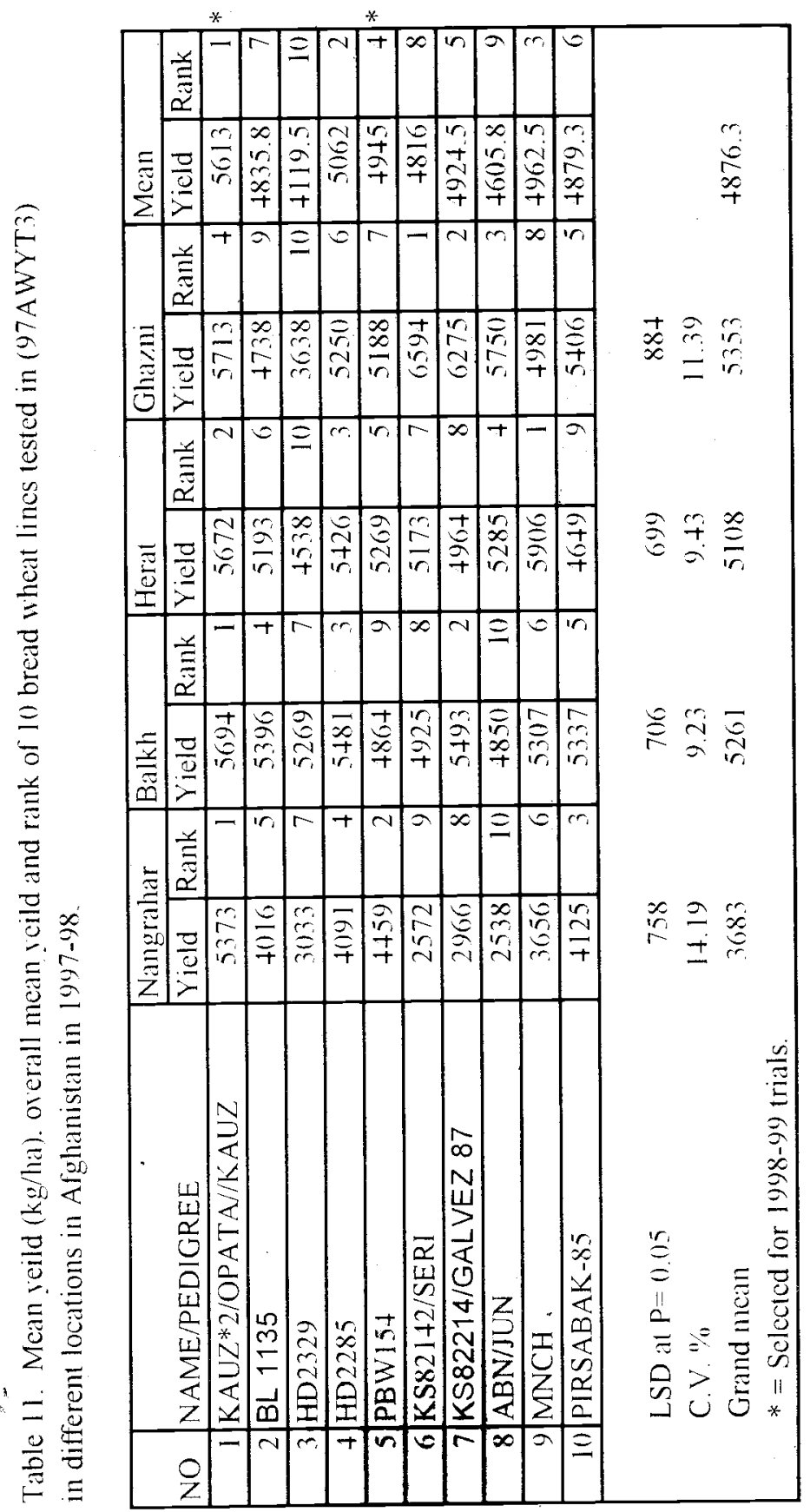




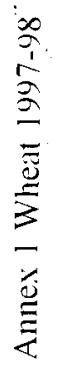

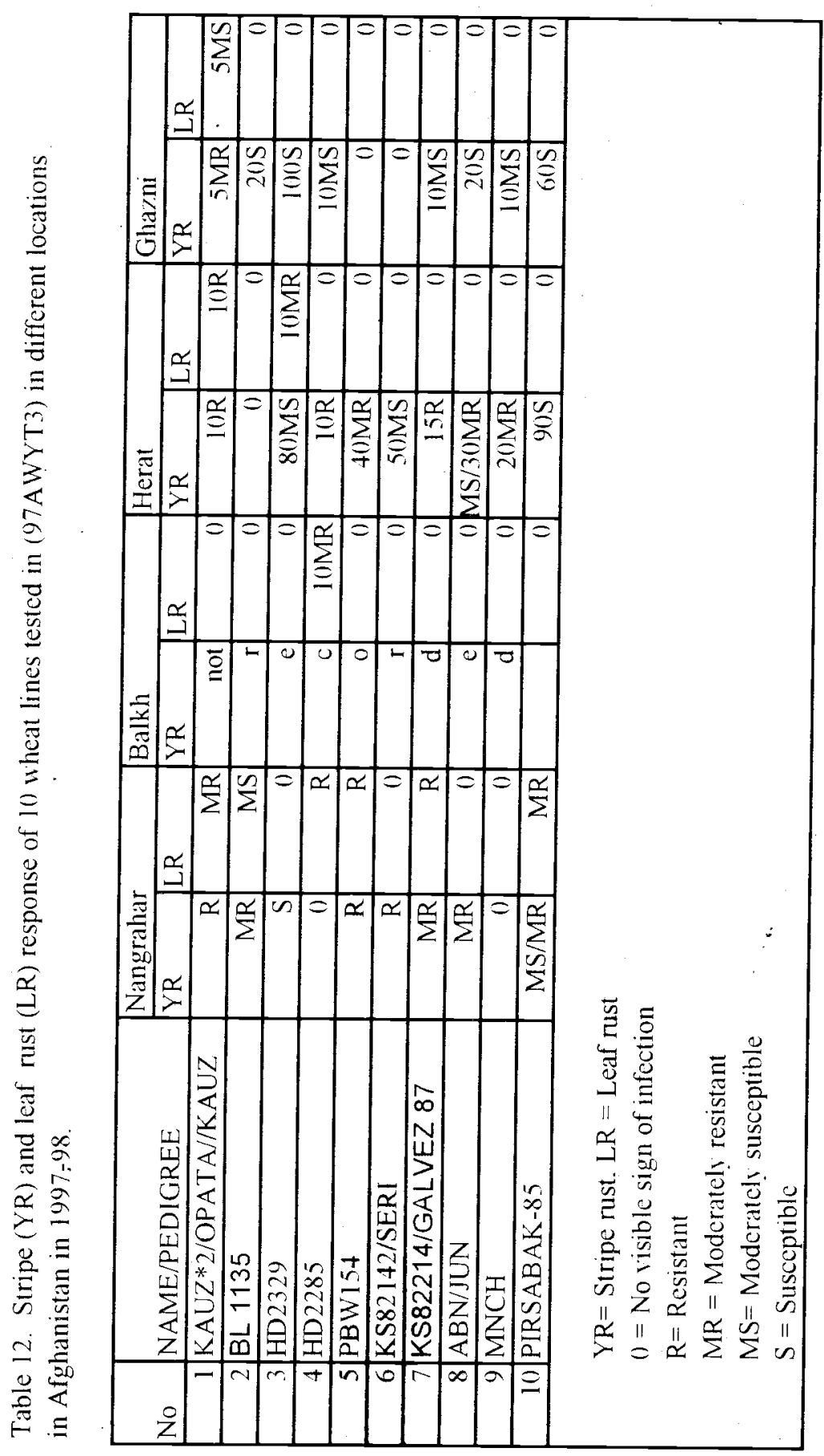




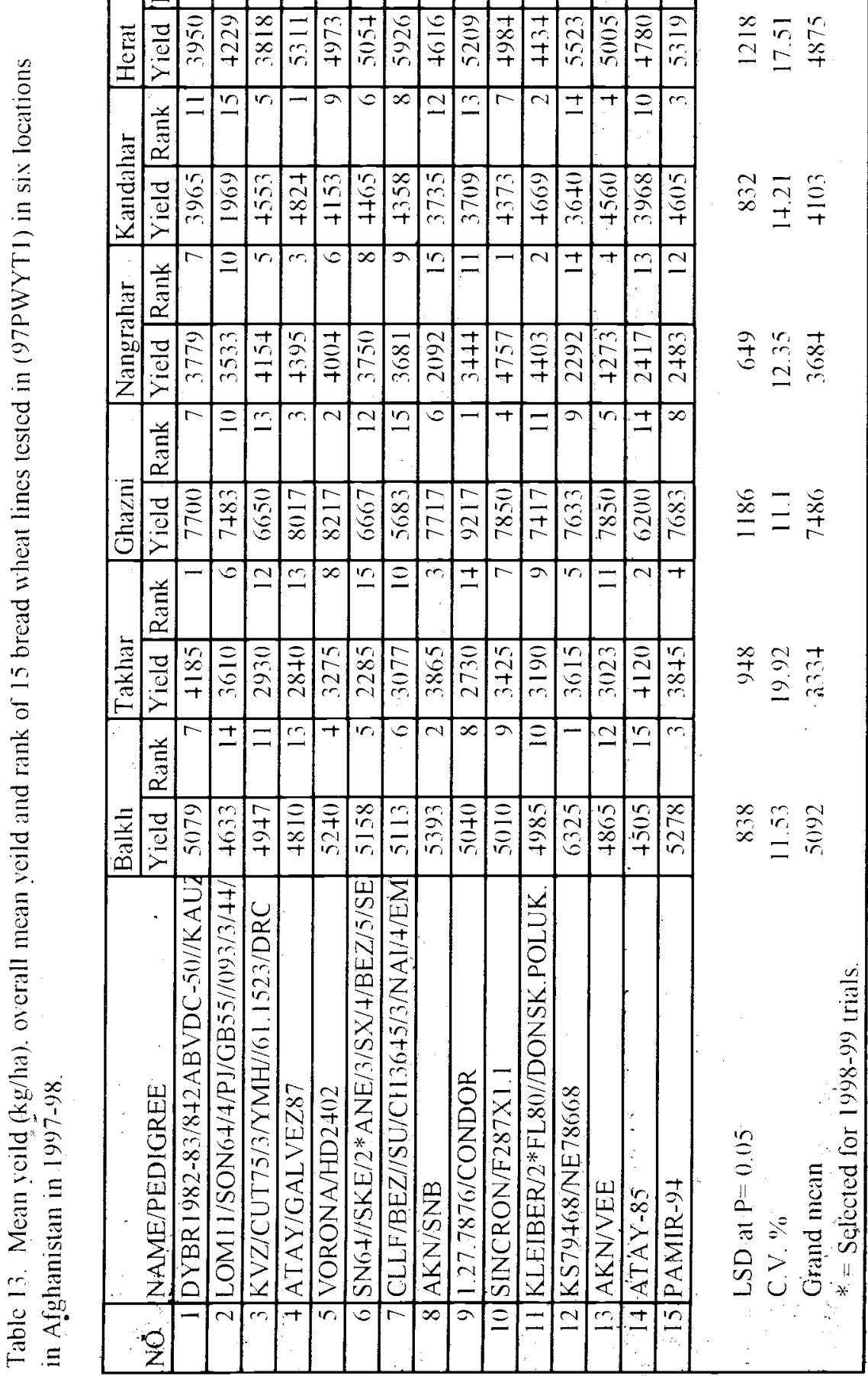




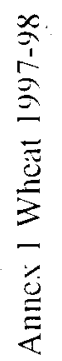

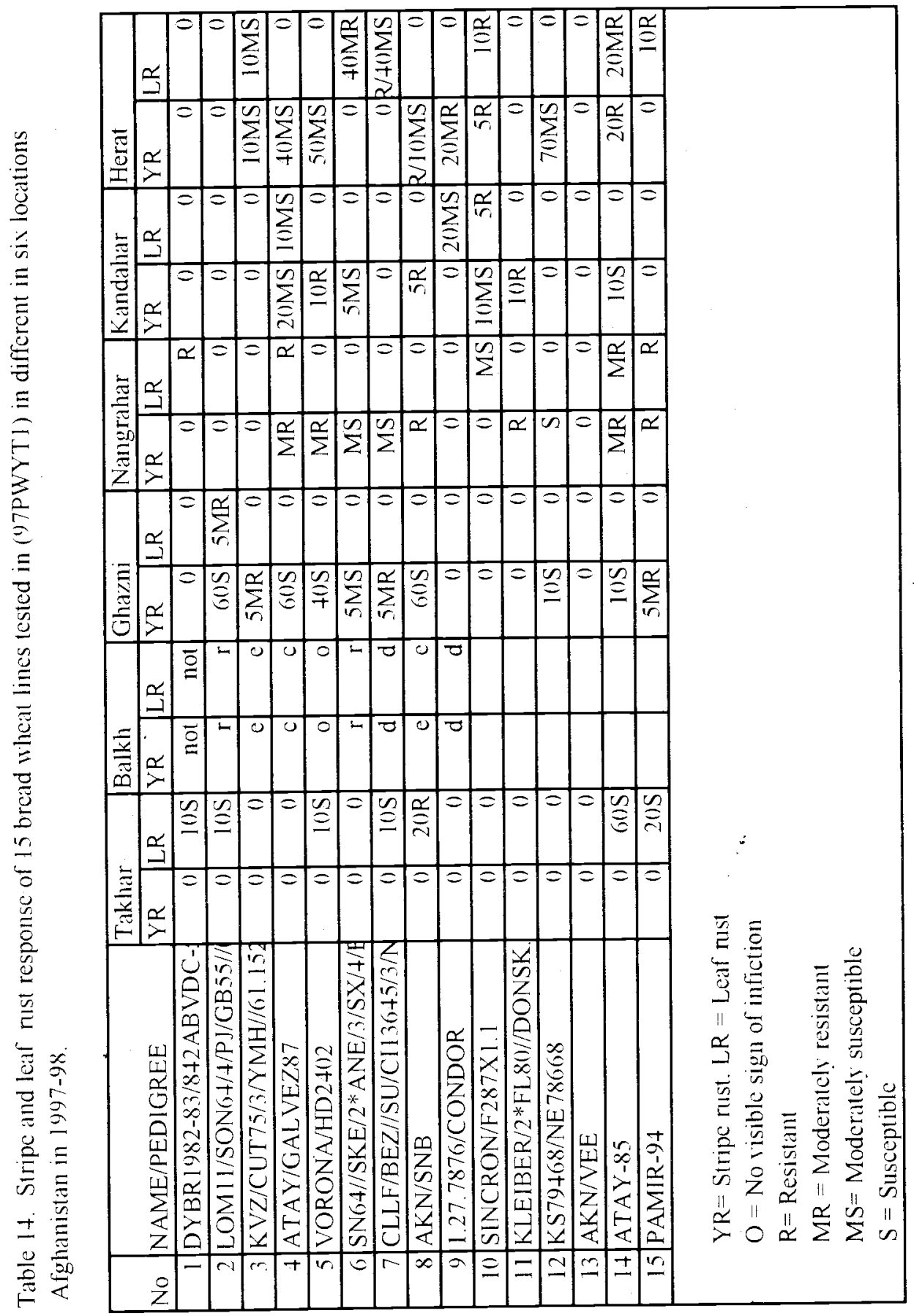



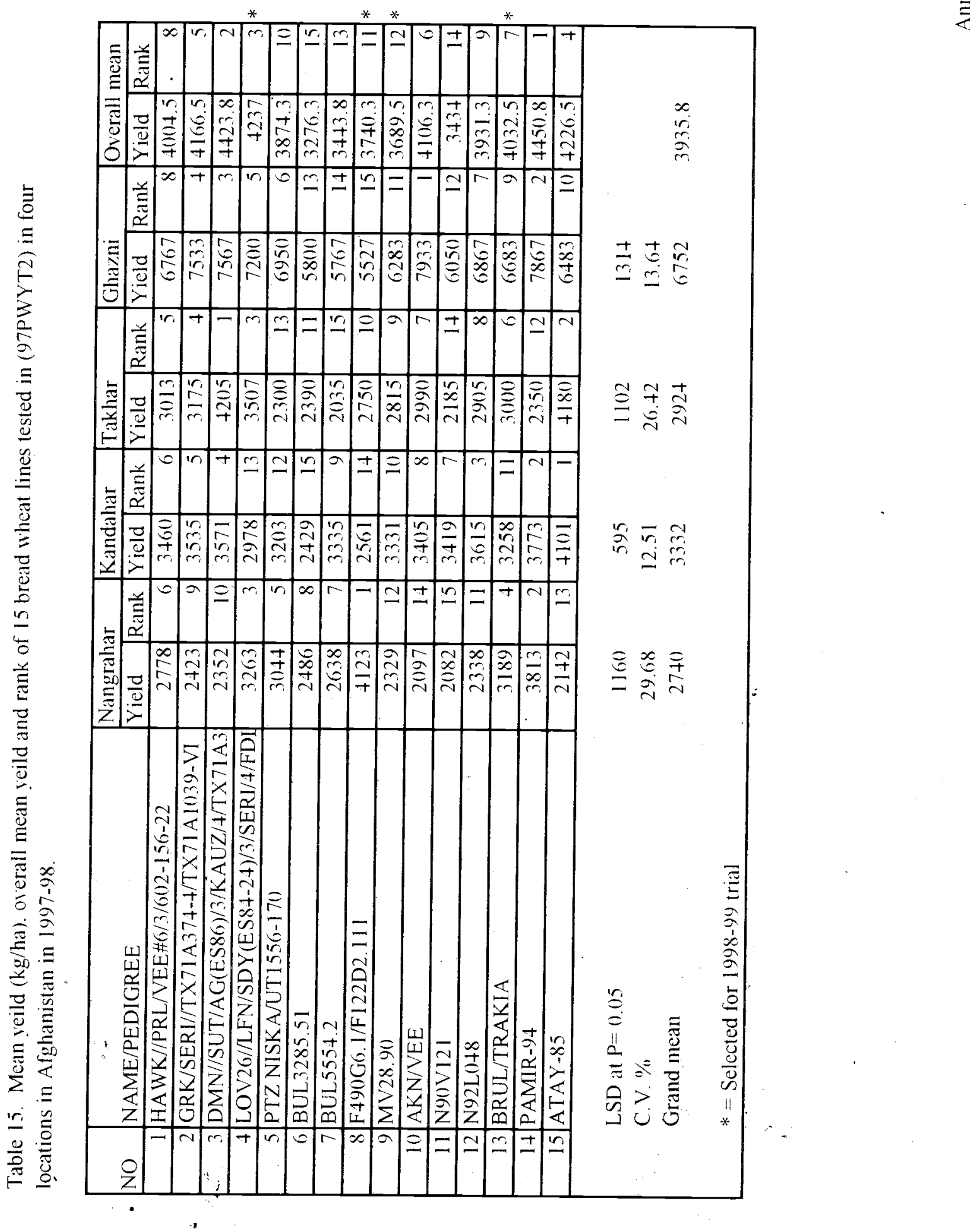


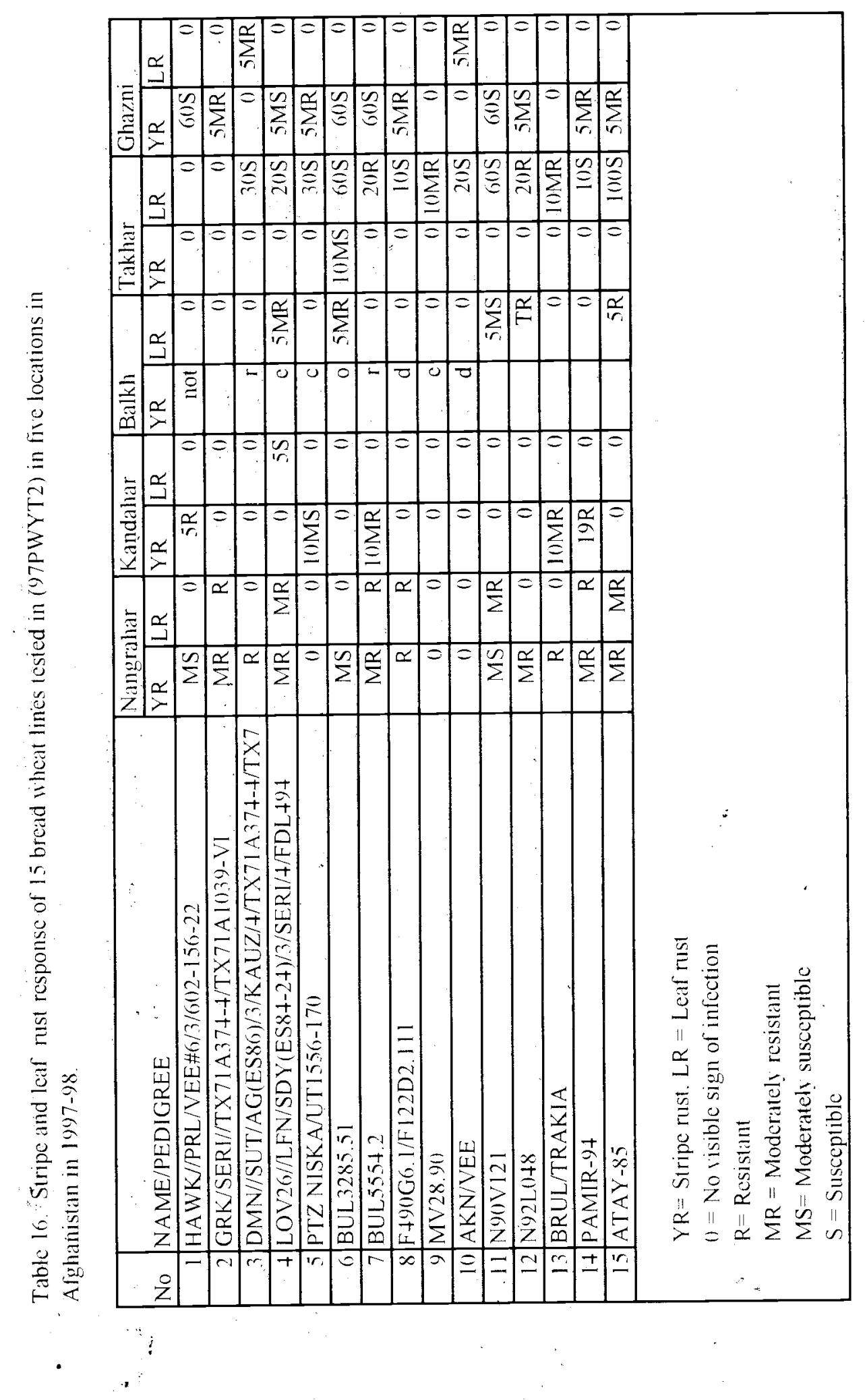




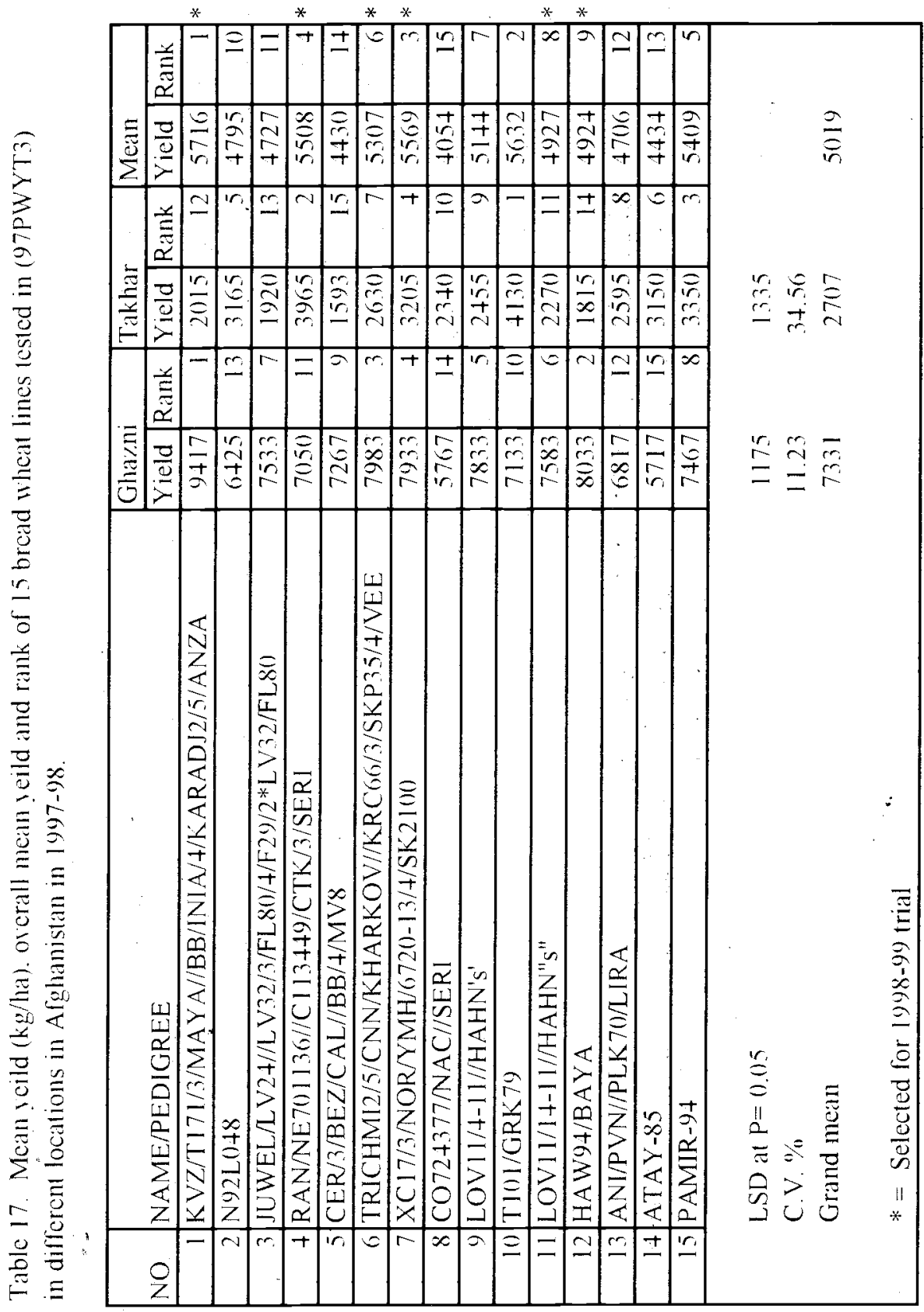




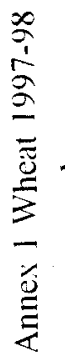

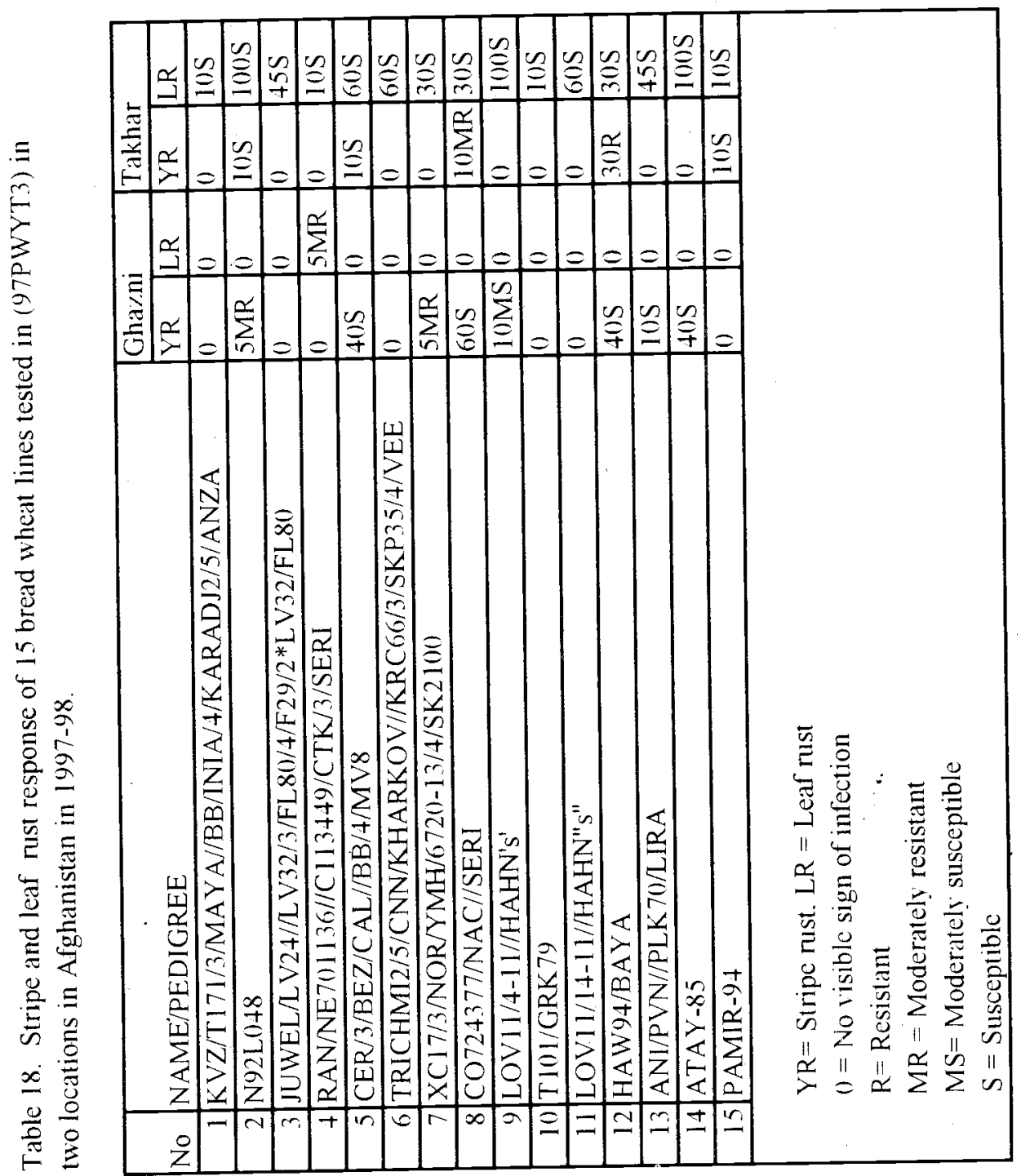




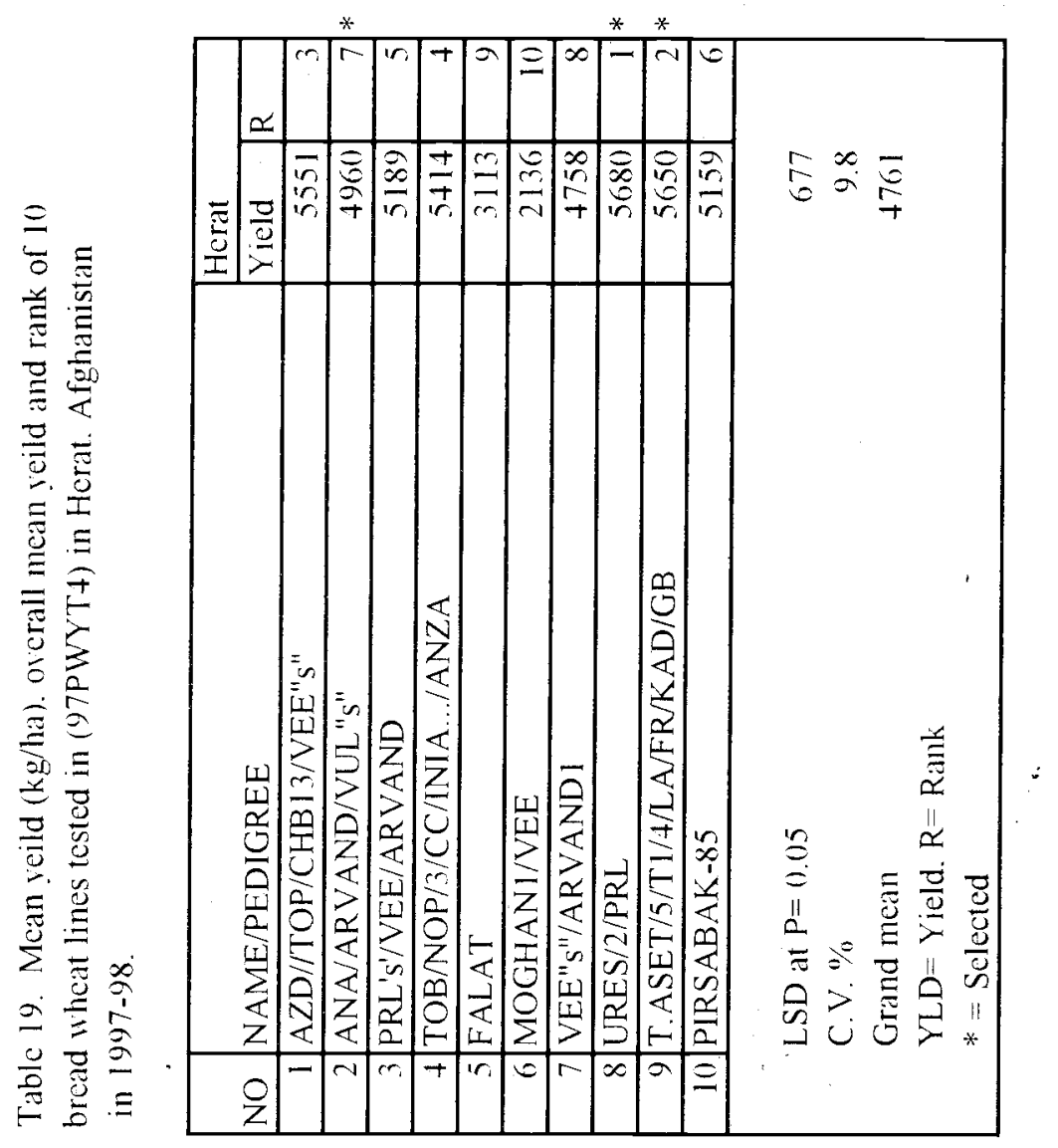




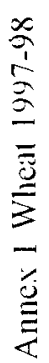

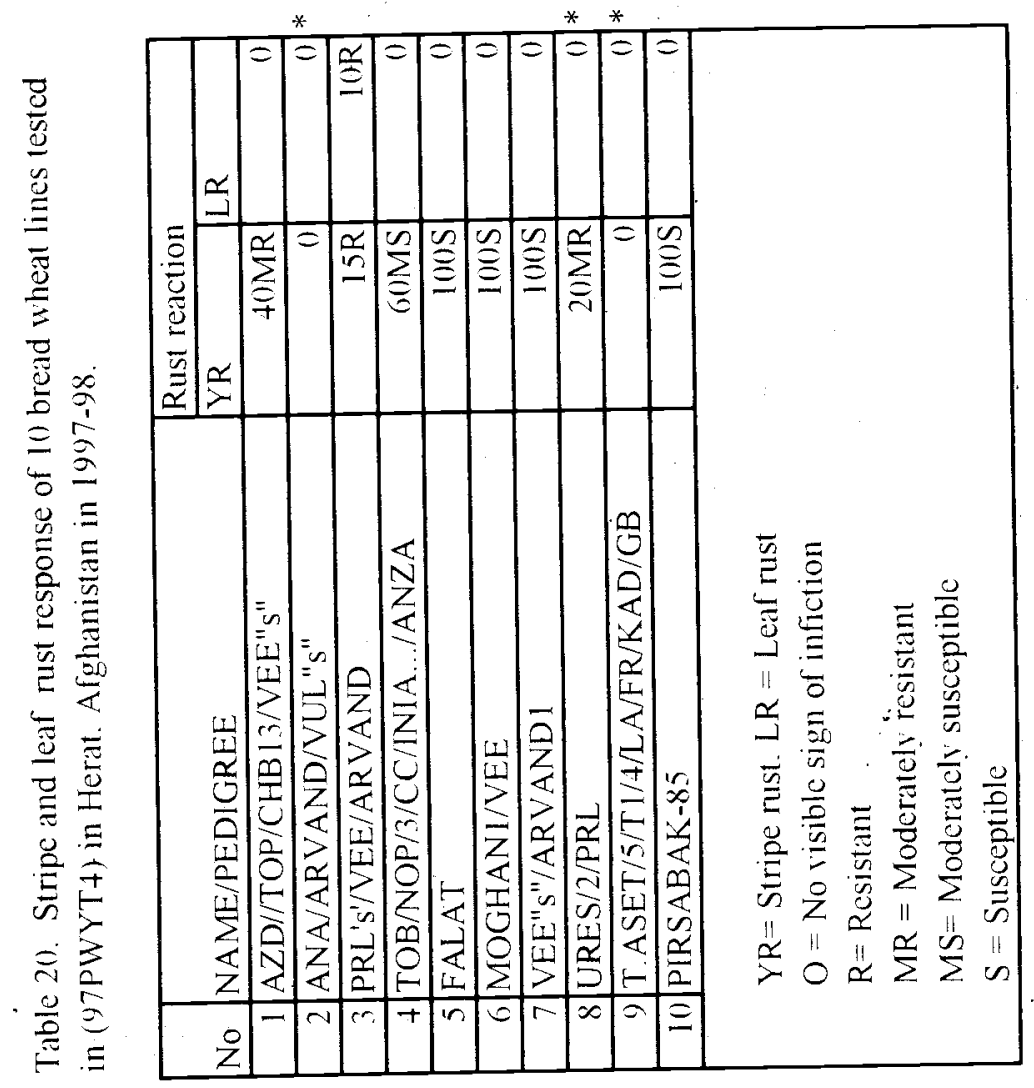




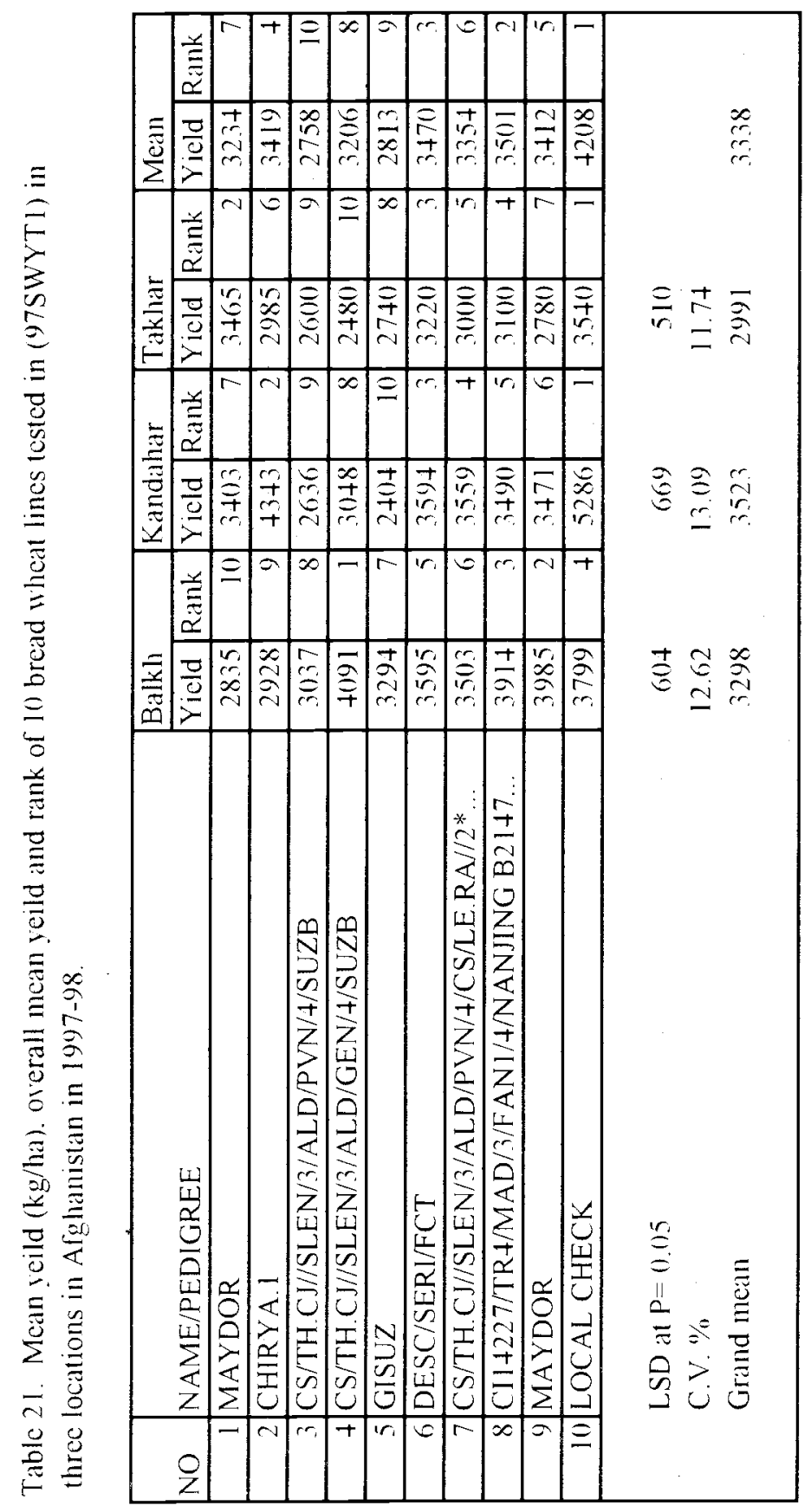




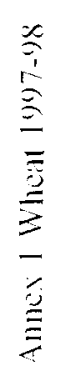

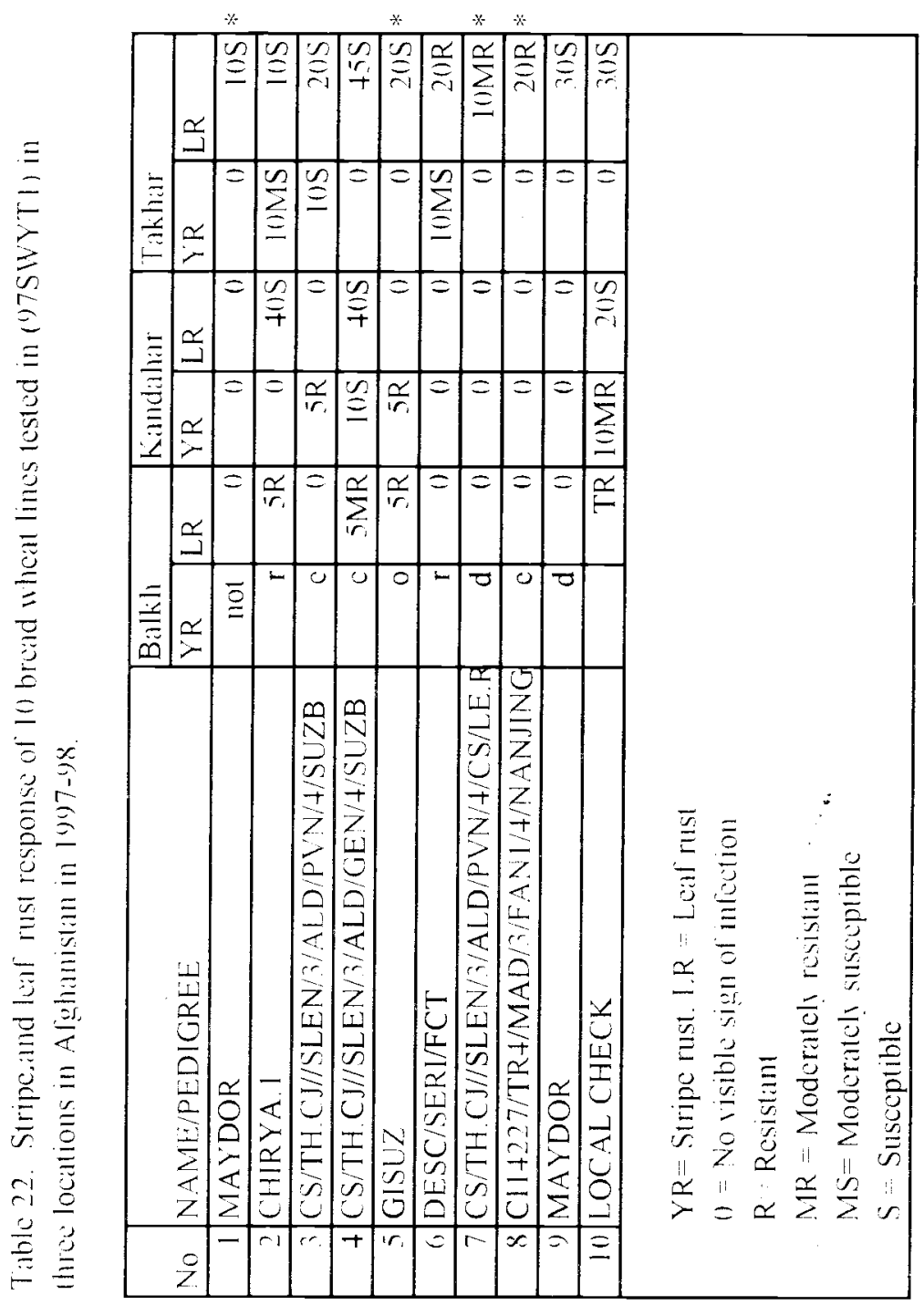




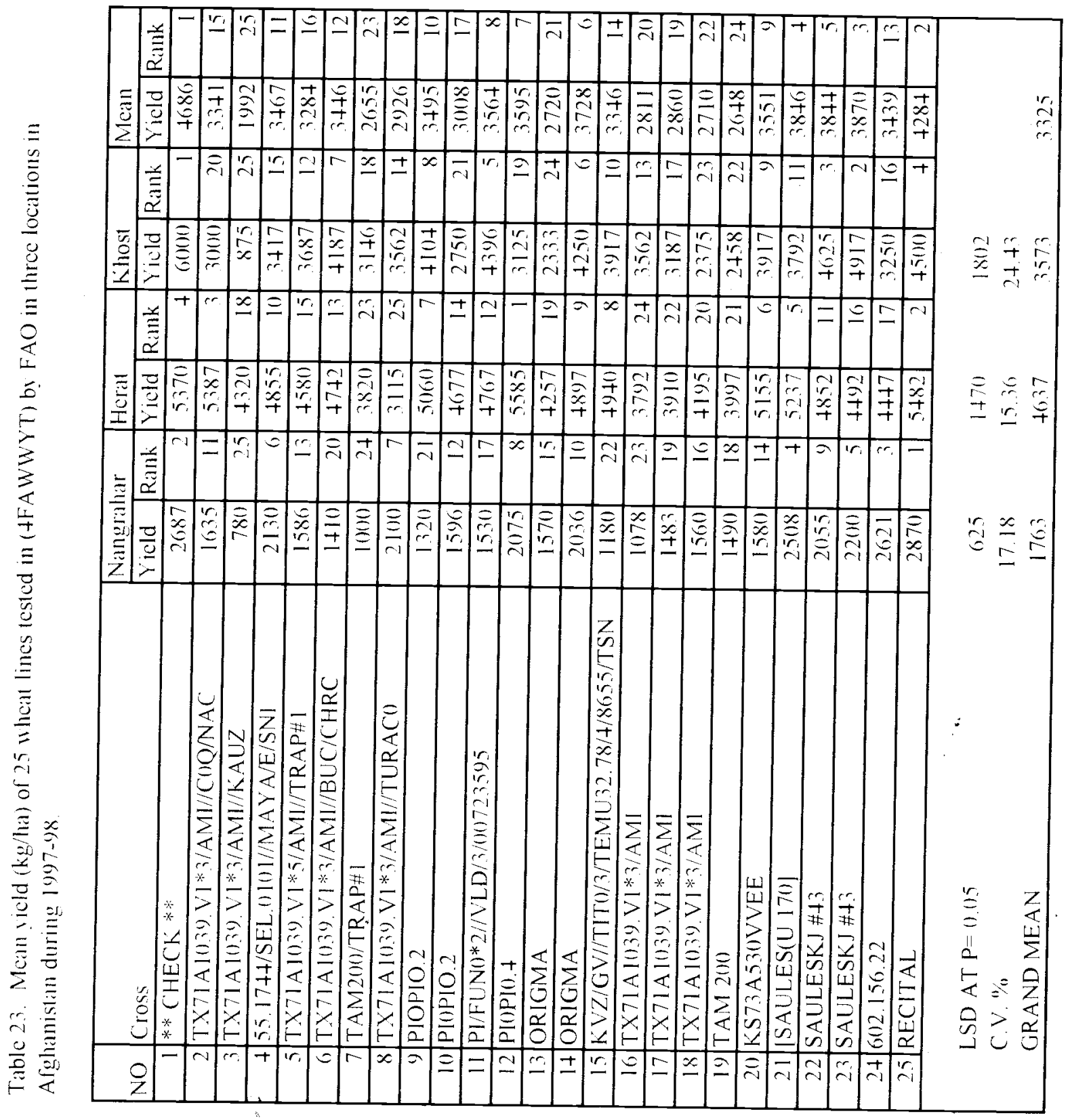




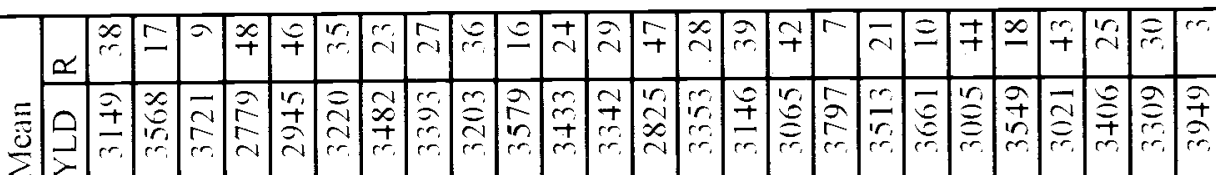

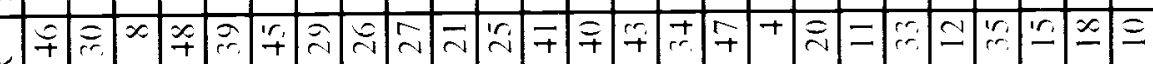

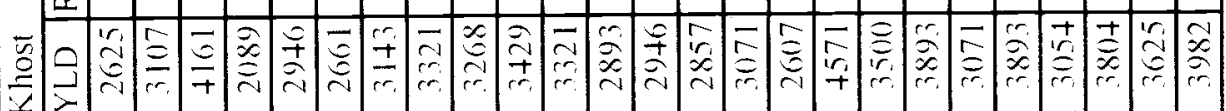

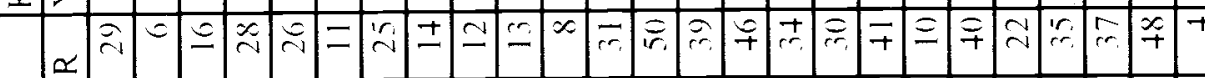

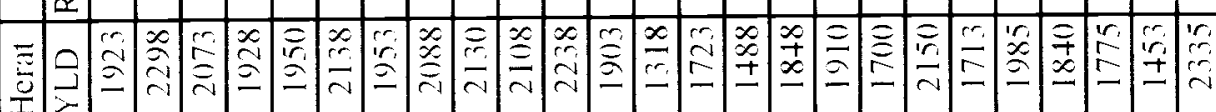

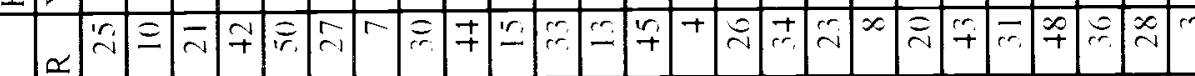

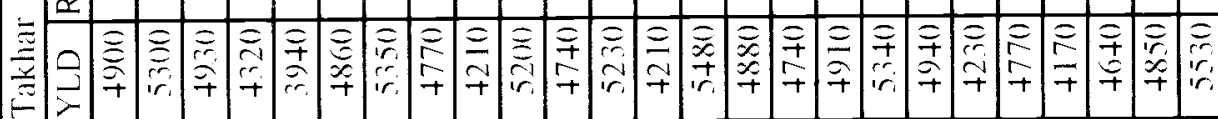

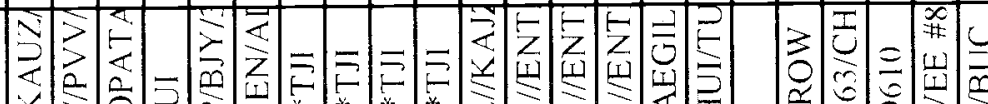

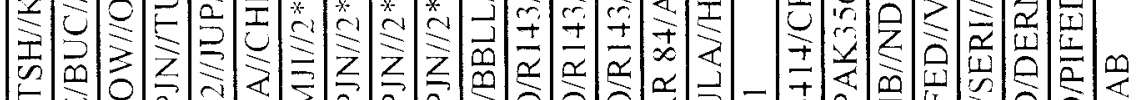

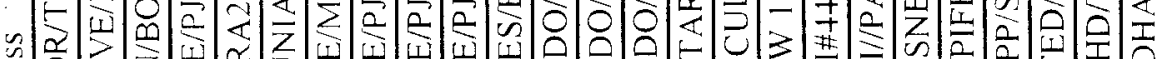

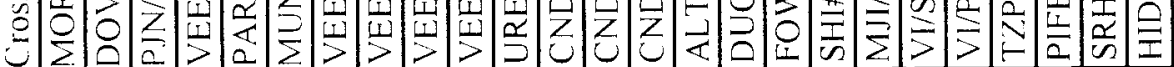
인

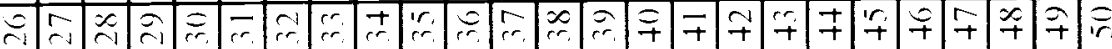

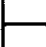

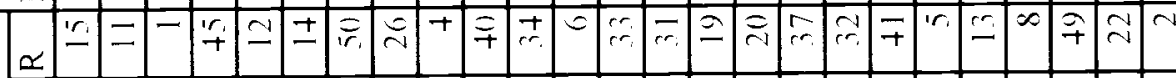

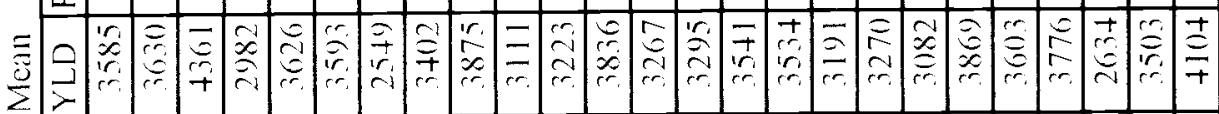

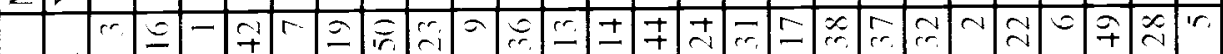

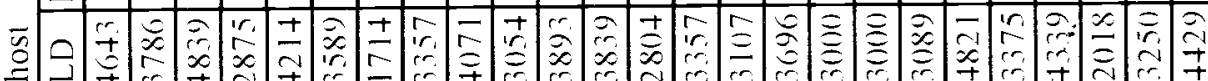

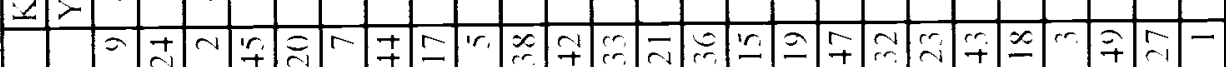

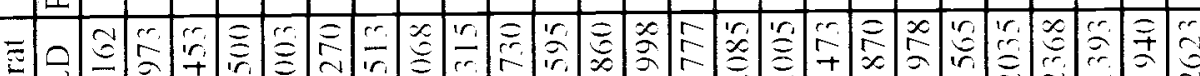

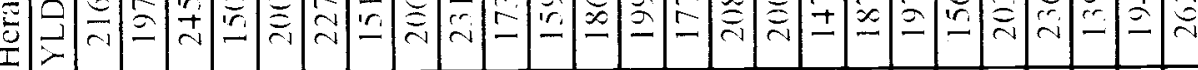

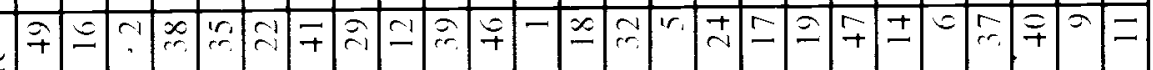

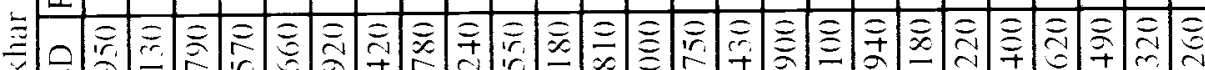

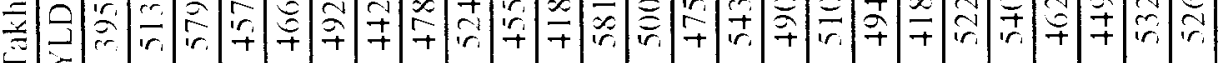

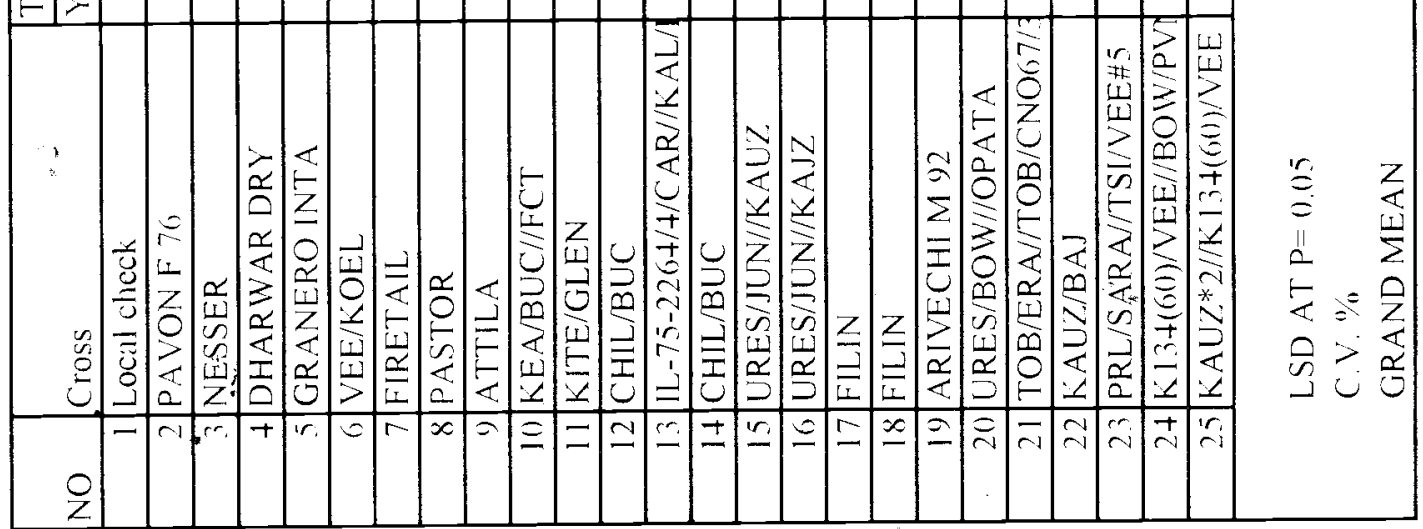




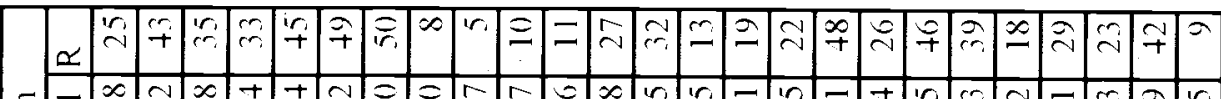

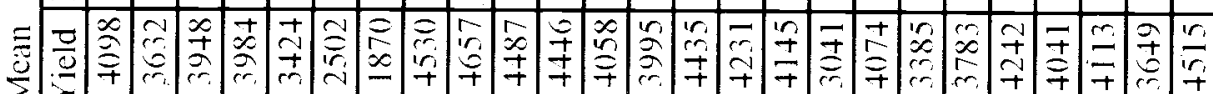

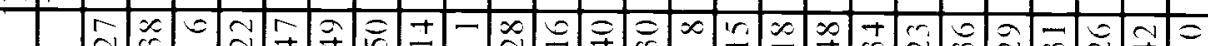

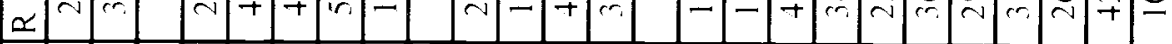

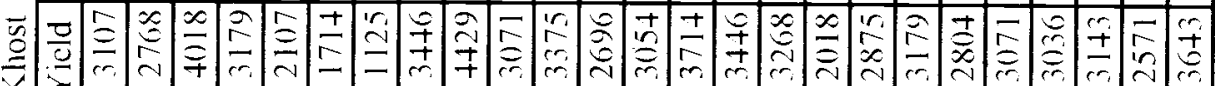

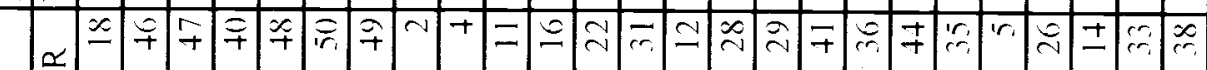

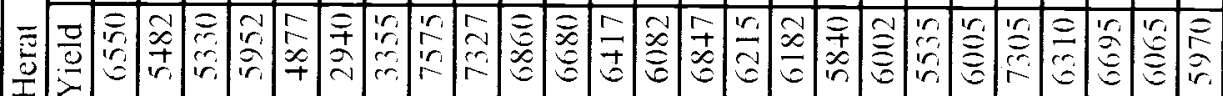

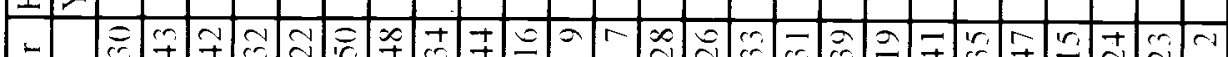

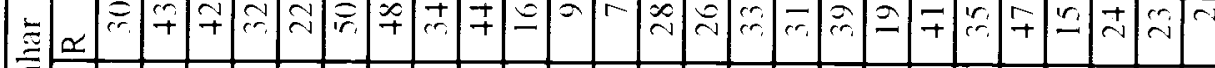

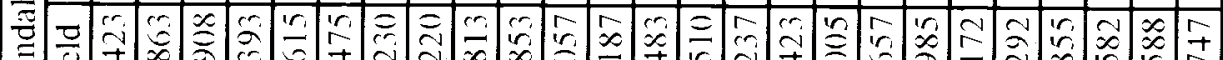

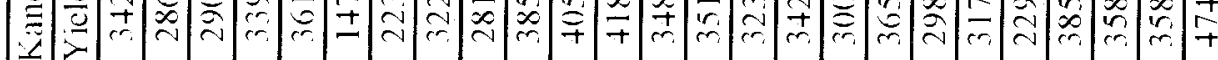

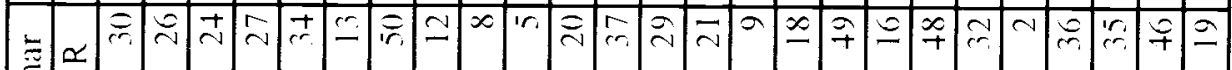
荡 $\stackrel{\Xi}{\Xi} \cong$

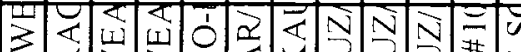

*

Sٕ

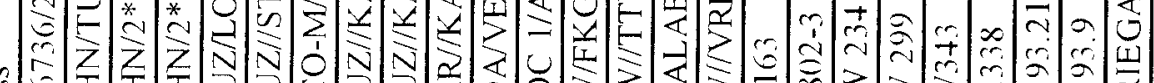

b

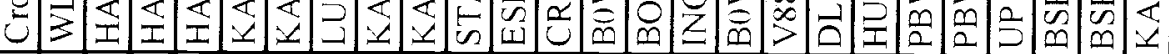

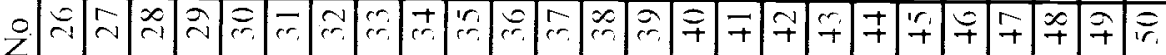

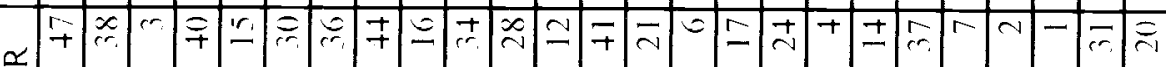

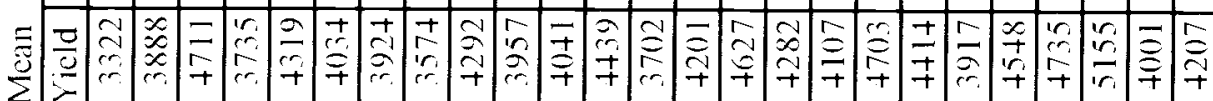

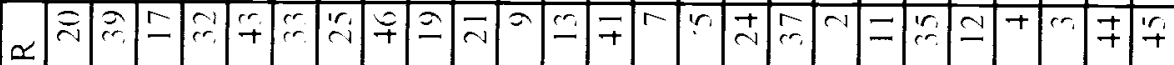

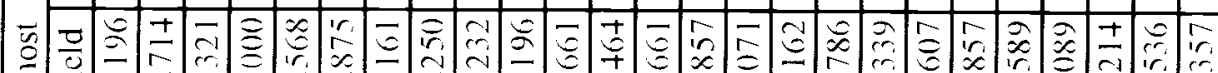

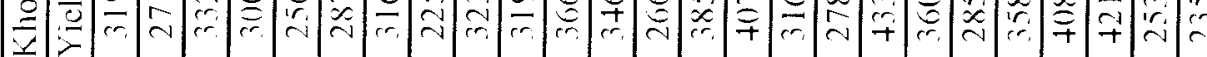

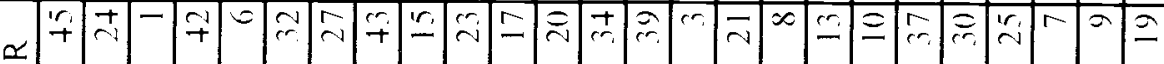

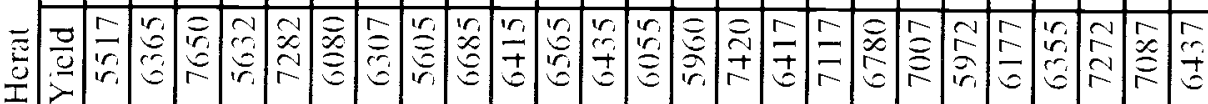

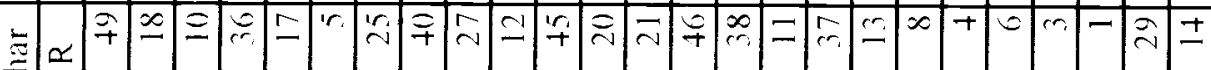

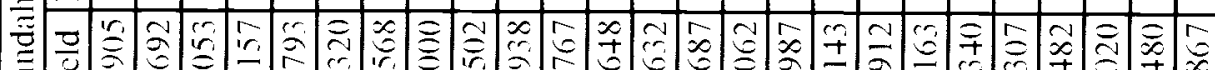

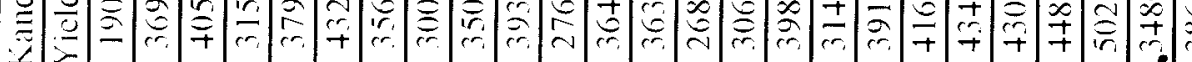

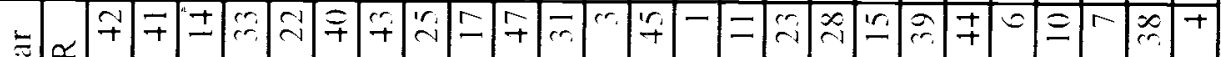

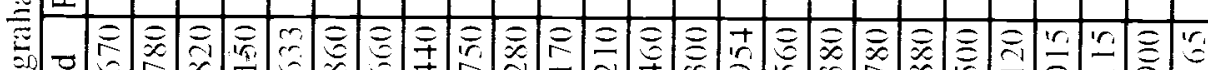

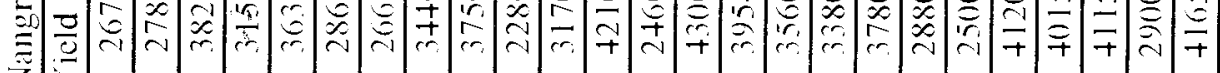
$\ddot{z}:$

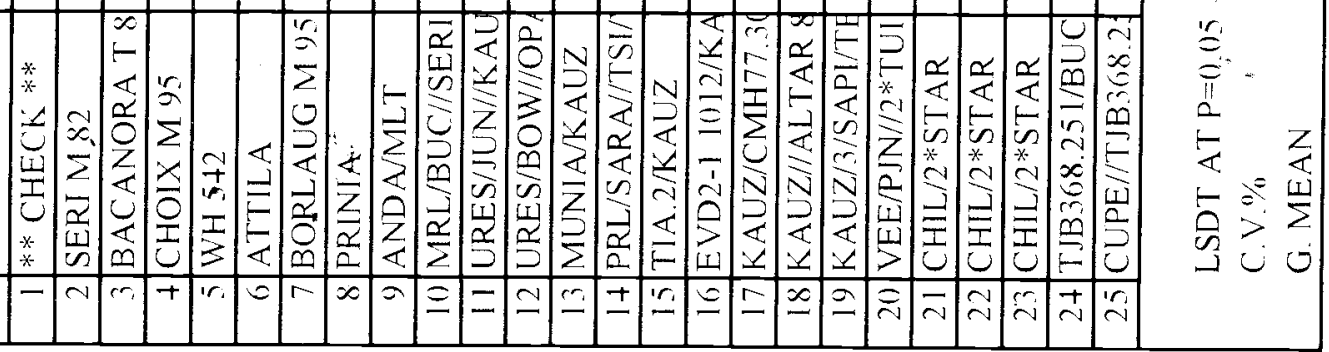




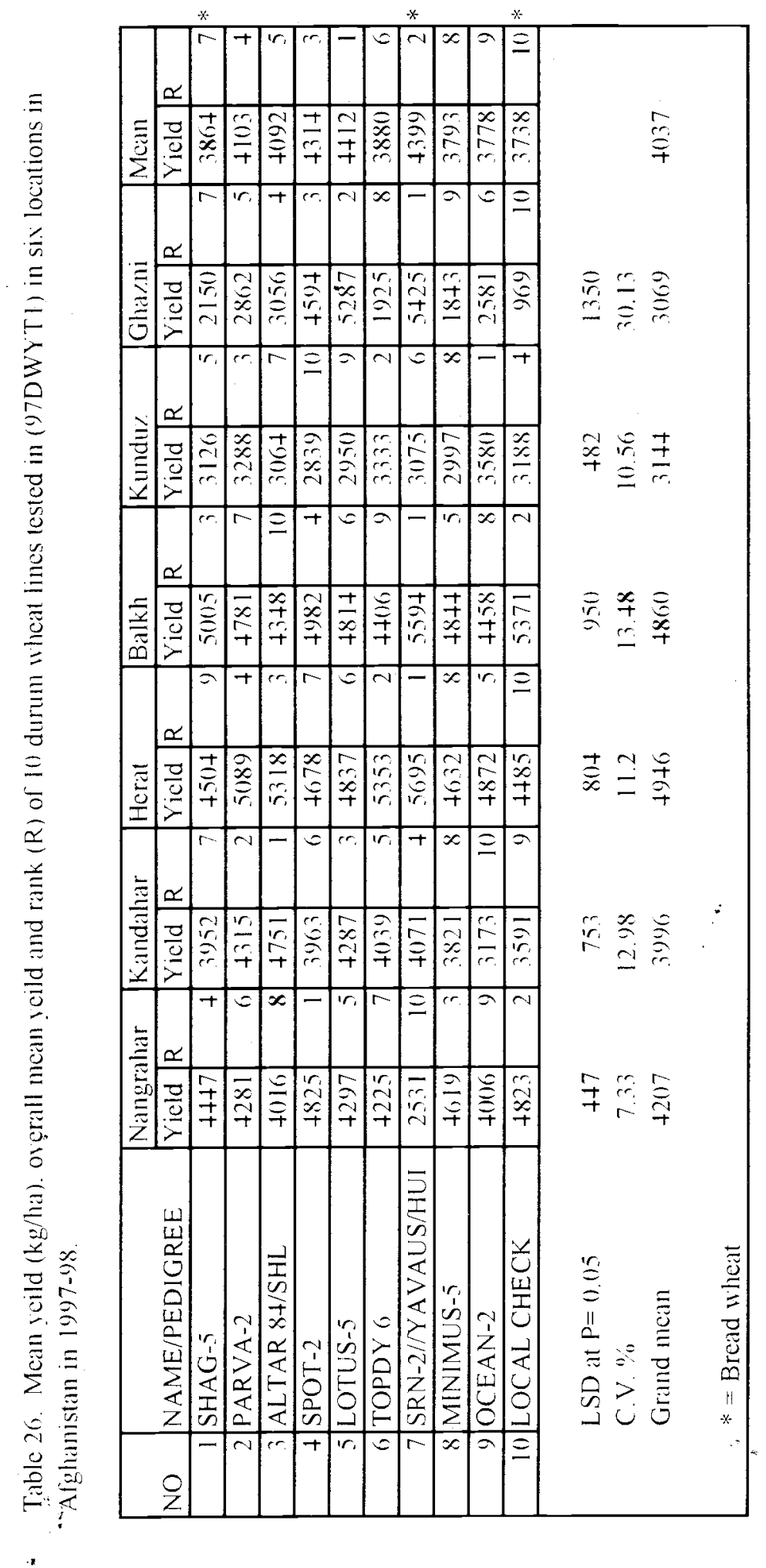




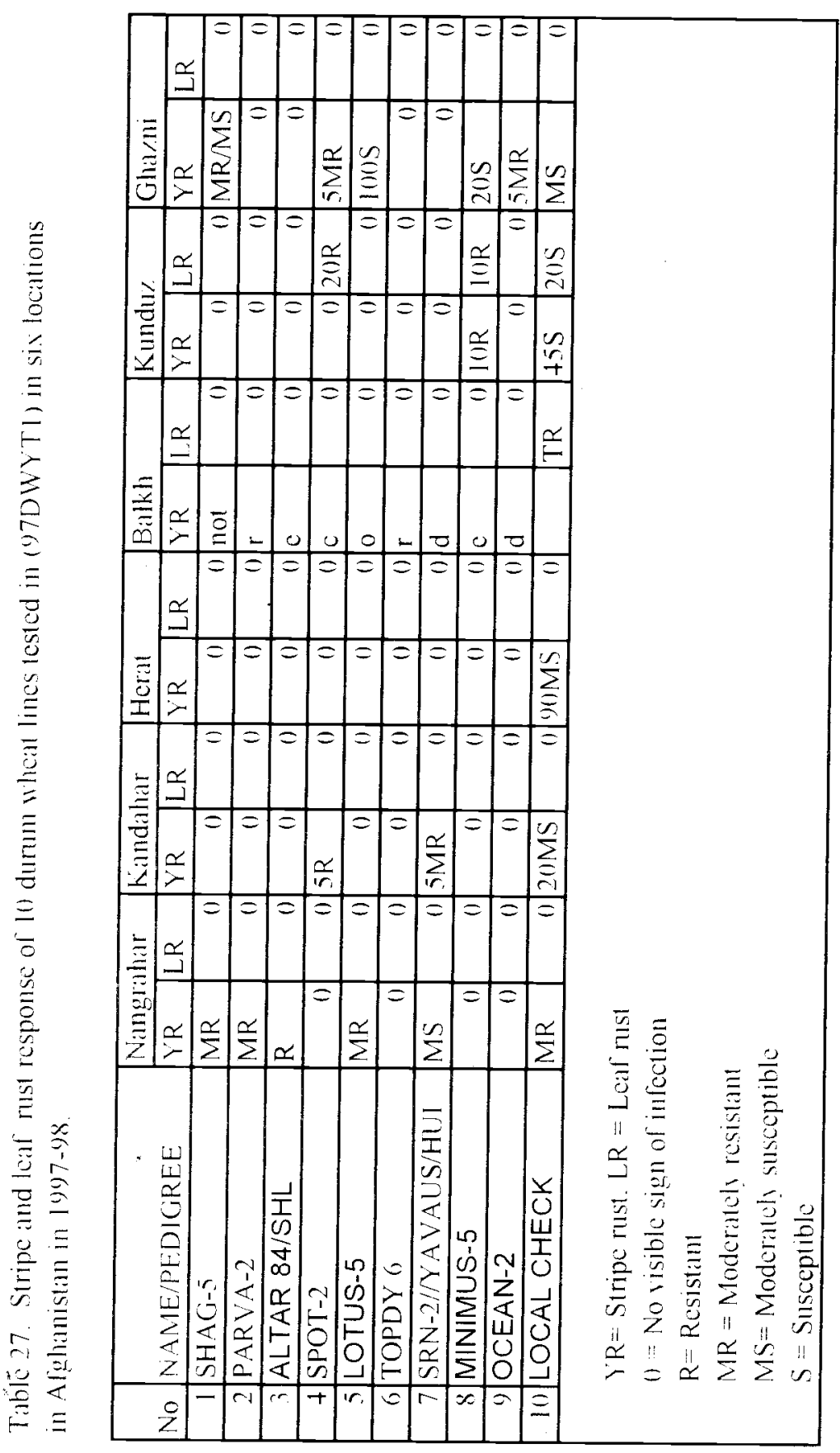




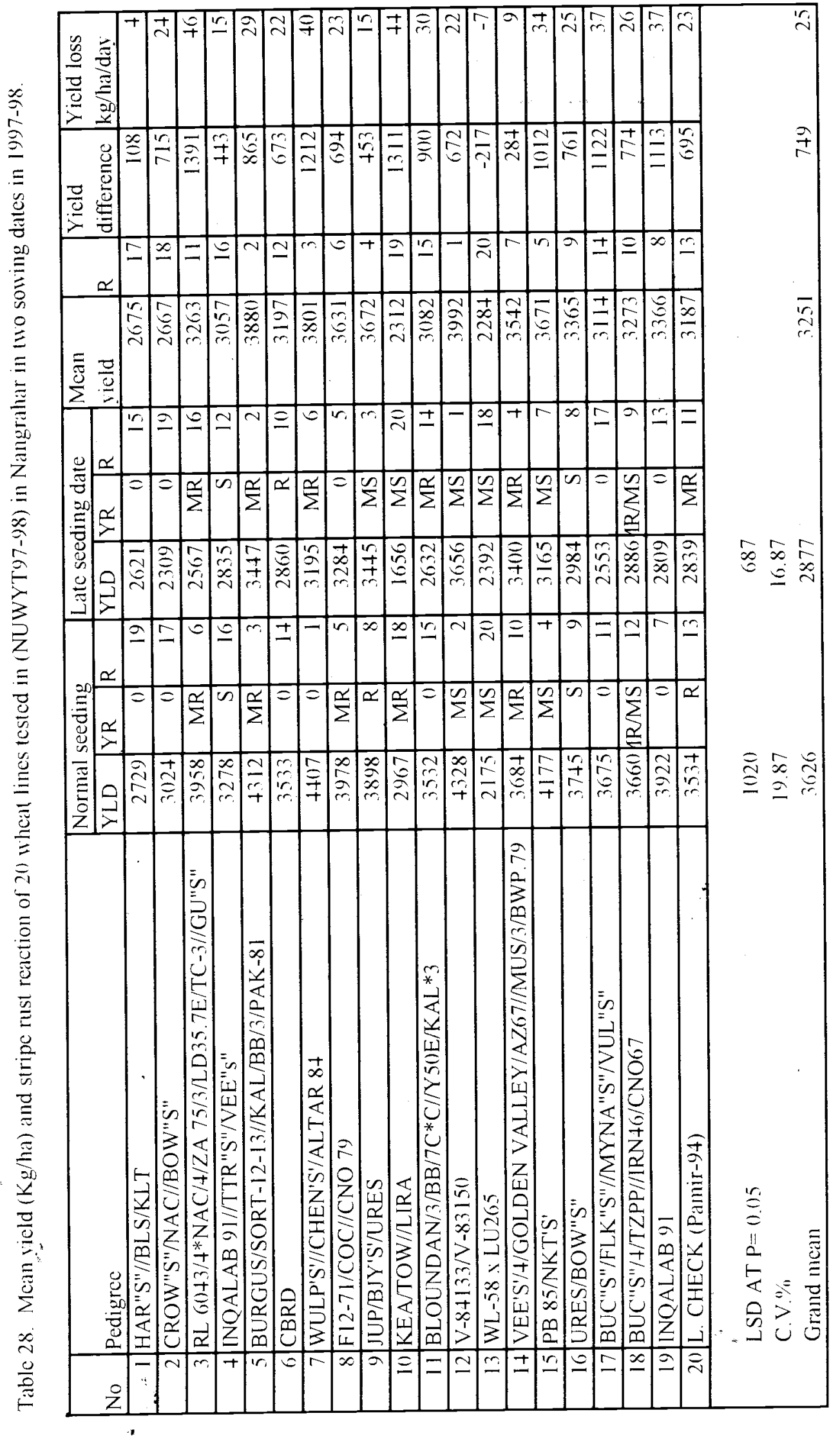




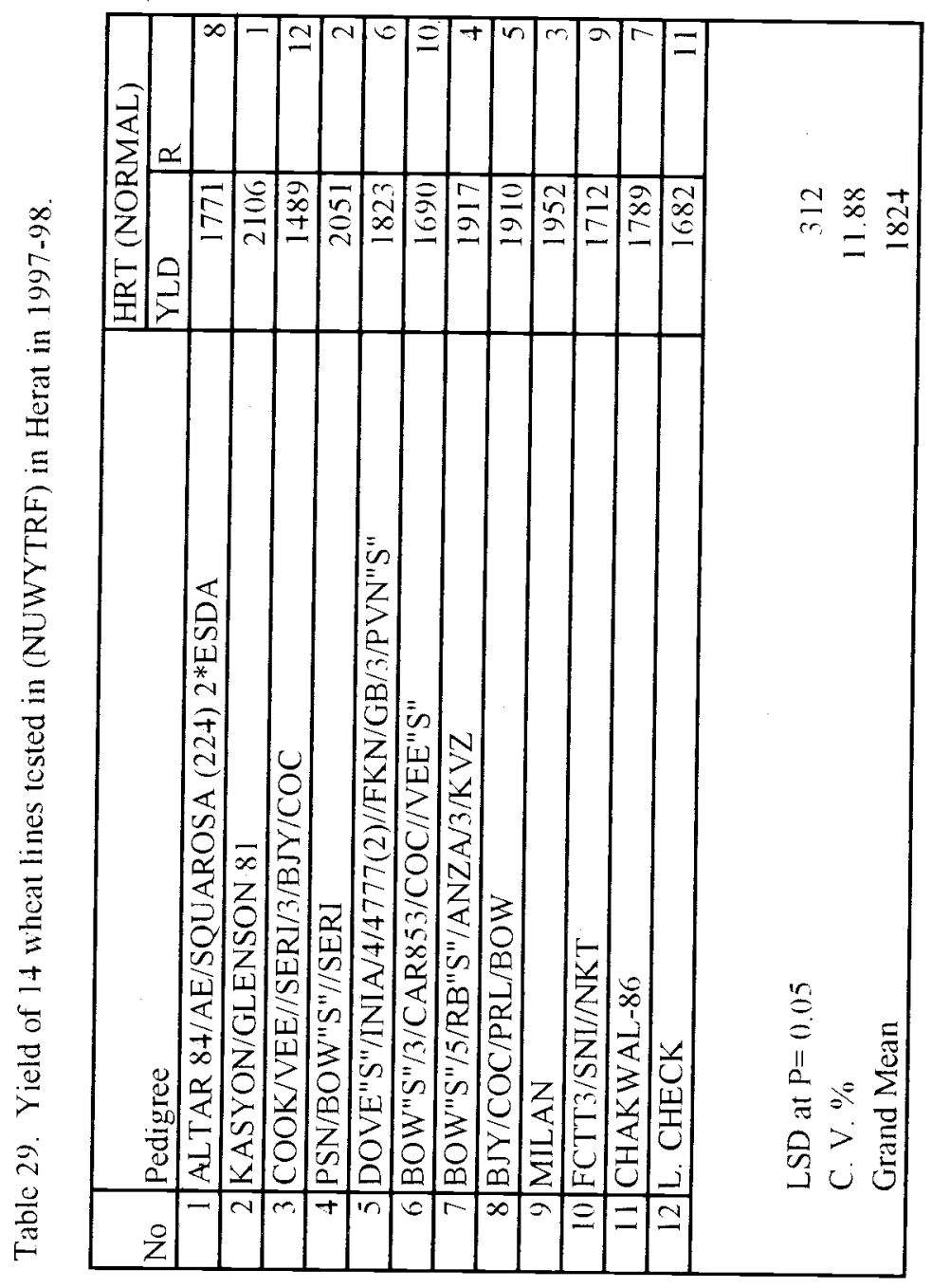




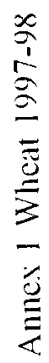

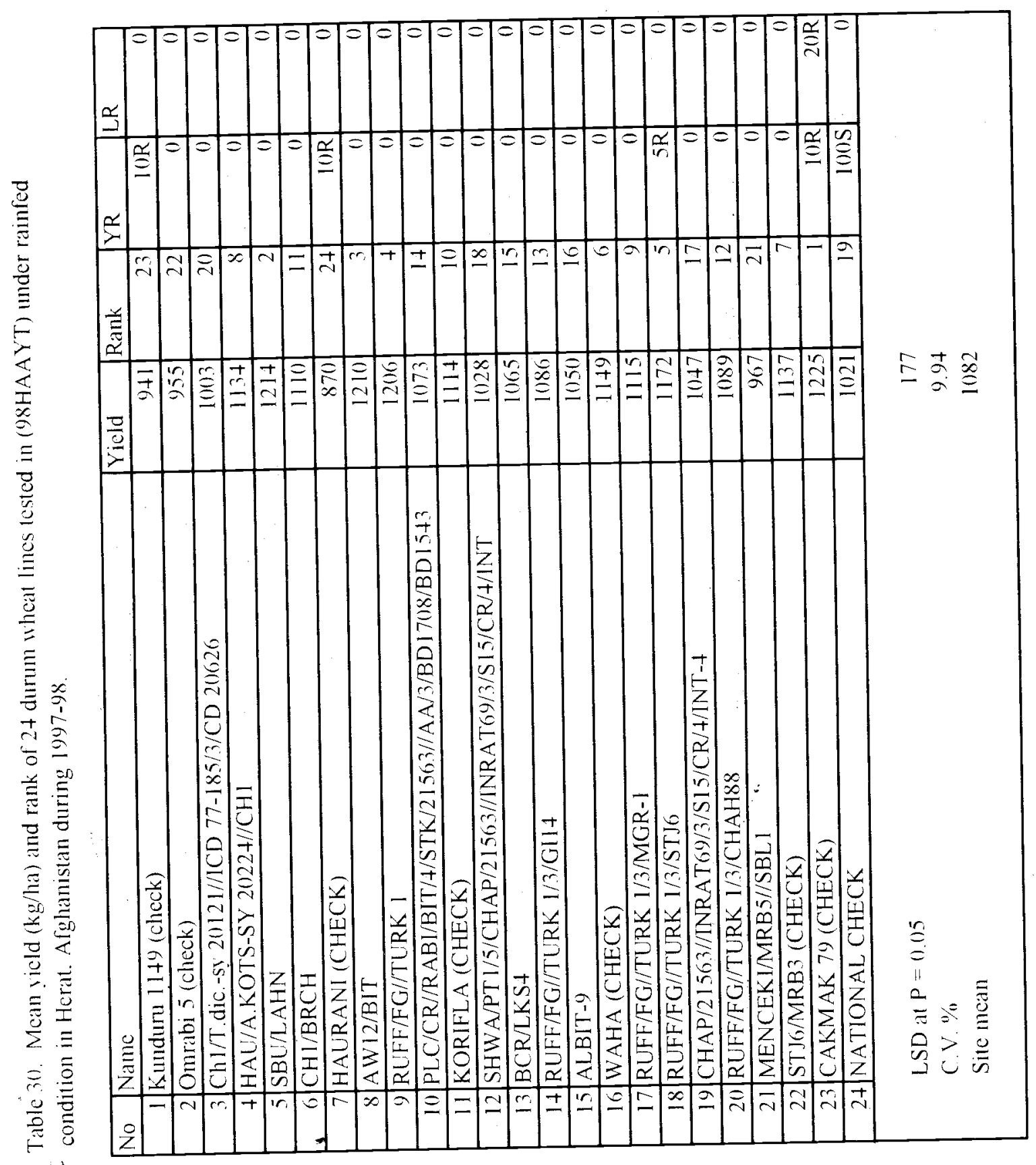




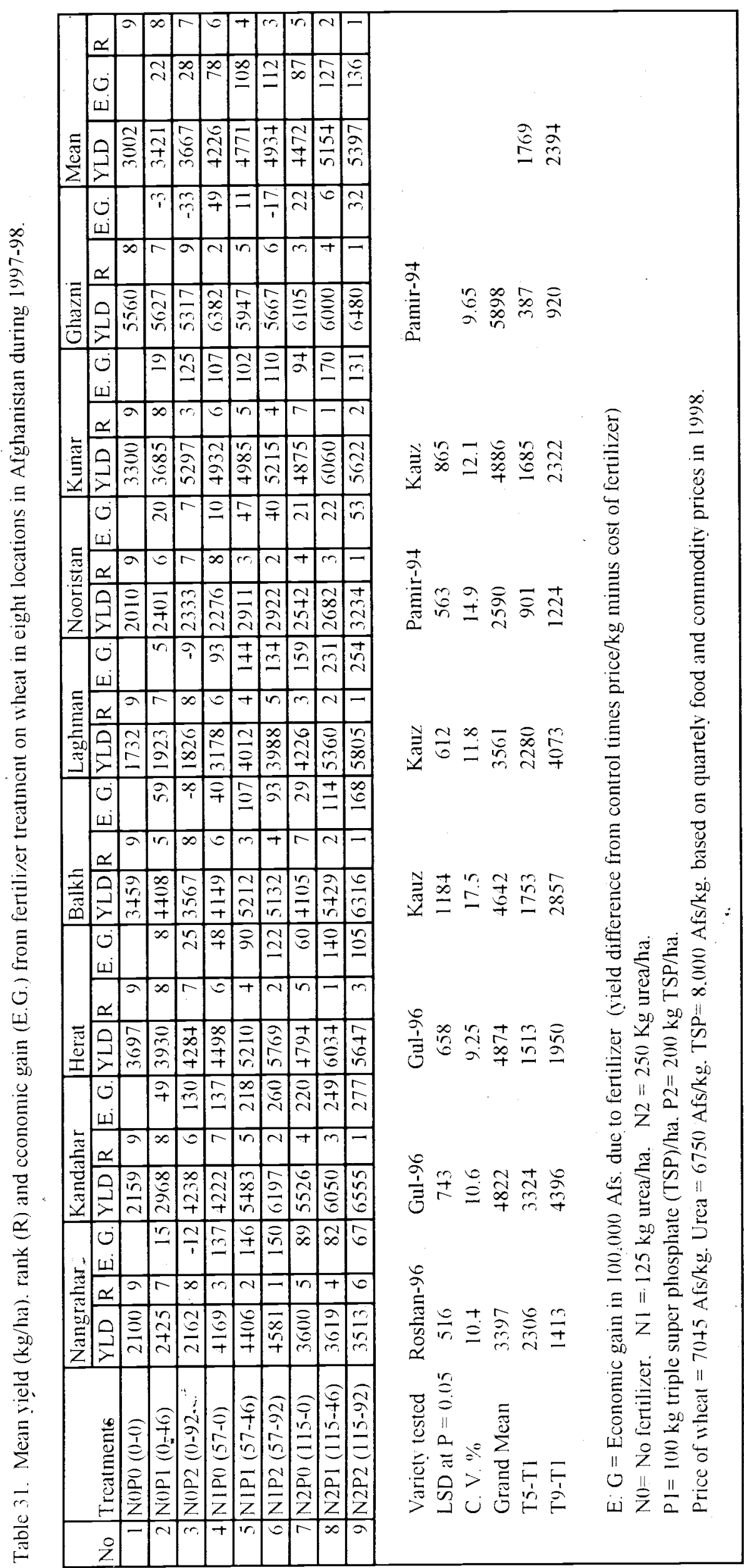

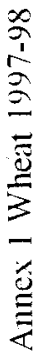




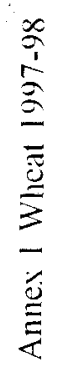

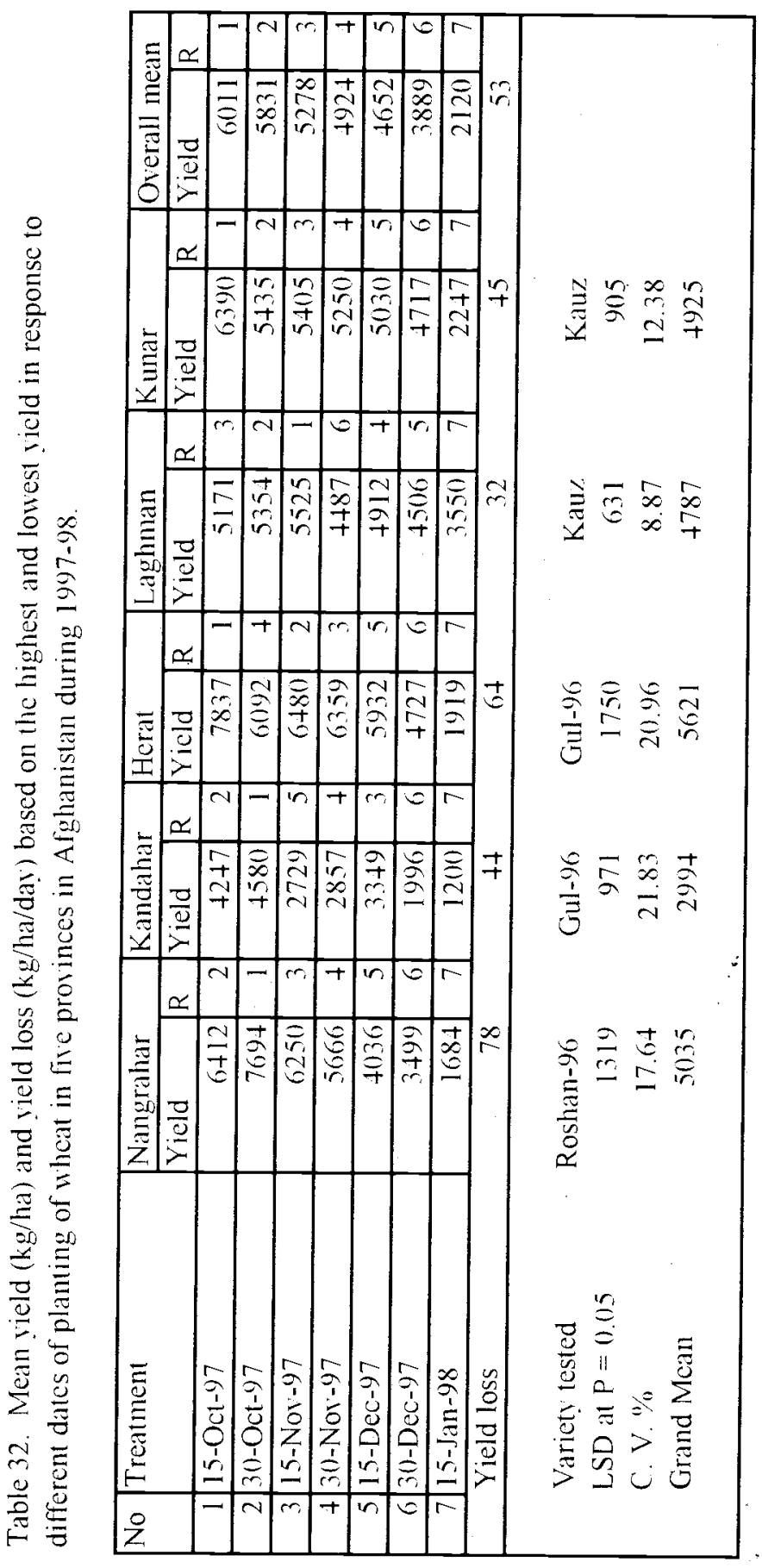




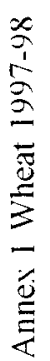

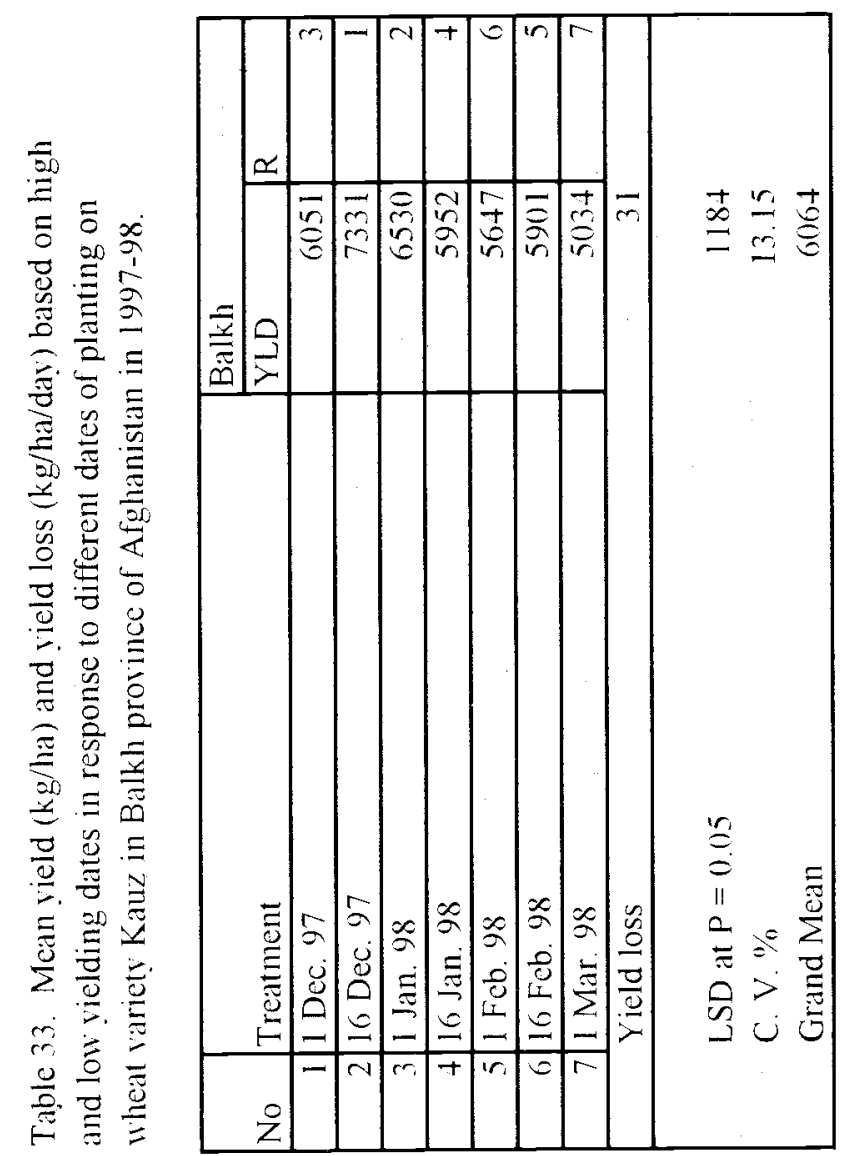




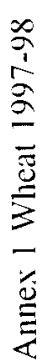

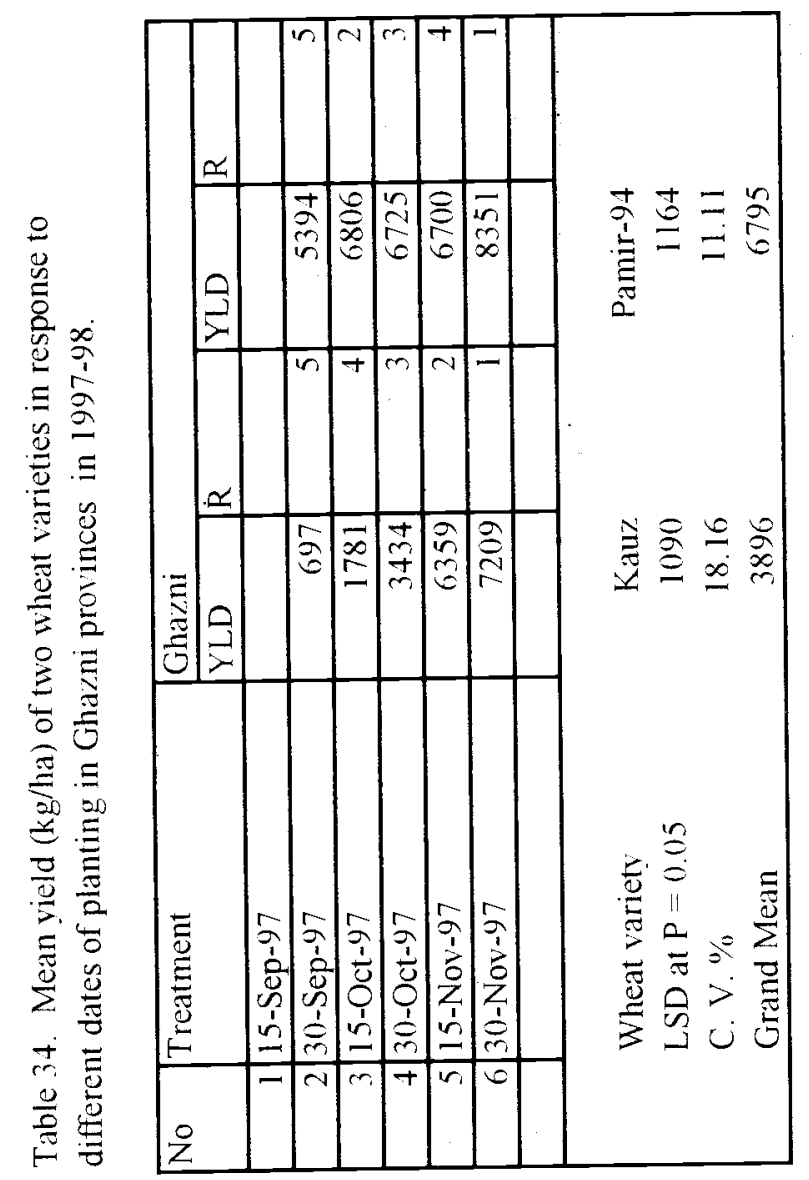




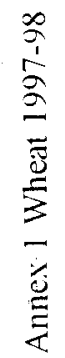

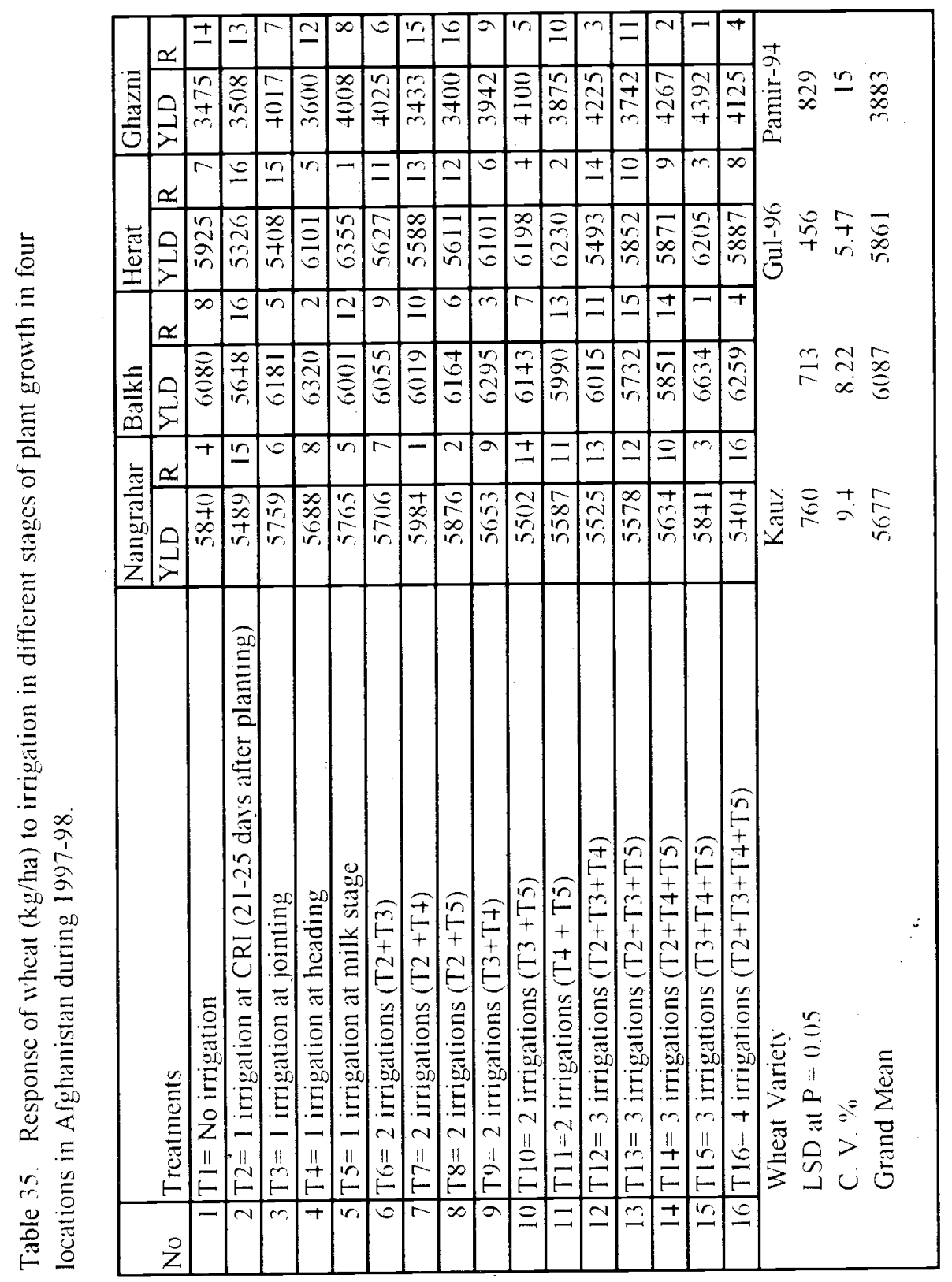




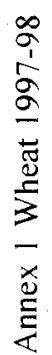

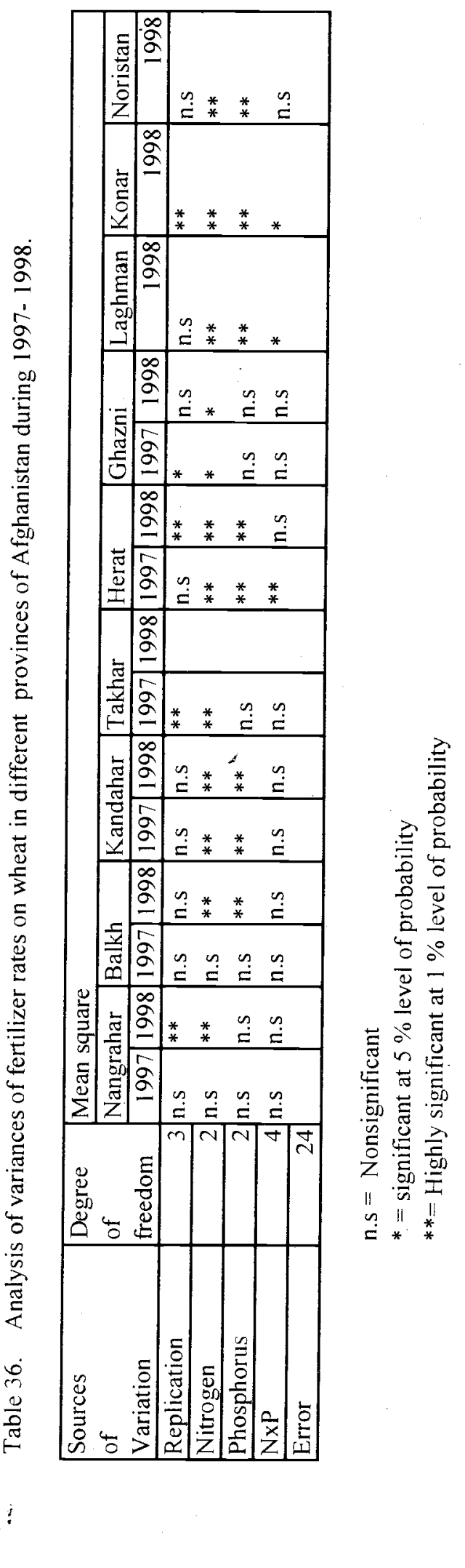


里

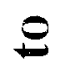

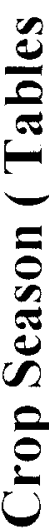

8

क

8

$\frac{\pi}{\sigma}$

$\frac{\tilde{E}}{2}$

N

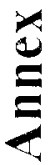



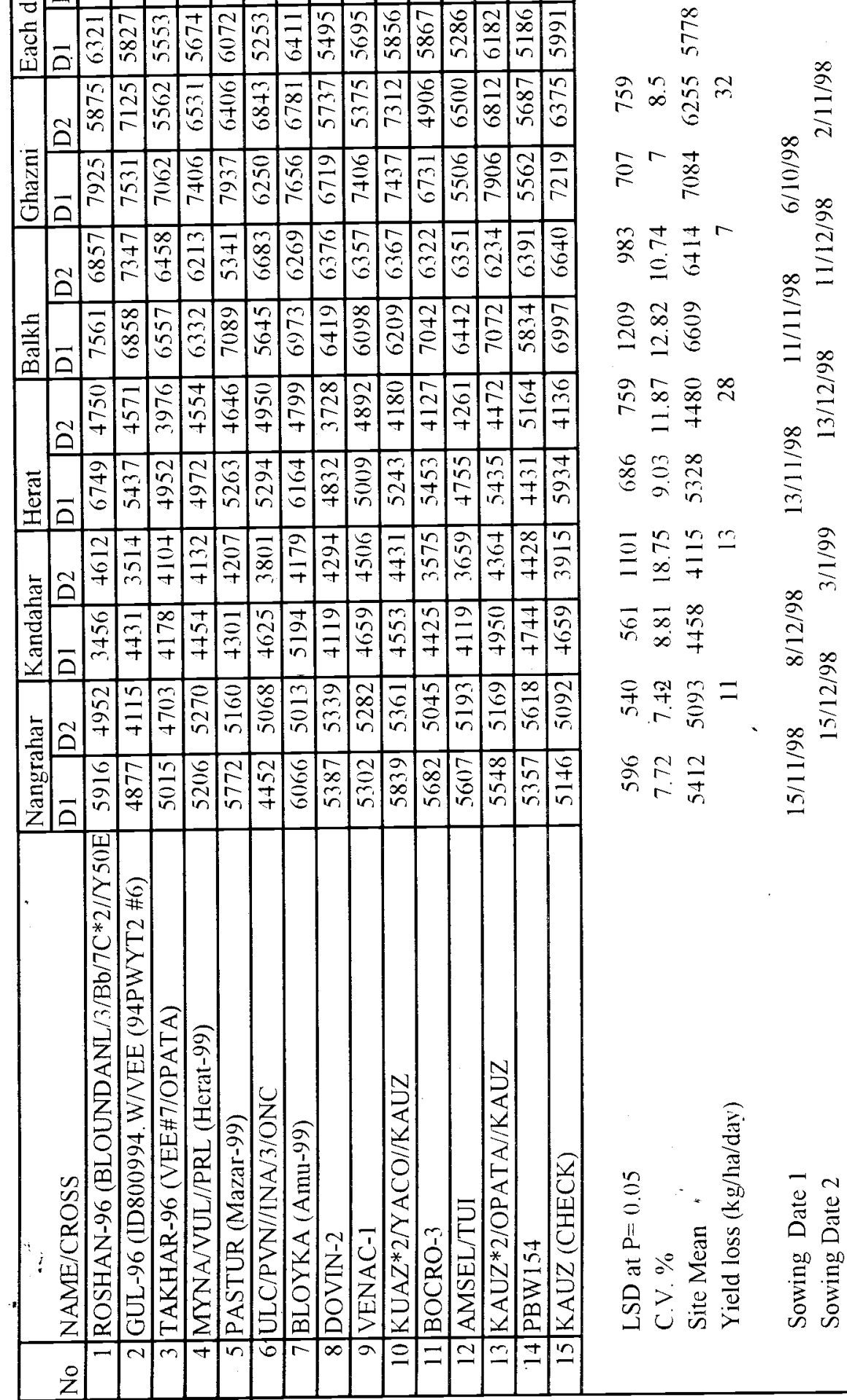

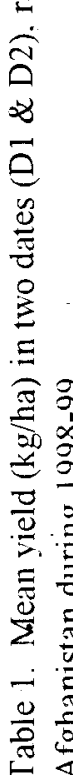

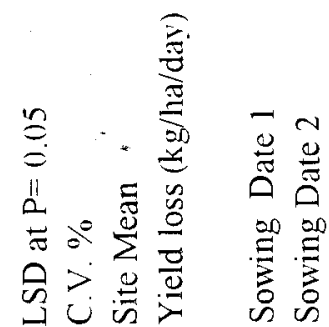




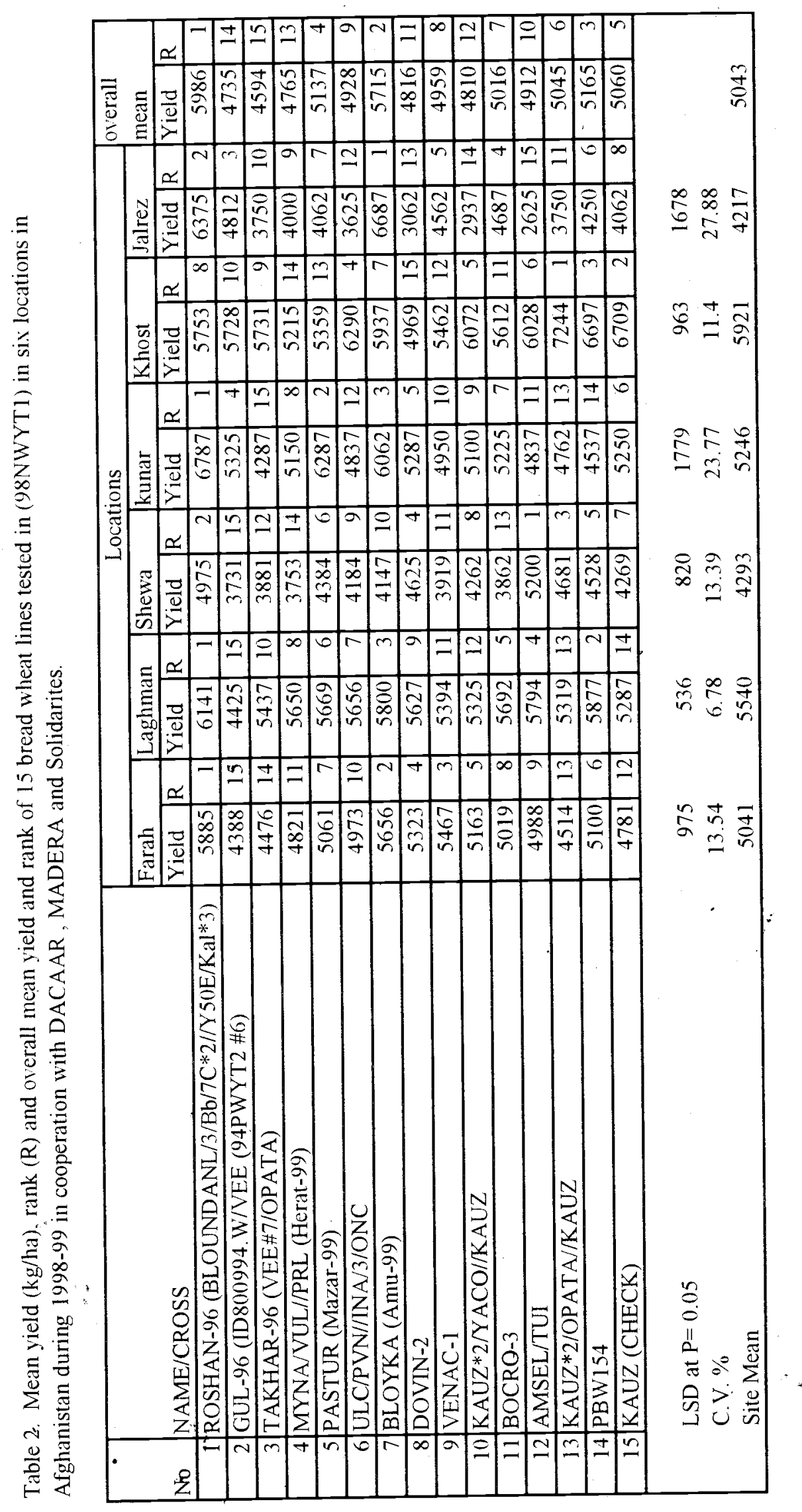




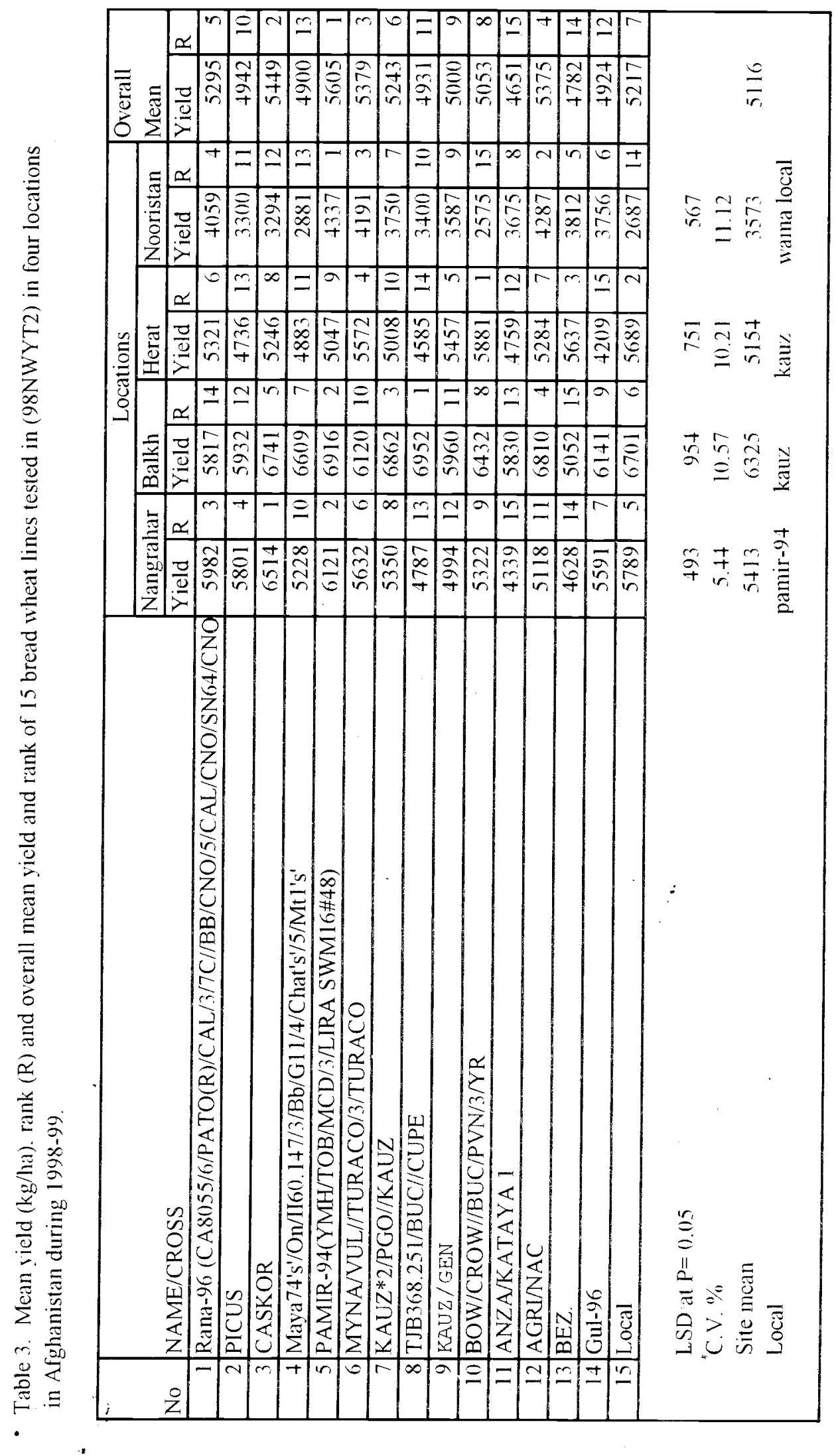




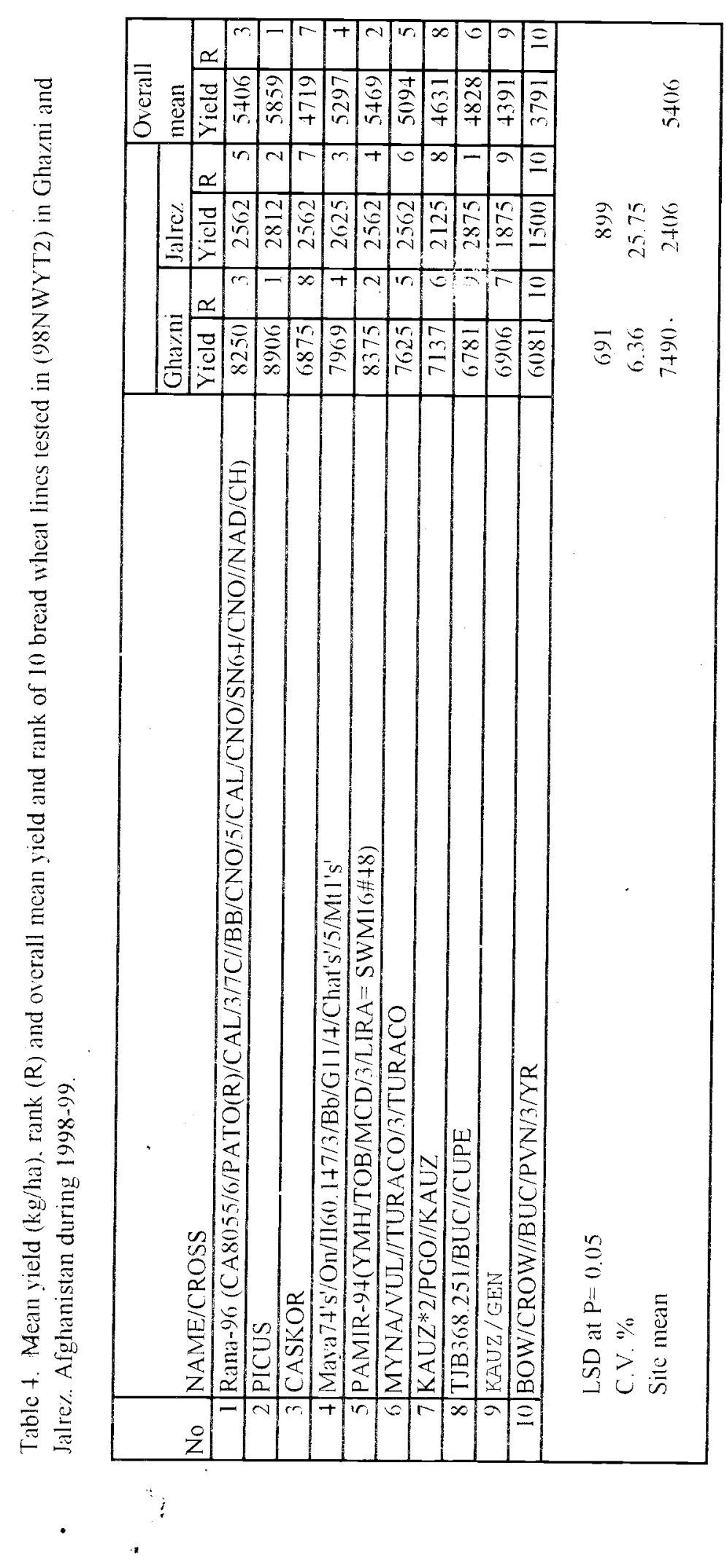

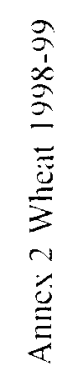




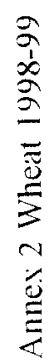

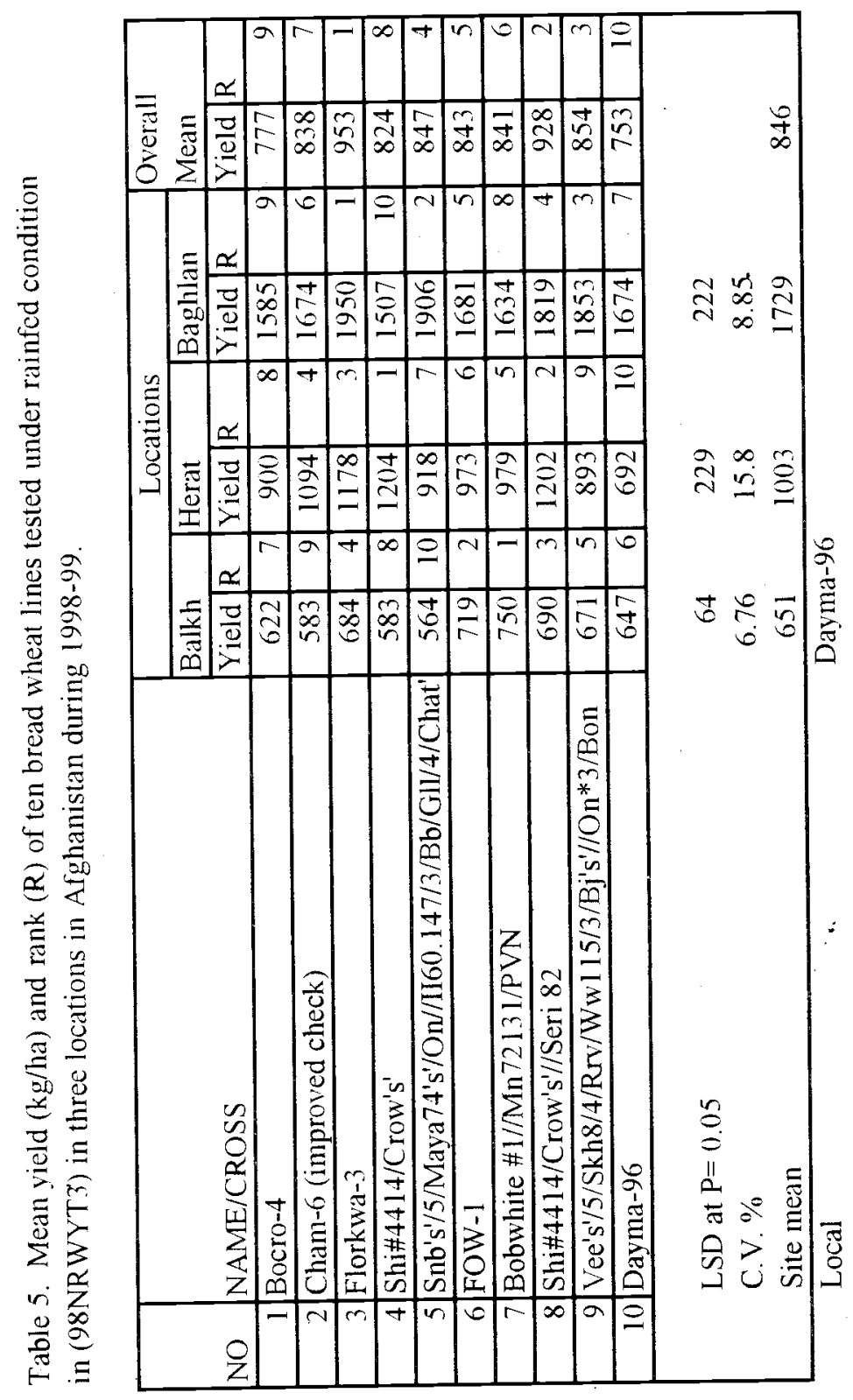




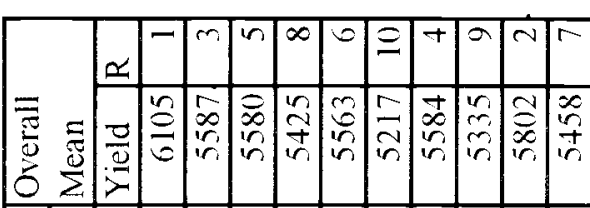

竞

$\hat{r} \sim \frac{0}{0}$

敢

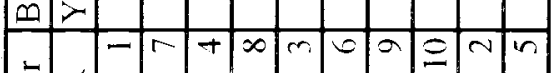

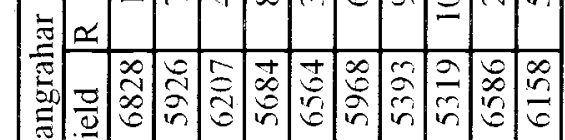

$\stackrel{\mathscr{e}}{\Xi}$

苞

$\frac{1}{3}$

导

它

ฮ

ชิ

㒸

蛋

홍

胥

인

章

要

$\sum$

용

\section{羊}

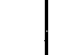




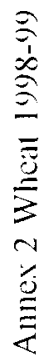

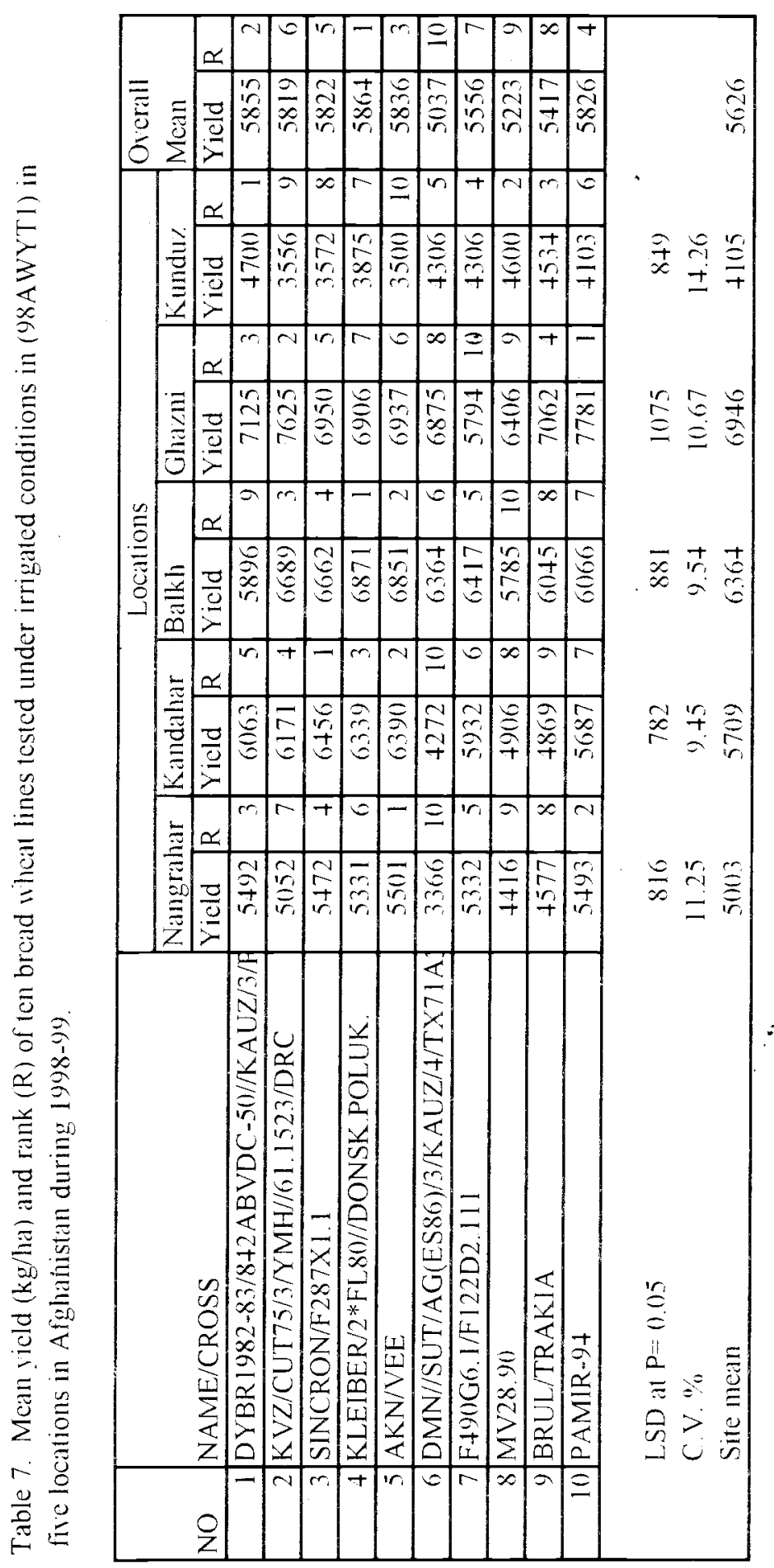




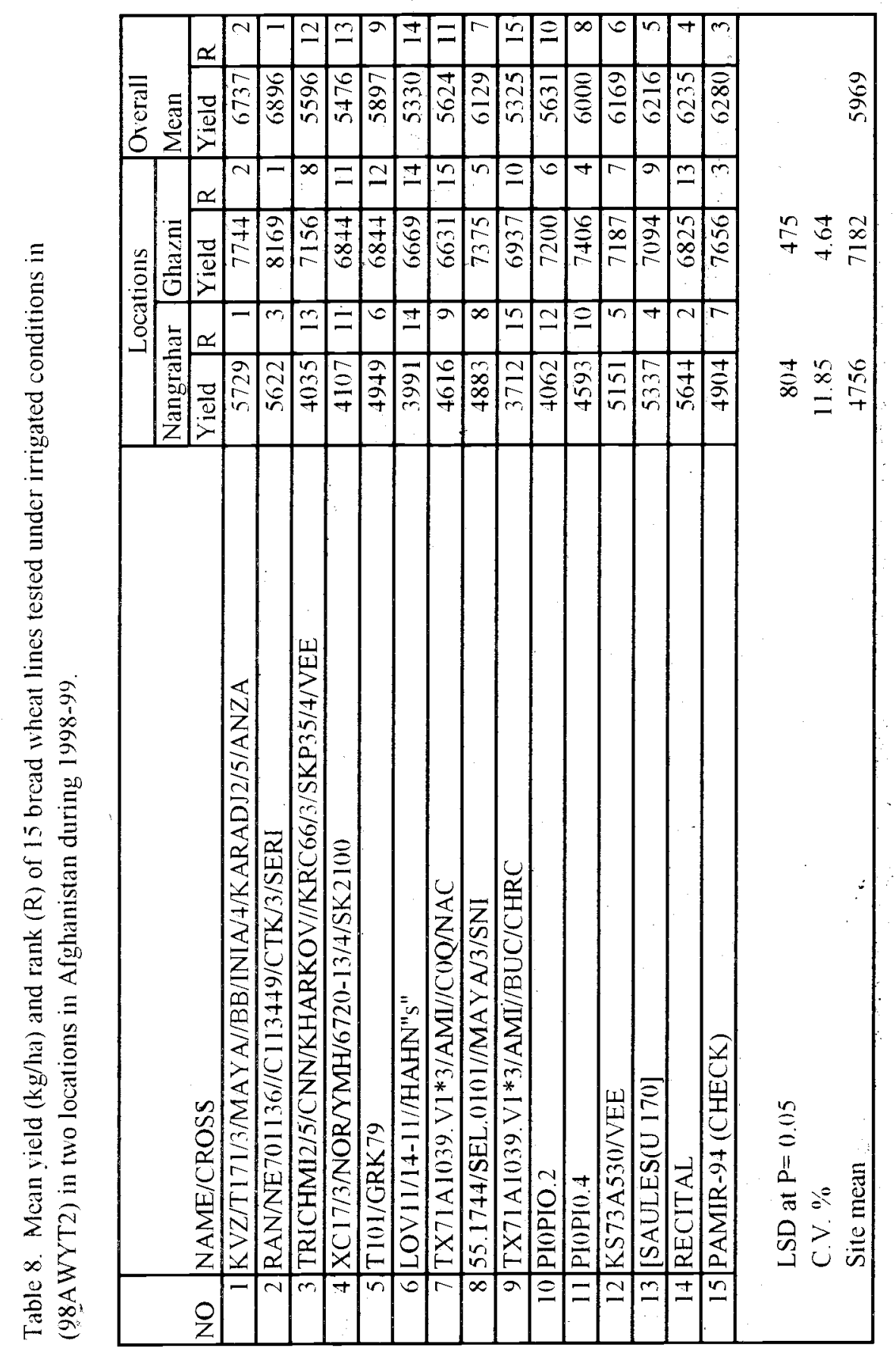




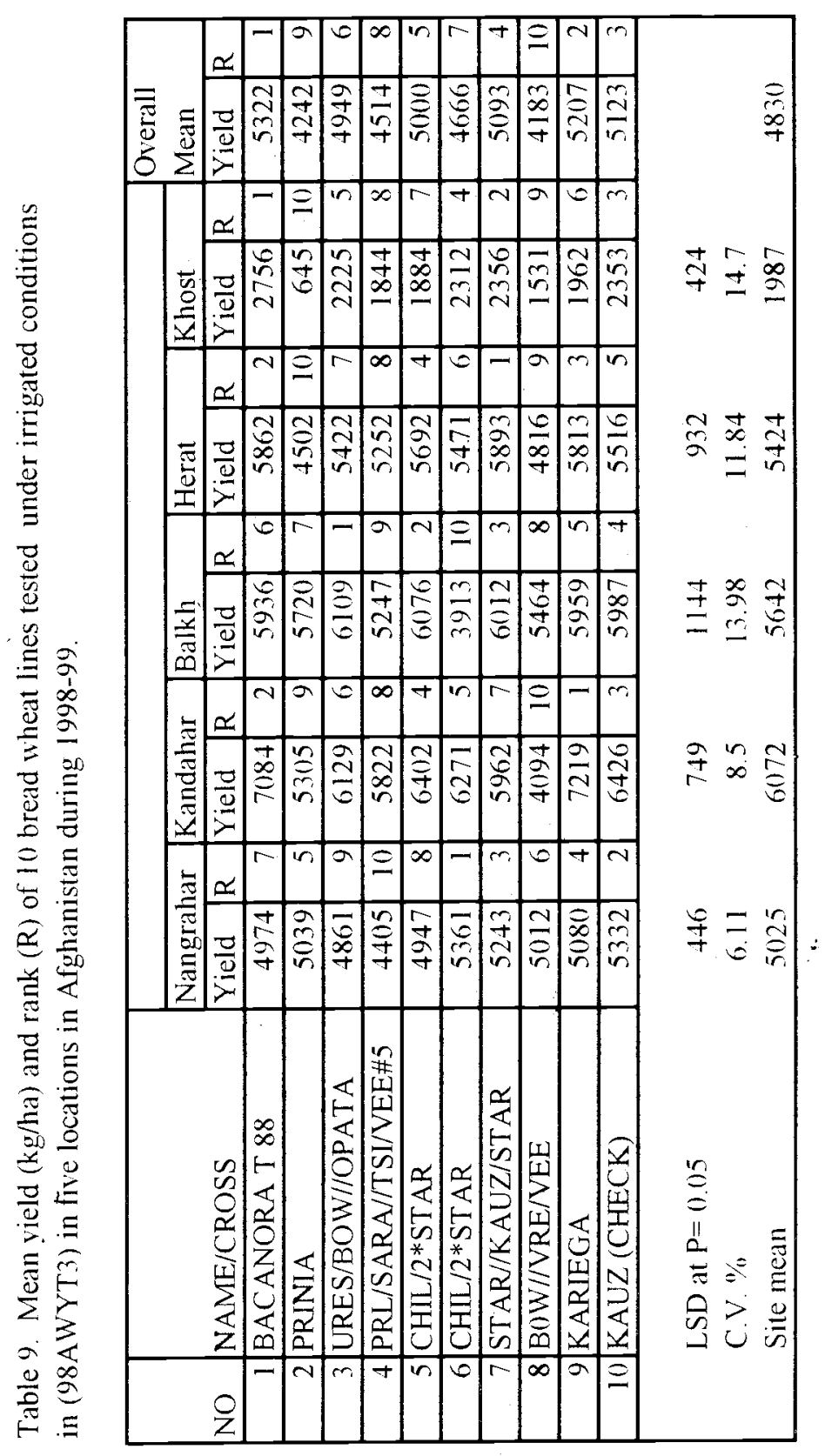




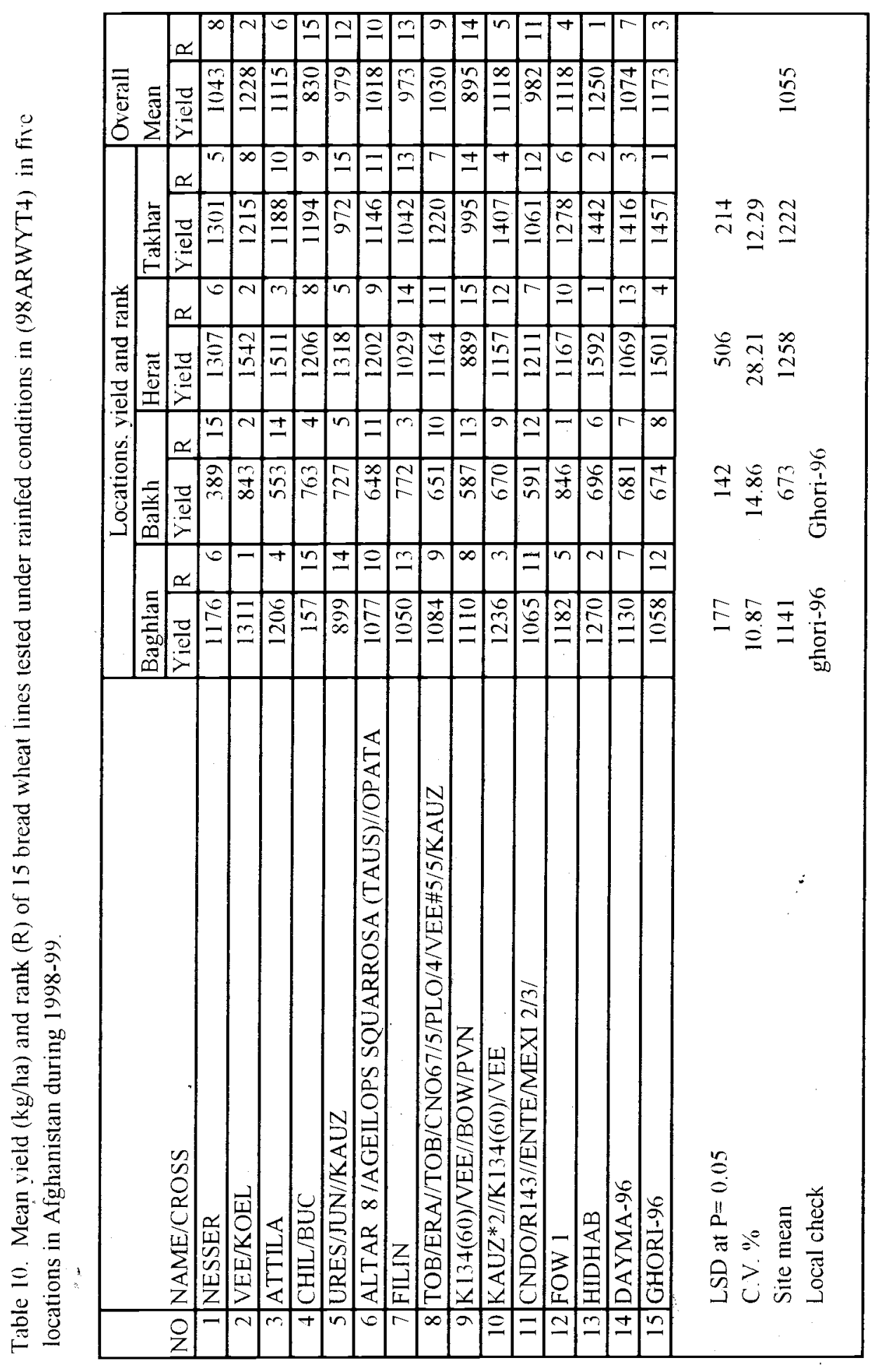




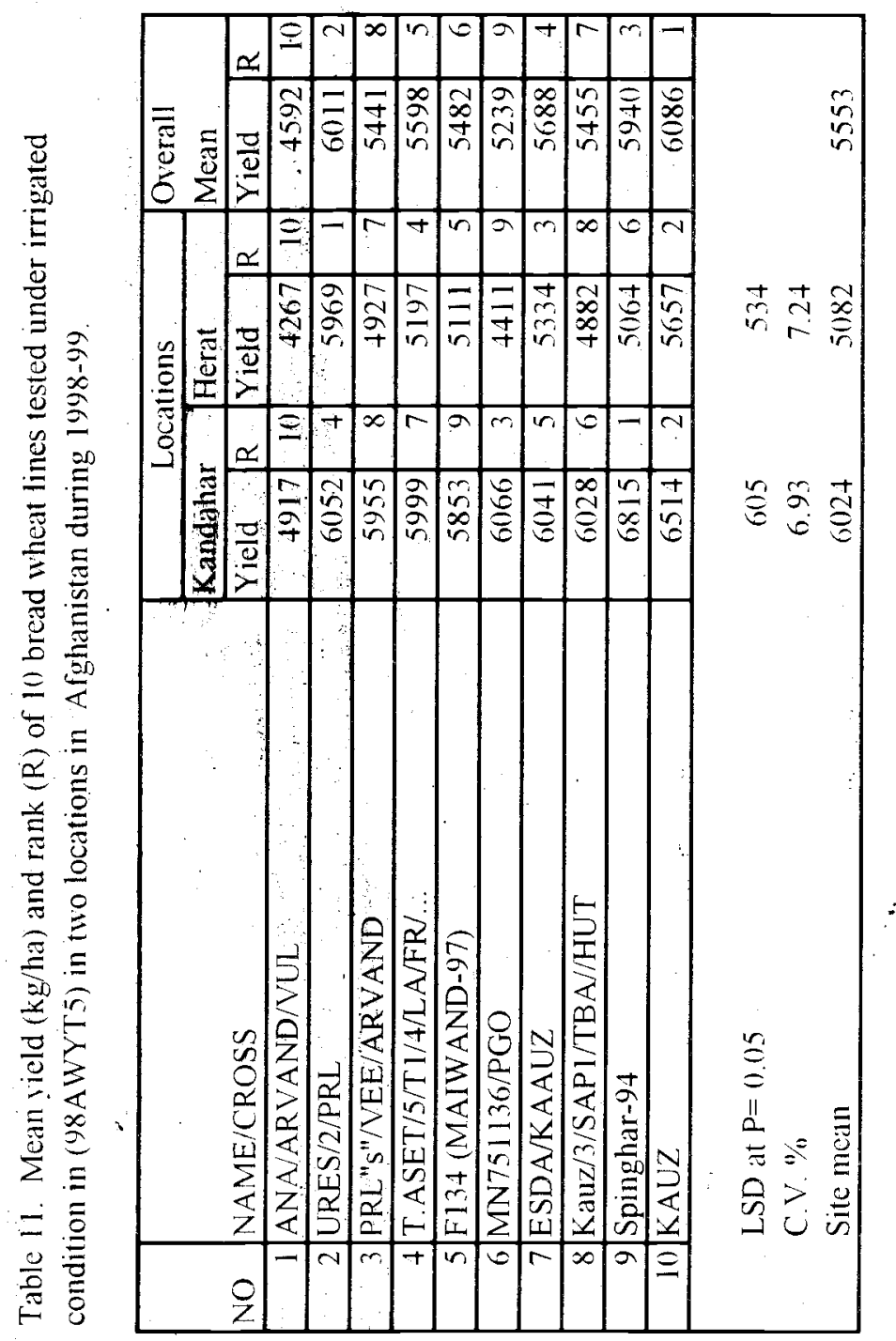




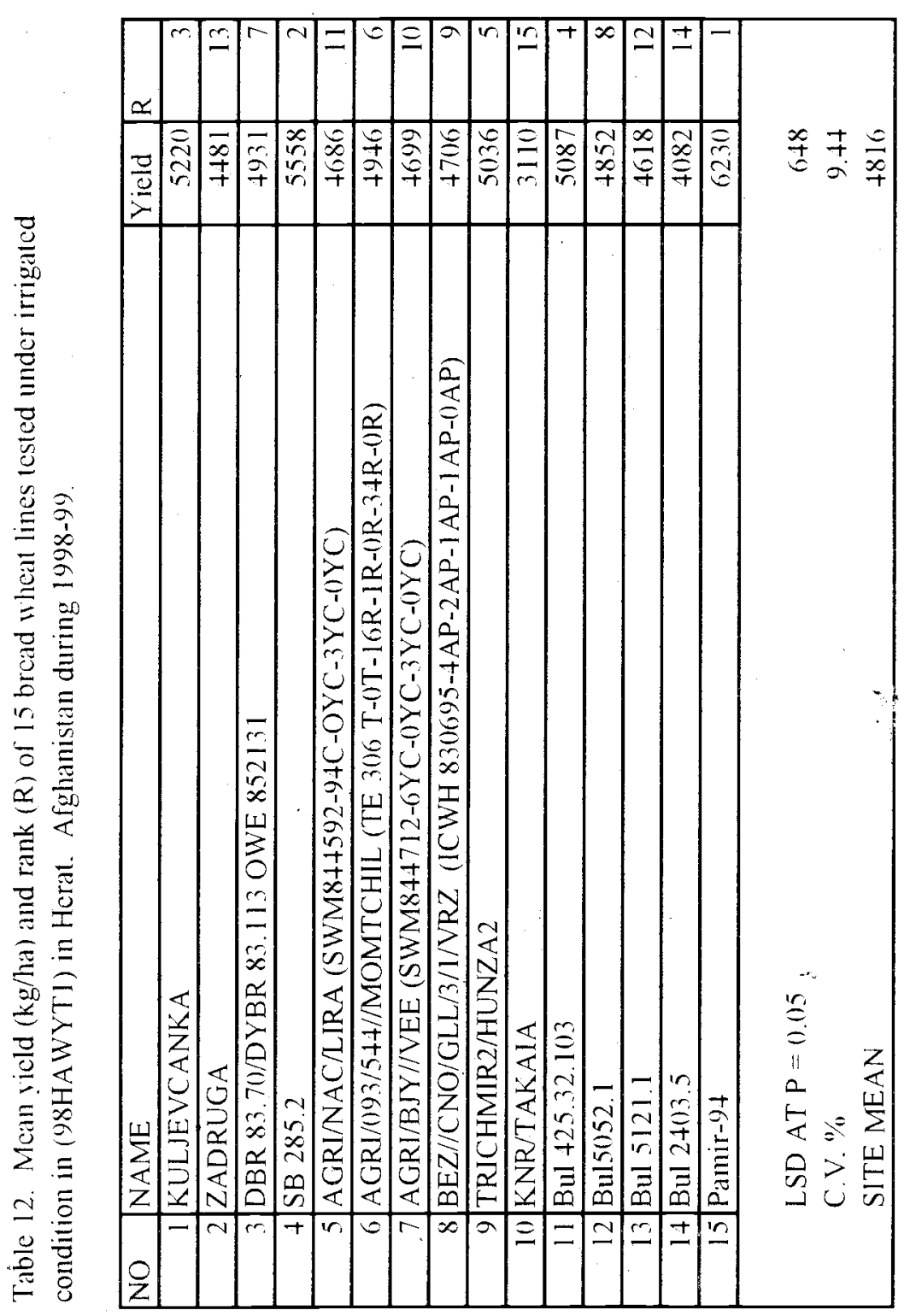




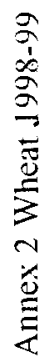

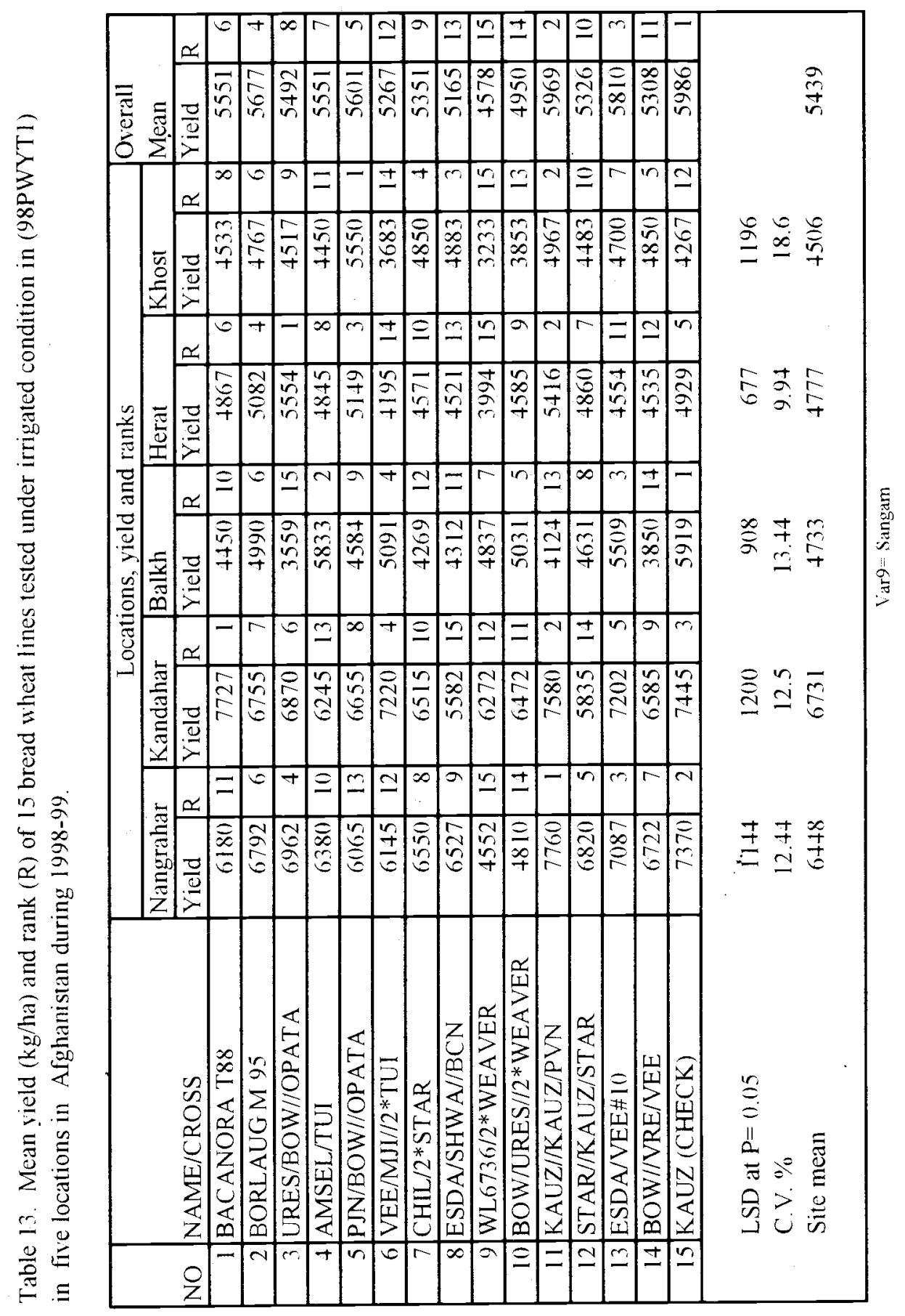




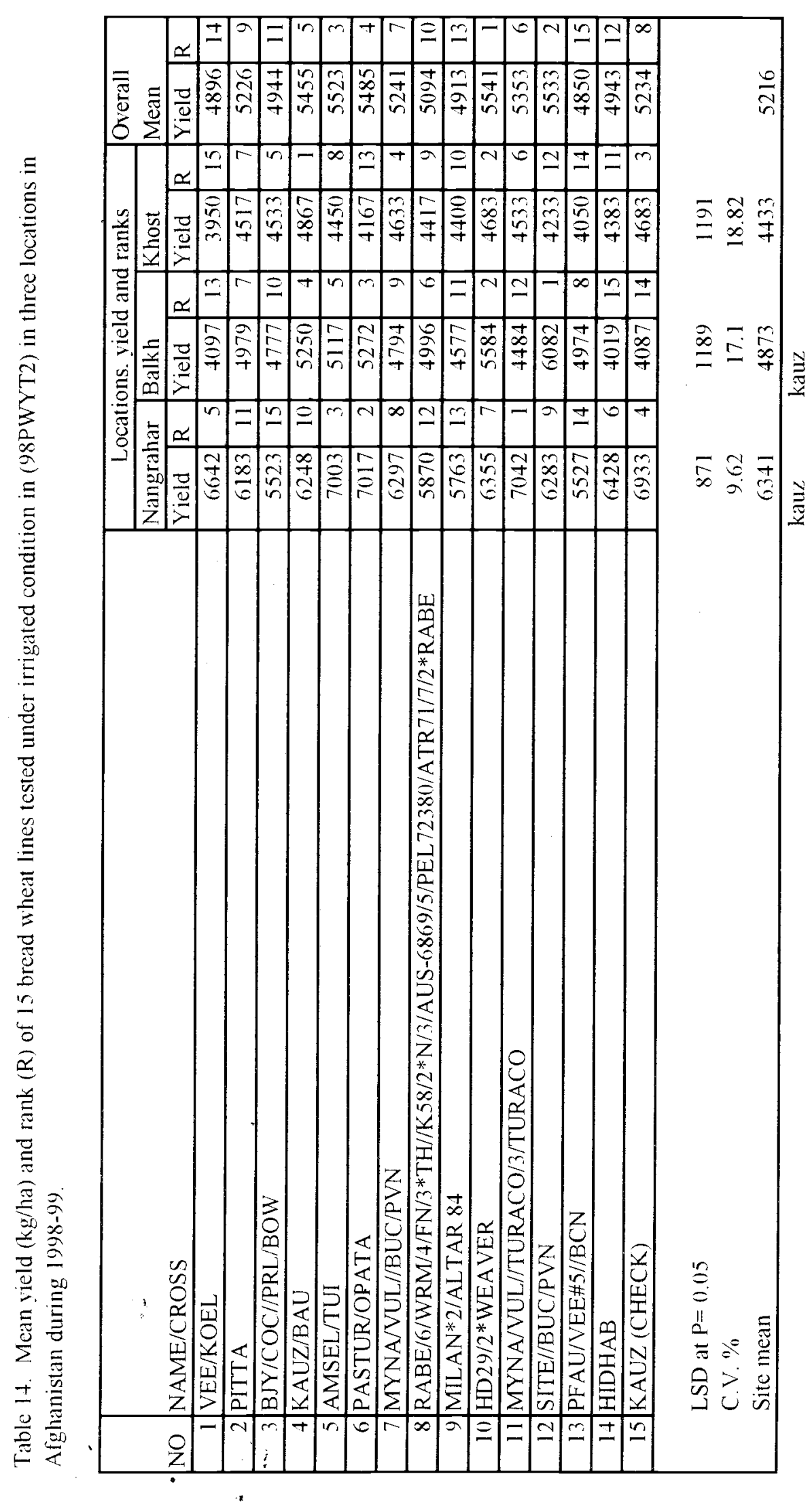




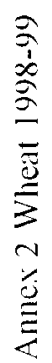

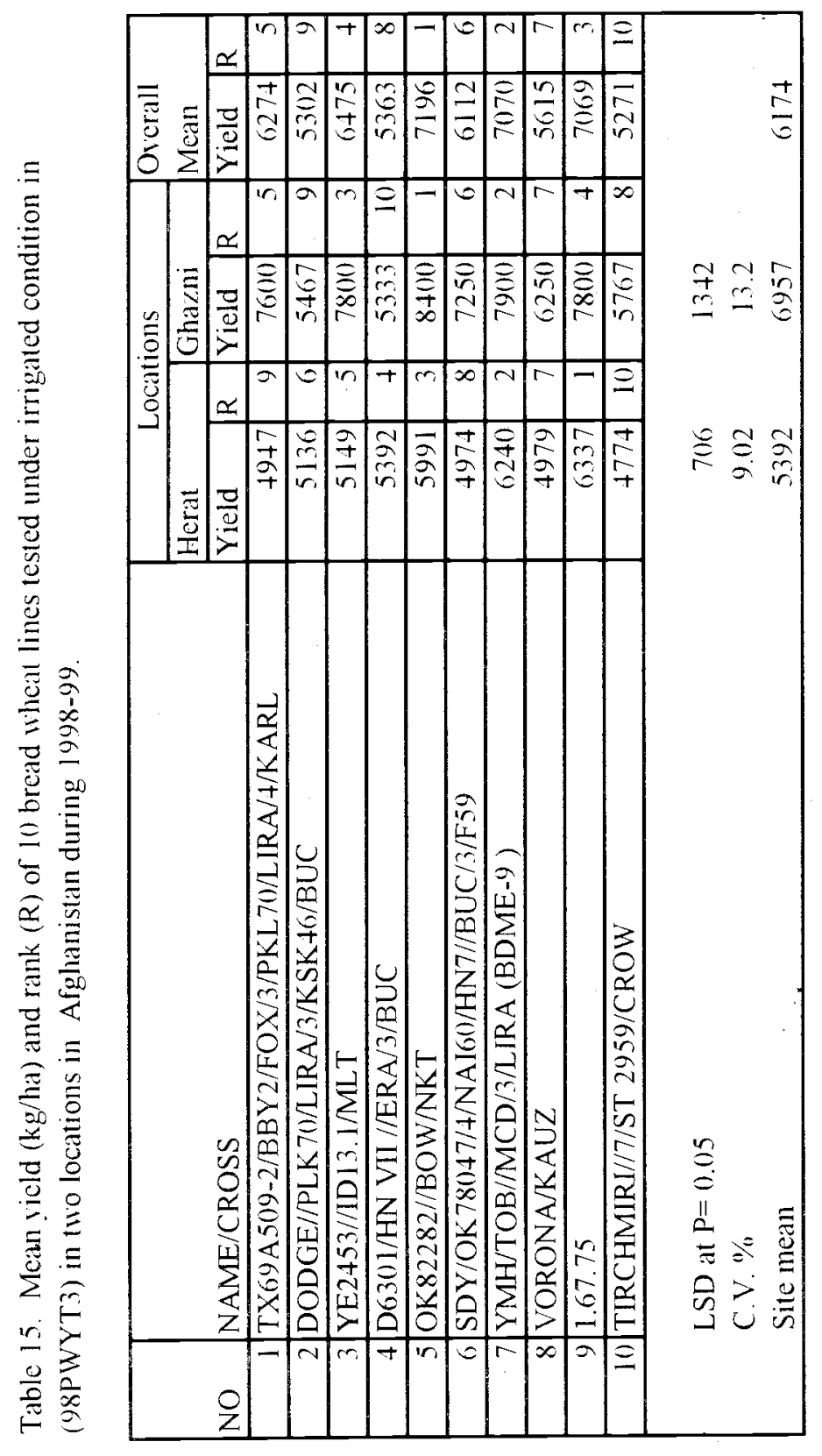




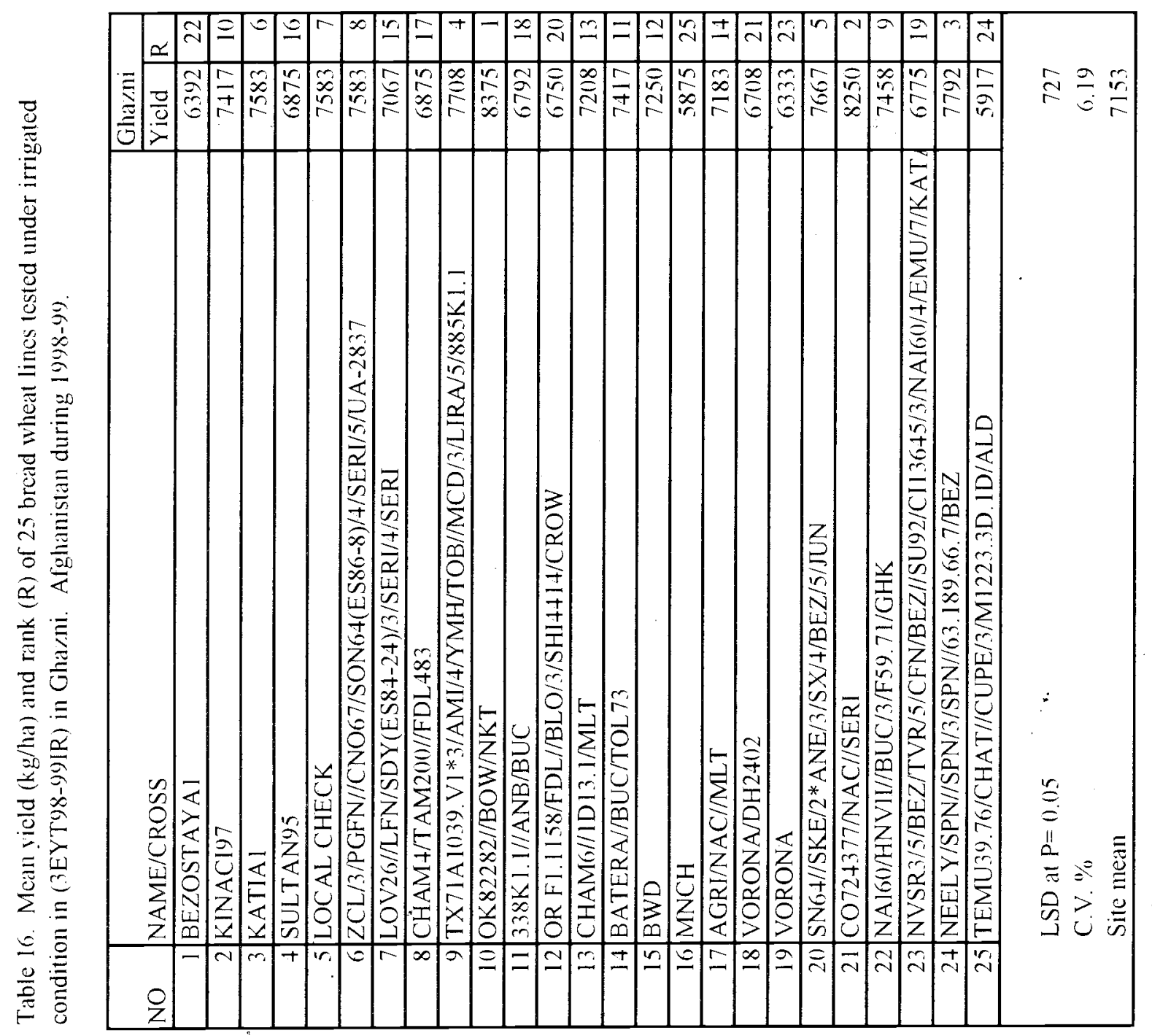




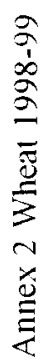

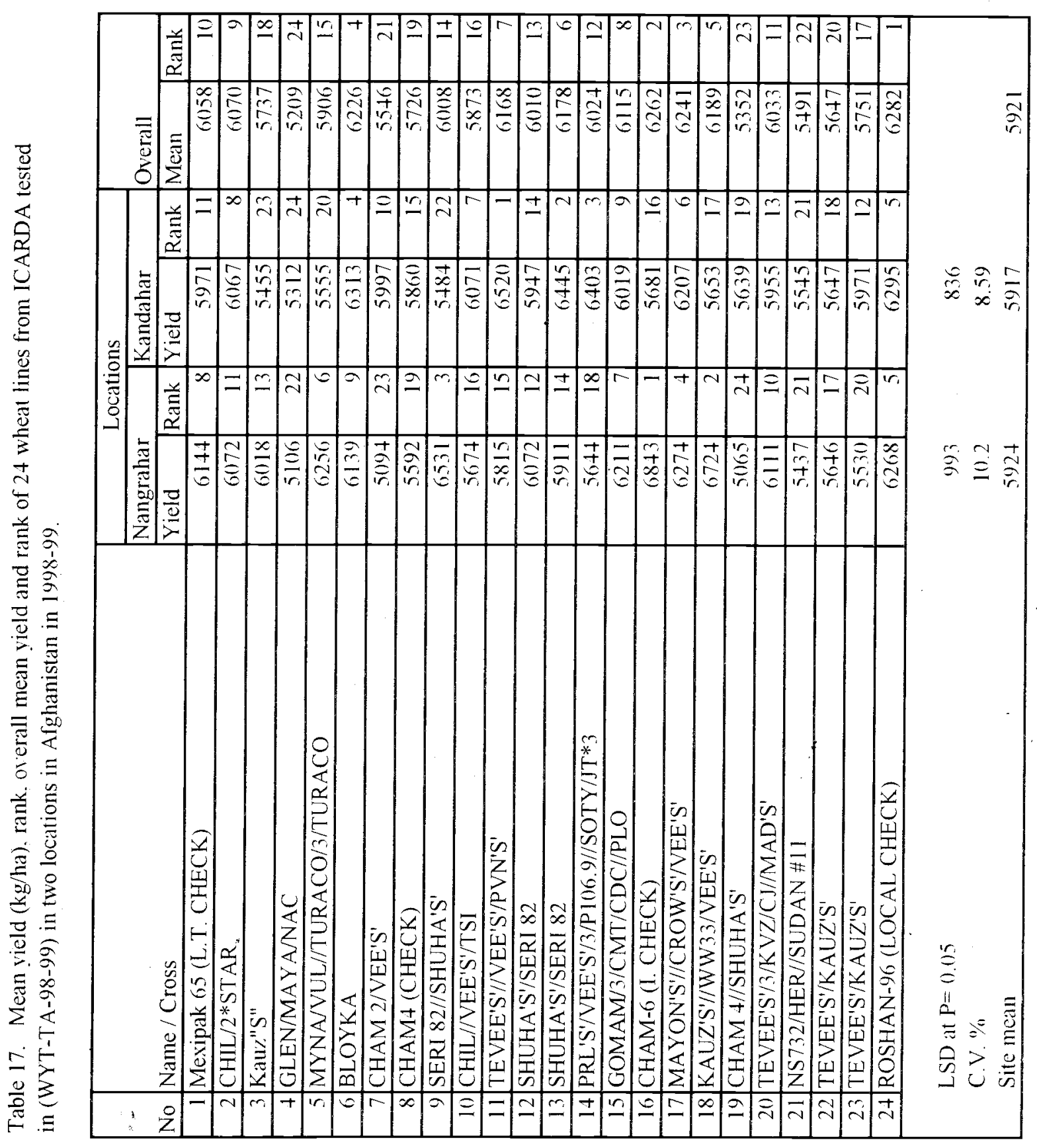




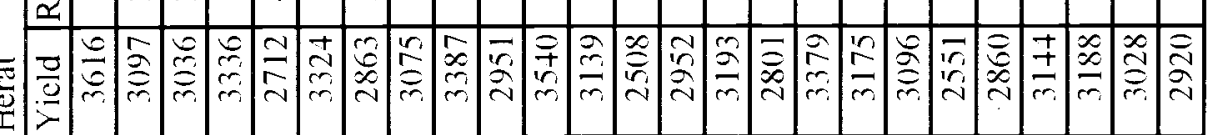

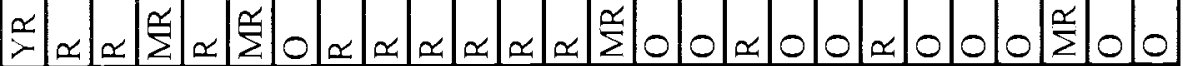

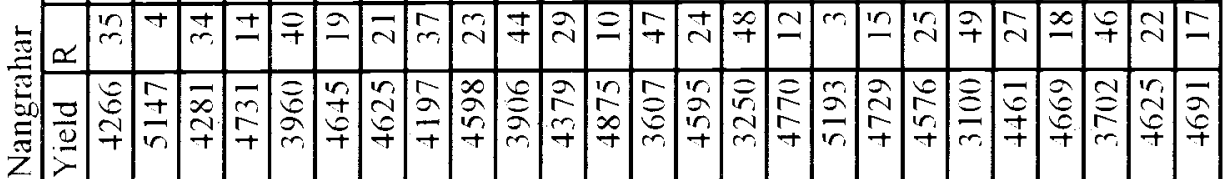

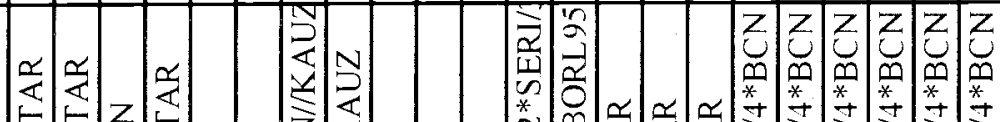
占 N $N$ N 综安

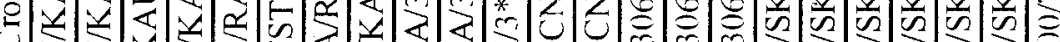

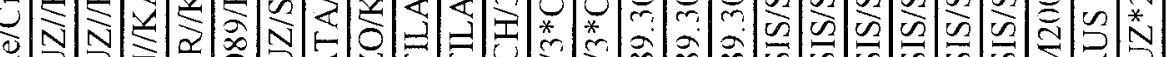

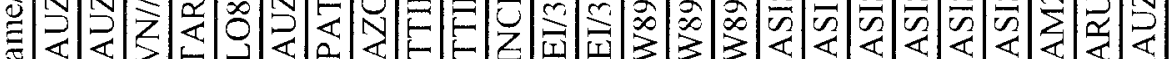

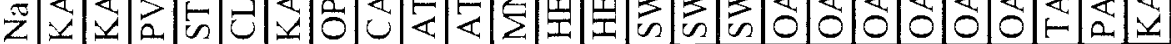
Z

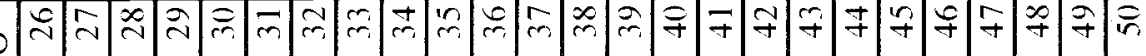

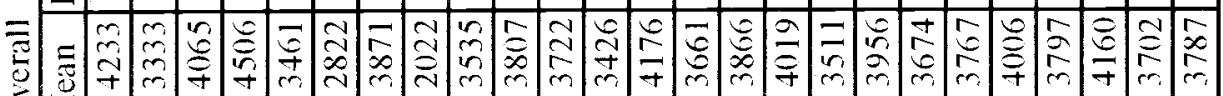
ठ)

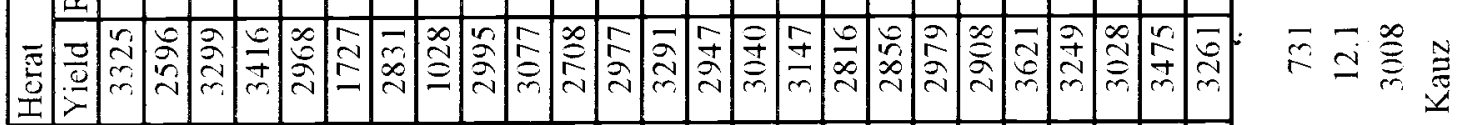

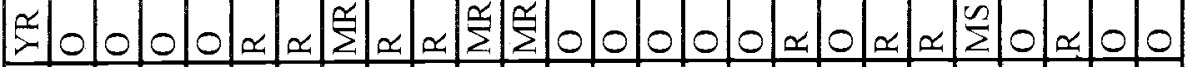

$\stackrel{\overbrace{}}{\varrho}$

壬

光

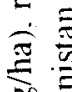

空

$\pm \frac{5}{2}$

至

$\Xi$

$\sum \stackrel{0}{0}$

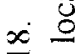

$\frac{0}{\approx} \equiv$

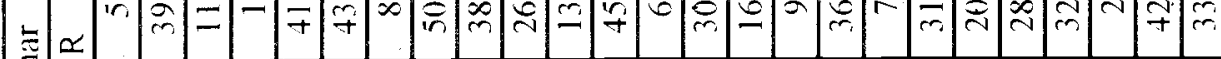

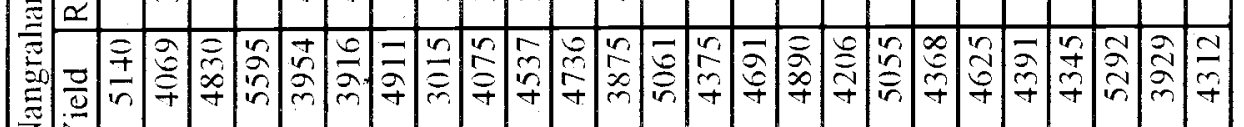

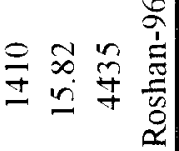

6

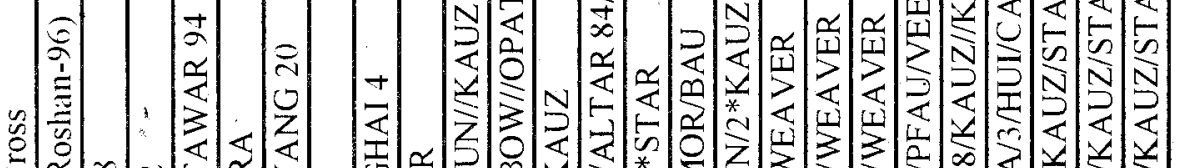

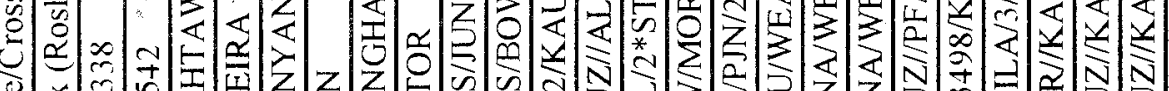

Q 三 Z

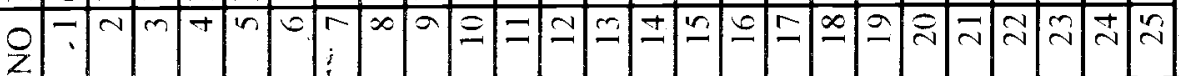

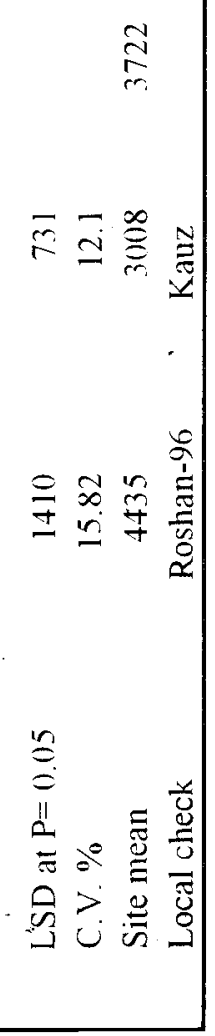




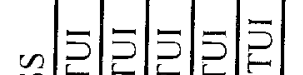

$\sum$

* * * F *

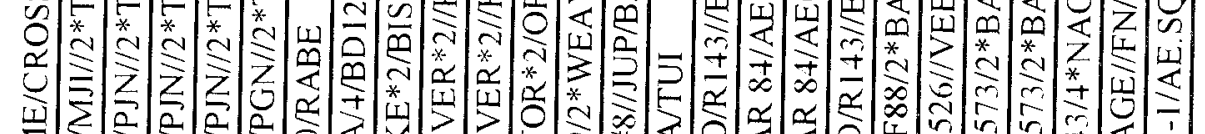

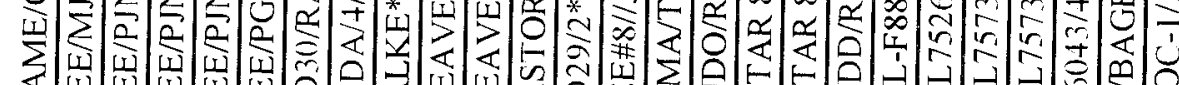

$\underline{\Xi}$

$\stackrel{8}{\Xi}$

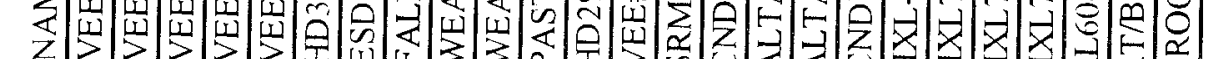

$\stackrel{\overline{8}}{\underline{3}}$

○)

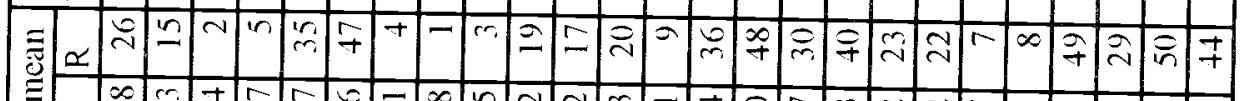

o

吾

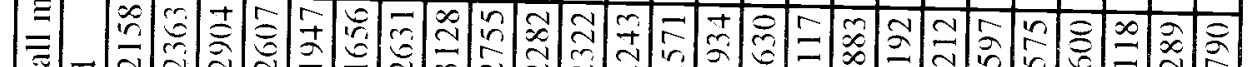

$\overline{\bar{\pi}}$

巳

$5 \div$

믕

三

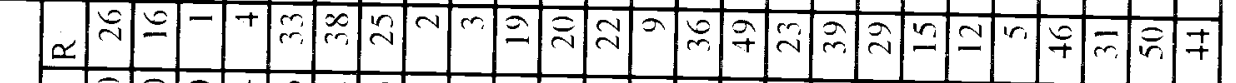

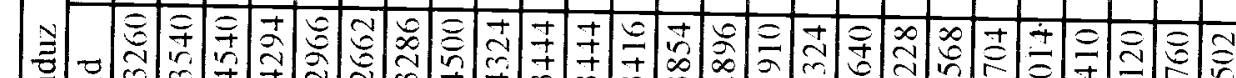

㱏

ธ

宅

总

灾

引

흘

芯

을 春

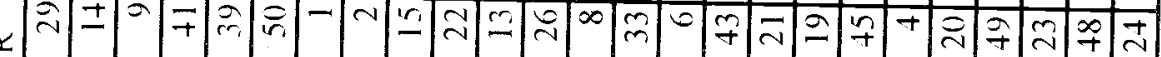

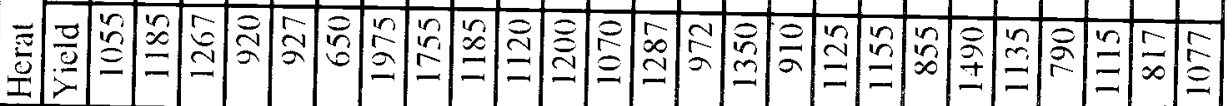

iो

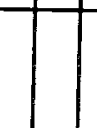

\section{$\tilde{\tilde{\theta}}$}

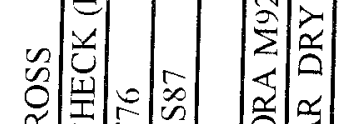

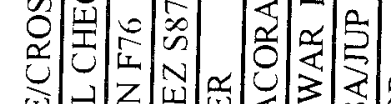

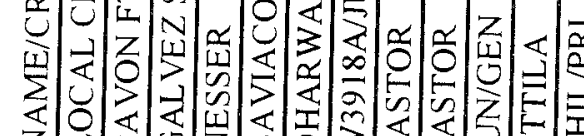

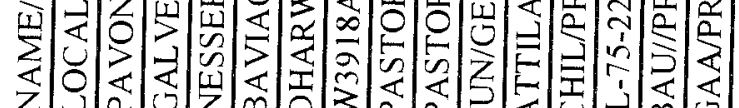

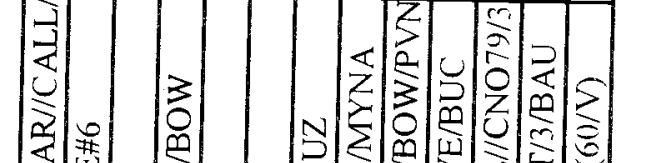

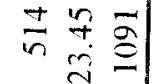

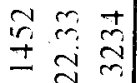

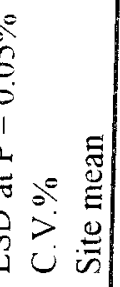




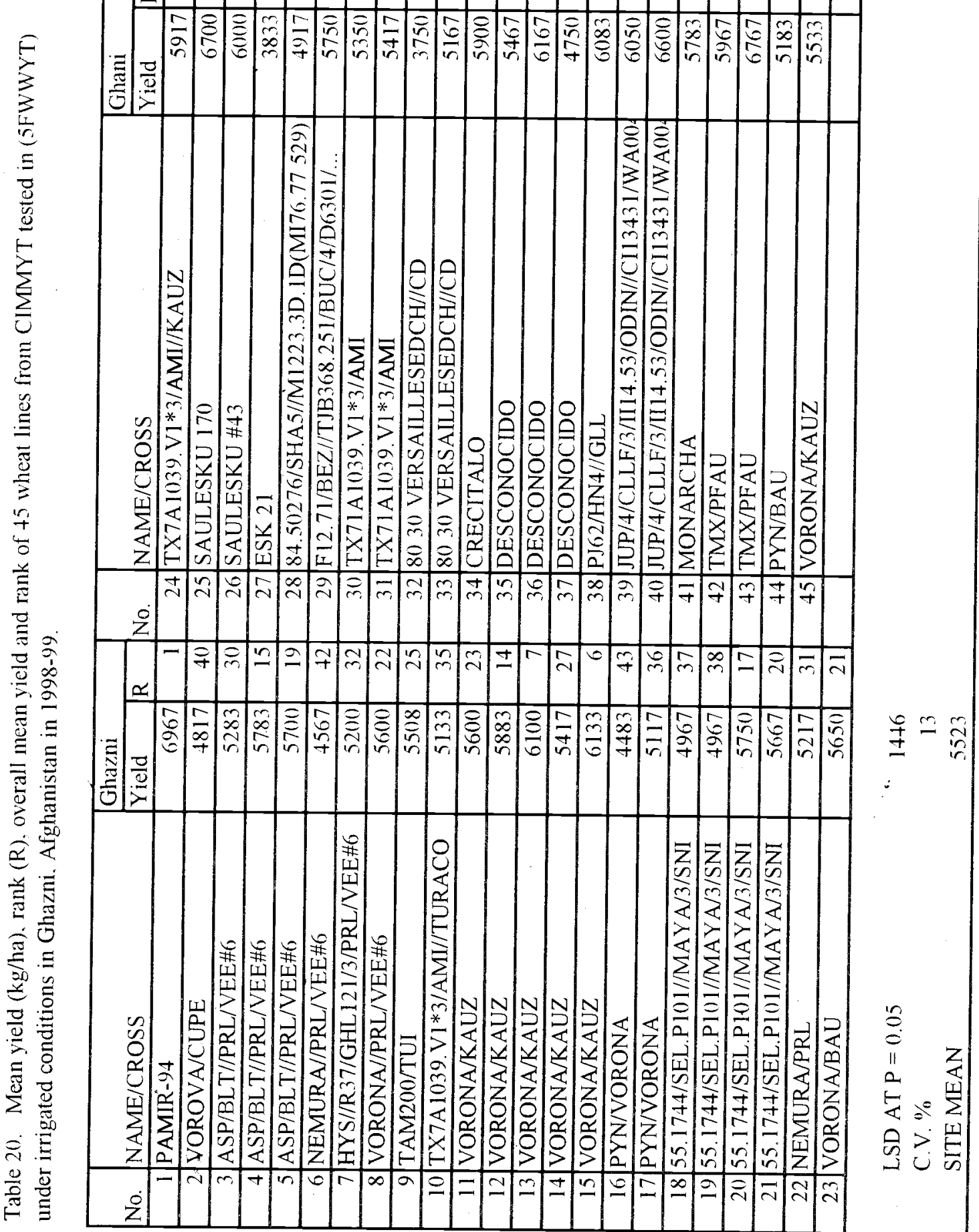




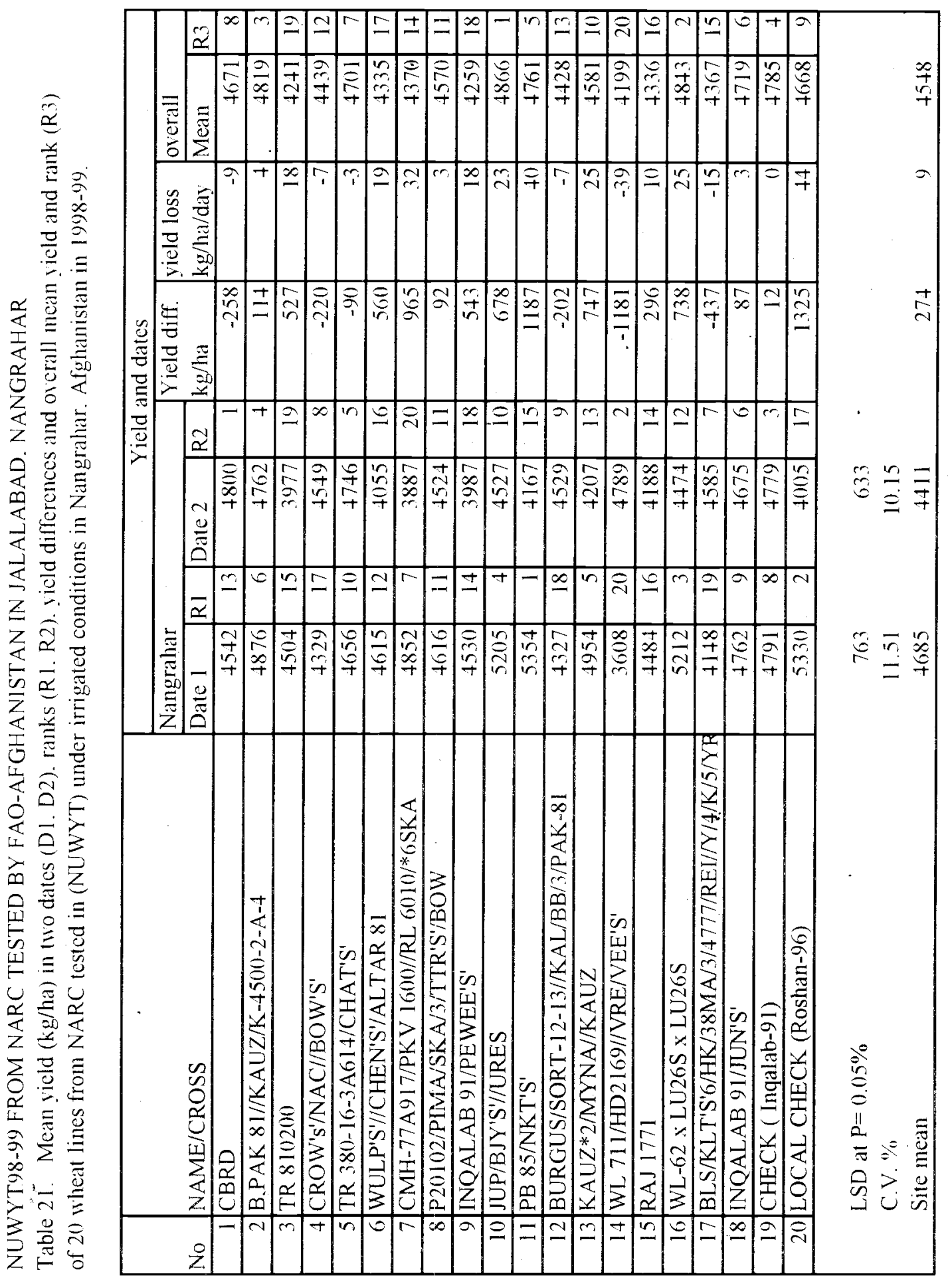




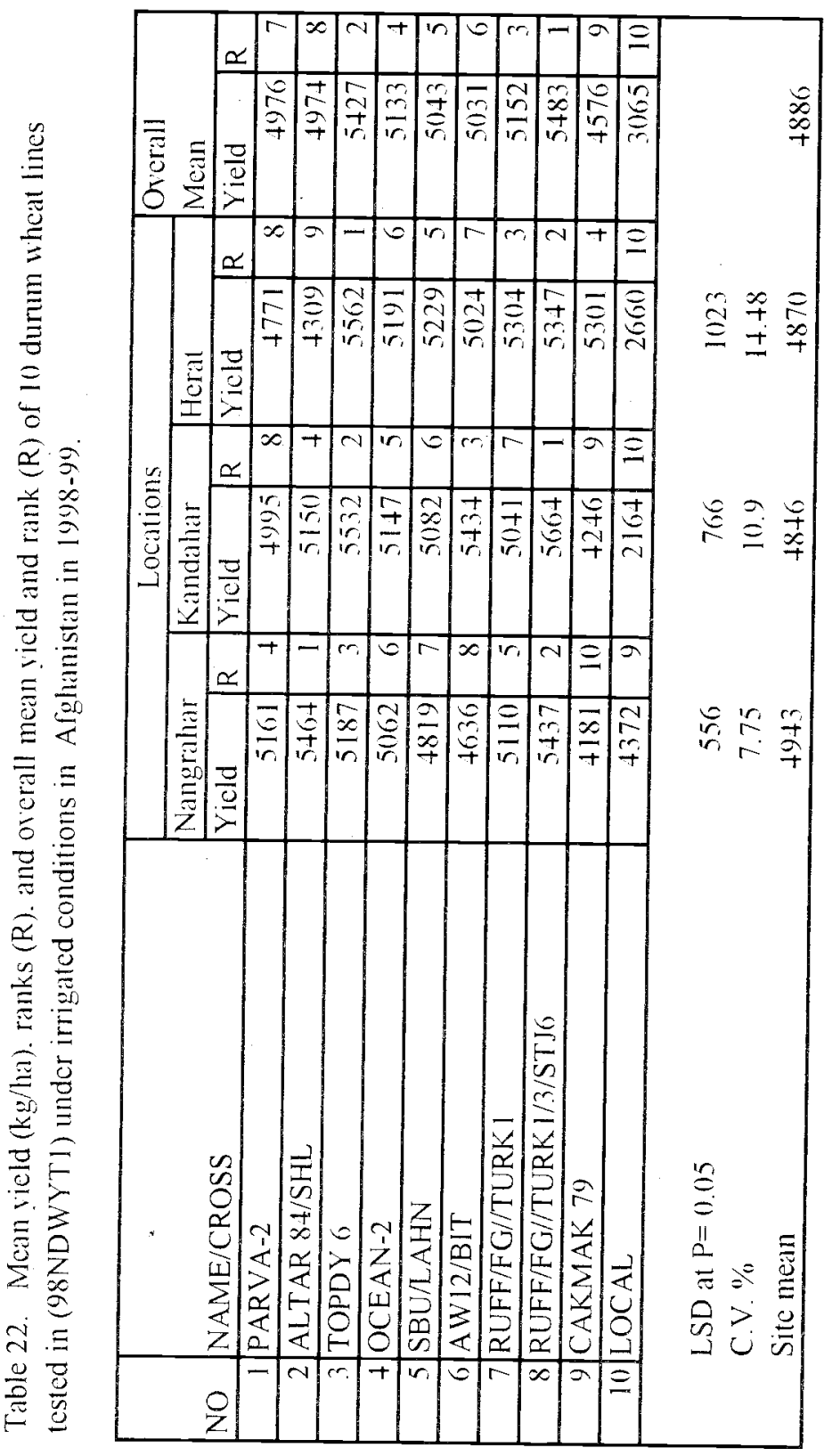




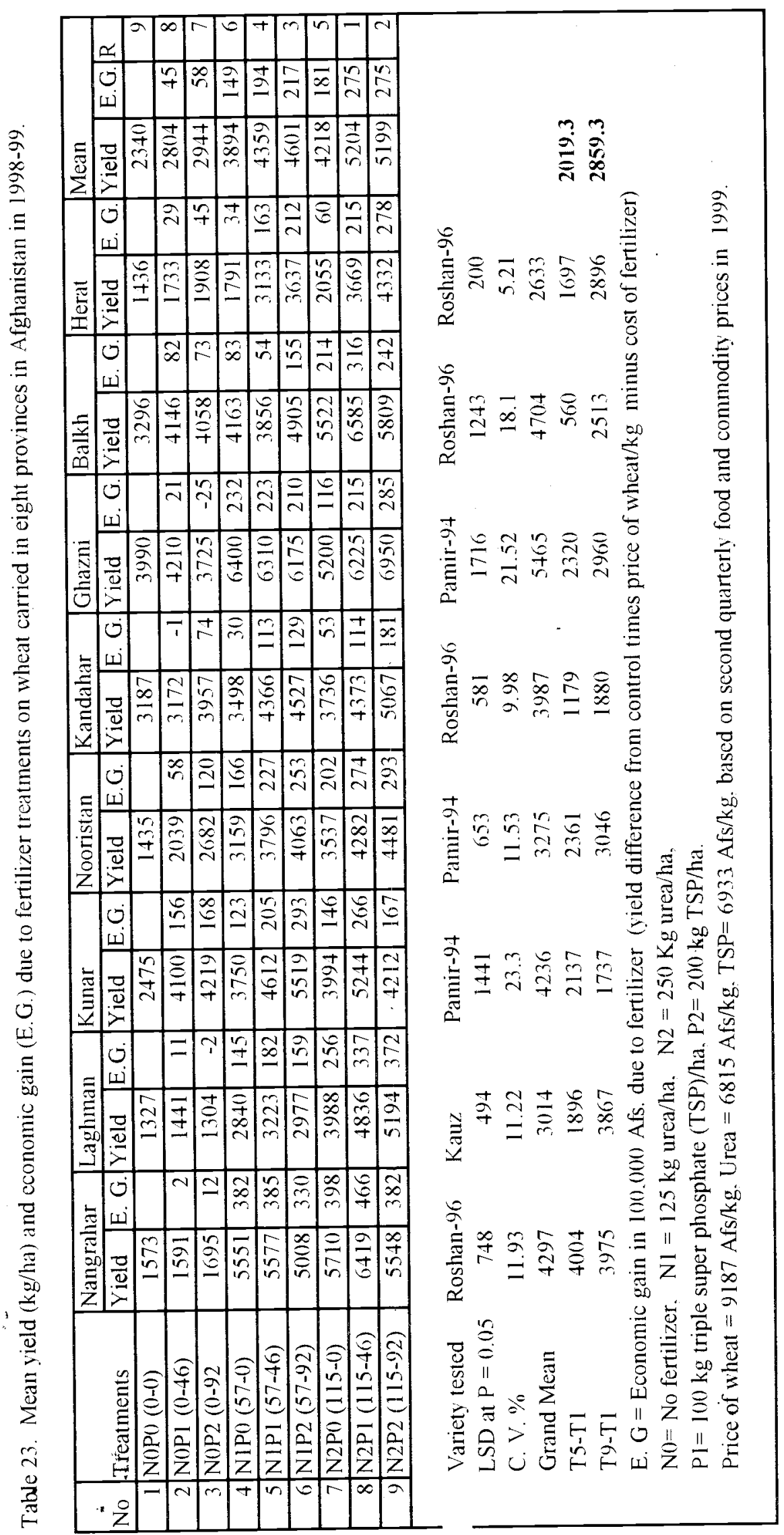




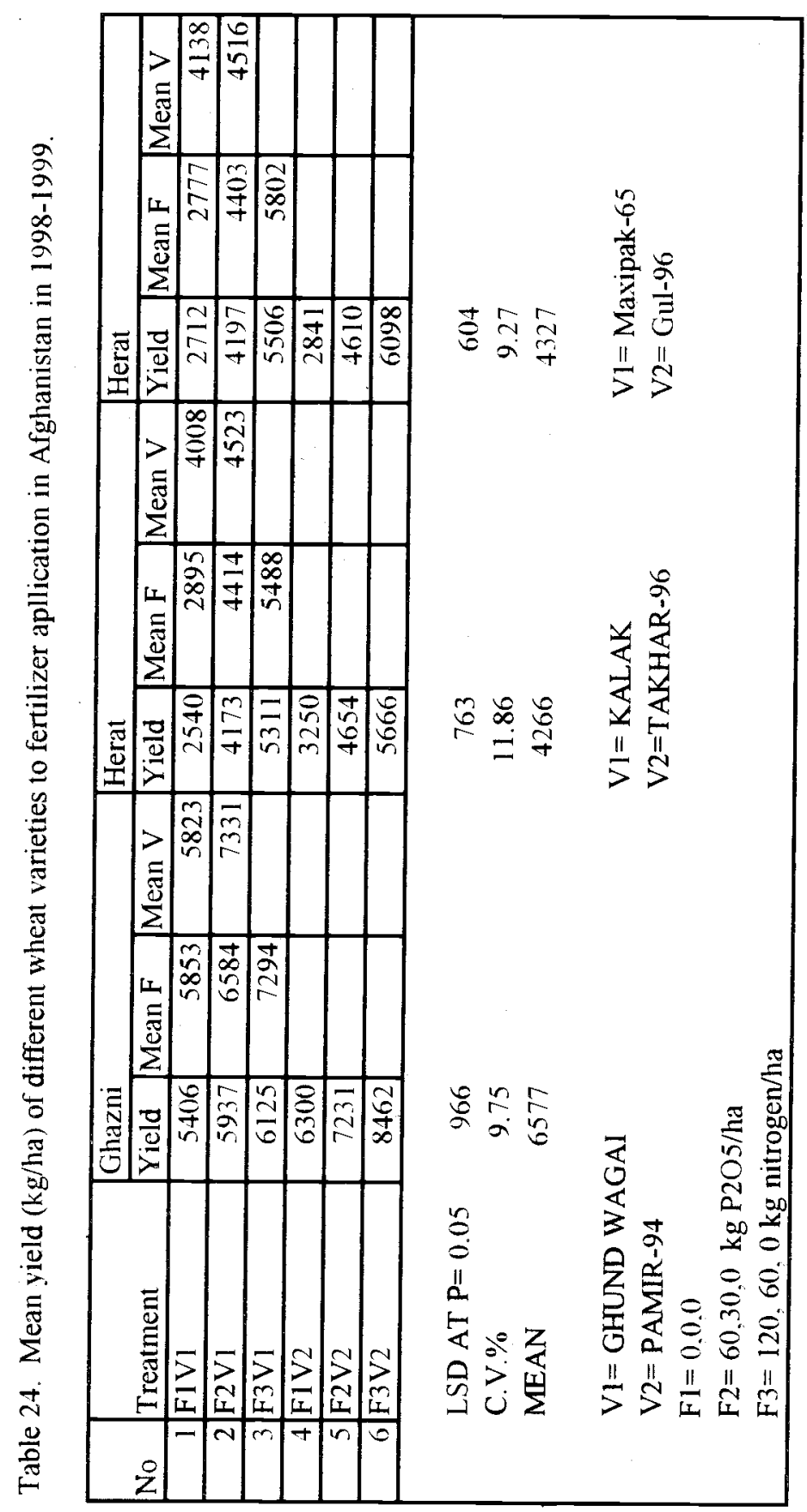




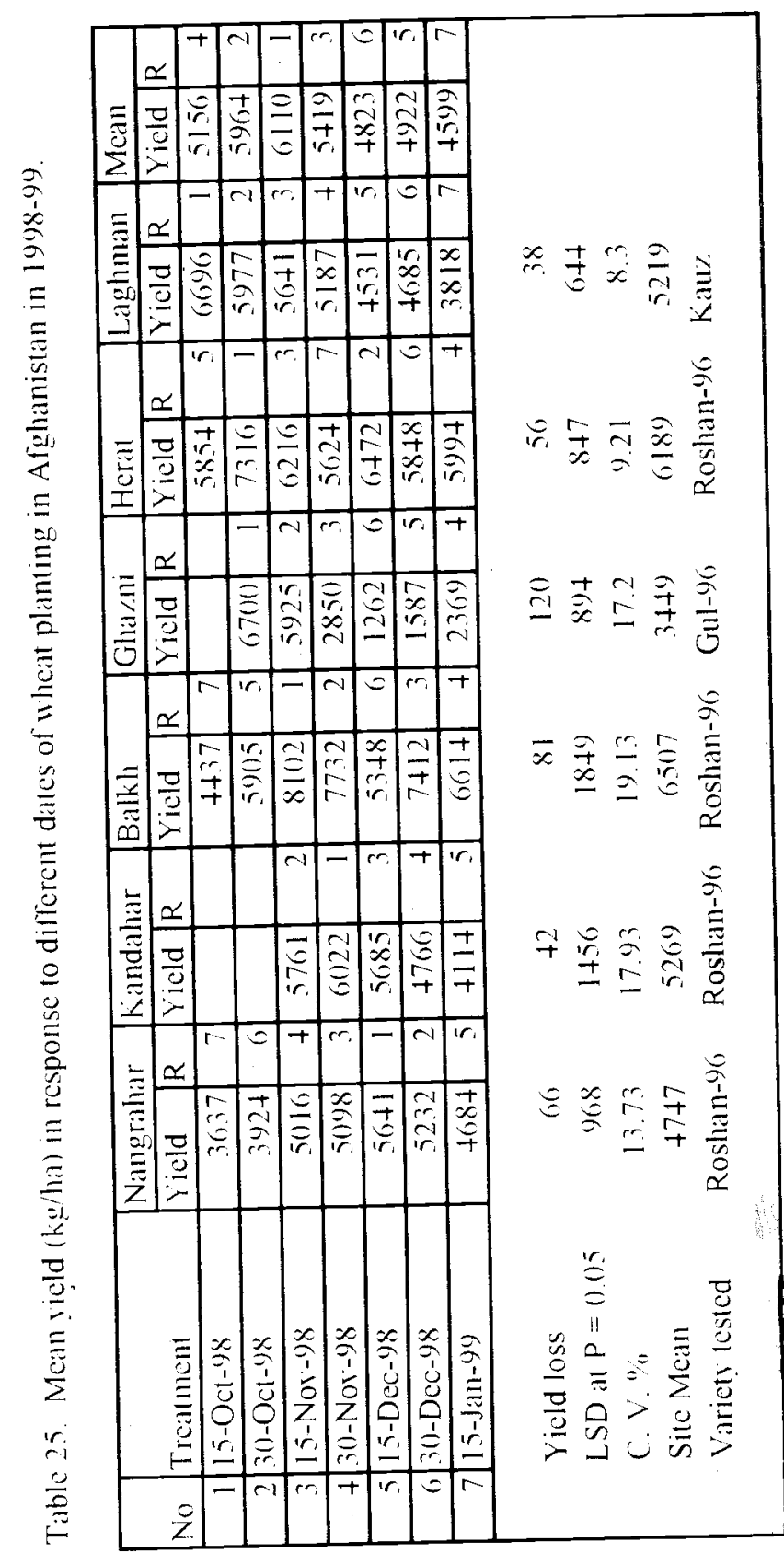




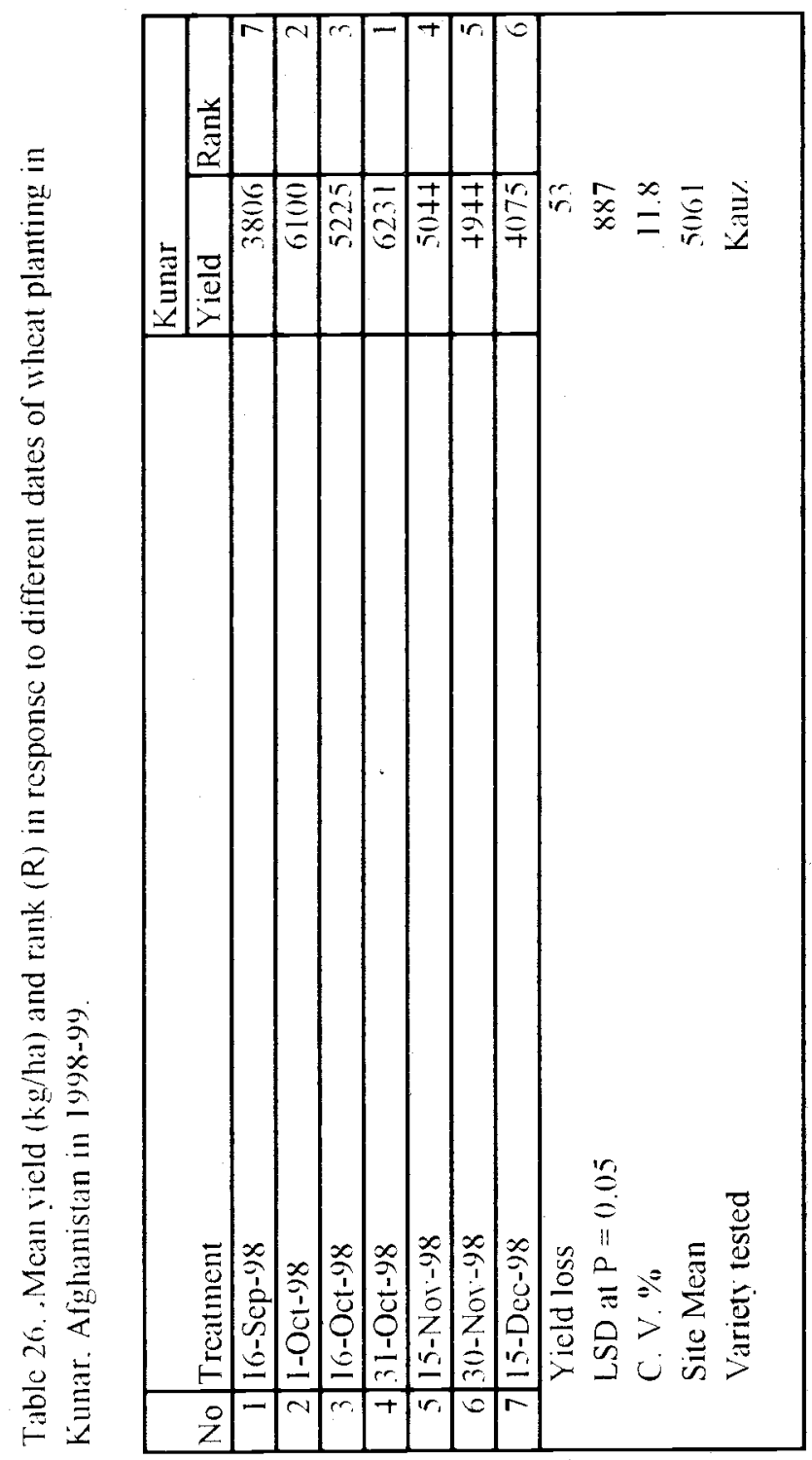




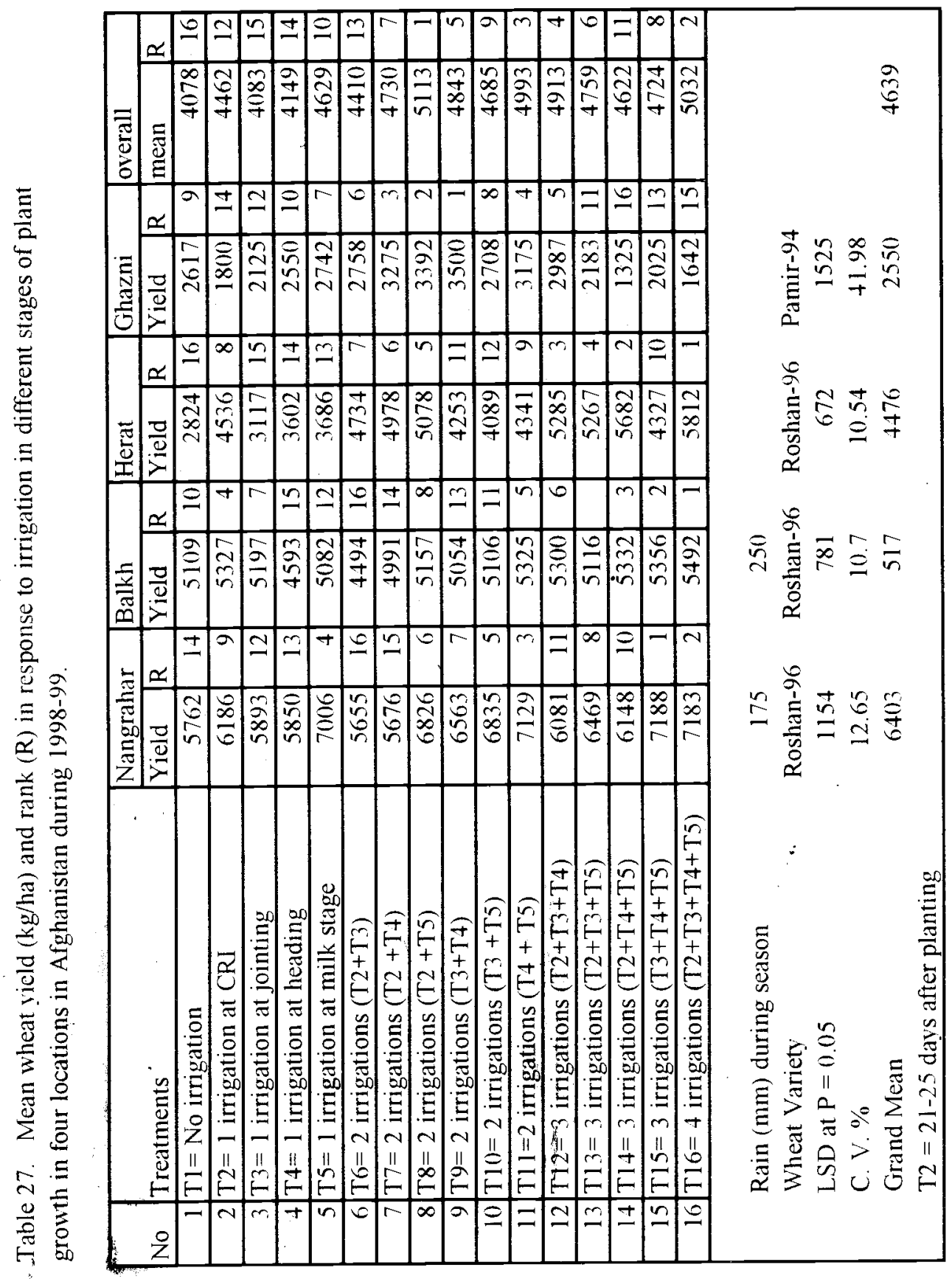




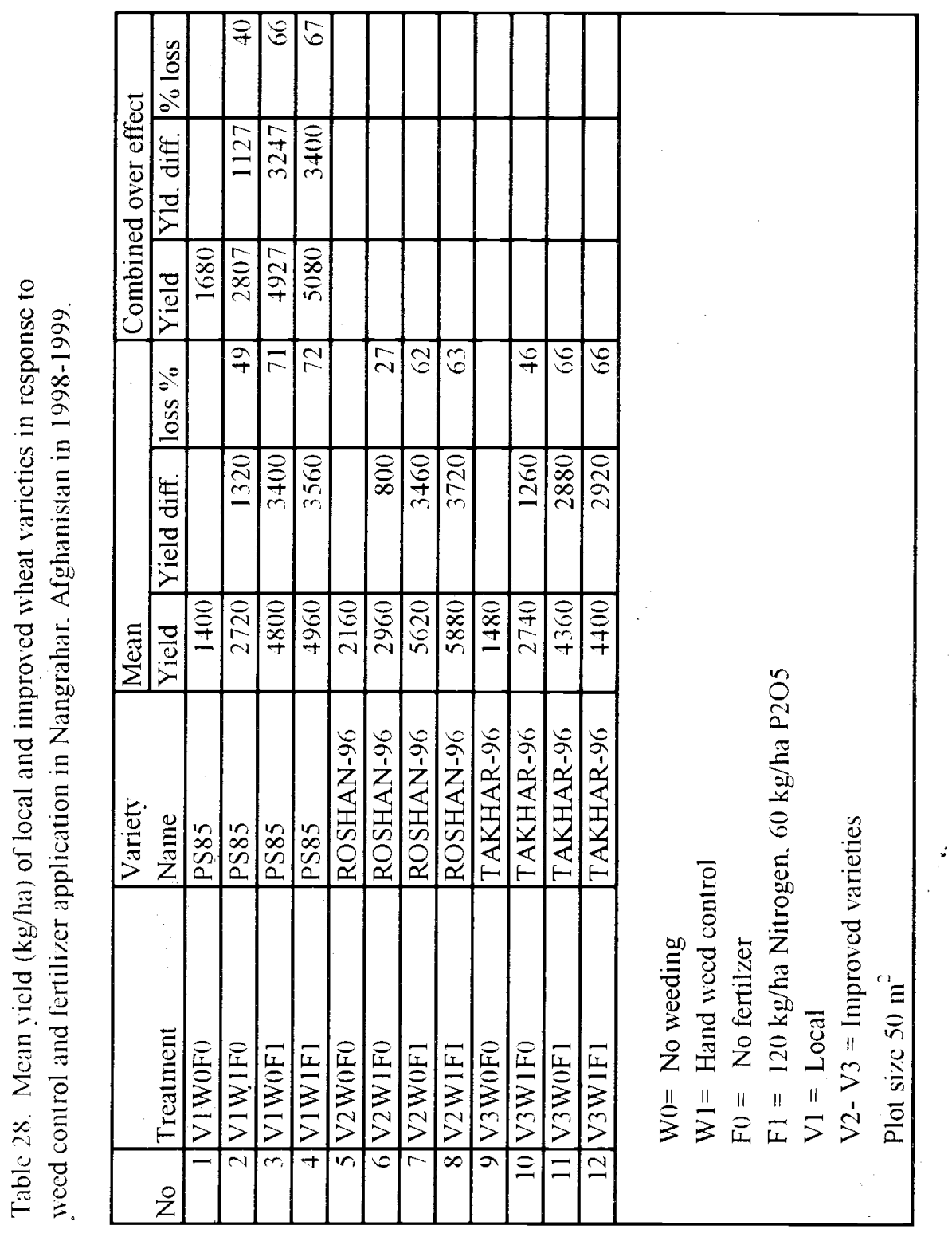




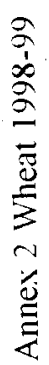

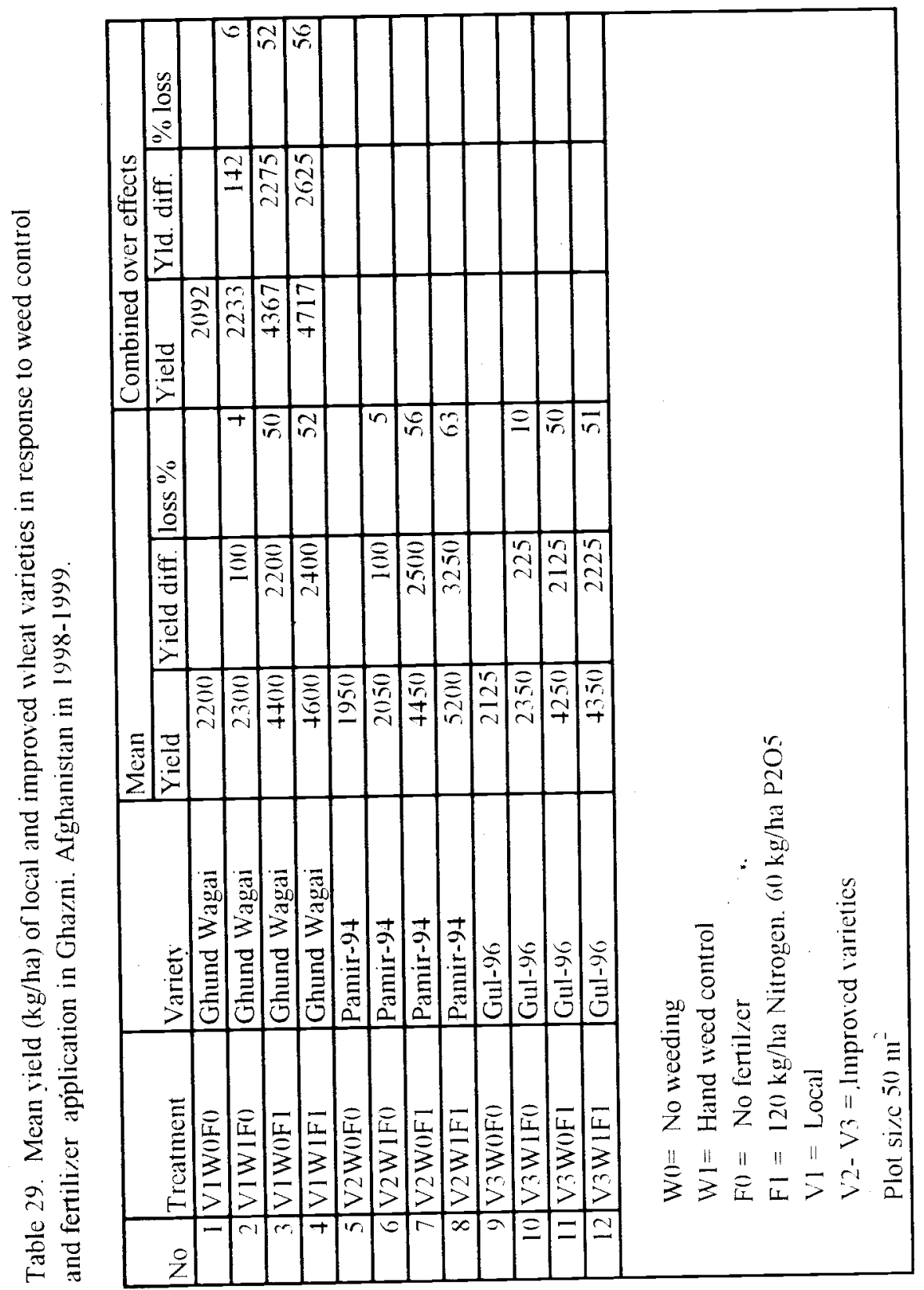




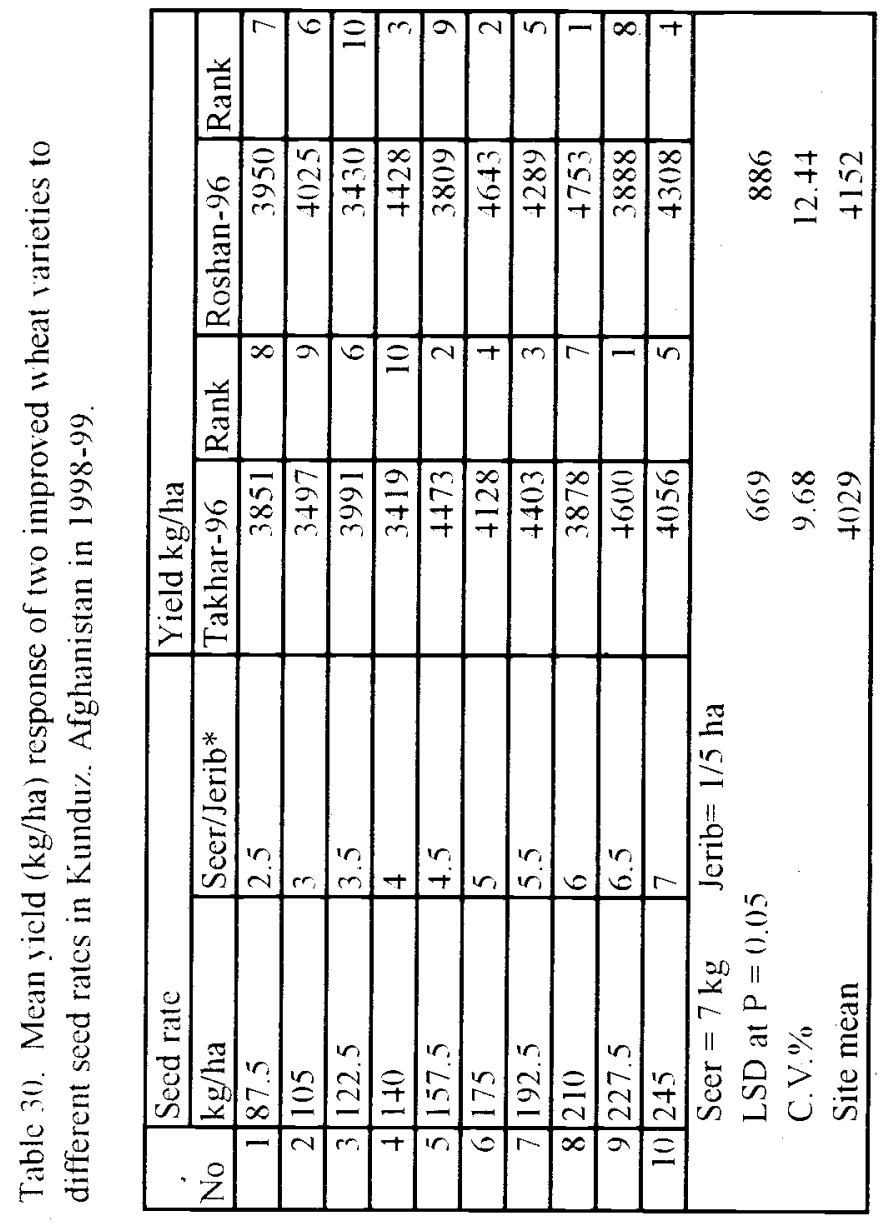




\section{Rice Varieties Selection Research}

\section{Introduction:}

Rice is an important food crop in Afghanistan. The farmers grow both types long and short grain rice. Generally short grain is planted in Wardak, Logar, Kapisa, and Khost provinces. Small acreage of short grain rice is also planted in other rice growing areas of the country. Long grain aromatic rice is cultivated in Sholgara district of Balkh province in the north, and north eastern provinces of (Baghlan, Kunduz, Takhar and Kishem and Faizabad of Badakhshan). In north west it is grown in (Gozara, Enjil, and Pushtoon Zarghoon) districts of Herat and in the eastern provinces of Laghman, Kunar and Nangarhar. Rice is also cultivated on small scale in Uruzgan, Zabul, Farah and Badghis provinces.

The total cultivated area of rice is estimated to be 210 thousand hectares with the total production of 450 thousand metric tones and an average yield of $2.03 \mathrm{MT} / \mathrm{ha}$. This yield in comparison to the world average is low, but the potential is there to get much higher yields. The main reasons for the low yields are:

- Lack of improved seeds.

- Susceptibility to diseases and lodging.

- Lack of improved cultural practices.

- Lack of fertilizer.

- Lack of trained personnel in rice research and extension.

During 1970-75, the Agricultural Research Department of the Ministry of Agriculture introduced some improved varieties of long grain rice such as Saturn, Della, Kolo Australia, CR44-11 and the short grain rice varieties of PADMA, IET-355, KH-7194 and TYCHING NATIVE-I. These genotypes were distributed to farmers.

In Mid 1970s with the financial support of the government of Japan, a rice research and extension institute was established in Nangarhar province in Shisham Bagh. The aim of this initiative was to train Afghans in all aspects of rice varieties release work. With the Russian invasion of 1979, the staff and facilities of this project met the same fate of destruction and looting as other research facilities for crop varieties selection and release.

Fortunately the systematic rice variety screening work of FAO with financial assistance from SIDA in 1996 came into effect. This work continued to end of 1999. This research has resulted in the release of three new rice varieties for Afghanistan and the recommendation of Basmati-385 for production in Eastern parts of the country.

\section{Material and Methods}

During 1998 and 1999 crop seasons two national yield trials on long grain and two national yield trials on short rice were conducted in rice growing areas of the country. Also two separate yield trials were carried out in Herat province in both years. During 1998 and 1999 two date of planting and two fertilizer trials were conducted in Nangarhar province. In 1999 crop season a date of planting trial was conducted on the new rice variety Baghlan 98 in Balkh province. The design of the yield trials was randomized complete block design with 10 entries and four replications. The plot size was 5 meter long, the number of rows were 6 and the row spacing was $20 \mathrm{~cm}$. The plant to plant spacing was $20 \mathrm{~cm}$. Harvested area for yield determination was 4 central rows, 4 meters 
long. The fertilizer rate was $120 \mathrm{~kg}$ nitrogen and $60 \mathrm{~kg} \mathrm{P} 205 / \mathrm{ha}$. All phosphate fertilizer and half of nitrogen was applied at transplanting time and the other half of nitrogen was applied at 30-35 days after transplanting. The seeding rate was $31.25 \mathrm{~kg} / \mathrm{ha}$. The nurseries were planted in the beginning of May and transplanting started from the middle of June to the first week of July. All the agronomic practices were applied uniformly.

The data of each experiment was analyzed separately for both years using MSTAT. statistical package. The yields were recorded in $\mathrm{g} /$ plots and changed to $\mathrm{kg} / \mathrm{ha}$ and is presented here.

\section{Results and Discussion (1998)}

\section{Long Grain Rice:}

The mean yield ( $\mathrm{kg} / \mathrm{ha}$ ), rank and overall mean yield of ten long grain rice lines tested in (98NRYTLL) in 8 locations during 1998 in Afghanistan is summarized in (Table 1 Annex 3). In Nangarhar the highest was produced by line 7 (Basemati-385) improved check with a mean yield of $8941 \mathrm{~kg} / \mathrm{ha}$ and ranked $1^{\text {st }}$. This yield is significantly higher than the yield of other lines. Line 10 ( $\mathrm{kC} \mathrm{1344)} \mathrm{with} \mathrm{a} \mathrm{mean} \mathrm{yield} \mathrm{of} 7905 \mathrm{~kg} / \mathrm{ha}$, line 6 (IR5287-15-2-1-2) with a mean yield of $7696 \mathrm{~kg} / \mathrm{ha}, 5$ (SAYBARE 1289) with mean yield of $7471 \mathrm{~kg} / \mathrm{ha}$ and $1(\mathrm{RP} 1670-7613-3-2)$ with a mean yield of $7328 \mathrm{~kg} / \mathrm{ha}$ ranked $2,3,4$, and $5^{\text {th }}$ respectively. There is no significant differences between the yields of these lines but these lines produced significantly higher yields than the remaining lines. This trial was conducted by MADERA in Shewa district (Nangarhar 1) and the highest mean yield was recorded by lines 6 (IR5287-15-2-1-2), 4 (DR 33), and 3 (IR62873-1474-10) with a mean yield of $5847 \mathrm{Kg} / \mathrm{ha}, 5447 \mathrm{Kg} / \mathrm{ha}$ and $5419 \mathrm{~kg} / \mathrm{ha}$ and ranking of $1,2,3$ respectively (Table 1, Annex 3).

In Laghman province the top yield ( $8297 \mathrm{~kg} / \mathrm{ha}$ ) was recorded for line 6 (IR5287-15-2-1-2). This yield is significantly higher than the yield of other lines and ranked $1^{\text {st }}$. Lines 7 (Basemati -385 ) improved check with the yield of $7191 \mathrm{~kg} / \mathrm{ha}, 4$ (DR 33) with mean yield of $7131 \mathrm{~kg} / \mathrm{ha}, 5$ (SAYBARE 1289)with mean yield of $6910 \mathrm{~kg} / \mathrm{ha}$, and 2 (IR62871-166-2-2) with a mean yield of $6884 \mathrm{~kg} / \mathrm{ha}$ ranked $2,3,4$, and $5^{\text {th }}$ respectively. These yields are significantly higher than the yields of the rest of the lines (Table 1, Annex 3)

In Kunar province the top yields were produced by lines 6( IR5287-15-2-1-2 ), 1(RP1670-76133-2), 10 (KC 1344), 5 (SAYBARE 1289), and 3 (IR62873-147-4-10) with yield of $5450 \mathrm{Kg} / \mathrm{ha}$, $5375 \mathrm{Kg} / \mathrm{ha}, 5181 \mathrm{Kg} / \mathrm{ha}, 5070 \mathrm{~kg} / \mathrm{ha}$, and $4762 \mathrm{~kg} / \mathrm{ha}$ respectively. There is no significant differences between the mean yields of these lines. The yields of these lines are significantly more than the mean yield of lines 4 and 9 (Table 1, Annex 3).

The Khost data by DACAAR is summarized in (Table 1, Annex 3). The highest yield (7570 $\mathrm{kg} / \mathrm{ha}$ ) was recorded for lines 6 ( IR5287-15-2-1-2 ) and ranked first. Lines 8 (Sarda Barah) with a mean yield of $6742 \mathrm{~kg} / \mathrm{ha}, 10$ (KC 1344) with a mean yield of $6641 \mathrm{~kg} / \mathrm{ha}$ and 2 (IR62871-166-22) with a mean yield of $6453 \mathrm{~kg}$ /ha ranked 2,3 , and $4^{\text {th }}$ respectively. There is no significant difference between the mean yields of these lines but these lines produced significantly more yields than the rest of the lines.

In Sholgara district of Balkh province the top yield $(6016 \mathrm{~kg} / \mathrm{ha})$ was recorded for line 1 (RP1670-7613-3-2) and ranked 1. This yield is significantly higher than the rest of the lines. Lines 9 (IR62871-544-3-6) with a mean yield of $3686 \mathrm{~kg}, 8$ (Sarda Barah) with a mean yield of $3656 \mathrm{~kg}$ and 2 (IR6287)-166-2-2) with a mean yield of $3492 \mathrm{~kg} / \mathrm{ha}$ ranked 2,3 and $4^{\text {th }}$ 
respectively. These lines produced significantly higher yields than the rest of the lines (Table 1 , Annex 3)

In Kunduz province (Table 1, Annex 3 ) the highest mean yield was given by lines 5 (SAYBARE 1289), 10 (KC 1344), and 7 (Basemati -385) the improved check. These lines produced mean yields of $6207 \mathrm{~kg} / \mathrm{ha}, 5992 \mathrm{~kg} / \mathrm{ha}$, and $5793 \mathrm{~kg} / \mathrm{ha}$ respectively and ranked 1, 2, and 3 . The yields of these lines are significantly higher than the yield of line 8 (Sarda Barah) $3773 \mathrm{~kg} / \mathrm{ha}$. In Takhar province the data revealed that lines 1 (RP1670-7613-3-2) with a mean yield of $8138 \mathrm{~kg} / \mathrm{ha}, 9$ (IR62871-544-3-6) with a mean yield of $7752 \mathrm{~kg} / \mathrm{ha}$, and 2 (IR62871-166-2-2) with a mean yield of $7309 \mathrm{~kg} / \mathrm{ha}, 5$ (SAYBARE 1289) with a mean yield of $7231 \mathrm{~kg} / \mathrm{ha}$ and 4 (DR 33) with a mean yield of $7175 \mathrm{~kg}$ /ha ranked $1,2,3,4$, and $5^{\text {th }}$ respectively. There is no significant differences between these yields, but these yields are significantly higher than the rest of the lines (Table 1, Annex 3).

The combined mean yields and ranking data of these lines over 8 locations indicated that lines 6 (IR5287-15-2-1-2) with a mean yield of $6023 \mathrm{~kg} / \mathrm{ha}, 1$ (RP1670-7613-3-2) with a mean yield of $5930 \mathrm{~kg} / \mathrm{ha}, 2$ (IR62871-166-2-2) with a mean yield of $5668 \mathrm{~kg} / \mathrm{ha}, 5$ (SAYBARE 1289) with a mean yield of $5631 \mathrm{~kg}$, and $10(\mathrm{KC} \mathrm{1344)}$ with a mean yield of $5618 \mathrm{~kg} / \mathrm{ha}$ are the top 5 highest yielding lines and have ranked 1, 2, 3, 4, and $5^{\text {th }}$ respectively. The improved check 7 (Basemati 385 ) with a mean yield of $5398 \mathrm{~kg} /$ ha ranked $8^{\text {th }}$. These lines compared to Basemati -385 (check) produced $12,10,5,4$, and $4 \%$ more yield.

The mean yield $(\mathrm{kg} / \mathrm{ha}$ ) and rank of ten long grain rice lines tested in (HNRYTL1) in Herat province during 1998 and 1999 crop season is summarized in (Table 3, Annex 3). The data of 1998 crop season shows that the highest yield was produced by line 7 (Alum Guli) with a mean yield of $8037 \mathrm{~kg} / \mathrm{ha}$ and ranked first. Line $3(\mathrm{H} 232-58-2)$ with a mean yield of $7527 \mathrm{~kg} / \mathrm{ha}$ ranked $2^{\text {nd }}$. There is not significant difference between the mean yield of these lines but these lines yielded significantly higher than the rest of the lines. The local line Sadri produced a mean yield of $6199 \mathrm{~kg} / \mathrm{ha}$ and ranked $8^{\text {th }}$. Compared to local these lines $(7,3)$ produced 30 , and $21 \%$ higher yield.

\section{Short Grain Rice:}

Table 2, Annex 3 shows the mean yield ( $\mathrm{kg} / \mathrm{ha}$ ), overall mean yield , and rank of 10 short grain rice lines tested in (98NRYTS1) in 9 locations in Afghanistan. In Nangarhar province the highest yield was produced by lines 1 (Swat-2), and 6 (KC 15) with mean yields of $7683 \mathrm{~kg}$ and $7359 \mathrm{~kg}$ /ha and ranked 1, and 2 respectively. These yields are significantly higher than the yields if the remaining lines. Line 2 (RP1670-7613-3-2) produced the mean yield of $6367 \mathrm{~kg} / \mathrm{ha}$ and ranked $3^{\text {rd }}$. The local line produced the mean yield of $6223 \mathrm{~kg} / \mathrm{ha}$ and ranked $4^{\text {th }}$. Compared to local check these lines produeed $23 \%, 18 \%$, and $2 \%$ more yield.

In Laghman province the top yield was produced by line 1 (Swat-2) with a mean yield of 8445 $\mathrm{kg} / \mathrm{ha}$ and ranked first. While lines 4 (DR 83) with a mean yield of $8320 \mathrm{~kg} / \mathrm{ha}, 8$ (IR 50 ) with a mean yield of $8301 \mathrm{~kg} / \mathrm{ha}$ and 7 (PAK 1379 ) with a mean yield of $8242 \mathrm{~kg} / \mathrm{ha}$ ranked 2, 3, and $4^{\text {th }}$ respectively. The local check yielded $7945 \mathrm{~kg} / \mathrm{ha}$. There is no significant difference between the mean yield of these lines. These lines produced significantly more yields than the rests of the lines. In comparison to the local check these lines produced $6 \%, 5 \%, 4 \%$, and $3 \%$ more yield (Table 2, Annex 3). 
In Kunar province in (Table 2, Annex 3), lines 4 (DR 83) produced the highest yield of 6246 $\mathrm{kg} / \mathrm{ha}$ and ranked first followed by lines $6(\mathrm{KC} \mathrm{15})$, and line 10 (local check) with a mean yield of $5656 \mathrm{~kg} / \mathrm{ha}$ and $5619 \mathrm{~kg} / \mathrm{ha}$ ranked 2 , and $3^{\text {rd }}$ respectively. These yields are significantly higher than the rest of the lines.

In Nangarhar the experiment was conducted in Agam district and the highest mean yield (6256 $\mathrm{kg} / \mathrm{ha}$ ) was produced by lines 4 (DR33). The yield of DR33 is not significantly different from the mean yield of lines 6 (KC 15), 3 (UTI), 10 (local check), 1 (SWAT-2 ) and 7 (PAK 1379), Table 2, Annex 3.

In Khost the data revealed that the top yields were produced by lines 6 ( $\mathrm{KC} \mathrm{15),} 1$ (Swat-2), and 4 (DR 33) with a mean yields of $8031 \mathrm{~kg} / \mathrm{ha}, 8023 \mathrm{~kg} / \mathrm{ha}$, and $7852 \mathrm{~kg} / \mathrm{ha}$ (Table 2, Annex 3). These lines ranked 1,2 , and $3^{\text {rd }}$ respectively. The local line with a mean yield of $7576 \mathrm{~kg} / \mathrm{ha}$ ranked $4^{\text {th }}$. However there is no significant difference between the mean yields of these lines. The yield of these lines are significantly different from the yields of lines 5 (SPTLR 81388) and 9 (H232-582) with yields of $5594 \mathrm{~kg}$ and $6242 \mathrm{~kg} /$ ha respectively.

In Herat province lines 4 (DR 33), I (Swat-2), 7 (PAK 1379), and 3 (UTI) with a mean yields of $8477 \mathrm{~kg}, 8419 \mathrm{~kg}, 8311 \mathrm{~kg}$, and $8011 \mathrm{~kg} / \mathrm{ha}$ are the highest yielding lines and ranked 1, 2, 3 and $4^{\text {th }}$ respectively. The mean yields of these lines are not significantly different from each other but they are significantly higher than the mean yield of the rest of the lines. The local line with a mean yield of $5930 \mathrm{~kg} /$ ha ranked $10^{\text {th }}$. Compared to local check these lines $(4,1,7,3)$ produced $43,42,40$, and $35 \%$ higher yields.

In Balkh province lines 2 (RP1670-7613-3-2) with a mean yield of $5531 \mathrm{~kg} / \mathrm{ha}, 8$ (IR50) with a mean yield of $5484 \mathrm{~kg} / \mathrm{ha}, 4$ (DR83) with a mean yield of $5481 \mathrm{~kg} / \mathrm{ha}$, and 1 (Swat-2) with a mean yield of $5125 \mathrm{~kg} /$ ha produced the top yields and ranked $1,2,3$, and $4^{\text {th }}$ respectively. The yields of these lines are significantly higher than the mean yields of lines 5, 6, 7, and the local check. These lines out yielded the local check by $182,180,179$, and $162 \%$

In Kunduz lines 3 (UTI), 8 (IR50), 7 (PAK 1379) with a mean yield of $7448 \mathrm{~kg}, 7072 \mathrm{~kg}, 6966$ $\mathrm{kg} / \mathrm{ha}$ are the highest yielding genotypes and ranked 1,2 , and $3^{\text {rd }}$ respectively. These yields are significantly higher than the mean yields of lines 2 (RP1670-7613-3-2), 5 (SPTLR 81388), 9 (H232-58-2) and 10 the local check. Compared to local check these lines produced 47, 40, and 38 $\%$ more yields. In Takhar province the highest yields were produced by lines 7 (PAK 1379) the mean yield of $7652 \mathrm{~kg}, 1$ (Swat-2) the mean yield $7483 \mathrm{~kg}$, and $6(\mathrm{KC} 15)$ the mean yield of 7166 $\mathrm{kg} / \mathrm{ha}$ and ranked 1,2 , and $3 \mathrm{rd}$ respectively. These yields are significantly higher than the mean yields of lines 2 (RP1670-7613-3-2), 4 (DR83), and 10 the local check. Compared to local check these lines produced 76,72 , and $65 \%$ more yield.

The combined mean yield and rank of these lines over 9 locations indicates that lines 1 (Swat-2) with an overall mean yield of $6957 \mathrm{~kg} / \mathrm{ha}, 4$ (DR83) with the overall mean yield of $6831 \mathrm{~kg} / \mathrm{ha}, 6$ (KC 15) with the overall mean yield of $6685 \mathrm{~kg} / \mathrm{ha}, 7$ ( PAK 1379) with the overall mean yield of $6508 \mathrm{~kg} / \mathrm{ha}$, and 3 (UTI ) with the overall mean yield of $6505 \mathrm{~kg} / \mathrm{ha}$ ranked $1,2,3,4$, and $5^{\text {th }}$ respectively. The local line with an overall mean yield of $5597 \mathrm{~kg} / \mathrm{ha}$ ranked $9^{\text {th }}$. These lines compared to local check produced $24,22,19,16$, and $16 \%$ more yield. 


\section{Results and Discussion of 1999 Data}

\section{Long Grain Rice:}

The mean yield ( $\mathrm{kg} / \mathrm{hra}$ ), rank and overalt mean yield of ten long grain rice lines tested in (99NRTL1) in 6 locations in Afghanistan in 1999 crop season is recorded in (Table 1 Annex 4). In Nangarhar province the highest yield was given by the line 6 (IR5287-15-2-12) with a mean yield of $7734 \mathrm{~kg} / \mathrm{ha}$. This yield is significantly higher than the rest of the lines. Lines 7 (Basemati385 ) improved check with a mean yield of $6398 \mathrm{~kg} / \mathrm{ha}, 1$ (RP16707613-3-2) with a mean yield of $6336 \mathrm{~kg} / \mathrm{ha}, 9$ (IR62871-544-3-6) with a mean yield of $6328 \mathrm{~kg} / \mathrm{ha}, 10$ (KC 1344) with a mean yield of $6187 \mathrm{~kg} / \mathrm{ha}$ and 2 (IR62871 166-2-2) with a mean yield of $5766 \mathrm{~kg} / \mathrm{ha}$ ranked 2, 3, 4, 5, and $6^{\text {th. }}$. There is no significant difference between the mean yields of these lines but these lines produced significantly higher yields than the rest of the lines.

In Balkh province the top yields were produced by lines 1 (RP1670-7613-3-2), and 8 (Sarda Barah) with a mean yield of $4606 \mathrm{~kg} / \mathrm{ha}, 4225 \mathrm{~kg} / \mathrm{ha}$ and ranked 1 , and $2^{\text {nd }}$ respectively. These yields are significantly higher than the yields of the remaining lines. In Takhar province the highest mean yields were produced by lines 1 (RP1670-7613-3-2) with a mean yield of 7952 $\mathrm{kg} / \mathrm{ha}, 2$ (IR62871 166-2-2) with a mean yield of $7523 \mathrm{~kg} / \mathrm{ha}, 9$ (IR62871- 544-3-6) with a mean yield of $7451 \mathrm{~kg} / \mathrm{ha}, 10$ (KC 1344) with a mean yield of $6908 \mathrm{~kg} / \mathrm{ha}$, and 6 (IR5287-15-2-1-2) with a mean yield of $6901 \mathrm{~kg} / \mathrm{ha}$ ranked $1,2,3,4$, and $5^{\text {th }}$ There is no significant difference between the mean yields of these lines. These lines produced significantly higher yield than the rest of the lines ( Table 1, Annex 4 ).

In Kunar province the highest mean yield ( $8969 \mathrm{~kg} / \mathrm{ha}$ )was produced by line 10 ( $\mathrm{KC} 1344)$ and ranked first. This yield is significantly higher than the rest of the lines. The lines 6 (IR5287-15-2$1-2)$ with a mean yield of $7725 \mathrm{~kg} / \mathrm{ha}$ and 1 ((RP1670-7613-3-2) with a mean yield of 7706 $\mathrm{kg} / \mathrm{ha}$ ranked $2 \mathrm{nd}$, and $3^{\text {rd }}$ respectively. In Laghman province lines 6(IR5287-15-2-1-2) with a mean yield of $5580 \mathrm{~kg}, 1$ (RPl670-7613 -3-2) with a mean yield of $5376 \mathrm{~kg}, 7$ (Basemati -385) with a mean yield of $5356 \mathrm{~kg}$, and $10(\mathrm{KC} \mathrm{1344)}$ with a mean yield of $5288 \mathrm{~kg} / \mathrm{ha}$ ranked $1,2,3$, and $4^{\text {th }}$ respectively. These lines produced significantly higher yields than the others. In Khaiwa district of Nangarhar province line 1(RPl670-7613-3-2) with a mean yield of $6456 \mathrm{~kg} / \mathrm{ha}$ ranked first. This yield is significantly higher than the yields of the remaining lines. Lines 4 (DR 33), and 6 (IR5287-15-2-1-2) with a mean yield of $5531 \mathrm{~kg}$ and $5525 \mathrm{~kg} / \mathrm{ha}$ ranked 2 , and $3^{\text {rd }}$ respectively. The mean yield of these two lines are significantly higher than the mean yields of lines 9 (IR62871 544 3-6) and 2 (IR62871 166-2-2) respectively.

When the mean yield data of 6 locations was combined the overall mean yield and rank showed that entry 1 (RP1670-7613 -3-2 = Afghan-98) with a mean yield of $6405 \mathrm{~kg} / \mathrm{ha}$, entry 10 (KC 1344) with a mean yield. of $5839 \mathrm{~kg} / \mathrm{ha}$, entry 6 (IR5287-15-2-1-2) with a mean yield of $571 \mathrm{l}$ $\mathrm{kg} / \mathrm{ha}$, entry 4 (DR33) with a mean yield of $5112 \mathrm{~kg} / \mathrm{ha}$ and entry 2(IR62871-166-2-2 = Baghlan98) with a mean yield of $5041 \mathrm{~kg} / \mathrm{ha}$ ranked $1,2,3,4$, and $5^{\text {th }}$ respectively (Table 1, Annex 4). The rice variety Afghan-98 has exceeded the improved check Basmati-385 by $1395 \mathrm{~kg} / \mathrm{ha}$ and the rice variety. Baghlan-98 is equally good yielding as the improved check.

Table 3, Annex 4 summarizes the mean yield (kg/ha) and rank of ten long grain rice lines tested in Herat province in (HNRYTL1) during 1999. The highest yield was produced by line 10 (Sadri) the local check with a mean yield of $6926 \mathrm{~kg} / \mathrm{ha}$ and ranked first. However, this yield is not significantly different from the mean yields of lines 7 (Alum Guli) with a mean yield of 5727 $\mathrm{kg} / \mathrm{ha}, \mathrm{l}$ (KC 344) with a mean yield of $5553 \mathrm{~kg} / \mathrm{ha}$, and 4 (Lawangi) with a mean yield of 5516 
$\mathrm{kg} / \mathrm{ha}$. These lines have ranked 2,3 , and $4^{\text {th }}$ respectively.

When two years data was combined, it shows that line 7 (Alum Guli) with an overall mean yield of $6882 \mathrm{~kg} / \mathrm{ha}$ is the top yielding and ranked first. The local line with an overall mean yield of $6563 \mathrm{~kg} / \mathrm{ha}$ ranked $2^{\text {nd }}$. Compared to local line, Alum Guli produced $5 \%$ more yield and compared to the nursery mean ( $6023 \mathrm{Kg} / \mathrm{ha}$ ) these two lines produced 14 and 9 the percent higher yield. Therefor the seed of "Alum Guli" and local rice should be purified and increased.

\section{Short Grain Rice}

The mean yield, overall mean yield $(\mathrm{kg} / \mathrm{ha})$ and rank of 10 short grain rice lines tested in (99NRYTS1) in Nangarhar, Herat, Balkh ,Takhar ,Kunar, Laghman, and Khaiwa district of Nangarhar of Afghanistan are summarized in (Table 2 Annex 4). The data indicates that in Nangarhar province the highest mean yield was obtained by lines 7 (PAK 1379) with a mean yield of $6944 \mathrm{~kg} / \mathrm{ha}, 6$ (KC 15) with mean yield of $6833 \mathrm{~kg} / \mathrm{ha}, 1$ (Swat -2 ) with mean yield of $6708 \mathrm{~kg} / \mathrm{ha}, 10$ local with mean yield of $6531 \mathrm{~kg} / \mathrm{ha}$, and 2 (RP1670-7613 -3-2) with a mean yield of $6371 \mathrm{~kg} /$ ha ranked $1,2,3,4$, and $5^{\text {th }}$ respectively. There is no significant difference between the mean yields of these lines. These lines produced significantly higher yield than the rest of the lines. Compared to local check $(6531 \mathrm{Kg} / \mathrm{ha})$, these lines produced 6,5 , and $3 \%$ higher yields.

In Herat province the highest mean yield was obtained by the variety 1 (Swat-2) $8880 \mathrm{~kg} / \mathrm{ha}$ followed by varieties 2 (RP1670-7613 -3-2) with a mean yield of $8459 \mathrm{~kg} / \mathrm{ha}, 3$ (UTI) 8060 $\mathrm{kg} / \mathrm{ha}$, and 4 (DR83) $8048 \mathrm{~kg} / \mathrm{ha}$. These varieties ranked $1,2,3$, and $4^{\text {th }}$ respectively. The yield differences between these lines are not significant. However these genotypes produced significantly higher yields than the rest of the lines tested. Compared to local check $(6259 \mathrm{Kg} / \mathrm{ha})$ these varieties yielded $86,35,29$, and $29 \%$ higher yields.

In Balkh province the top yield was recorded for the lines 1 (Swat-2) $4869 \mathrm{~kg} / \mathrm{ha}, 2$ (RPl6707613 -3-2) $4327 \mathrm{~kg} / \mathrm{ha}, 3$ (UTI) $4238 \mathrm{~kg} / \mathrm{ha}, 9$ (H232-58-2) $3918 \mathrm{~kg} / \mathrm{ha}, 6$ (KC 15) $3887 \mathrm{~kg} / \mathrm{ha}$, and 4 (DR83) $3574 \mathrm{~kg} / \mathrm{ha}$. These entries ranked 1, 2, 3, 4, and $5^{\text {th }}$ respectively. There is no significant yield differences between the mean yields of these genotypes but these entries yielded significantly higher than the rest of the lines. The local variety yielded $2991 \mathrm{~kg} / \mathrm{ha}$ and ranked $7^{\text {th }}$. In comparison to the local check these varieties produced $63,45,42,30$, ard $19 \%$ higher yields.

In Takhar province the highest yielding entries are 7 (PAK 1379) $8160 \mathrm{~kg} / \mathrm{ha}, 2$ (RP1670-7613 3-2) $7604 \mathrm{~kg} / \mathrm{ha}, 1$ (Swat-2) $7506 \mathrm{~kg} / \mathrm{ha}$, and 6 (KC 15) $7451 \mathrm{~kg} / \mathrm{ha}$ respectively. These entries have ranked $1,2,3$, and $4^{\text {th }}$ with no significant yield differences in their mean yield. These varieties yielded significantly higher than the rest of the entries. The local check produced a mean yield of $5019 \mathrm{~kg} / \mathrm{ha}$ and ranked $10^{\text {th }}$. Compared to local check these varieties produced $63,51,50$, and $\$ 8 \%$ higher yields.

In Kunar the highest yield was produced by the local line, the mean yield of $7313 \mathrm{~kg} / \mathrm{ha}$ and ranked first. The lines 4 (DR 33), and 5 (SPTLR 81383) with a mean yield of $6625 \mathrm{~kg}$ and 6594 $\mathrm{kg} / \mathrm{ha}$ ranked 2 , and $3^{\text {rd }}$ respectively. There is no significant difference between the mean yield of these three lines but the yields of these lines are significantly higher than the rests of the lines.

In Laghman the top yield was obtained by the lines $6(\mathrm{KCl})$ and the local with mean yields of $8545 \mathrm{~kg} / \mathrm{ha}$ and $7783 \mathrm{~kg} / \mathrm{ha}$ and ranked 1 and $2^{\text {nd }}$ respectively with no significant differences between the yields of these two lines. The yield of line 6 is significantly higher than the yields of the remaining lines. 
In Khaiwa district of Nangarhar province lines 2 (RP1670-7613-3-2) with a mean yield of 7225 $\mathrm{kg}, 3$ (UTI) with a mean yield of $6981 \mathrm{~kg}, 6(\mathrm{KC} 15)$ with a mean yield of $6819 \mathrm{~kg} / \mathrm{ha}$ are the top yielding lines and ranked 1,2 , and $3^{\text {rd }}$ respectively. The mean yields of these lines are significantly different than the mean yields of lines 8 (IR50) and 5 (SPTLR 81388) with mean yields of $5119 \mathrm{~kg} / \mathrm{ha}$ and $4925 \mathrm{~kg} / \mathrm{ha}$ respectively. The local line with a mean yield of $6775 \mathrm{~kg} / \mathrm{ha}$ ranked $4^{\text {th }}$. Lines 2,3 , and 6 yielded 7,3 , and $1 \%$ more than the local check.

The 7 locations overall mean yield data showed that the varieties 2 (RP1670-7613-3-2), 6 (KC 15), 1 (Swat-2), 4 (DR33), and 7(PAK 1379) with the overall mean yields of $6769 \mathrm{~kg} / \mathrm{ha}, 6683$ $\mathrm{kg} / \mathrm{ha}, 6623 \mathrm{~kg} / \mathrm{ha}, 6476 \mathrm{~kg} / \mathrm{ha}$, and $6360 \mathrm{~kg} / \mathrm{ha}$ produced the highest yield and ranked 1, 2, 3, 4, and $5^{\text {th }}$ respectively. The local variety with an overall mean yield of $6096 \mathrm{~kg} / \mathrm{ha}$ ranked $7^{\text {th }}$. Compared to local check these varieties yielded $11,10,9,6$, and $4 \%$ higher yields (Table 2 , Annex 4).

Tables 5 and 6, Annex 3, summarizes the analysis of variance of 10 long and 10 short rice varieties tested by FAO during 1998 crop season in 8 rice growing locations. There are significantly differences between the mean yields of the rice varieties tested. The location ranking shows the wide adaptability of some varieties over environments.

\section{Agronomy Trials 1998 and 1999}

During 1998 and 1999 experiments on rates of fertilizer and dates of planting were conducted in Nangarhar province of Afghanistan. The objective of these trials is to recommend a package of improved agro-techniques along with the introduction of improved varieties of rice to the farmers for maximum yields per unit area.

\section{Dates of Planting}

Table 4, Annex 3 shows the mean yield ( $\mathrm{kg} / \mathrm{ha}$ ) of the date of planting trial implemented in Nangarhar province. During 1998 the highest yield was recorded for June 25 up to July 05 . These dates yielded $8906 \mathrm{~kg}, 8516 \mathrm{~kg}$, and $7344 \mathrm{~kg} / \mathrm{ha}$ respectively. There is no significant differences between the mean yields of these dates but these dates produced significantly higher yields than July 10 and July 15 planting with mean of $6328 \mathrm{~kg}$, and $4375 \mathrm{~kg} / \mathrm{ha}$ respectively. The June 25 , June 30 and July 05 planting produced 41,35 , and $16 \%$ more yield in comparison to July 10 and yielded 104,95 , and $68 \%$ more than July 15 planting. During 1999 the June 30 and July 10 date gave the highest yields with no significant differences between the mean yields of these two dates (Table 5, Annex 4). The combined mean yield and rank of the two years data revealed that June 30 with an overall mean yield of $8682 \mathrm{~kg} / \mathrm{ha}$, June 25 with an overall mean yield of $8220 \mathrm{~kg} / \mathrm{ha}$, and July 5 with an overall mean yield of $7383 \mathrm{~kg} / \mathrm{ha}$ ranked 1,2 , and $3^{\text {rd }}$ respectively. These dates out yielded July 10 with the overall mean yield of $7191 \mathrm{~kg} / \mathrm{ha}$ by 21,14 , and $3 \%$ and July 15 by 141,128 , and $105 \%$.

Table 6, Annex 4 summarizes the mean yield $(\mathrm{kg} / \mathrm{ha})$ and rank of 5 dates of transplanting rice variety Baghlan-98 in Balkh province during 1999 crop season. The data shows that the highest yield was obtained by date June 10 the mean yield of $9367 \mathrm{~kg} / \mathrm{ha}$ and ranked first. However this yield is not significantly higher than the mean yield of June 1 , June 5 and June 15 with a mean yield of $9192 \mathrm{~kg} / \mathrm{ha}, 9030 \mathrm{~kg} / \mathrm{ha}$ and $8846 \mathrm{~kg} / \mathrm{ha}$ respectively. These yields ranked 2,3 , and $4^{\text {th }}$. The lowest yield was given by date June 20 the mean yield of $5455 \mathrm{~kg} / \mathrm{ha}$ and ranked $5^{\text {th }}$. Planting on June 10, 1, 5, and 15 yielded $72,69,66$, and $62 \%$ more compared to planting on June 20 , 


\section{Fertilizer Experiment}

Table 4, Annex 4 shows the mean yield ( $\mathrm{kg} / \mathrm{ha}$ ) of rice in response to different rates of fertilizer in Nangarhar province. The data revealed that the top yield was obtained by the treatment 7 (138 kg $\mathrm{N} / \mathrm{ha}$ and $115 \mathrm{Kg} \mathrm{P205}$ ) with a mean yield of $9144 \mathrm{~kg} / \mathrm{ha}$. This yield is not significantly higher than the mean yields of treatments 4 (69 kg N and $115 \mathrm{Kg} \mathrm{P205}), 5(69 \mathrm{~kg} \mathrm{~N}$ and $57 \mathrm{~kg} \mathrm{P205}), 6$ ( $69 \mathrm{~kg} \mathrm{~N}$ and $115 \mathrm{~kg}$ P205 ), 8 (138 kg N and $57 \mathrm{Kg} \mathrm{P205),} \mathrm{and} 9$ (138 kg N and $115 \mathrm{Kg} \mathrm{P205)}$ with a mean yields of $8363,8457,8250,8838$, and $8461 \mathrm{~kg} / \mathrm{ha}$ respectively. All these treatments yielded significantly higher than treatments 1 (0 N and 0 P205), $2(0 \mathrm{~N}$ and $57 \mathrm{~kg} \mathrm{p} 205), 3(0 \mathrm{~N}$ and $115 \mathrm{~kg}$ P205) with a mean yield of $6644 \mathrm{~kg}, 6350 \mathrm{~kg}$, and $6094 \mathrm{~kg} / \mathrm{ha}$ respectively.

Table 4, Annex 4 shows the mean yield ( $\mathrm{kg} / \mathrm{ha}$ ) and rank of the fertilizer rate experiment during 1996-1999 crop season in Nangarhar province. The overall mean yield and rank over 4 years indicates that the highest mean yield was obtained by the treatments $7,(7210 \mathrm{~kg} \mathrm{~N}$ and $0 \mathrm{~kg}$ P2O5 $\mathrm{kg} / \mathrm{ha}$ ), 9 (138 kg N and $115 \mathrm{~kg} \mathrm{P} 205 \mathrm{~kg} / \mathrm{ha}$.) and, 8 (138 kg N and $57 \mathrm{~kg} \mathrm{P} 205 \mathrm{~kg} / \mathrm{ha}$ ) the mean yield of $7210 \mathrm{~kg} / \mathrm{ha}, 7155 \mathrm{~kg} / \mathrm{ha}$ and $7121 \mathrm{~kg} / \mathrm{ha}$ and ranked 1,2 , and $3^{\text {rd }}$ respectively. The check plot with no fertilizer produced the overall mean yield of $5353 \mathrm{~kg} / \mathrm{ha}$ and ranked $7^{\text {th }}$. The yield of these treatments are 35,34 , and $33 \%$ higher than the check plot. This data shows that there is no significant yield increase in response to the application of phosphorous fertilizer alone, but in combination with nitrogen yield increase is significant. These trials have been conducted on farmers fields and due to variable fertility status the experimental control was not effective.

\section{Conclusion and Recommendations}

Based on the combined data of 4 years, the following conclusion and recommendations are drawn:

Phosphorous contributed less to yield increase of rice while nitrogen was highly effective in increasing of the rice yields. There was not significant differences between the mean yield of 138 $\mathrm{kg}$ nitrogen and 0,57 , and $115 \mathrm{~kg}$ P2O5/ha. Therefore the amount of $138 \mathrm{~kg}$ nitrogen and $57 \mathrm{~kg}$ $\mathrm{P} 2 \mathrm{O} 5 /$ ha was recommended in Nangarhar areas. 


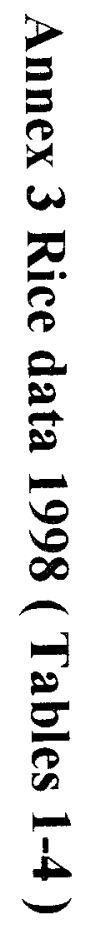




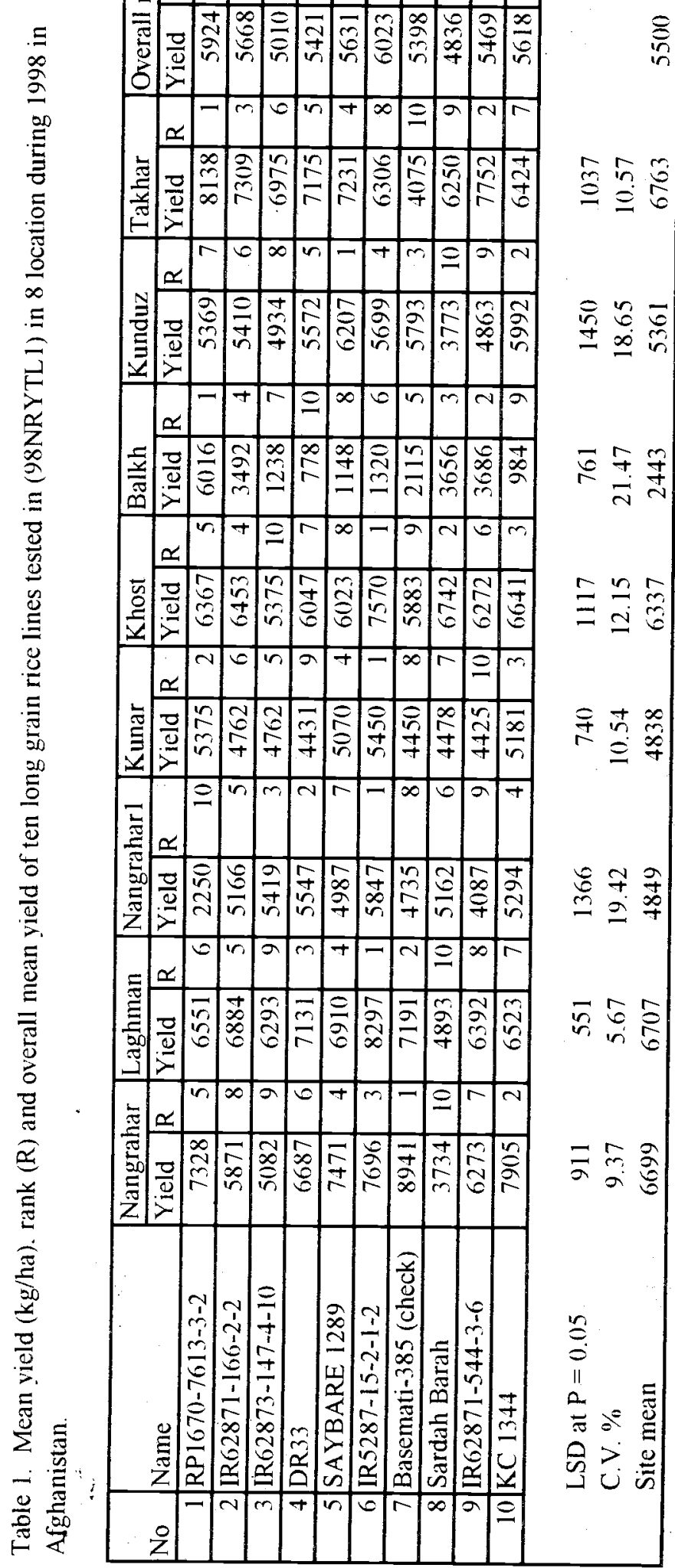




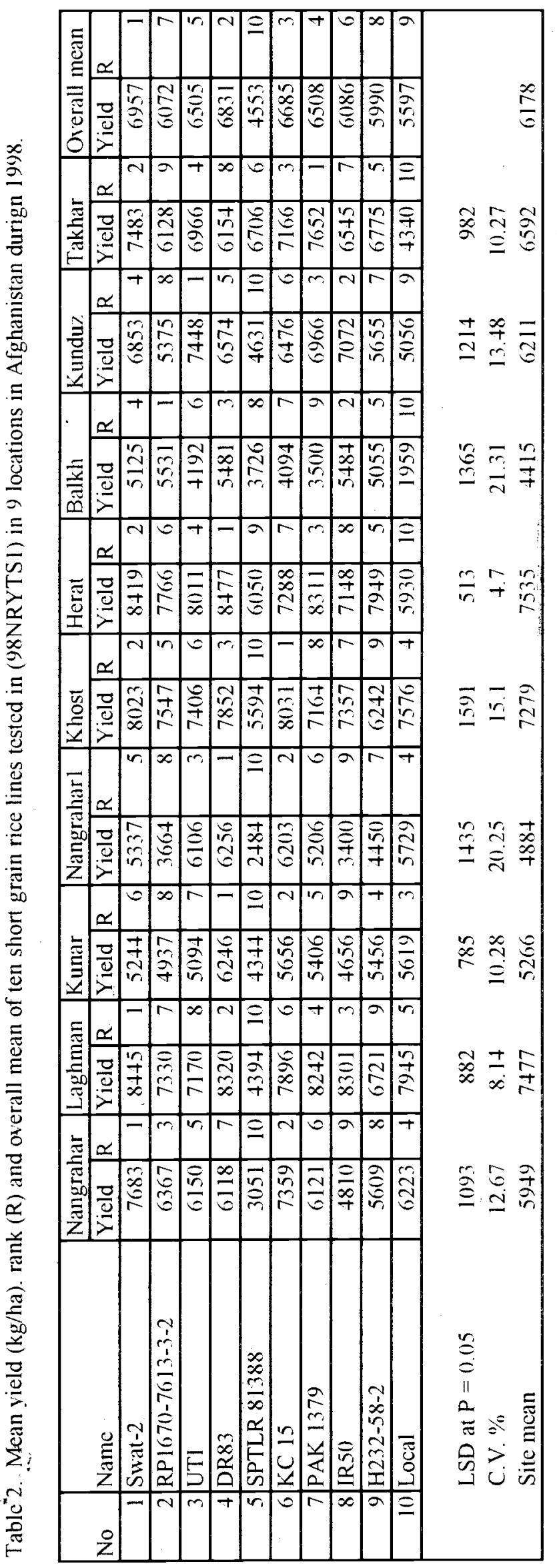



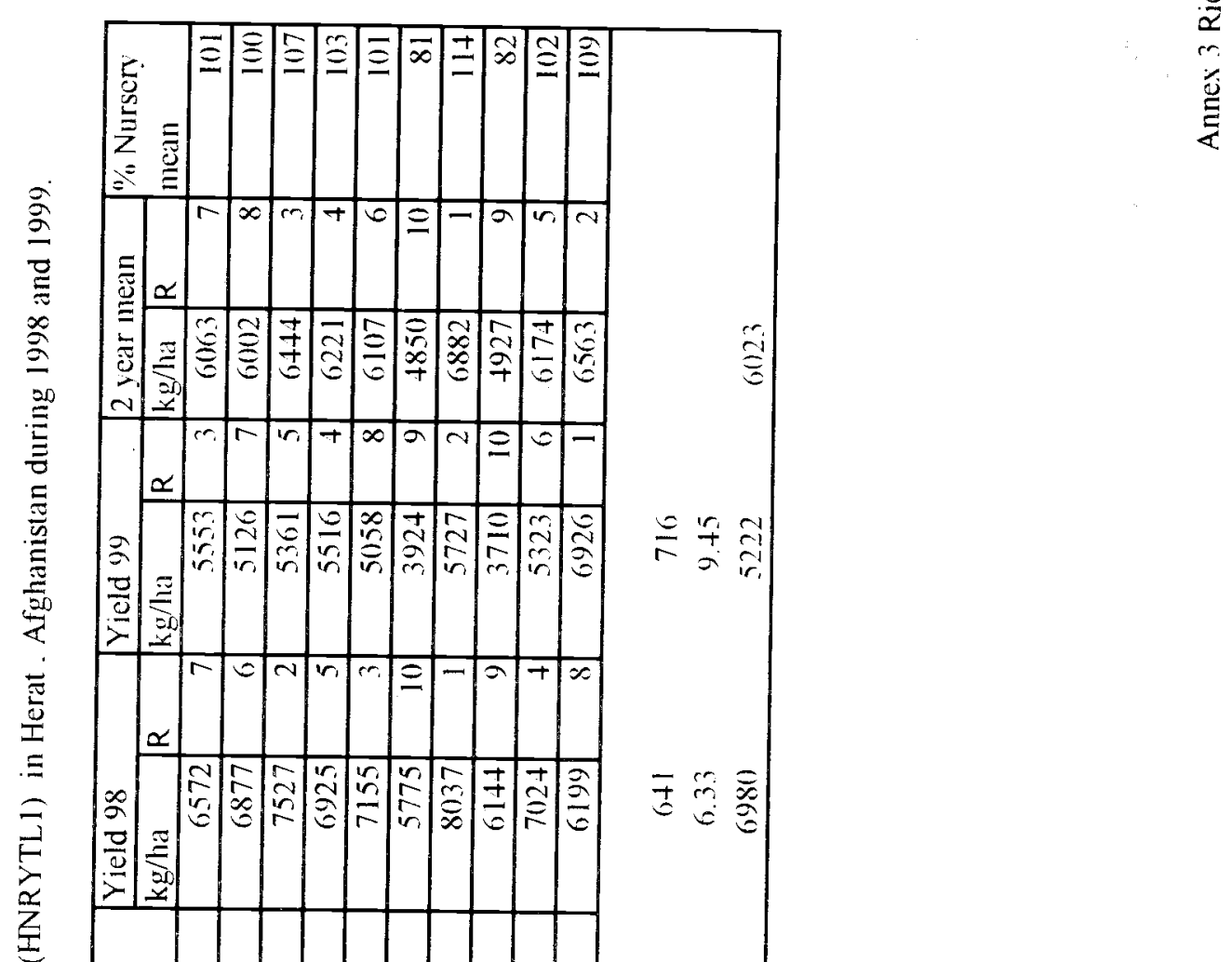


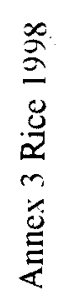

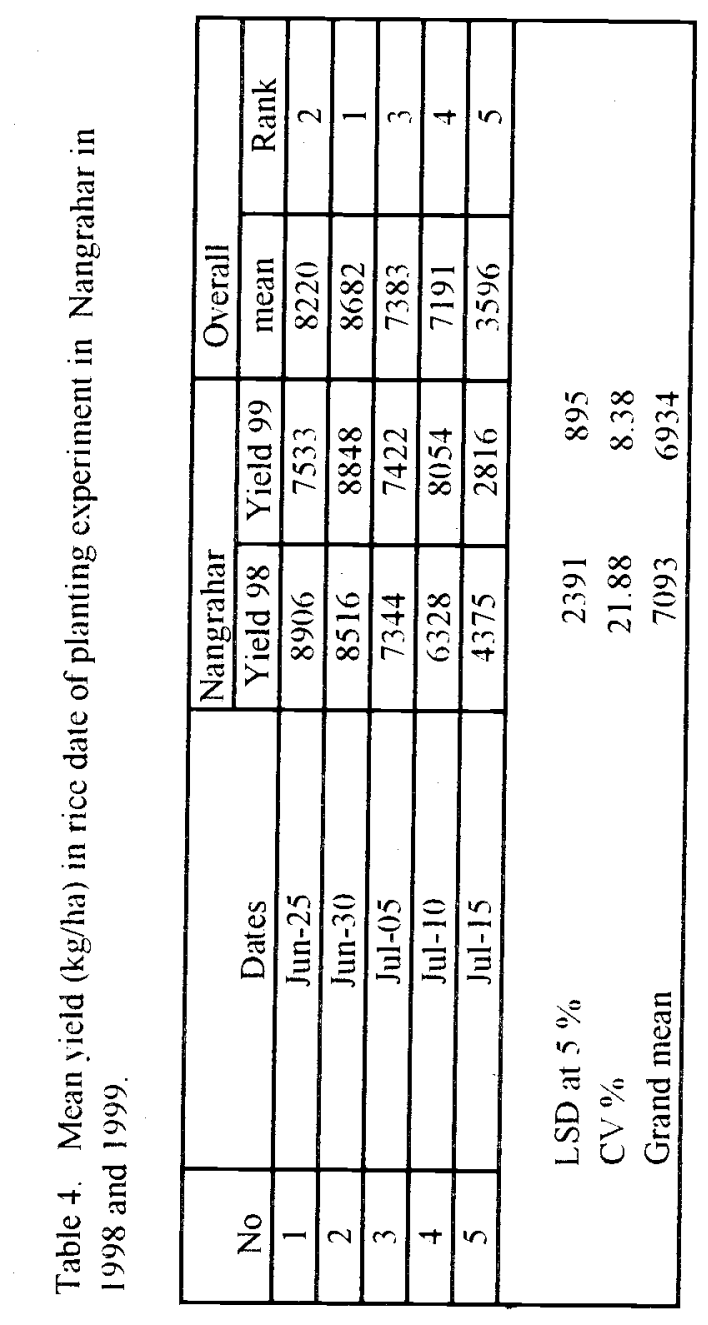




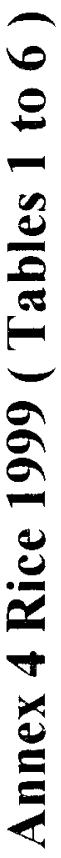
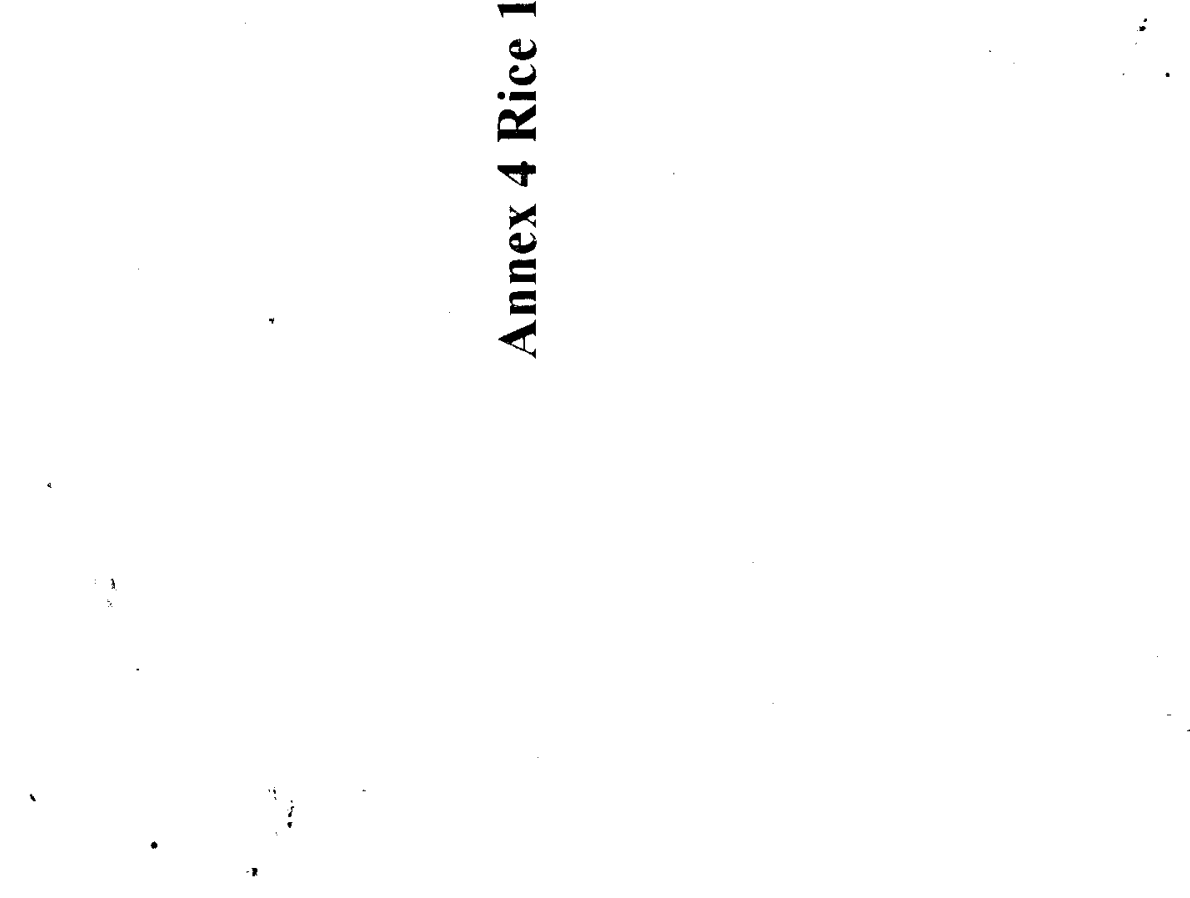

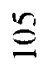




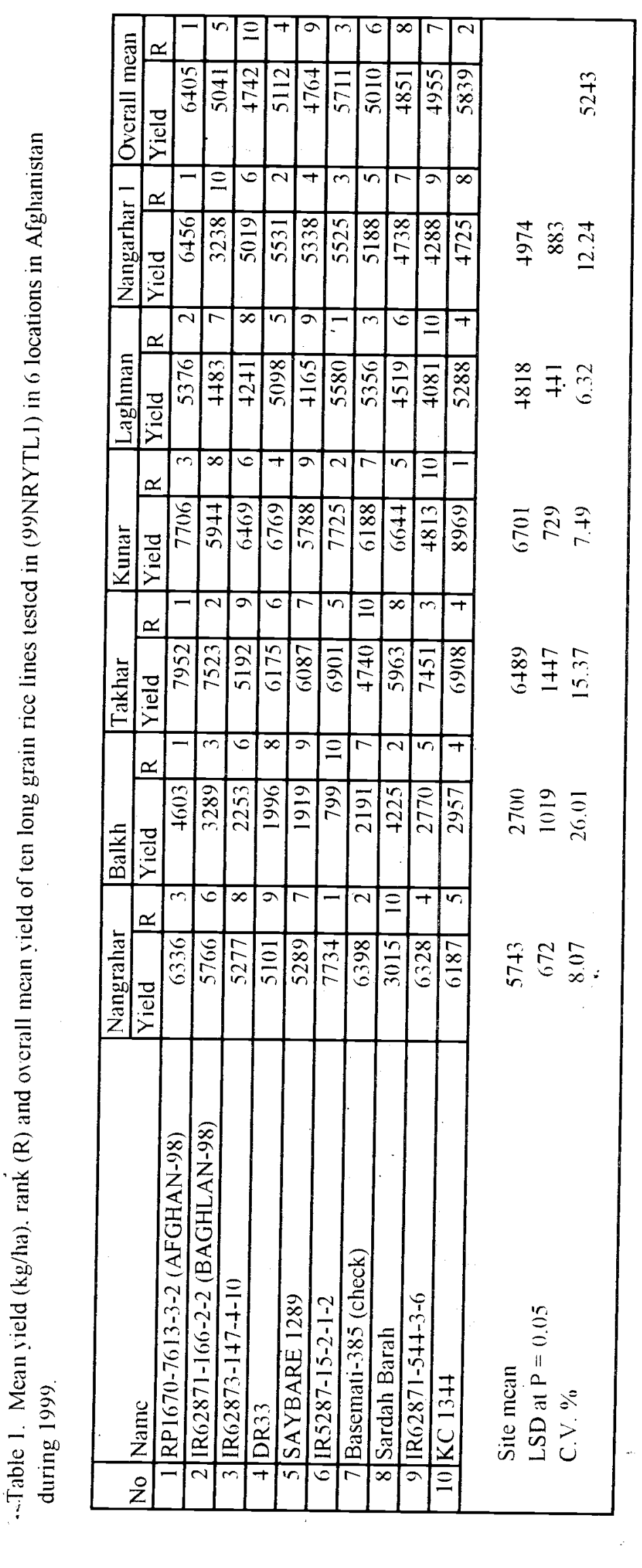




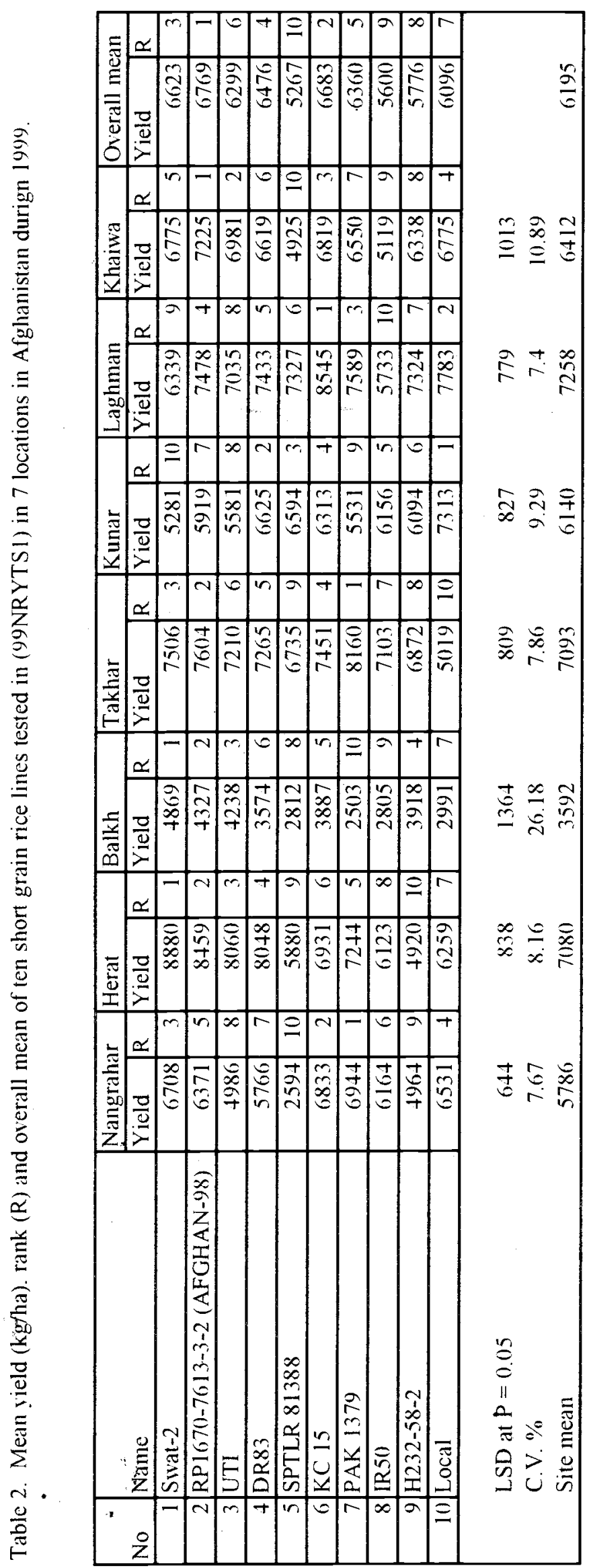

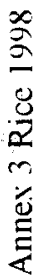


$\frac{\infty}{2}$

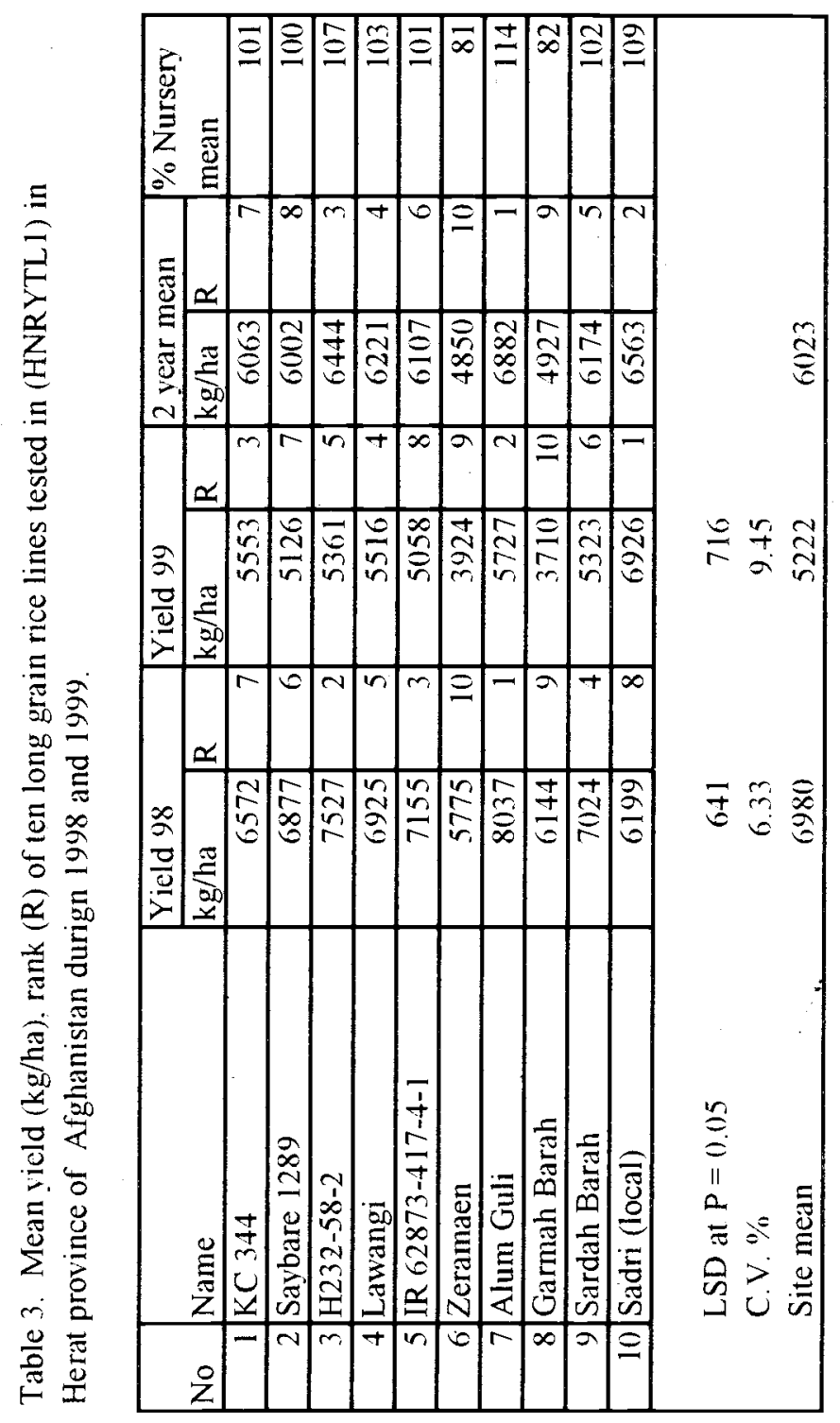




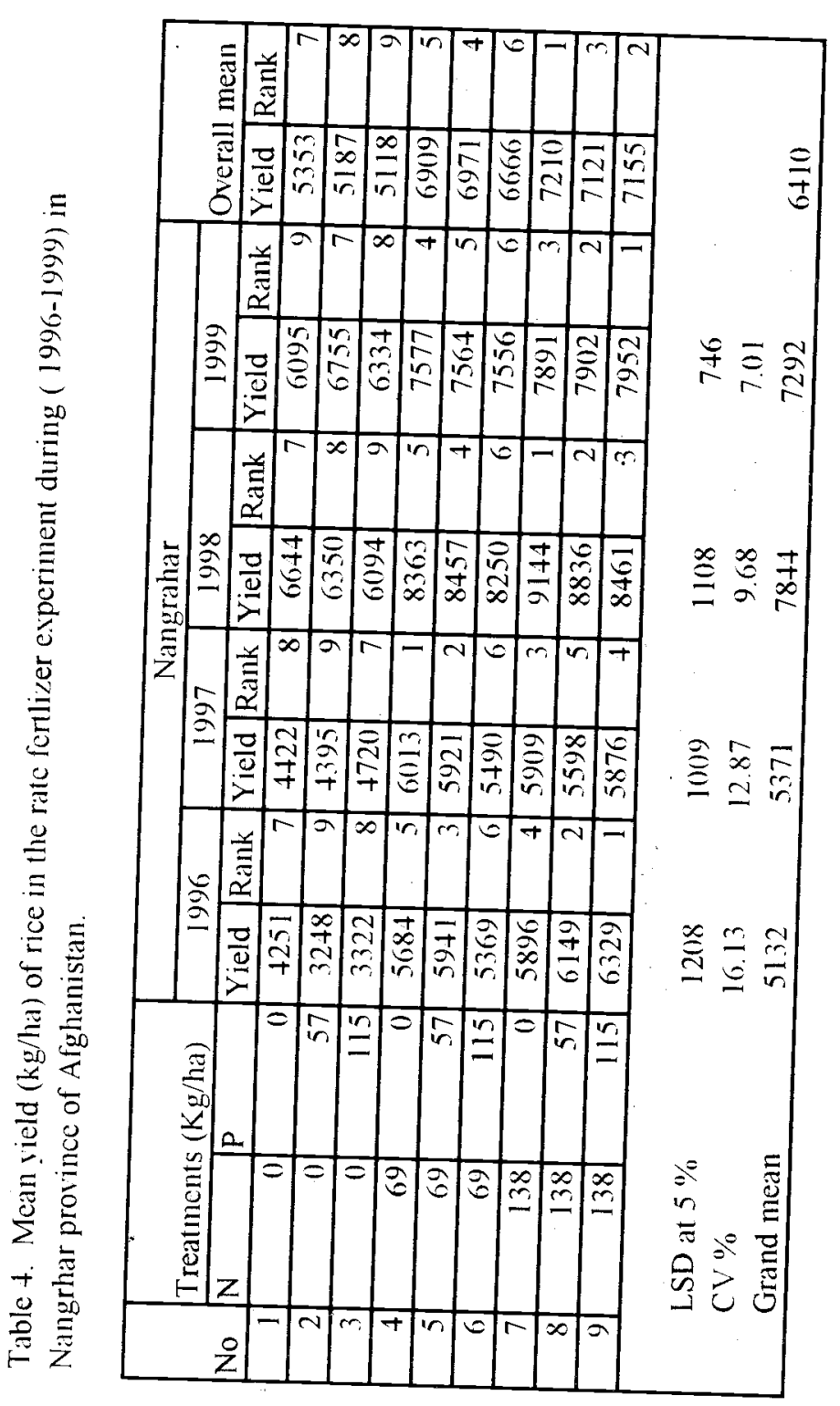


茶

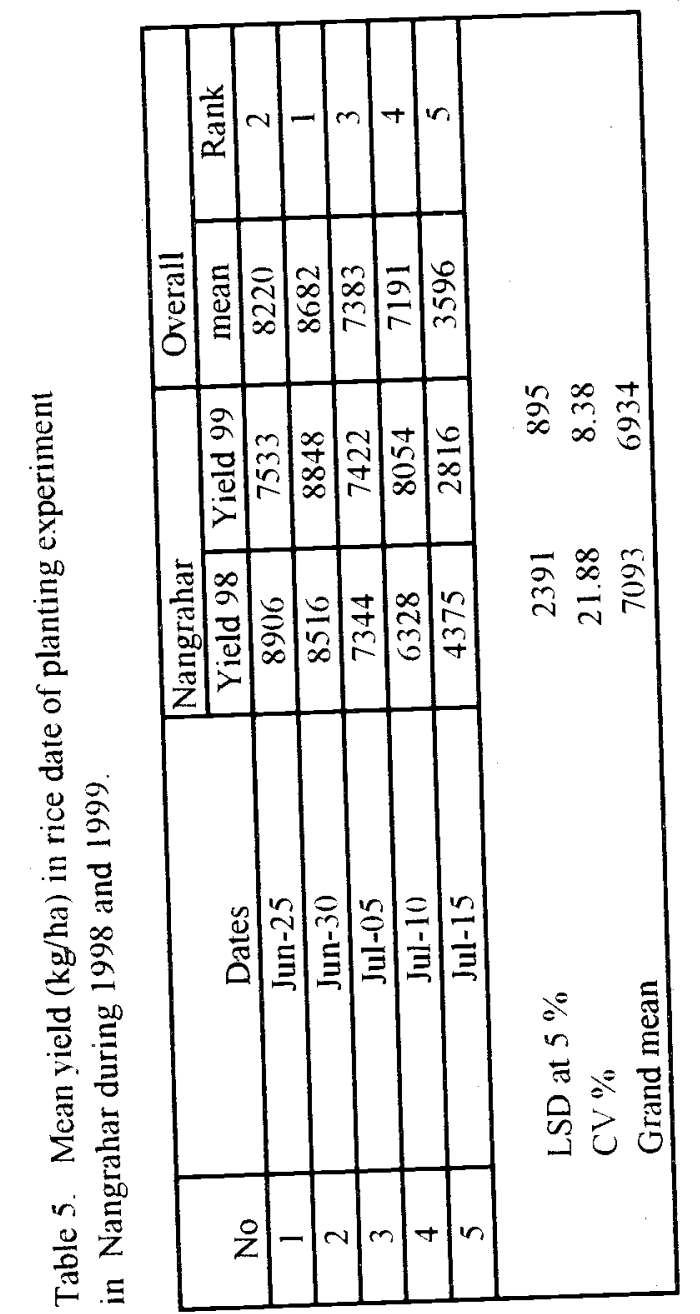


w

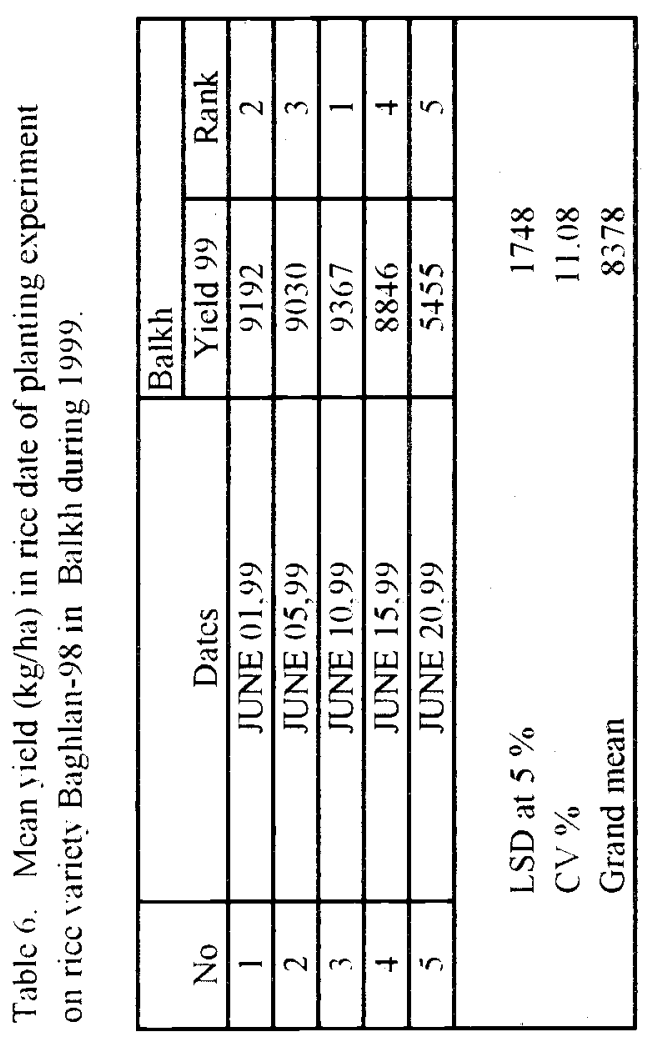




\section{Introduction}

\section{Barley Varieties Selection Research}

Barley is an important crop for animal feed and in times of hardship it is used as food in some parts of the country. Farmers grow both two and six row barley. It is grown in both fall and spring time. It used generally as animal feed only in food deficit areas it is used as human food. The total area under barley is decreasing for example during 1979 the area under barley production was 310 thousand hectares but in 1990 it decreased 256 thousand hectares. Yield are low because the farmers are using varieties that are susceptible to diseases and lodges severely. In the early 1970s the Agricultural Research Institute of Afghanistan ( ARIA ) selected barley varieties 54Trax and Beecher from the barley yield trials of ICARDA. These varieties were distributed to farmers in barley growing areas of the country. These two barley varieties are now susceptible to major barley diseases and their yields are low.

The FAO crop improvement project AFG/94/A02 (UNO/AFG/ 001/DPS ) from 1996 to 999 conducted 31 trials on barley in different zones of Afghanistan to select and identify high yielding. disease resistant lines. Through this process two lines were selected for multiplication and production of basic and pre-basic seed. Other promising lines have been selected for inclusion in 1999-2000 trials.

During 1997-98 two barley varietal trials were conducted. The first one (97NBYTI) consisted of 10 varieties was conducted in 6 locations, and the second (20 IBYT) consisted of 25 varieties was carried out in 5 locations). During 1998-99 a national barley yield trial (98NBYTl) consisting of 10 barley varieties was tested in 5 locations. The international barley yield trial for low rainfall and mild winter areas (IBYT-LRA) was conducted in 3 locations in Afghanistan. Similarly the $6^{\text {th }}$ International Winter and Facultative Barley Yield Trial, International Winter and Facultative Forage Barley Observation Nursery, International Facultative Barley Yield Trial and International Winter and Forage Barley Observation Nursery from $1996-97$ were planted during 1998-99 crop season. The International Barley Observation Nursery (MRA) was planted in Kandahar province, the International Barley Observation Nursery (LRA) and the International Barley Yield Trial (LRA) for cool winter areas were planted in Ghazni and International Barley Yield Trial (LRA) mild winter was carried in Herat province.

\section{Methods and Materials}

National barley yield trials (97NBYT) were conducted in Nangrahar, Kandahar. Herat. Balkh, and Takhar and Kunduz provinces. Ten varieties were tested in RCBD design with four replications. There were 6 rows per plot and the row length was 5 meters. The row to row distance was $25 \mathrm{~cm}$. Seed rate was $100 \mathrm{~kg} / \mathrm{ha}$, the fertilizer rate was $100 \mathrm{~kg} / \mathrm{ha}$ of nitrogen and $60 \mathrm{~kg} / \mathrm{ha} \mathrm{P} 205$. The $20^{\text {th }}$ international barley yield trial was designed in RCBD in 2 replications. Each replication contained 25 lines. There were 6 rows per plot, with a row length of 2.5 meter and row spacing of $25 \mathrm{~cm}$. During 1998-99 the national barley yield trial in Nangarhar, Kandahar, Farah, Kunduz, and Takhar provinces were carried out on using the same design and procedures as 1997-98. The International barley yield trial- low rainfall areas was conducted in Kandahar, Herat, and Ghazni provinces. This trial had 24 lines replicated three times. The number of rows per plot were 6 , row length of 2.5 meter and row spacing of $25 \mathrm{~cm}$ was used. The fertilizer dose was $20 \mathrm{~kg} \mathrm{~N}$ and $20 \mathrm{~kg} \mathrm{P} 2 \mathrm{O} 5 / \mathrm{ha}$. Four middle rows with an area of $2.5 \mathrm{~m} 2$ were harvested for yięld. 
The international facultative barley yield trial had 24 lines in 3 replication. It was planted in Balkh province. The plot size was 6 rows, $30 \mathrm{~cm}$ apart with row length of 2.5 meters. The International Winter and Facultative Forage Barley Observation nursery contained 46 lines. The plot size for this trial was 2 rows 2.5 meters long with $25 \mathrm{~cm}$ spacing between the rows. The International Barley Yield Trial (low and moderate rainfall areas) cool and mild winter were planted in 3 replications. Each trial consisted of 24 lines and were conducted in Kandahar, Herat and Ghazni provinces. The plot size was 6 rows, 2.5 meters long and $25 \mathrm{~cm}$ apart. The rate of the fertilizer was $20 \mathrm{~kg} /$ nitrogen and $20 \mathrm{~kg}$ /ha of P2O5. The International Barley Observation Nursery (LRA) cool winter had 105 lines. The $6^{\text {th }}$ International Winter and Facultative Barley Yield Trial consisted of 24 lines in 3 replications. The fertilizer rate was $100 \mathrm{~kg}$ nitrogen and 60 $\mathrm{kg}$ P2O5 ha. The plot size was 6 rows, 2.5 meters long and $25 \mathrm{~cm}$ apart. International Barley Observation Nursery (MRA) planted in Kandahar consisted of 98 lines. There were 2 rows, 25 $\mathrm{cm}$ apart and 2.5 meters long. The International Barley Yield Trial (MRA) that was planted in Kandahar had 24 lines replicated 3 times. The plot size was 6 rows, 2.5 meters long and $25 \mathrm{~cm}$ apart. The rate of fertilizer was $20 \mathrm{~kg}$ nitrogen and $20 \mathrm{~kg}$ of $\mathrm{P} 2 \mathrm{O} 5 / \mathrm{ha}$.

\section{Results and Discussions}

The data of each experiment was analyzed separately for 1997- 98 and 1998 -99 using MSTAT Statistical Package. The analysis of the variances (ANOVA) for yield (MT/ ha) combined over locations of 10 barley and 25 barley lines tested in (98 NBYT1) in 1997-98 showed highly significant differences between locations, genotypes and genotype by environment interactions (Table 4 and 5 Annex 5). This shows the different responses of each line to agro-climatic condition of test site. The mean yield in $\mathrm{kg} / \mathrm{ha}$, overall, and rank of 10 barley lines tested in (97NBYT) in six locations is summarized in (Table 1, Annex 5). In Nangarhar province the mean yields of lines 1, 2, 3, 4, 6 and 8 were significantly higher than the others. The highest yield was produced by lines $8(4534 \mathrm{~kg} / \mathrm{ha})$ followed by line $1(4430 \mathrm{~kg} / \mathrm{ha})$ and line $6(4332 \mathrm{~kg} / \mathrm{ha})$ with ranking of 1,2 and 3 respectively. The yield advantages of these three lines over the local check are $123 \%, 118 \%$ and $113 \%$.

In Kandahar province the highest yield was recorded for line $3(4018 \mathrm{~kg} / \mathrm{ha})$ followed by line I (3890 kg /ha). The yield increase of these lines over local check $(3875 \mathrm{~kg} / \mathrm{ha}$ ) was $4 \%$. In Herat province no significant yield differences were observed between the mean yields of lines 1, 3, 4 and 9 . However, the highest yield $(6944 \mathrm{~kg} / \mathrm{ha})$ was recorded for line 4 followed by lines 3 $(646 \mathrm{lg} / \mathrm{ha}$ ) and line I (6378 $\mathrm{kg} / \mathrm{ha})$. These yields are $170 \%, 151 \%$ and $150 \%$ higher than the local check $(2572 \mathrm{~kg} / \mathrm{ha})$. In Balkh province the highest yields were produced by lines 8 $(5781 \mathrm{~kg} / \mathrm{ha})$, line $1(5620 \mathrm{~kg} / \mathrm{ha})$ and line $4(5219 \mathrm{~kg} / \mathrm{ha})$. These yields are not significantly different from each other but, they are $37 \%, 33 \%$ and $23 \%$ higher than the local variety (4227 $\mathrm{Kg} / \mathrm{ha}$ ).

In Takhar province lines 2 to 9 produced significantly higher yields than line 1 and 10 . The highest yields were produced by line $7(3590 \mathrm{~kg} / \mathrm{ha})$ and $9(3500 \mathrm{~kg} / \mathrm{ha})$. These yields are 103 $\% .99 \%$, and $98 \%$ higher than the yield of the local check $(1770 \mathrm{~kg} / \mathrm{ha})$. In Kunduz province the highest mean, yield was recorded for lines 3 and 6 (3594 kg/ ha) followed by lines 7 (3375 kg / ha), $9(3250 \mathrm{~kg} / \mathrm{ha})$ and I $(3200 \mathrm{~kg} / \mathrm{ha})$. These yields are not significantly different from each other. However, they are $87 \%, 69 \%$ and $66 \%$ higher than the local check (1925 kg / ha).

When the yields were averaged over locations, it showed that lines 3,4 , and 1 ranked 1,2 and 3 with yields of $4212 \mathrm{~kg} / \mathrm{ha}, 4242 \mathrm{~kg} / \mathrm{ha}$. and $4196 \mathrm{~kg} / \mathrm{ha}$. These yields are $58 \%, 55 \%$ and 53 $\%$ higher than the local check. 
Stripe and leaf rust response of 10 barley lines tested in (97 NBYT) in different locations in Afghanistan are shown in (Table 2. Annex 5). In Balkh province the disease data is not recorded .The barley variety Rihane- 03 in Herat and Takhar provinces showed a reaction of $90 \mathrm{~S}$ and $10 \mathrm{~S}$ to stripe and leaf respectively. All the other lines are resistant to both rusts.

The mean yields, overall mean yields and rank of 25 barley lines tested in (20th- IBYT) in Nangarhar, Kandahar, Herat, Khost, and Takhar provinces are summarized in ( Table 3. Annex 5 ). Based on the overall mean, 5 top yielding lines were selected for further testing during 1998-99 growing season.

The mean yield (kg/ha) and rank of 10 barley lines tested in (98NBYTl) in 5 locations during 1998-99 is summarized in Table 4, Annex 5. The data shows that in Nangarhar province there is no significant difference between the mean yield of lines $1,2,3,4,5,7$ and 8 . All produced significantly higher than lines 6 and 10 .

In Kandahar province the highest yield was produced by line 1, but this yield falls in the same category of significance with lines $2,5,6,8$ and 10 . The yields of these lines are significantly higher yields than the yields of lines $3,4,7$, and 9 .

In Farah province line 8 produced the highest yield ( $2729 \mathrm{~kg} / \mathrm{ha}$.) but this yield is not significantly higher than the yields of lines $1,2,3,5$, and 9 . These lines produced higher yield than lines $4,6,7$, and 10 the local check.

In Kunduz province, there is no significant difference between the mean yield of lines 1, 2, 3, 5 , $6,8,9$, and 10 the local check, but these lines produced significantly higher yield than lines 4 , and 7 . In Takhar province this experiment was conducted under rain-fed situation, therefore their yields are less than other locations. The highest yield (1788 kg/ ha) was produced by line 9 . This yield is not significantly higher than the mean yield of the lines 5,8 , and 10 local check. They produced significantly higher yields than $1,2,3,4,5,6$, and 7 . The line 4 produced the lowest amount of yield.

When the mean yield data of the 5 locations was combined. line 1 with the mean yield of $3113 \mathrm{~kg}$ /ha, line 8 with the mean yield of $2965 \mathrm{~kg}$ /ha and line 9 with the mean yield of $2963 \mathrm{~kg} / \mathrm{ha}$ ranked 1, 2 and 3 respectively. They yielded $17 \%, 11 \%$ and $10.9 \%$ higher yields than local check. The mean yield of the line 5, 6. and 2 are higher than the site mean and the local check by $9 \%$.

The mean yield ( $\mathrm{kg} / \mathrm{ha}$ ) of 24 barley lines which were tested in International Barley Yield TrialLow Rainfall Areas (IBYT-LRA) mild winter in Kandahar, Herat, and Ghazni provinces of Afghanistan is summarized in Table 5, Annex 5. In Kandahar the highest mean yield of $7327 \mathrm{~kg}$ /ha was produced by line 16 , followed by the lines 22 and 14 with the mean yield of $7324 \mathrm{~kg} / \mathrm{ha}$. and $7283 \mathrm{~kg}$ /ha respectively. In Herat line 16 also gave the highest yield, followed by lines 17 and 21 with mean yields of $2145 \mathrm{~kg}, 2041 \mathrm{~kg}$ and $1987 \mathrm{~kg} / \mathrm{ha}$ respectively. In Ghazni province line 21 with the mean yield of $1044 \mathrm{~kg} / \mathrm{ha}$, line 4 with the mean yield of $1011 \mathrm{~kg} / \mathrm{ha}$ and line 24 with the mean yield of $1011 \mathrm{~kg} / \mathrm{ha}$ ranked 1.2 and 3 respectively.

When the mean yield of these 3 locations were combined, it revealed that line 16 with the mean yield of $3283 \mathrm{~kg} / \mathrm{ha}$, line 20 with the mean yield of $3139 \mathrm{~kg} / \mathrm{ha}$ and line 21 with the mean yield of $3128 \mathrm{~kg} /$ ha ranked 1,2 , and $3^{\text {rd }}$ respectively. These lines produced 28,22 , and $21 \%$ more yield than the local cheç. 
In Ghazni province the $6^{\text {th }}$ International Winter and Facultative barley yield trial from 1996-97 crop season was planted in 1998-99. The mean yield (kg/ha) is presented in (Table 8, Annex 5). The highest mean yield (9156 kg /ha) was produced by line 19 followed by lines $14(9133 \mathrm{~kg} / \mathrm{ha})$ and $6(9044 \mathrm{~kg} / \mathrm{ha})$. The local check produced the mean yield of $(6956 \mathrm{~kg} / \mathrm{ha})$ These lines have respectively produced $32 \%, 31 \%$ and $30 \%$ more yield compared to the local barley. The top yielding lines from this trial are selected for further testing in 1999-2000 trials.

\section{Recommendation}

The overall mean yields of the 3 years, 9 locations and 17 national barley yield trials were combined. The data showed that the varieties Hewad 98 and Watan 98 and LIRAN /UNA $80 / /$ LIGNEE are the top yielding varieties. These genotypes are resistant to yellow rust and leaf rusts. They produced as an average 24,23 and $21 \%$ higher yields than the local variety $(3320 \mathrm{~kg}$ ha). The barley varieties Watan 98 and Hewad 98 are adapted well in the barley growing areas of the country and are recommended for release and multiplication in Afghanistan. 


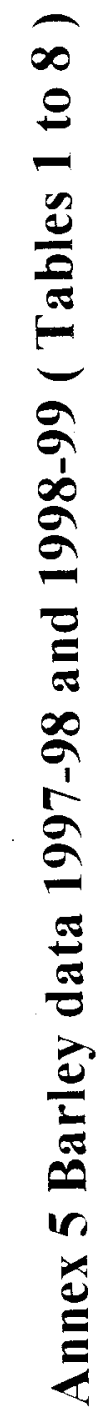




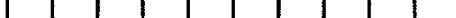




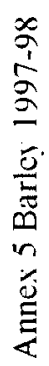

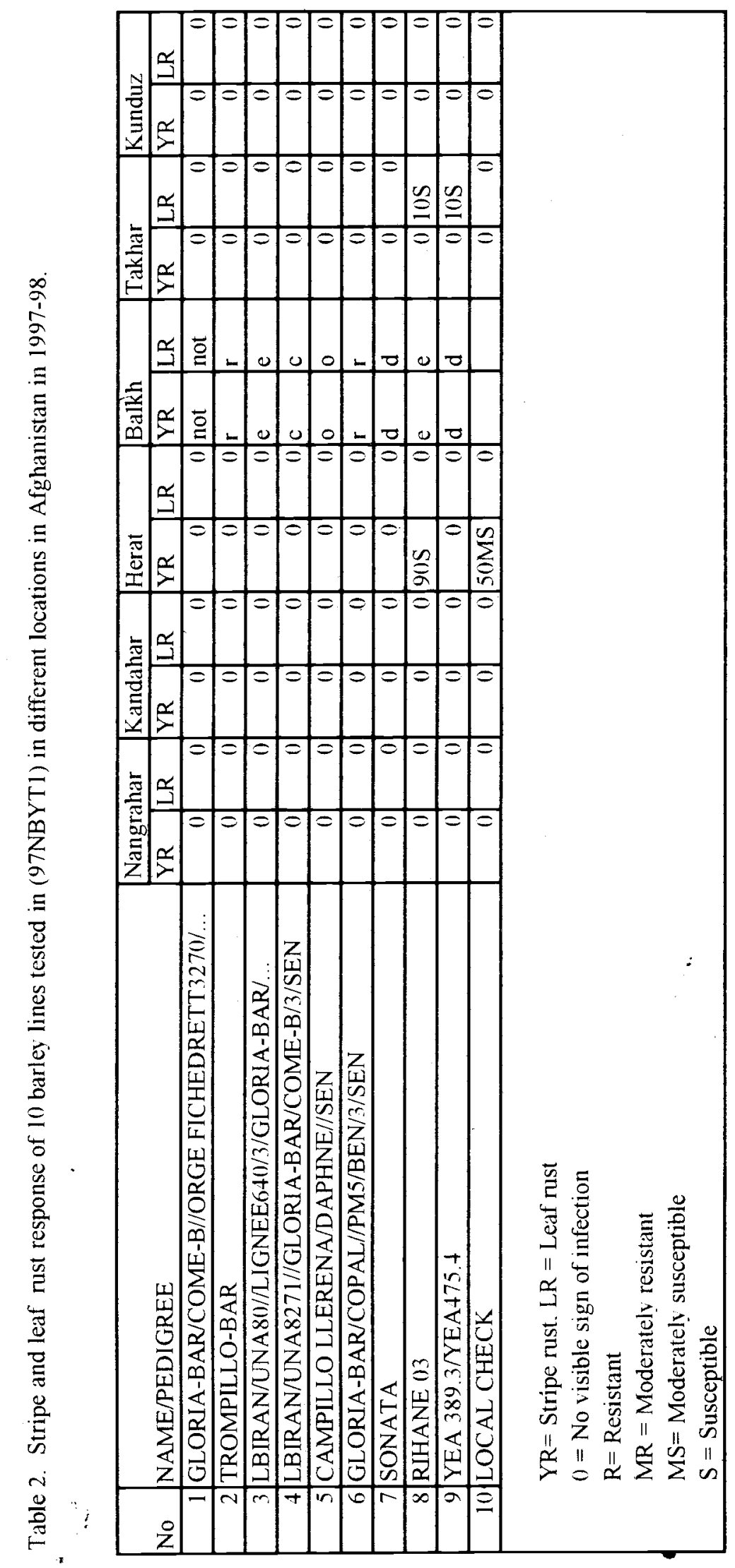




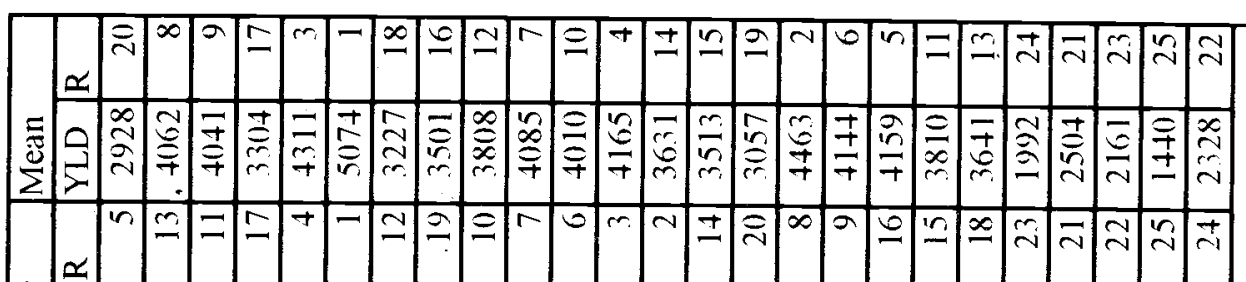

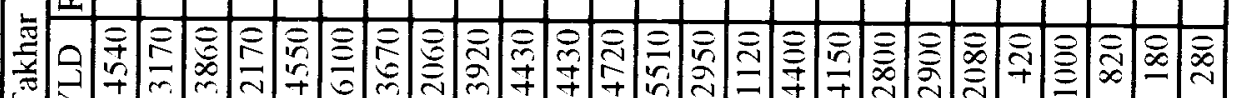

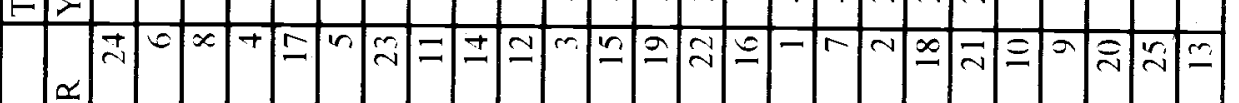

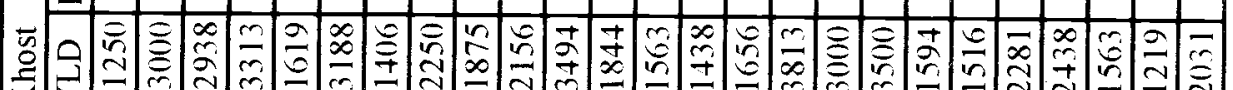

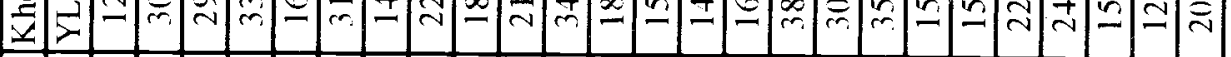

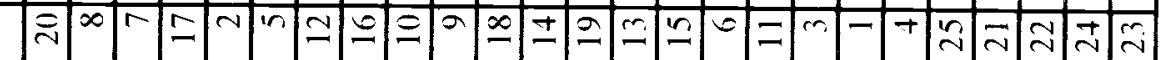

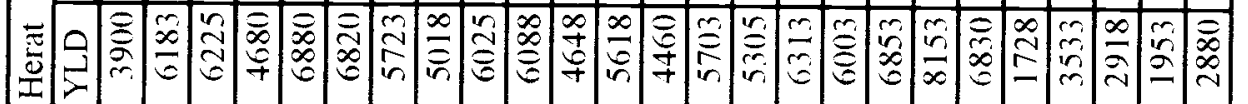
뜽

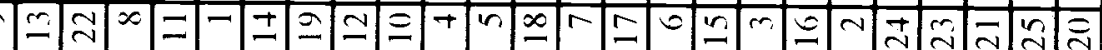
苞田

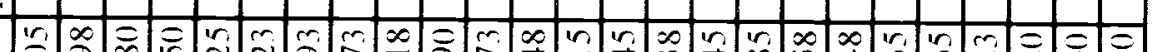

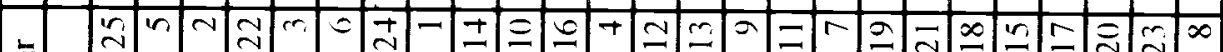
氞

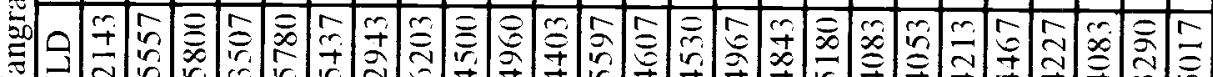

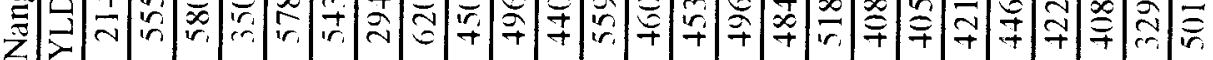

$+\div \quad+\frac{3}{2}$ 


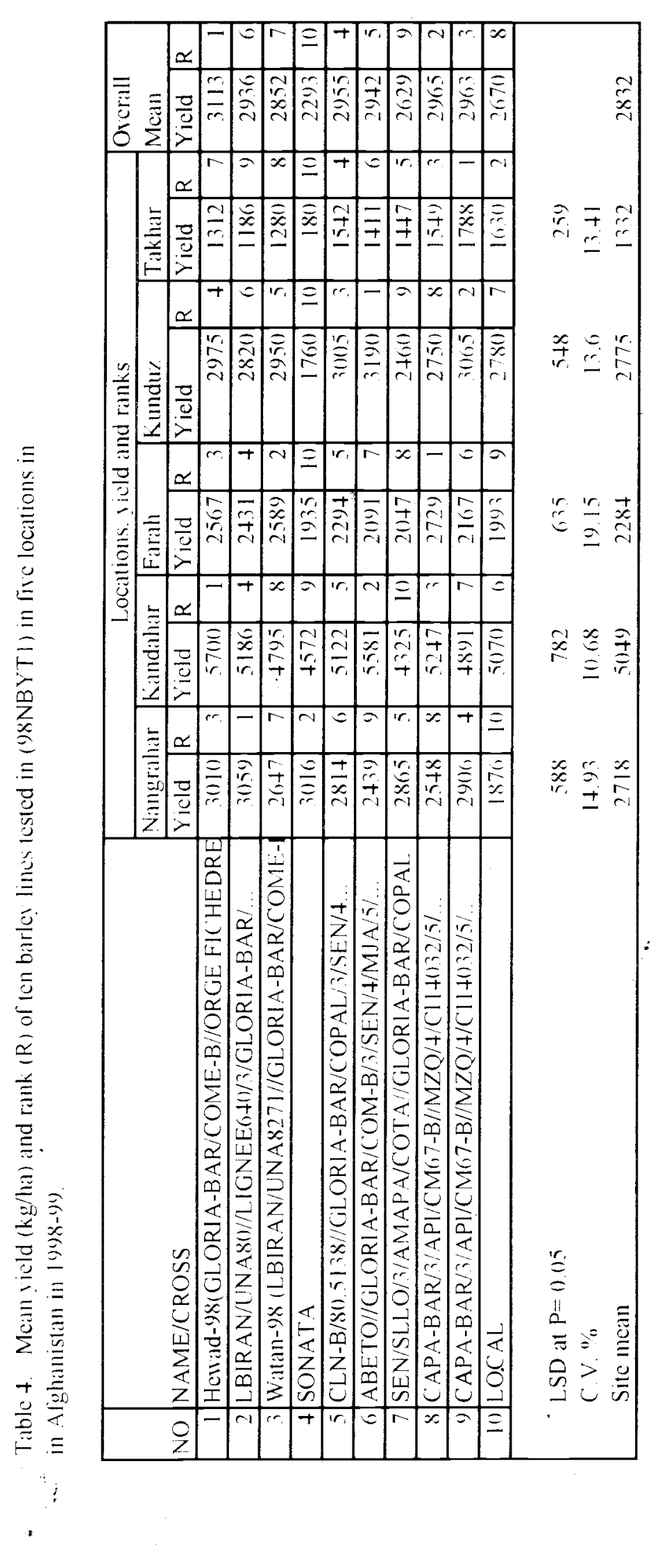




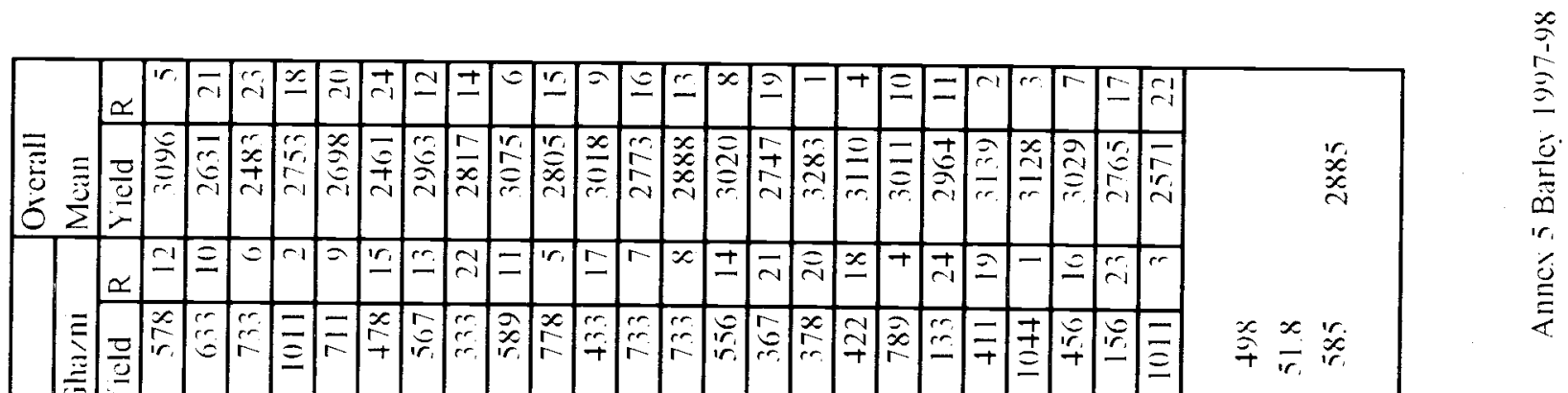

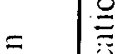

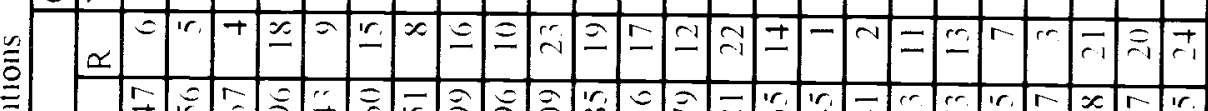

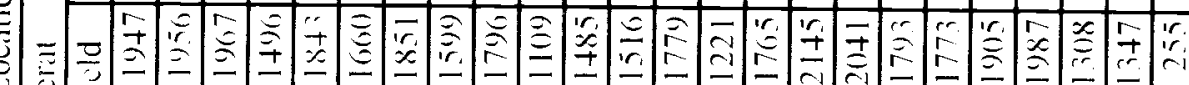

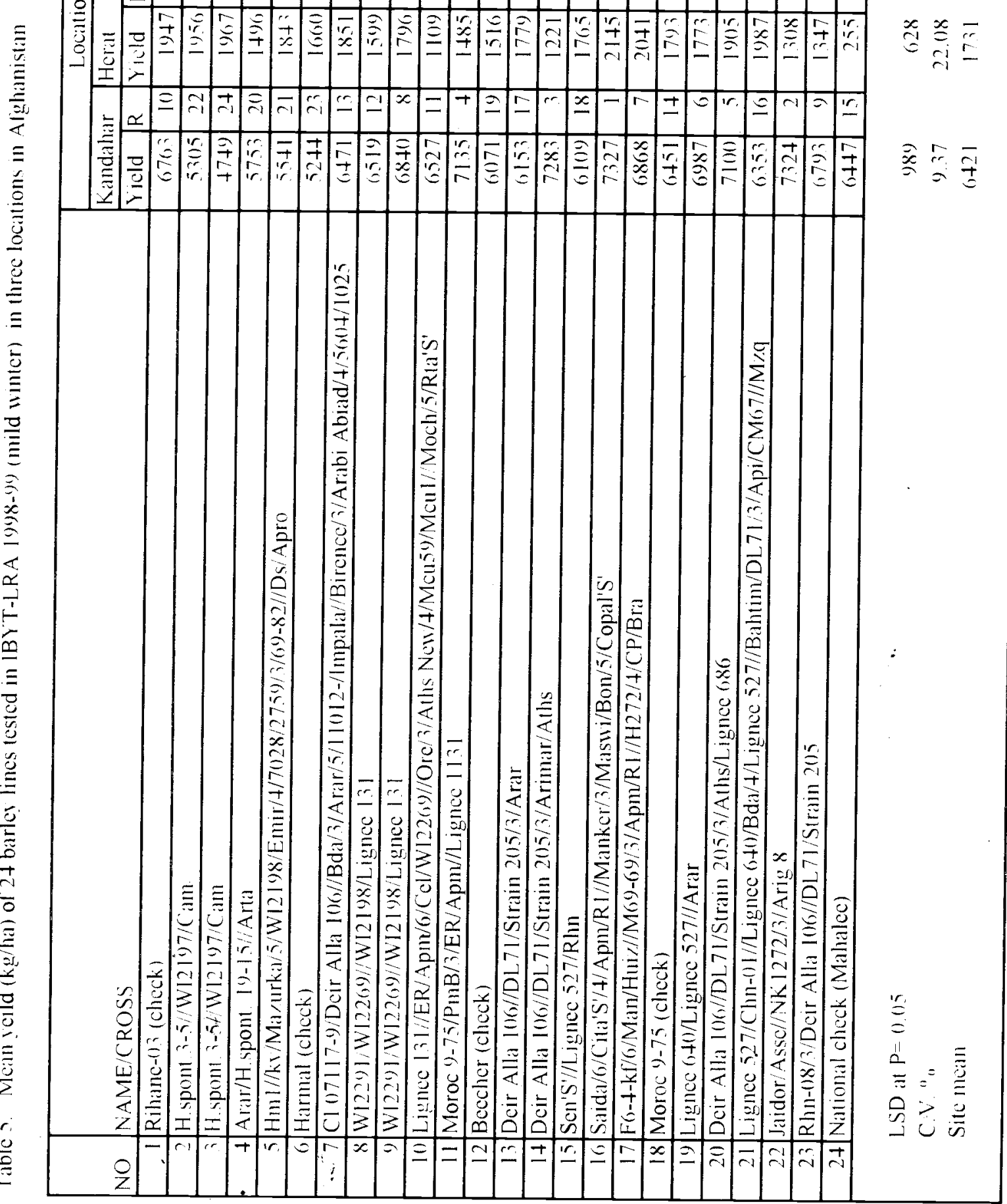




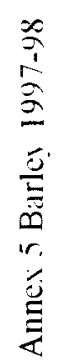

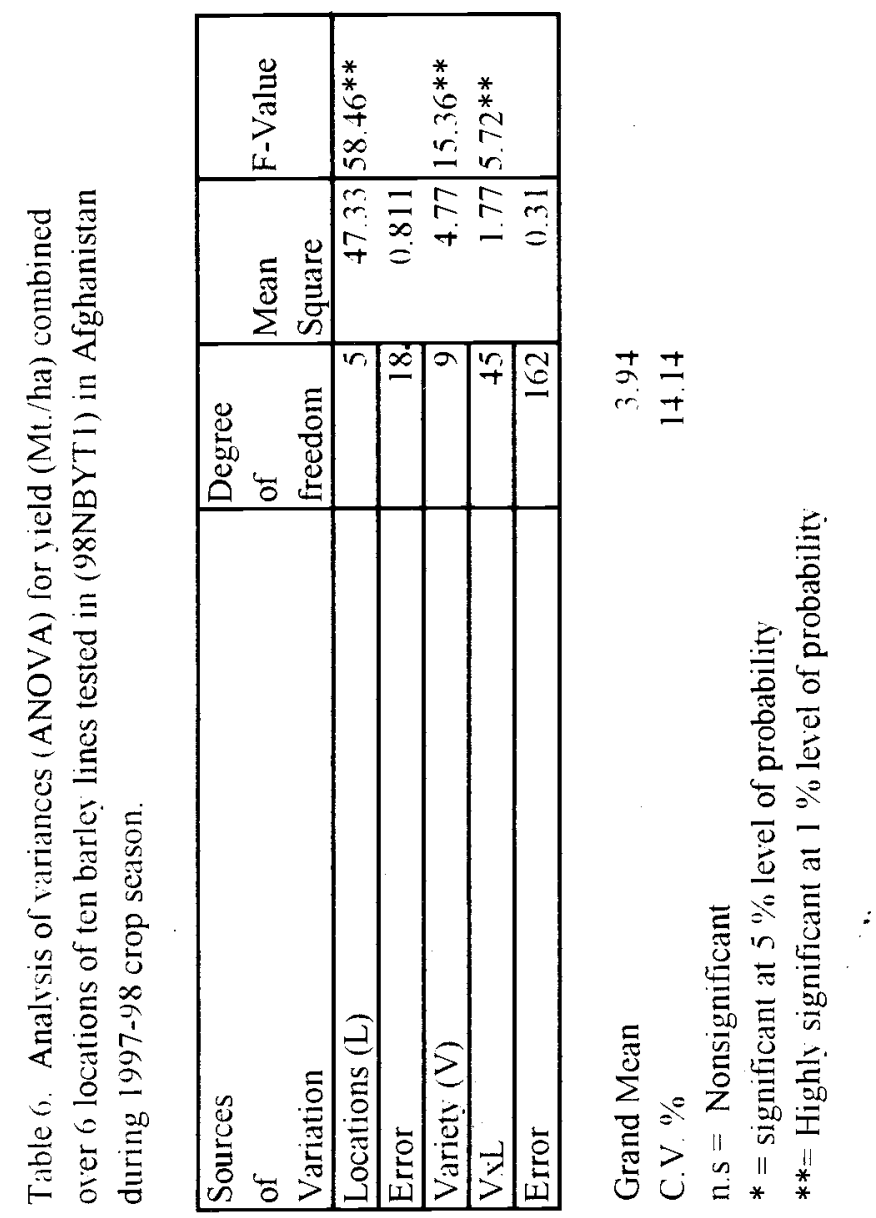




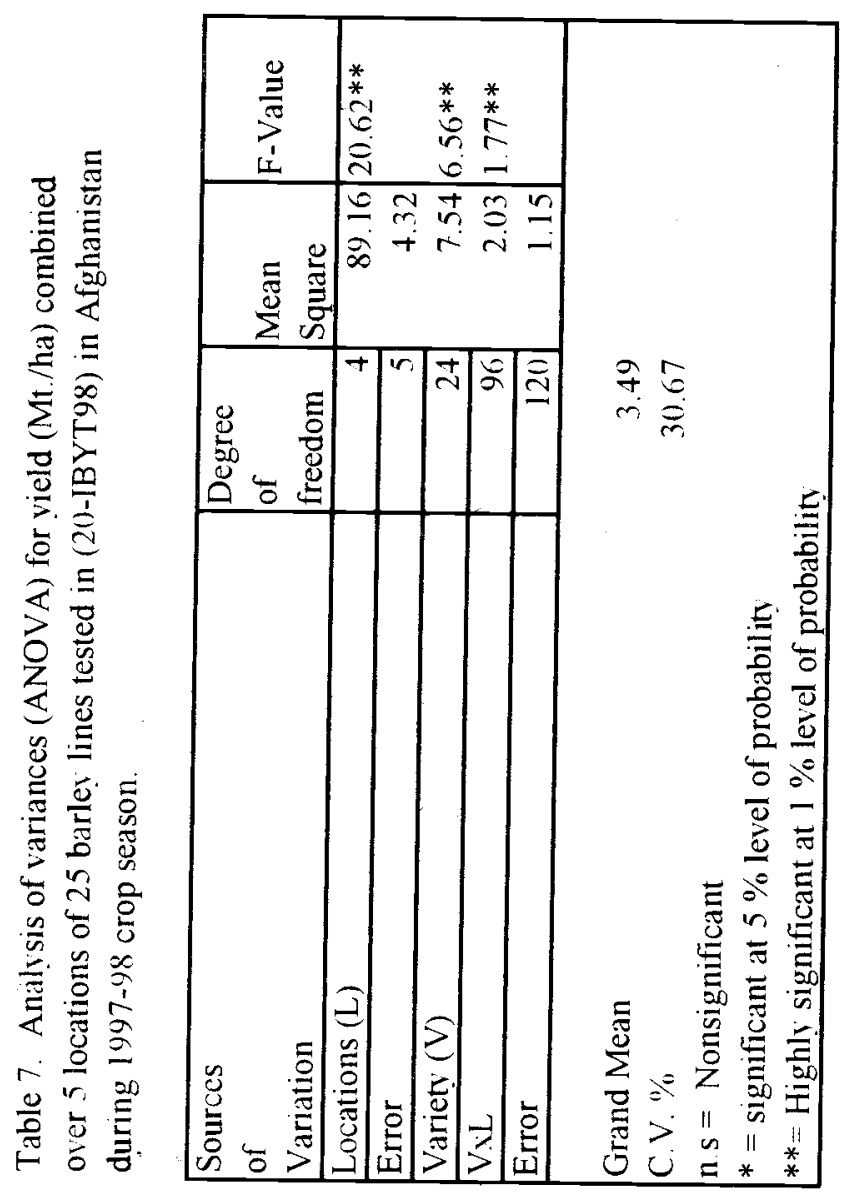




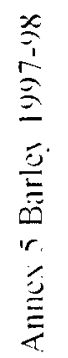

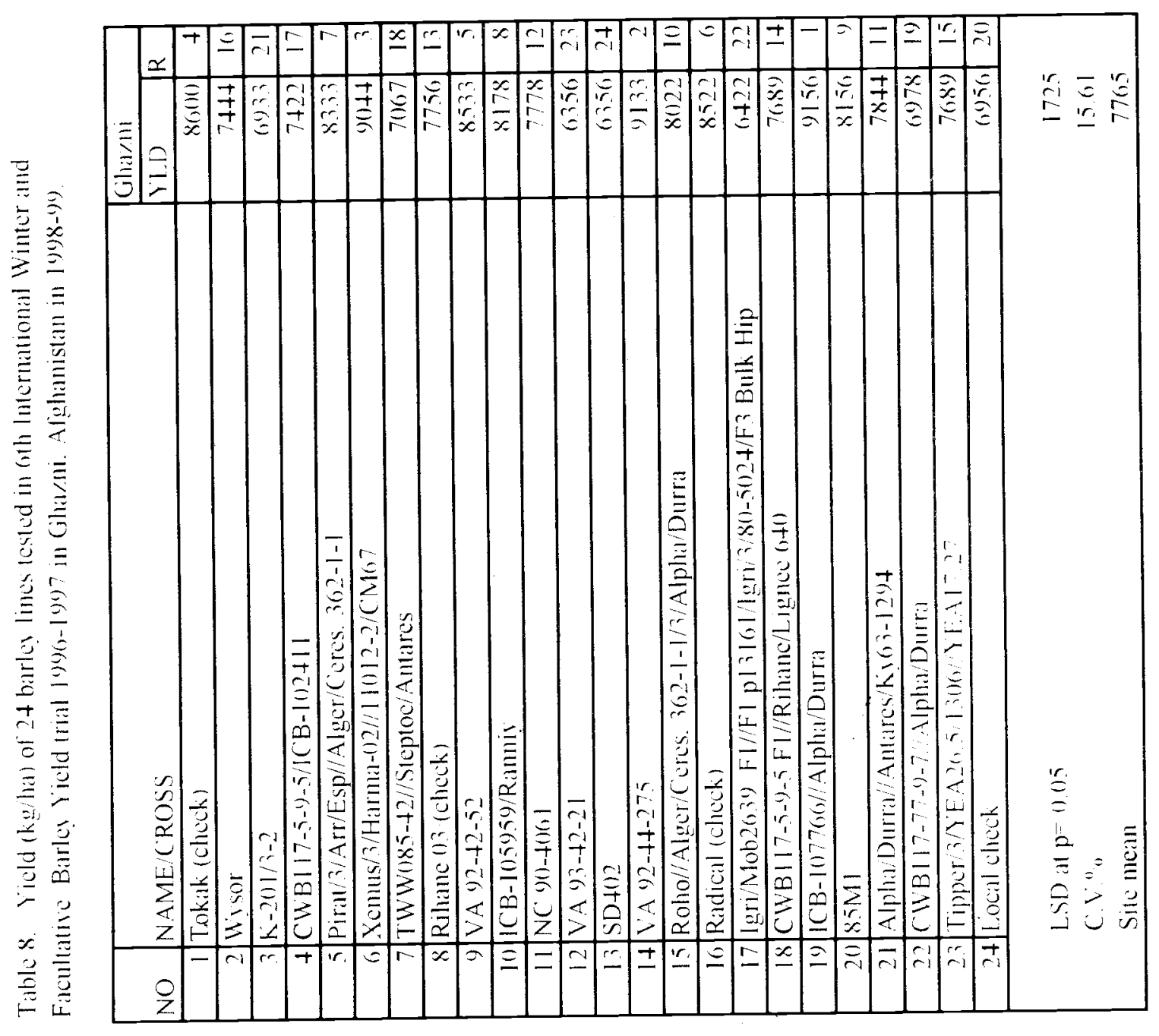




\section{Food Legumes Variety Selection}

\section{Introduction}

Pulses are rich in protein and are important as food crops in Afghanistan. Because of the long civil conflict in the country large numbers of animals (sheep. goat and cattle) were killed. In order to avoid malnutrition and supply nutritious and protein rich diet. it is necessary to work on selection of improved varieties of food legumes in the country. The important food legumes crops in Aghanistan are chichpea. beans. Mung beans. broad beans and lentil. Among the pulses chickpea and lentil are grown under irrigation and rain-fed situations and large areas are under these two crops, while beans, broad beans and Mung beans are grown only under irrigated conditions. In Kunar and Nooristan provinces dry beans (Phaseolus vulgaris) are grown as companion crop with maize (Zea mans). Mung bean is also cultivated as mised crop or in monoculture.

The average yield of the pulses is very low in Afghanistan and is about $0.5 \mathrm{MT} / \mathrm{ha}$. Any improvement in yield per unit area of food legumes crops will contribute significantly to the welfare of Afghans. FAO crop improvement project AFG/94/A02 (UNO/AFG/00 1/DPS) during 1997-99 conducted a number of trials on different food legumes chickpea ( (icer corierimmm). lintel ( leens culinuris), beans ( Phaseolus vulgaris). and Mung beans ( Vigna mungo). in different locations in the country under both rain-fed and irrigated situations to identify high yielding lines for multiplication and further testing in the country for 2000 crop season.

\section{Methods and Materials}

During 1998 four beans variety trials, one Mung bean variety trial. ten chickpea trials. one pea trial, and four lentil variety trials. and in 1999 crop season 3 bean trials, one pea trial, and 3 lentil variety trials were conducted in different agro-climatic conditions in $A$ fghanistan. The purpose of these trials was to find high yielding. stress resistant lines for release as new varieties.

Dry bean (Phaseolus vulgaris) lines of pinto, nay, and hidney types were arranged in R(BD) design with 4 replications. There were 10 lines in each replication, with 4 rows in each plot. The row length was 2.5 meters, the spacing between row was $40 \mathrm{~cm}$ and plant to plant spacing " 10 $\mathrm{cm}$. The amount of the fertilizer was $125 \mathrm{~kg}$ DAP/ha. Only the kidney bean trial consisted of 15 lines. These trials were conducted in Herat. Nangarhar. and (ihazni provinces of Afghanistan during 1998 and 1999.

The national, advanced and chickpea preliminary yield trials were arranged in RCBD design. There were 4 replications with 10 entries in each replication. Each plot was consisted of with 6 rows. The row length was 4 and 2.5 meters. The distance between the row was $45 \mathrm{~cm}$ and between plant to plant 1 as $10 \mathrm{~cm}$. The fertilizer rate was 40 nitrogen and $30 \mathrm{~kg} \mathrm{P} 205 / \mathrm{ha}$. Similarly chickpea international yield trials ICARDA were planted in different locations of Afghanistan during 1988 and 1999 crop season.

During 1998 one pea (Pismm sativum) trial from ICARDA was tested in Takhar and Nangarhar provinces. Ten selections from this trial were planted in 1999 in Baghlan province. The design of the experiments in both years was randomized complete block design $w$ ith + replications. The row length was 4 meters and row width was $30 \mathrm{~cm}$ in 1998 and $60 \mathrm{~cm}$ during 1999 growing period. The plant to plant space was $10 \mathrm{~cm}$. The fertilizer rate was $30-\mathrm{kg}$ nitrogen and $40 \mathrm{~kg}$ P205/ha. 
1.entil trials were conducted in Takhar, Kunduz. Herat, and Nangarhar provinces of Afghanistan during 1998, but in 1999. it was conducted in Baghlan under rainfed situation and in Balkh province under irrigated conditions. The design of the experiments was randomized complete block design with 4 replications. The national yield trial, cold tolerance yield trial, and lentil preliminary s ield trials consisted of 10 entries in both years. There were 6 rows with 4 meters length. The distance between row was $25 \mathrm{~cm}$ and the plant to plant space $w$ as $2 \mathrm{~cm}$. The fertilizer rate was 40-kg nitrogen and $30 \mathrm{~kg}$ P2O5 /ha. The (LIYT-98) conducted in Takhar and Nangarhar provinces and lentil drought tolerance trial (LDTl-99) conducted in Baghlan province consisted of 25 lines each. L.DTT-99 was carried out under rainfed situations. The number of replications "were 3 during 1998 and in 1994 crop season it was planted in 2 replications. The number of rows was $t$ in 1998 and one in 1999. The row length was 4 meters and row spacing of $25 \mathrm{~cm}$. The amount fertilizer was 40 nitrogen and $30 \mathrm{~kg} \mathrm{P205/ha.} \mathrm{The} \mathrm{trials} \mathrm{were} \mathrm{hand} \mathrm{weeded} \mathrm{when} \mathrm{during}$ the growing season. Yield per plot was in gram and converted into $\mathrm{Kg} / \mathrm{ha}$. The data of each experiment was analyzed using MASTAT Statistical Package.

\section{Results and Discussions}

\section{Beans (Phaseolus vulgaris) 1998}

lable I. Annex 6 shows the mean yield ( $\mathrm{kg} / \mathrm{ha}$ ) of 10 beans lines tested in Herat province. The data indicates that the highest yield was obtained from line $7(1775 \mathrm{~kg} / \mathrm{ha})$. This yield is significantly higher than the yields of lines 8 and 9 with mean yields of (789 $\mathrm{kg} / \mathrm{ha})$ and $(1160$ $\mathrm{k} g$ ha) respectively. The second and third highest yields were produced by line $2(1677 \mathrm{~kg} / \mathrm{ha})$ and line $5(1644 \mathrm{~kg} / \mathrm{ha})$. The local lines 10 produced $(1601 \mathrm{~kg} / \mathrm{ha})$. These lines produced 10.5 and $3 \%$ more yeld than the local line.

Ihe ! icld data of pinto beans from. Agam district of Nangarhar province revealed that the highest yick was produced by line $5(4930 \mathrm{~kg} / \mathrm{ha}$ ) but this yield is not significantly higher than the yield of lines ? (4678 kg/ha). 9 (4486 kg/ha). 8 (4389 kg/ha). 3 (4000 kg/ha) and 10 (3867 kg/ha). Howere lines 5.7 and 9 produced 27.21 , and $16 \%$ more yield than the local line (Table 2 . Ammer 6). These yields under irrigated conditions are very good.

The mean yield (kg/ha) and rank of 10 white bean lines is shown in (Table 3. Annex 6). No significant : ield differences were observed, but the highest yields were produced by lines 2 (2264 hgha). I (2083 kg ha) and $8(2028 \mathrm{~kg} / \mathrm{ha}$ ). The local check yielded (1694 kg/ha). These lines produced 3. 2.3. and $20 \%$ higher yield than the local check respectively. Table 4 Annex 6 summarises the mean yeld (kg/ha) and rank data of 15 kidney bean in the same location. It revealed that the highest vield was produced by the local $(1630 \mathrm{Kg} / \mathrm{ha})$. This yield is significantly higher than the vield of others dines. The reason for these was that most of the introduced lines were damaged during shipping and had poor germination.

The mean yield (kg ha) and rank of 9 Mung bean lines in Nangarhar showed that the local line "wth the mean yeld of (2209 $\mathrm{kg} / \mathrm{ha}$ ) produced the highest yeld(Table 5 . Annex 6). But th is yield is not signilicantly different fiom the mean sield of the other lines. The $1 . \mathrm{SD}$ ) at $0.05 \% \mathrm{C.V}$. of this trial ale wery high. The project did not have aceess to superior genotypes of this crop. If local germplasm is collected and evaluated, the chances are high to identifying superior material. 


\section{2- Chickpea (Cicer arietinum) 1998}

Table 6. Amnex 6 shows the mean yield ( $\mathrm{kg} / \mathrm{ha}$ ) and rank of 10 chickpea lines in Takhar province. The highest mean yield was produced by line $1(2861 \mathrm{hg} / \mathrm{ha})$. This yield is not significantly more than the yields of line $5(270+\mathrm{kg} / \mathrm{ha})$. line $4(2595 \mathrm{~kg} / \mathrm{ha})$. line $7(2365 \mathrm{~kg} / \mathrm{ha})$ and line $6(2177$ $\mathrm{kg} / \mathrm{ha}$ ). However lines 1.5 and 4 produced 82,74 , and $65 \%$ higher y ield than the local chect.

In Kunduz province the highest was produced by line 8 (1683 $\mathrm{kg} / \mathrm{ha})$. This yeld is significantly higher than the yield of line $3(813 \mathrm{~kg} / \mathrm{ha}$ ) and the local check ( $1151 \mathrm{~kg} / \mathrm{ha})$. I.ines $2(1662 \mathrm{~kg} / \mathrm{ha})$ and $7(1571 \mathrm{~kg} / \mathrm{ha})$ ranked $2^{\text {nd }}$ and $3^{\text {ril }}$ respectively. These lines produced $+6,44$ and $36 \%$ more yicld in comparison to the local check.

In Balkh province the highest yield was obtained by line $7(226+\mathrm{kg} / \mathrm{ha})$ followed by line $6(2180$ $\mathrm{kg} / \mathrm{ha})$ and line $4(2128 \mathrm{~kg} / \mathrm{ha})$. These yield were significantly higher than the vield of line 3 (160) kg/ha). The local check yielded (1914 kg/ha). In comparison to the local chech. these lines vielded 18.14 , and $11 \%$ higher yields.

In Herat province under irrigated situations the highest yield was produced by line $8(1758 \mathrm{~kg} / \mathrm{ha})$. This yiek is not significantly higher than the yields of lines $7(1451 \mathrm{~kg} / \mathrm{ha}), 9$ $(1675 \mathrm{~kg} / \mathrm{ha})$ and $10(167 \mathrm{hg} / \mathrm{ha})$ respectively. Line 8 produced $5 \%$ more yield than the local check.

Inder rain- fed condition in Iterat province the highest yield was obtained by line

\& $(3117 \mathrm{~kg} / \mathrm{ha})$. followed by line 10 the local check $(3108 \mathrm{~kg} / \mathrm{ha})$. These velds are significantly higher than the yields of lines $3(2287 \mathrm{~kg} / \mathrm{ha})$ and $8(2318 \mathrm{~kg} / \mathrm{ha})$ respectively. The performance of these lines under rainfed conditions can be very good when the rans are distributed evenly. When the mean yield of 5 locations were combined the overall mean showed that line $4(2095$

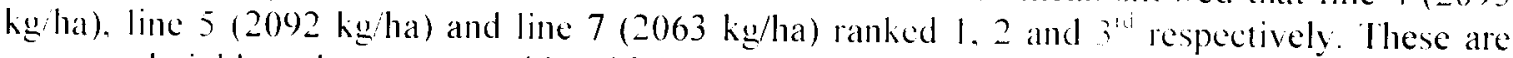
very good yields and are comparable with best yielding material else where.

The mean yicld ( $\mathrm{kg} / \mathrm{ha}$ ) and rank of 10 chickpea tested in (98AC $\mathrm{YT} 1)$ in 2 locations is presented in (lable 7. Annex 6). In Takhar province it slowed that there is no significant difference between the yield of these lines. However the highest yeld was obtained from lines 6 (3+76 $\mathrm{kg} / \mathrm{ha})$. followed by lines $2(3452 \mathrm{~kg} / \mathrm{ha})$ and $8(3349 \mathrm{~kg} / \mathrm{ha})$. These lines produced 50.49 . and 44 $\%$ higher yields than the local check. In Kunduz province no significant y ield differences were noticed between the mean yields of lines 1, 3, 4, 5, 7. and 8 . The highest yeld was obtained by 8 (2049 kg/ha) followed by line $5(1956 \mathrm{~kg} / \mathrm{ha})$ and line $1(1772 \mathrm{~kg} / \mathrm{ha})$. While the local line gave the mean yield of (1236 kg/ha). These lines showed vield advantage of 66,58 , and $43 \%$ compared to the local line. From the data it can be concluded that Takhar is a suitable site for chichpea. The 2 locations combined data showed that line 8 "ith overall mean vield of (2699 $\mathrm{hg} / \mathrm{ha})$, line 1 with $(2248 \mathrm{~kg} / \mathrm{ha})$ and line 6 with $(24+1 \mathrm{~kg} / \mathrm{ha})$ ranked 1.2 and $3^{\text {id }}$ respectively These lines out yielded the local line $(1779 \mathrm{~kg} / \mathrm{ha})$ by 52.38 , and $37 \%$ respectivel:

Table 8. Annex 6 shows the mean yield ( $\mathrm{kg} / \mathrm{ha}$ ) and rank of 10 chickpea lines tested in (98P(Y (T1) in Takhar. The highest yield was obtained by line $9(4271 \mathrm{~kg} / \mathrm{ha})$. linc $3(3989 \mathrm{~kg} / \mathrm{ha})$ and line $8(3969 \mathrm{~kg} / \mathrm{ha})$. These yields ranked 1.2 and $3^{\text {red }}$ respectively. Compared to local check $(3750 \mathrm{hg} / \mathrm{ha}$ ) these lines gave 14,6 , and $5 \%$ higher yield.

The mean yield ( $\mathrm{kg} / \mathrm{ha}$ ) and rank of 10 chickpea lines tested in (98PCYT2) in Takhar and Kunduz provinces are presented in (Table 9. Annex 6). No significant yield differences appeared between the mean yield of lines 1, 3.4,5.7 and 9, but the highest yield was produced by line $3(3,347$ $\mathrm{kg} / \mathrm{ha})$ and ranked first. Line 5 with the mean yield of $(3139 \mathrm{~kg} / \mathrm{ha})$ and 7 with the mean yietd of $(3+40 \mathrm{~kg} / \mathrm{ha})$ rankẹd 2 and $3^{\text {'d }}$ respectively. In comparison with the local check $(2604 \mathrm{~kg} / \mathrm{ha}$ ). 
these lines produced 29, 21, and $19 \%$ higher yields. In Kunduz prov ince the data revealed that there are no significant differences between the mean yields of these lines. However the highest vield were produced by the lines 1 ( $1808 \mathrm{~kg} / \mathrm{ha}) .9(1785 \mathrm{~kg} / \mathrm{ha})$ and $6(1757 \mathrm{~kg} / \mathrm{ha})$. They ranked 1. 2 and $3^{\text {rid }}$ respectively. These lines yielded 9.7 and $6 \%$ higher than the local line. When the overall mean vield of the 2 locations were combined it showed that. line $3(2526 \mathrm{~kg} / \mathrm{ha})$, line 5 $(2427 \mathrm{~kg} / \mathrm{ha})$ and line $9(2365 \mathrm{~kg} / \mathrm{ha})$ ranked 1. 2. and $3^{\text {rd }}$. These lines produced 18.14 , and $11 \%$ higher yield in comparison to the local check.

Table 10. Annex 6 shows the mean yield and rank of 10 chickpea lines tested in (98 PCYT3) in Takhar province. In this location the highest yield was recorded for local check ( $4368 \mathrm{~kg} / \mathrm{ha}$ ) and ranked 1. While line $4(4222 \mathrm{~kg} / \mathrm{ha})$ and line $9(3881 \mathrm{~kg} / \mathrm{ha})$ ranked 2 and $3^{\text {rd }}$ respectively. The genotypes in this trial are high yielding.

The mean yicld data ( $\mathrm{kg} / \mathrm{ha}$ ) and rank of 10 chickpea lines tested in (98 P( Y T4) in Takhar and Kunduz provinces of Afghanistan is summarized in (Table 11. Annex 6). In Takhar the highest yield was recorded for line $1(3233 \mathrm{~kg} / \mathrm{ha})$ and ranked first. This yield is significantly different from the mean y ield of lines 6.7 .9 and 10 . Line $5(3160 \mathrm{~kg} / \mathrm{ha})$ and line $8(3115 \mathrm{~kg} / \mathrm{ha})$ ranked $2^{\text {ind }}$ and $3^{\text {id }}$ respectively. The local check produced the mean yield of $(2726 \mathrm{~kg} / \mathrm{ha})$. These lines out vielded the local by 19.16, and 14\%. In Kunduz province, no significant yield differences were observed between lines 1-9. I.ines 1,3,5, and 8-10 fall in the same group and their yields are not significantly different from each other. The highest yield was obtained by line $2(1831 \mathrm{~kg} / \mathrm{ha})$ and ranked first. 1 ine 4 gave the mean yield of $(1814 \mathrm{~kg} / \mathrm{ha}$ ) and line 6 with the mean yield of ( 1806 $\mathrm{kg} / \mathrm{ha}$ ) ranked $2^{\text {nit }}$ and $3^{\text {nd }}$ respectively. These lines produced 46.44 , and $43 \%$ higher yield compare to the local check ( $1256 \mathrm{Kg} / \mathrm{ha}$ ). The combined data showed that the highest yield was obtained by lines $4(2428 \mathrm{~kg} / \mathrm{ha}) .1(2425 \mathrm{~kg} / \mathrm{ha})$ and $5(2399 \mathrm{~kg} / \mathrm{ha})$. These three lines yielded 8 . 8 and $7 \%$ higher yield than the overall nursery mean ( $2248 \mathrm{Kg} / \mathrm{ha}$ ). In both locations the local chech was lower yielding than the top producing lines.

The mean yield ( $\mathrm{kg} / \mathrm{ha})$ and rank of 25 spring chickpea lines tested in (CIYT-SP 98) in 3 locations of Afghanistan is tabulated in (Table 12 Annex 6). In lakhar the highest yield was produced by the line $18(4792 \mathrm{~kg} / \mathrm{ha})$ and ranked first. Lines I with mean yield of ( $4536 \mathrm{~kg} / \mathrm{ha})$ and line 2 with mean y ield of ( $4455 \mathrm{~kg} / \mathrm{ha}$ ) ranked $2^{\text {mb }}$ and $3^{\text {th }}$. The local line yielded (4092 $\mathrm{kg} / \mathrm{ha}$ ) and ranked $11^{\text {th. }}$. These lines out yielded the local line by 17,11 , and $9 \%$. The percent increase in vield of these lines over nursery mean ranged from 22 to $14 \%$ but these yicld differences are statistically non significant. In Kunduz province lines $10(1+31 \mathrm{~kg} / \mathrm{ha}) .8(1+22 \mathrm{~kg} / \mathrm{ha})$ and line 22 $(1242 \mathrm{~kg} / \mathrm{ha})$ ranked first. 2nd and $3^{\text {thl }}$ respectively. The local line with the yeld of $(902 \mathrm{~kg} / \mathrm{ha})$ ranked $14^{111}$. In comparison to the local line these lines produced 59.58 and $38 \%$ more yield but these differences are not significant. In Herat the highest yield was obtained by the lines 6 (1670 $\mathrm{kg} / \mathrm{ha}$ ). followed by local check $(1659 \mathrm{hg} / \mathrm{ha})$. These lines ranked $^{\mathrm{h}}$ and $2^{\text {nd }}$ in respectively, but these differences are not significant. These lines produced significantly higher yield than lines 10 , 14. 15 and 16. When mean yield of these locations were combined, it showed that line 6 (229) $\mathrm{kg} / \mathrm{hat})$. line $21(2282 \mathrm{~kg} / \mathrm{ha})$ and $10(2266 \mathrm{~kg} / \mathrm{ha})$ ranked $1^{\prime \prime}, 2^{\text {nd }}$ and $3^{\text {id }}$ respectively. The local line produced (2218 kg/ha). These lines out yielded the local by 3.2 .8 and $2 \%$ and the nursery mean $(2052 \mathrm{Kg} / \mathrm{ha})$ b! 10 to $12 \%$.

Mean yeld and rakk of 25 chickpea lines tested in (CIYT-W-MR -98) in two locations is presented in (Table 13 Annex 6). In Takhar province the top three high lines are 16 ( $4595 \mathrm{~kg} / \mathrm{ha}$ ). $13(4+05 \mathrm{~kg} / \mathrm{ha})$ and $15(4396 \mathrm{~kg} / \mathrm{ha})$ with yeld ranking of 1.2 and $3 \mathrm{rd}$ respectively. The local check produced a mcan yicld of (3929 kg/ha) and ranked 10 . Compared to the local check, these lines produced 17.12, and $11 \%$ higher yield and compared to nursery mean ( $3866 \mathrm{Kg} / \mathrm{ha}$ ) the vield advantage of these three lines ranges from $14 \%$ to $19 \%$. These are cold tolerant lines have 
produced yields between 3 to $4.5 \mathrm{MT}$ per hectare which are the best yields for chickpea. In Herat province these 25 lines have also given good yields but compared to Takhar the yields are $50 \%$ less. There are lines in this trial that have specific adaptation and produced more than 2100 $\mathrm{Kg} / \mathrm{ha}$. In this location lines $22(2273 \mathrm{~kg} / \mathrm{ha}), 21(2251 \mathrm{~kg} / \mathrm{ha})$, and $20(2176 \mathrm{~kg} / \mathrm{ha})$ produced the highest yields and ranked 1.2. and $3^{\text {rd }}$ respectively. The local line gave the mean yield of ( 1627 $\mathrm{kg} / \mathrm{ha}$ ) and ranked $13^{\text {th }}$. These lines out yielded the local line by 40,38 , and $34 \%$ and the nursery mean ( $1684 \mathrm{Kg} / \mathrm{ha}$ ) by $291035 \%$. When the 2 locations yield data was combined, the overall mean and rank showed that lines $16(3144 \mathrm{~kg} / \mathrm{ha}), 22(3125 \mathrm{~kg} / \mathrm{ha})$ and $1(3083 \mathrm{~kg} / \mathrm{ha})$ were the top yielding lines and in both locations the yield differences of these lines were not significantly different from each other. These lines produced 13. 12. and $11 \%$ higher yield compared to the local check and $11 \%$ to $13 \%$ higher yield compared to nursery mean ( $2775 \mathrm{Kg} / \mathrm{ha}$ ). The mean yield in $(\mathrm{kg} / \mathrm{ha})$ and rank of 76 chickpea cold tolerant lines tested in (CICTN-98) in Takhar province is presented in (Table 14 Annex 6). It shows that lines 30, 26, and 13 with the mean yield of ( $4944 \mathrm{~kg} / \mathrm{ha}) .(4722 \mathrm{~kg} / \mathrm{ha}$ ) and $(4667 \mathrm{~kg} / \mathrm{ha})$ produced the top yields and ranked 1. 2. and $3^{\text {lid }}$ respectively. These lines are the highest yielding among the 24 top yielding lines and have been selected for further evaluation. The advantages of cold tolerant chickpea lines for Alghan farmer is that these lines can be planted in the fall in mild winter areas and the crop will take full advantage of winter rainfall and will producing high yield.

\section{Pea (Pisum sativam) 1998}

The mean yield and rank of 25 pea lines from ICARDA tested in (PIAT98) in 2 locations i summarized in (Table 15 Annex 6). In Takhar province lines 9. 18. and 6 with the mean yield of $(4576 \mathrm{~kg} / \mathrm{ha}) .(4278 \mathrm{~kg} / \mathrm{ha})$ and $(4229 \mathrm{~kg} / \mathrm{ha})$ ranked 1.2 and $3^{\text {'d }}$. The local line yielded the amount of (3472 $\mathrm{hg} / \mathrm{ha}$ ) and ranked 20 . These lines in comparison to the local check produced 32. 23. and $22 \%$ more yield. In Nangarhar the highest mean yield was produced by line 9 followed by lines 16 and 24 with the mean yield of $(2393 \mathrm{~kg} / \mathrm{ha}),(2211 \mathrm{~kg} / \mathrm{ha})$ and $(2185 \mathrm{~kg} / \mathrm{ha})$ respectively and ranked 1,2 , and $3^{\text {rid }}$. The local check produced the mean yield of $(1787 \mathrm{~kg} / \mathrm{ha})$ and ranked $15 \mathrm{~h}$. These lines out yielded the local check by 34,24 , and $23 \%$. The combined mean yields and ranking data of these lines indicates that the highest yield was produced by lines $9(3485 \mathrm{~kg} / \mathrm{ha}), 16(3206 \mathrm{~kg} / \mathrm{ha})$ and $18(3157 \mathrm{~kg} / \mathrm{ha})$ respectively. The local line produced the mean yield of $\left(2630 \mathrm{~kg} / \mathrm{ha}\right.$ ) and ranked $20^{\mathrm{ht}}$. Compared to the local check these lines produced 33 . 22 . and $20 \%$ higher yields and compared to nursery mean over two locations $(2838 \mathrm{Kg} / \mathrm{ha})$. the yield increase ranges from $11 \%$ to $23 \%$. It seems that line 9 has good yield potential in both locations. The potential of high yield from pea (Pisum salirum) in this location is very good. but storage, marketing and distribution needs study and attention.

\section{Lentil (Lens culinaris) 1998}

The mean vield (hg/ha) and rank of 10 lentil entries tested in National I entil. Yield Trial (98NI,YT1) in Takhar and Kunduz provinces of Afghanistan are summarized in (1 able 16. Annex 6). The data shows that in Takhar the highest yield was produced by lines $2(3657 \mathrm{~kg} / \mathrm{ha})$. $5(355+\mathrm{kg} / \mathrm{ha})$ and $3(3104 \mathrm{~kg} / \mathrm{ha})$ and ranked 1. 2. and $3^{\text {1" }}$ respectively. The local line with the mean yield of $\left(2661 \mathrm{~kg} / \mathrm{ha}\right.$ ) ranked $10^{1 /}$. These lines in comparison to local check produced 37.33 and $17 \%$ higher yield and these yield are significantly higher than the yield of local chech and remaining entries. The yields of these lines are significantly higher than the nursery mean. In Kundu/ province the highest vielding entries are $1(1815 \mathrm{~kg} / \mathrm{ha})$ and 4 ( $1.472 \mathrm{~kg} / \mathrm{ha}$ ) within the same significance group followed by entry $3(1322 \mathrm{~kg} / \mathrm{ha})$. These entries ranked 1, 2. and $3^{\text {ral }}$ respectively. The local line produced the mean yield of $(489 \mathrm{~kg} / \mathrm{ha})$ and ranked $10^{\text {th. }}$. These lines out yielded the local by 271. 201. and $170 \%$ and nursery mean (1071 Kg/ha) by $23 \%$ to $69^{\circ} 0$. When the mean yiets sis of the two locations were combined, the top five yielding lines are $1(2+10$ 
kg/ha). $2(2372 \mathrm{~kg} / \mathrm{ha}) .3(2213 \mathrm{~kg} / \mathrm{ha}) .4(2168 \mathrm{~kg} / \mathrm{ha})$ and $5(2153 \mathrm{~kg} / \mathrm{ha})$ ranked 1. 2. 3. 4. and $5^{\text {th }}$ respectively. The local line showed the overall mean yield of $(1575 \mathrm{~kg} / \mathrm{ha})$ and ranked $10^{\text {th }}$. In comparison to the local line these lines produced $53,51,41,38$ and $37 \%$ extra yield.

In (Table 17 Anne $\times 7$ ) the mean yield ( $\mathrm{kg} / \mathrm{ha}$ ) and rank of 10 cold tolerant lentil lines tested in (98PI.YTl) in Takhar is summarized. There is no significant different between the mean yield of these lines. However the highest yield was obtained by the lines $1(3194 \mathrm{~kg} / \mathrm{ha}), 8(3119 \mathrm{~kg} / \mathrm{ha})$ and 7 (2994 $\mathrm{kg} / \mathrm{ha})$. These lines ranked 1, 2, and $3^{\text {rid }}$ respectively. While the local line produced the mean vield of (2237 $\mathrm{kg} / \mathrm{ha}$ ) and ranked $7^{\text {th }}$ In comparison to the local these lines gave 43,39 . and $34 \%$ more yield.

The mean yield (kg/ha) and rank of 10 small seeded lentil lines tested in (98PL.YT2) in Herat province is summarized in (Table 18. Annex 6). The highest yield was produced by the local check, but this yield is not significantly different from the mean yield of lines 7,8 , and 9 . These lines produced significantly higher yields than the other lines.

Iable 19. Annex 6 summarizes the mean yield ( $\mathrm{kg} / \mathrm{ha}$ ) and rank of 25 large seed lentil lines tested in (I.IY T-98) in Takhar and Nangarhar provinces of Afghanistan. In Takhar the highest yield was obtained by lines $24(3060 \mathrm{~kg} / \mathrm{ha}) .17(3043 \mathrm{~kg} / \mathrm{ha})$ and $23(3009 \mathrm{~kg} / \mathrm{ha})$ and ranked 1,2 , and $3^{\text {td }}$ respectively. While the local line yielded $(2225 \mathrm{~kg} / \mathrm{ha}$ ) and ranked $22 \mathrm{nd}$. The yield differences between these lines are non significant. These lines produced significantly more yield than the local line and out yielded the local line by 36,35 , and $34 \%$ extra yield. In Nangarhar province lines $5(79 \mathrm{~kg} / \mathrm{ha}) .24(739 \mathrm{~kg} / \mathrm{ha})$ and $6(657 \mathrm{~kg} / \mathrm{ha})$ showed the top yields and ranked 1 , 2. and $3^{\text {nit }}$ respectively. These yields are not significantly higher than the yields of the other lines. The local line produced the mean yield of $(615 \mathrm{~kg} / \mathrm{ha})$ and ranked $6^{\text {th }}$. These lines out yielded the local line by 29.20 , and $7 \%$. When the mean yield of these 2 locations was combined, the data showed that lines $24(1900 \mathrm{~kg} / \mathrm{ha}), 5(1791 \mathrm{~kg} / \mathrm{ha})$ and $17(1712 \mathrm{~kg} / \mathrm{ha})$ produced the highest yield While the local line gave the mean yicld of (1434 kg/ha). These lines in comparison to the local produced 32,25 , and $19 \%$ extra yiekds.

\section{Beans (Phaseolus vulgaris) 1999}

The mean yield ( $\mathrm{kg} / \mathrm{ha}$ ) and rank of the 10 pinto class bean lines tested in (99BEAN $)$ ) in (ihazni and Nangarhar provinces of Afghanistan is summarized in (Table 1. Annex 7). In (ihazni line 9 $(3422 \mathrm{~kg} / \mathrm{ha})$ produced the top yield and ranked first. Lines $10(3422 \mathrm{~kg} / \mathrm{ha})$ and $6(2987 \mathrm{~kg} / \mathrm{ha})$ ranked $2^{\text {thl }}$ and $3^{\text {thl }}$. These lines yielded significantly higher than lines $2(1800 \mathrm{~kg} / \mathrm{ha})$ and $4(2111$ $\mathrm{kg} / \mathrm{ha})$. In Nangarhar the highest mean was produced by lines $9(4521 \mathrm{~kg} / \mathrm{ha}), 1$ (4458 kg/ha) 5 $(3950 \mathrm{~kg} / \mathrm{ha})$, and $10(3696 \mathrm{~kg} / \mathrm{ha})$. These lines ranked 1.2 .3 and $4^{\text {th }}$ respectively There is no significant yield differences between the mean yield of these lines but these yields are significantly higher than the yield of other lines. The combined data shows that lines 9 (39.72 $\mathrm{kg} / \mathrm{ha}) .10(3559 \mathrm{~kg} / \mathrm{ha}), 5(3409 \mathrm{~kg} / \mathrm{ha})$ and $4(3396 \mathrm{Kg} / \mathrm{ha})$ are the top yielding lines and ranked 1.2. and 3. and 4 respectively.

The mean yield ( $\mathrm{kg} / \mathrm{ha}$ ) and rank of 10 white bean lines tested in (99BFAN2) in Ghazni and Nangarhar provinces is summarized in (Table 2 Annex 7). In Ghazni the highest yield was given by lines 3.1 , and 2 with yields of $(1755 \mathrm{~kg} / \mathrm{ha}),(1511 \mathrm{~kg} / \mathrm{ha})$ and $(1300 \mathrm{~kg} / \mathrm{ha})$ respectively. These lines produced significantly higher yield than line $4(622 \mathrm{~kg} / \mathrm{ha})$. In Nangarhar there is no significant yield difference between the mean yield of these lines. However, lines $9(2504 \mathrm{~kg} / \mathrm{ha})$. $2(2342 \mathrm{~kg} / \mathrm{ha})$ and $7(2183 \mathrm{~kg} / \mathrm{ha})$ are the highest yielding lines. The two locations combined data revealed that lines $2(1821 \mathrm{~kg} / \mathrm{ha}), 9(1747 \mathrm{~kg} / \mathrm{ha})$ and $3(1717 \mathrm{~kg} / \mathrm{ha})$ are the top yielding lines. These lines ranked 1. 2. and 3 rd respectively. 
The mean vields and rank of 15 kidney bean lines tested in (99BEAN3) in Ghazni. and Nangarhar provinces is summarized in (Table 3 Annex 7). In Ghazni the highest mean yield is produced by lines 12 and 13 the amount of (2689 kg/ha ) and (2244 kg/ha) respectively. These lines produced significantly higher yields than the other lines. These lines out yielded the local check (1189 $\mathrm{kg} / \mathrm{ha}$ ) by 126 and $89 \%$. In Nangarhar lines 14, 6, 13, 15,7 and 12 obtained the highest yield. These lines yielded (2108 kg/ha). (2067 kg/ha), (2025 kg/ha), (1917 kg/ha). (1850 kg/ha) and $(1746 \mathrm{~kg} / \mathrm{ha})$ respectively and ranked $1,2,3,4,5$, and $6^{\text {th }}$. The yields of these lines are not significantly more than each other but are significantly more than the others. However lines 14.6 . and 13 out yielded the local line $(1917 \mathrm{Kg} / \mathrm{ha})$ by 9.8 and $6 \%$. When the mean yields were combined over these two locations. it showed that lines 12,13 , and 14 yielded $(2218 \mathrm{~kg} / \mathrm{ha})$. $(2135 \mathrm{~kg} / \mathrm{ha})$, and $(1693 \mathrm{~kg} / \mathrm{ha})$ and ranked 1,2 and $3^{\text {rd }}$ respectively. The local line produced the overall mean yield of $(1553 \mathrm{~kg} / \mathrm{ha})$ and ranked $4^{\text {th }}$. These lines compared to local yielded 43,37 and $9 \%$ more.

\section{Chickpea (Cicer arietinum) 1999}

The mean yield (kg/ha) and rank of 10 chickpea lines tested in (99NCYTl) under rainfed condition in Herat and Takhar provinces and irrigated condition in Balkh are presented in (Table 4 Annex 7). In Takhar the highest mean yield was produced by the lines 7 (FLIP 95-60C). 5 (ILC 482). and 4 (FLIP 93-93C ) with mean the yield of (1290 kg/ha), (1288 kg/ha) and (1 $168 \mathrm{~kg} / \mathrm{ha})$ and ranking of 1 and 2 and $3^{\text {id }}$ respectively. The yields of these lines are significantly higher than others. The local line gave the mean yield of $(1154 \mathrm{~kg} / \mathrm{ha})$ and ranked $4^{\text {th. }}$. The yields of lines 7,5 , and 4 are 12.11, and $1 \%$ higher than local. In Herat the highest mean yield was obtained by lines 5 (ILC 482). 7 (FLIP95-60C) and 2 (FLIP9I-220C) with mean yields of (1056 kg/ha). (1027 $\mathrm{kg} / \mathrm{ha})$ and (990 kg/ha). These lines ranked 1,2 and $3^{\text {rd }}$ respectively. The vield of these lines is significantly higher than local check $(51+\mathrm{kg} / \mathrm{ha})$. These lines out y ielded the local line by 105 . 99. and $92 \%$. In Balkh province the highest mean yield is produced by lines 9 (F1.1P95-59). 8 (1.1.1P95-67C), and 7 (11.1P95-60C) with mean yields of (1070 kg/ha). (998 kg/ha) and (905 $\mathrm{kg} / \mathrm{ha}$ ) respectively. The mean yields of these lines are significantly higher than the yields of lines 1.5. and (o) the local check. The local line yielded the mean yield of ( $545 \mathrm{~kg} / \mathrm{ha}$ ). In comparison to local check. lines (9.8. and 7 ) produced 96.83 , and $66 \%$ higher yield. When the mean yield data of the 3 locations was combined the overall mean yield showed that lines $7(1074 \mathrm{~kg} / \mathrm{ha}), 9$ $(1060 \mathrm{~kg} / \mathrm{ha})$ and $4(991 \mathrm{~kg} / \mathrm{ha})$ ranked 1.2 . and $3^{\text {id }}$ respectively. The local line with overall mean yield of ( $738 \mathrm{~kg} / \mathrm{ha}$ ) ranked $10^{\mathrm{th}}$. These lines in comparison to the local yielded 46.44 . and $34 \%$ more.

The mean yield (kg'ha) and rank of 15 chickpea lines tested in (99ACYT1) in Balkh and Takhar provinces is summarized in (lable 5 Annex 7). In Takhar under rainfed situation the highest yicld was produced by lines 1.LIP93-58C (1215 kg/ha), 11.C $142(1096 \mathrm{~kg} / \mathrm{ha})$ and FLIP94-6/C (1030 $\mathrm{kg}$ ha). These lines ranked 1. 2. and $3^{\text {'t }}$ respectively. The mean yield of these lines are not significantly different than the yiekls of FLIP95-56C and II (C 4339 with a mean yield of (1029

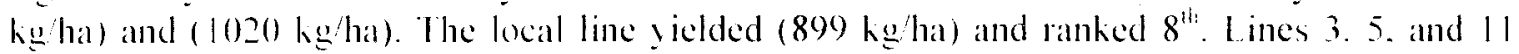
compare to hocal produced 40. 22. and 15\% extra yiekls. In Balkh province the highest yield was produced by $111.1 P 93-1810(1065 \mathrm{~kg} / \mathrm{ha}) .1 \% 1 \mathrm{IP9} 3-174 \mathrm{C}(958 \mathrm{~kg} / \mathrm{ha})$ and $11.1 \mathrm{P} 93-58 \mathrm{C}(904 \mathrm{~kg} / \mathrm{ha})$ with ranking 1. 2. and $3^{\text {te }}$ respectively. The local check yelded $(512 \mathrm{~kg} / \mathrm{ha})$ and ranked $15^{\mathrm{t}}$. These lines compare to local produced 166.87 and $77 \%$ higher yield. When the mean yield data of the 2 locations was combined. I1.1PO3-58( with the overall mean yield of ( 1060 hg/ha). FI.IP $93-181(978 \mathrm{~kg} / \mathrm{ha})$ and $11(-1+2(9+3 \mathrm{~kg} / \mathrm{ha})$ are the top y jelding lines. These lines out yielded the heal chech $(706 \mathrm{~kg}$ ha) by 50.39 and $34 \%$. 
Table 6 Annex 7 shows the mean yield and rank of 10 chickpea lines tested in (99ACYT2) in Balkh province of Afghanistan. This nursery was planted in fall under irrigated condition. The top yield was obtained by lines 3 and 10 the local check with a mean yield of ( $758 \mathrm{~kg} / \mathrm{ha}$ ) and (756 $\mathrm{kg} / \mathrm{ha}$ ) respectively. This has been the poorest yielding site this season.

The mean yield ( $\mathrm{kg} / \mathrm{ha}$ ) and rank of 10 chickpea lines tested in (99P( $\mathrm{Y} \mathrm{Tl}$ ) which were selected from (CICTN98) nursery was summarized in (Table 7 Annex 7). This trial was planted in Takhar and Balkh provinces during the fall 1998. In Takhar the highest yield was obtained by lines FI.IP95-68C. SEI, 93TH24483 and local check with mean yields of (1369 kg/ha). (1355 kg/ha) and $(981 \mathrm{~kg} / \mathrm{ha}$ ) respectively. These yields are significantly higher than the yields of others lines. Line 2 and 6 out yielded the local by 40 and $38 \%$. In Balkh province the highest vield was recorded by lines FLIP95-68C, and SEL 93 TH24483 with mean yields of (1006 kg/ha) and ( 890 $\mathrm{hg} / \mathrm{ha}$ ) respectively. Lines FI.IP $94-108 \mathrm{C}$ and local yielded $(784 \mathrm{~kg} / \mathrm{ha})$ and $(759 \mathrm{~kg} / \mathrm{ha})$. These yields ranked 1.2.3. and $4^{\text {th }}$ respectively and produced 33.17 , and $3 \%$ more yield than the local line. When the mean yield of the 2 locations was combined the data showed that lines 2 ( 1188 $\mathrm{hg} / \mathrm{ha}$ ) and $6\left(1123 \mathrm{~kg} / \mathrm{ha}\right.$ ) ranked 1 , and $2^{\mathrm{nd}}$ and the local line with the overall mean yield of ( 870 $\mathrm{kg} / \mathrm{ha}$ ) ranked $3^{\text {rd }}$. These lines out yielded the local line by 37 . and $29 \%$.

\section{Pea (Pisum sativam) 1999}

The mean yicld ( $\mathrm{kg} / \mathrm{ha}$ ) and rank of 10 pea lines tested in (99PYTl) in Baghlan province is summarized in (Table 8 Annex 7). The highest mean yield were obtained by lines 4.8 and 1. these lines yielded $(831 \mathrm{~kg} / \mathrm{ha}) .(769 \mathrm{~kg} / \mathrm{ha})$ and $(761 \mathrm{~kg} / \mathrm{ha})$ respectively. These yields are significantly higher than the yields of lines 2 and local. The local line produced the mean yield of $(4+2 \mathrm{~kg} / \mathrm{ha})$. These lines compared to local produced 88,74 and $72 \%$ higher yield.

\section{Lentil (Lens culinaris) 1999}

The mean yield ( $\mathrm{kg} / \mathrm{ha}$ ) and rank of 10 lentil lines tested in (99LNYTl) in Baghlan and Balkh provinces is summarized in (Table 9 Annex 7). In Baghlan under rain fed condition the lines 4 (11.IP96-151.). 3 (SIL.) and 8 (FLIP88-10L) with the mean yield of ( $1447 \mathrm{~kg} / \mathrm{ha})$. (1387 $\mathrm{kg} / \mathrm{ha})$ and (1352 kg/ha) are the top yielding lines and ranked 1. 2. and $3^{\text {th }}$ respectively. However the vields of these lines are significantly higher than the yield of lines 2. 9 and 10 the local check. The local line produced the mean yield of $(958 \mathrm{~kg} / \mathrm{ha})$. In comparison to the local check. lines 4. 3 . and 8 produced 47,45 , and $41 \%$ higher yields. In Balkh province under irrigated condition the highest yield was obtained by lines 1.5, and 7 . These yields are significantly higher yielding than lines 4.9 and the local check. I.ines I (ILL323) with mean yield of (1182 hg/ha), 5 (FLIP87-91) with the mean yield of (1126 kg/ha) and line 7 (FLIP96-9L) with the mean yield of (1104 kg/ha) ranked 1.2 and $3^{\text {rd }}$ respectively. The local line produced the mean y ield of ( $646 \mathrm{~kg} / \mathrm{ha}$ ) and ranked $8^{\mathrm{th}}$. In compared to the local check these lines yielded 83,74 , and $71 \%$ higher grain yield. The two locations mean yield data revealed that lines $1(1224 \mathrm{~kg} / \mathrm{ha}), 7(1213 \mathrm{~kg} / \mathrm{ha}), 5(1212 \mathrm{~kg} / \mathrm{ha})$, $3(1129 \mathrm{~kg} / \mathrm{ha}) .2(1086 \mathrm{~kg} / \mathrm{ha})$ and $8(1078 \mathrm{~kg} / \mathrm{ha})$ ranked 1.2 .3 .4 .5 and $6^{\text {th }}$ respectively. The overall means yield of the local line was $(802 \mathrm{~kg} / \mathrm{ha})$ and ranked $10^{\text {th }}$. The yield advantage of these lines over the local line is $53.51,51,41.35$, and $34 \%$ respectively:

In (Table 10.. Annex 7) the mean yield and rank of 25 drought tolerant lentil lines tested under rain fed conditions in Baghlan Province is summarized. The highest mean grain yield was recorded for lines 9, 13,3, 20, 11, and I with mean yields of (2095 kg/ha). (1845 kg/ha). (1680 $\mathrm{kg} / \mathrm{ha})$. (1670 kg/ha). (1655 kg/ha) and (1650 kg/ha) respectively. There is no signilicant difference between the mean yields of these lines. These lines yielded significantly higher than other lines and ranked $1,2,3,4,5$, and $6^{\text {th }}$. While the local line produced the mean yield of ( 985 $\mathrm{kg} / \mathrm{ha}$ ) and ranked $22^{\text {Ind }}$. These lines out yielded the local line by $113,87.71 .70,68$, and $67 \%$ respectively. 


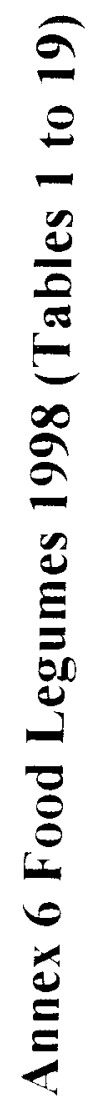




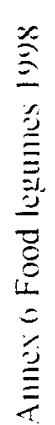

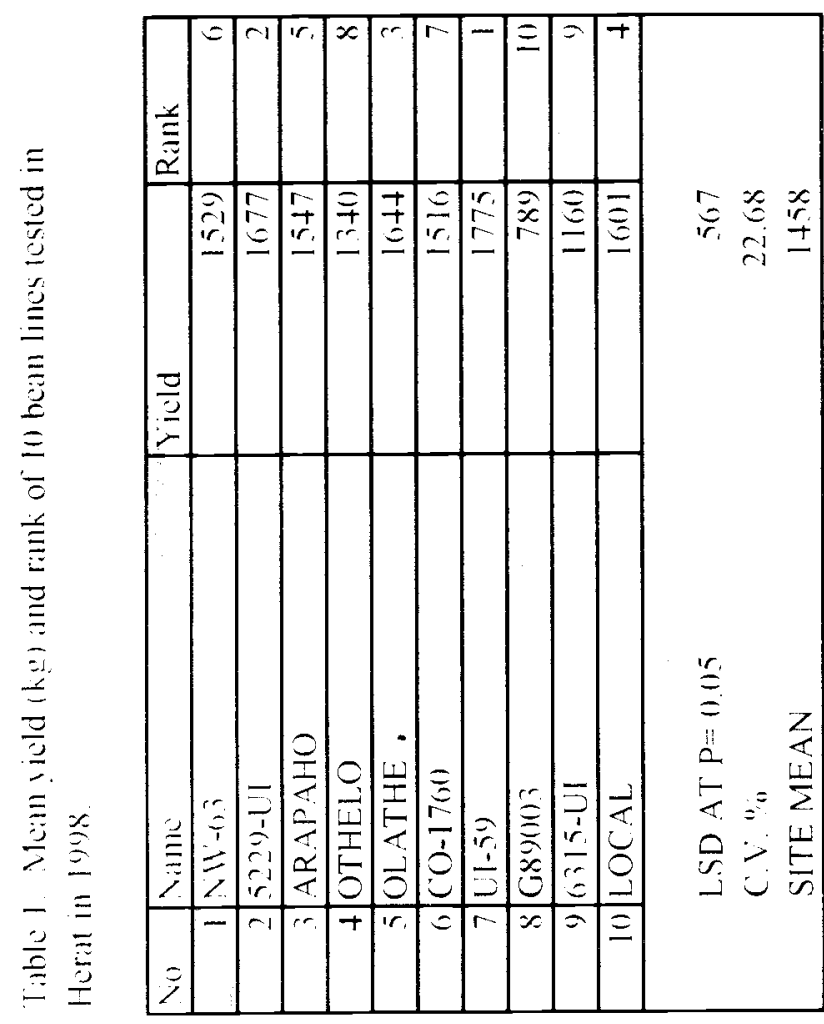




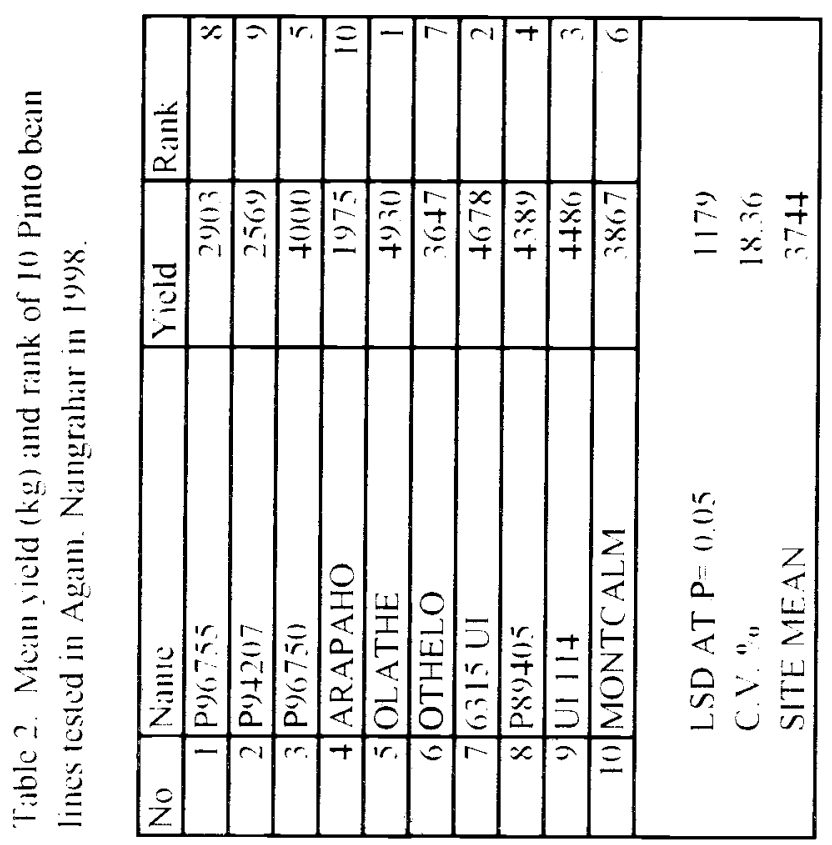




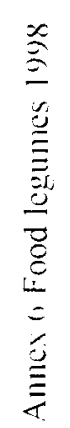

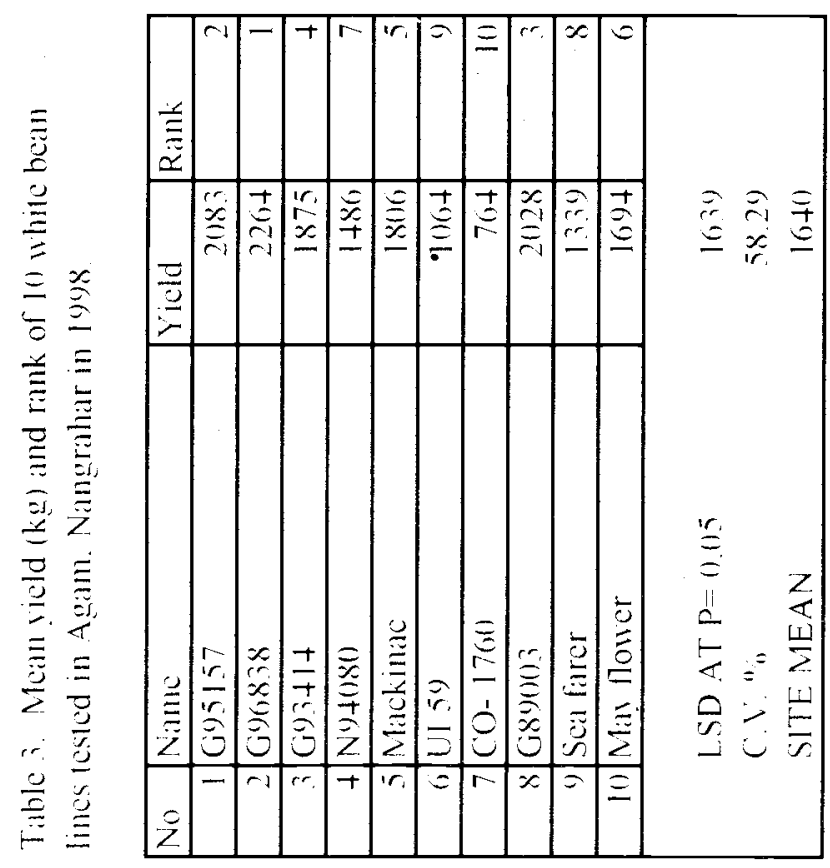




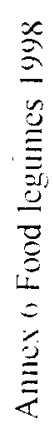

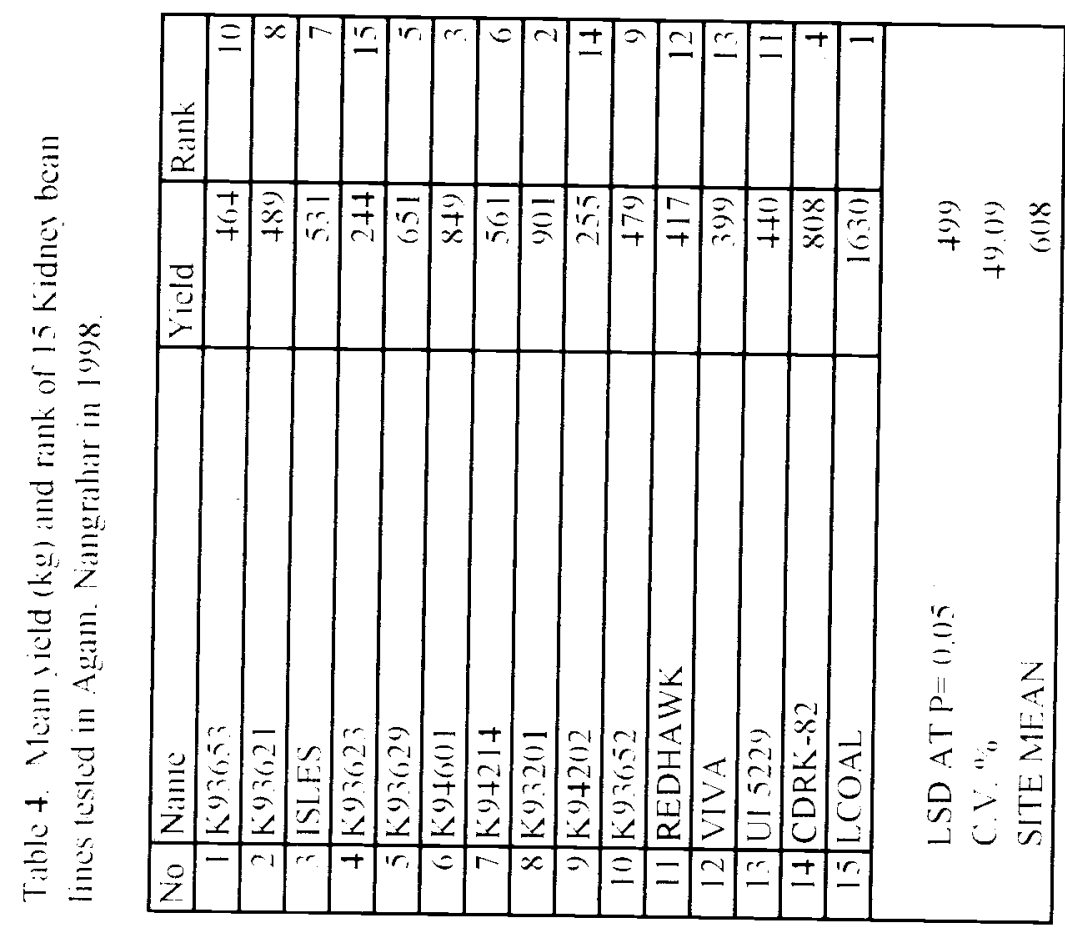




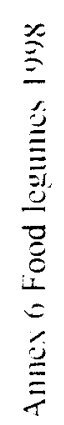

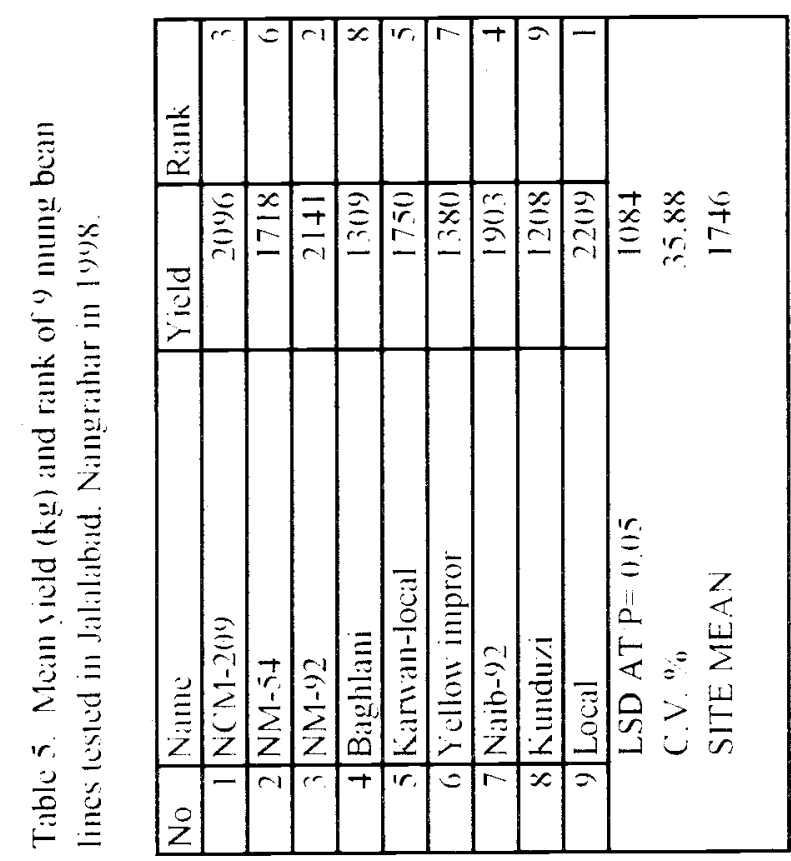




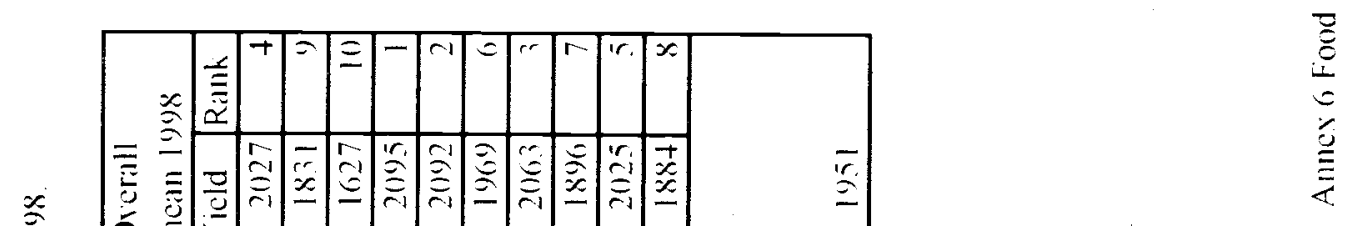

竞

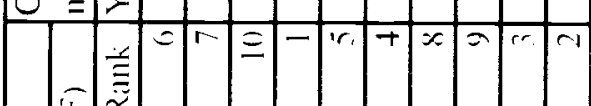

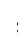

$\equiv$

$\stackrel{0}{\Xi}$

芯

$\Xi$
0
0
0
$\Xi$
$\Xi$

采 은

I $r$

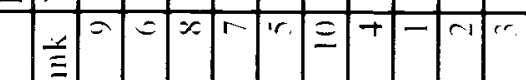

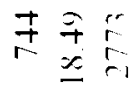

$\underline{x}$

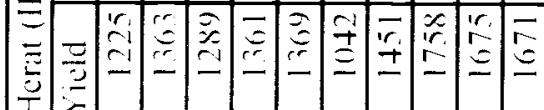

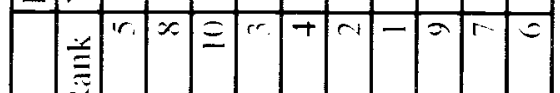

$\begin{array}{ccc}0 & 0 \\ 0 & 0 & 0 \\ 0 & 0 & 0\end{array}$

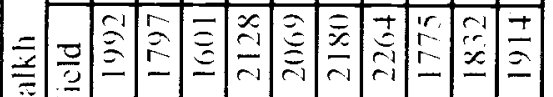

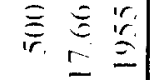

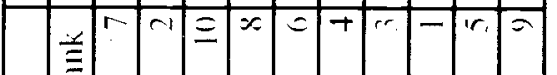

$\stackrel{\Xi}{\Xi}$

$\stackrel{\Xi}{ٍ}$

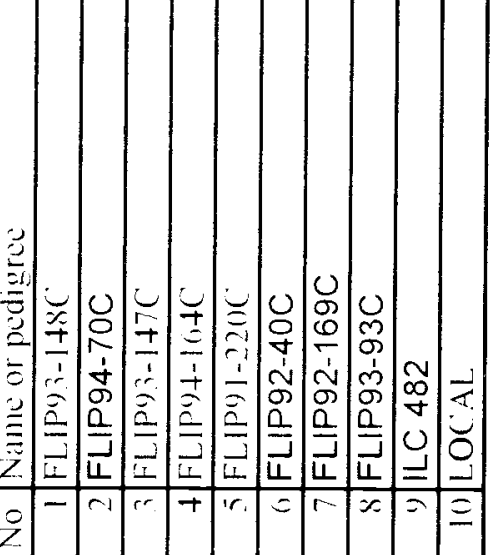

$\stackrel{r}{=}$

$\stackrel{11}{\bar{a}}=$

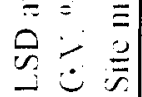


产

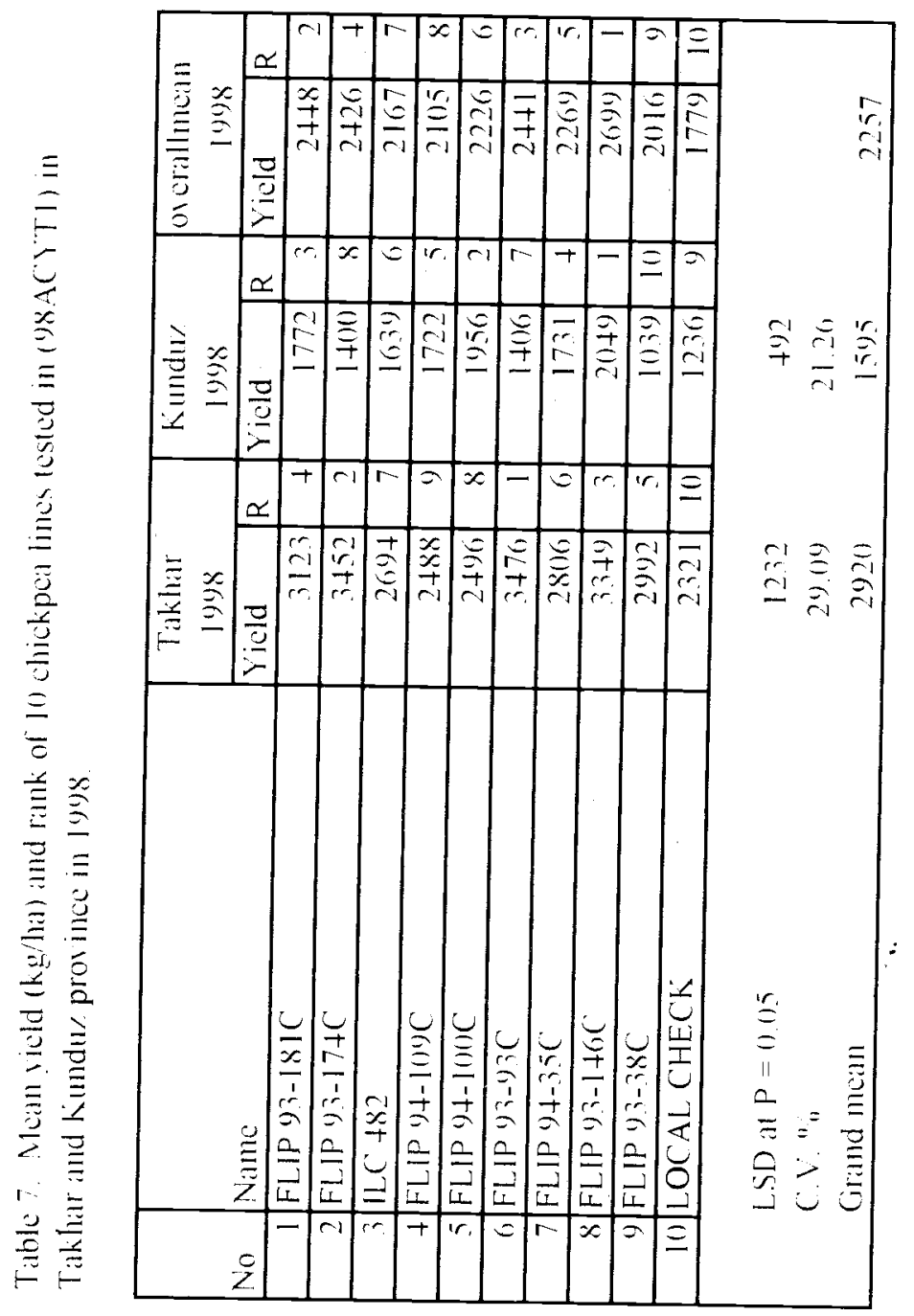




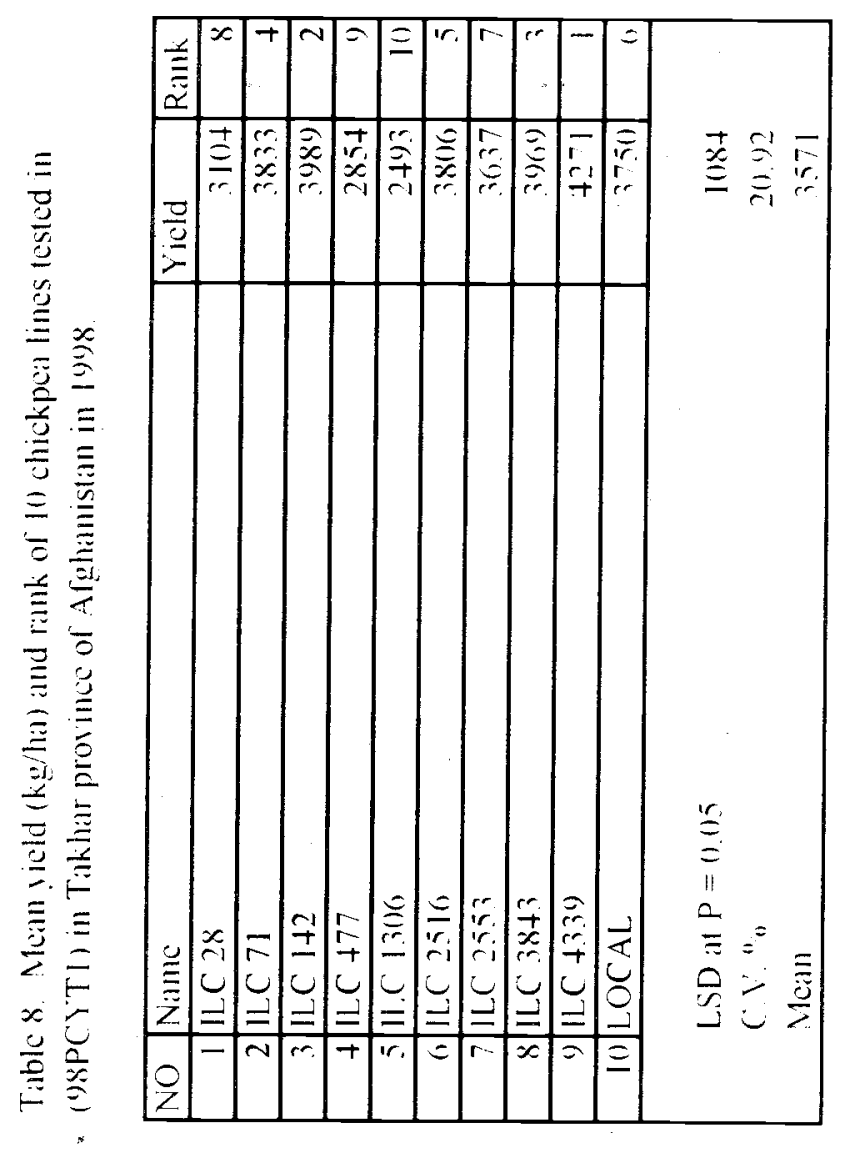




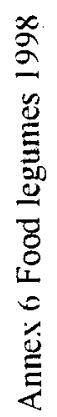

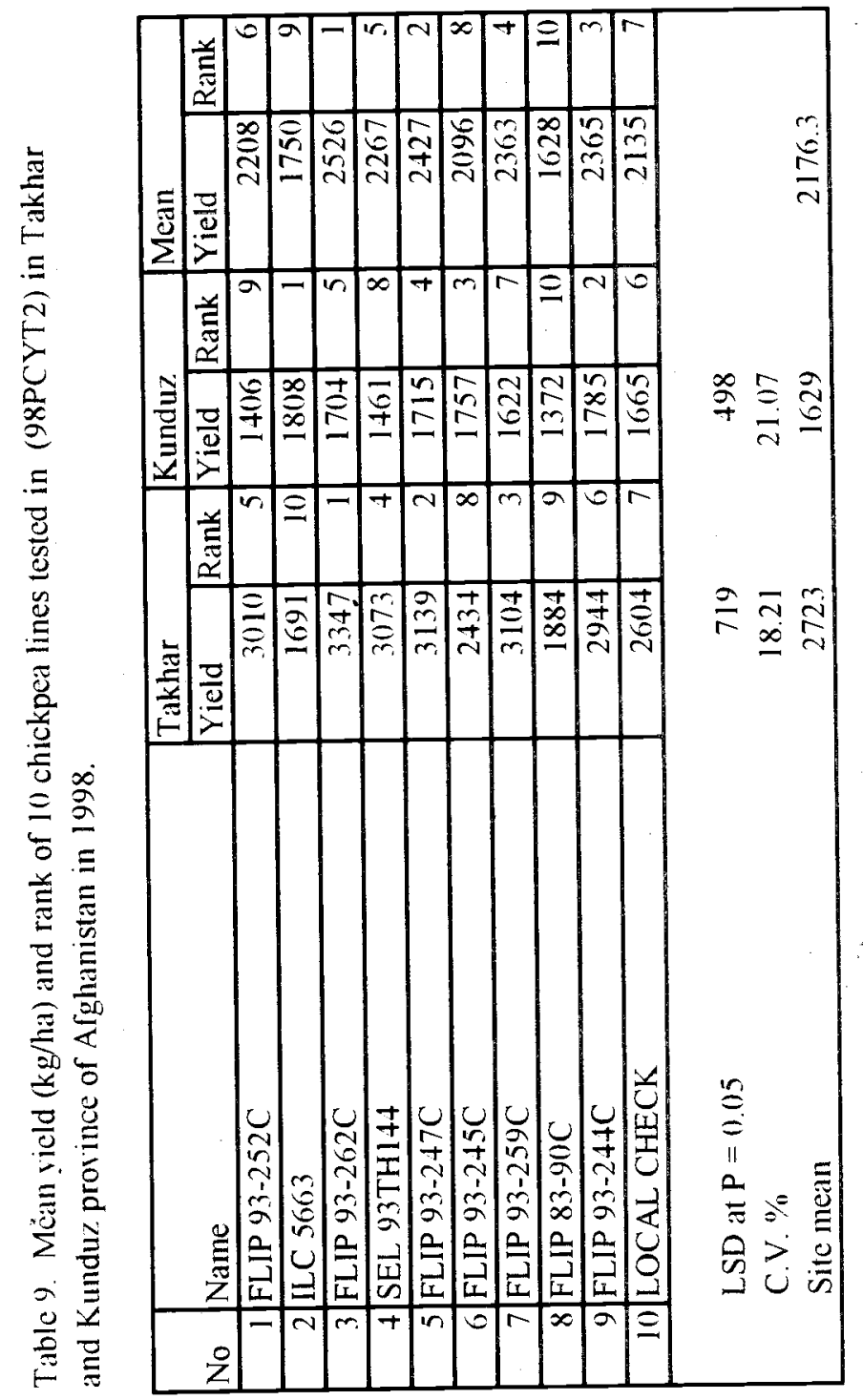




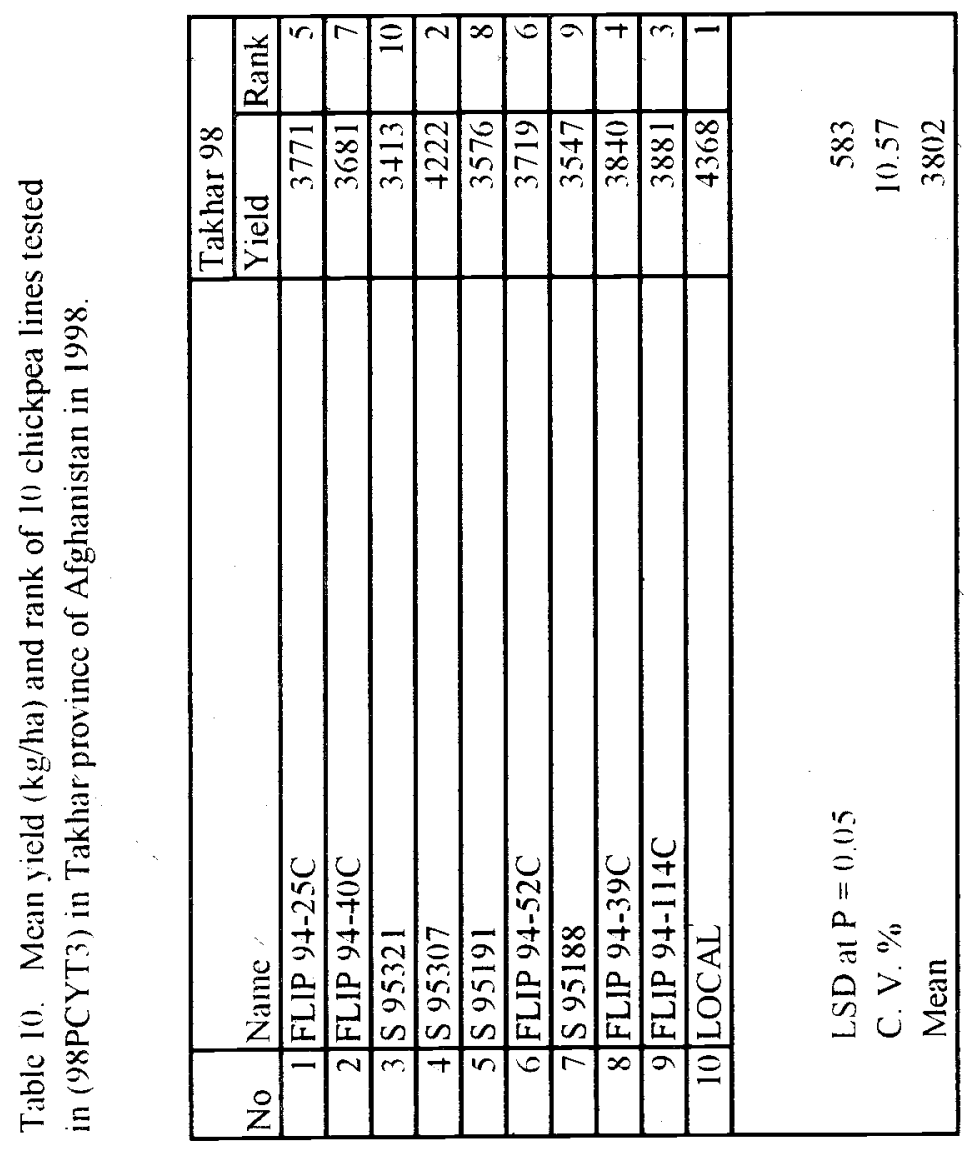




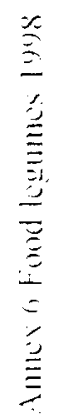

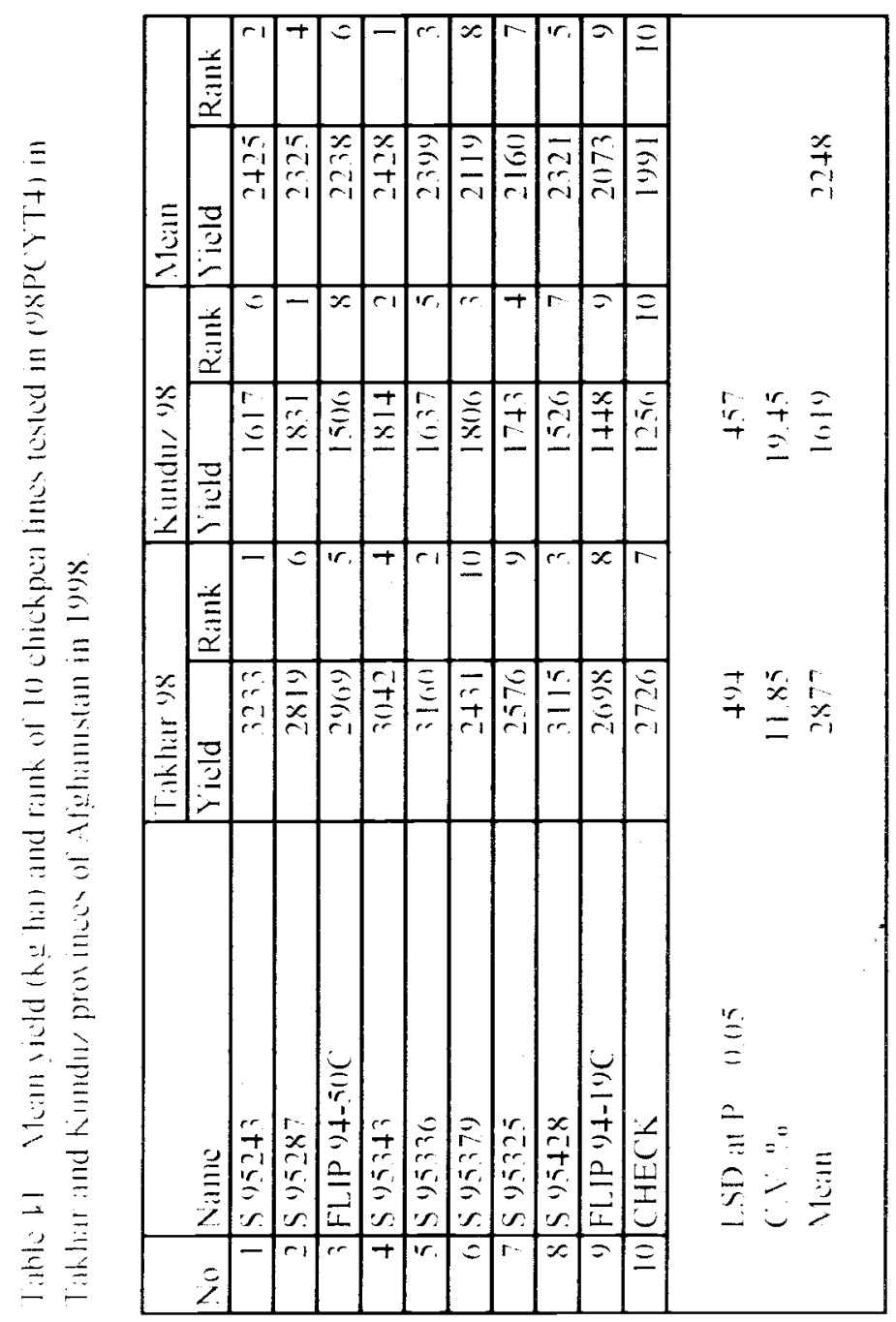




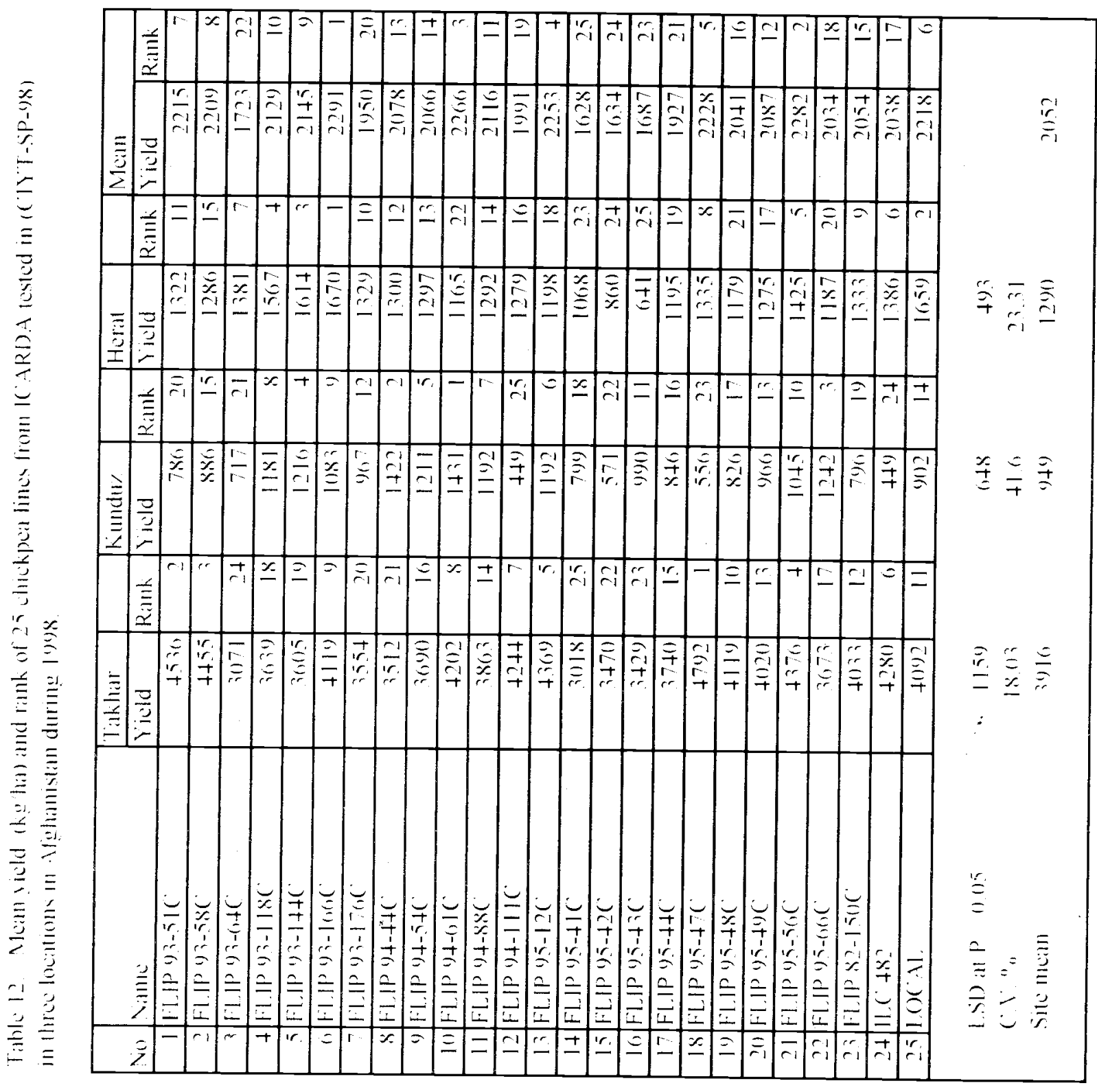




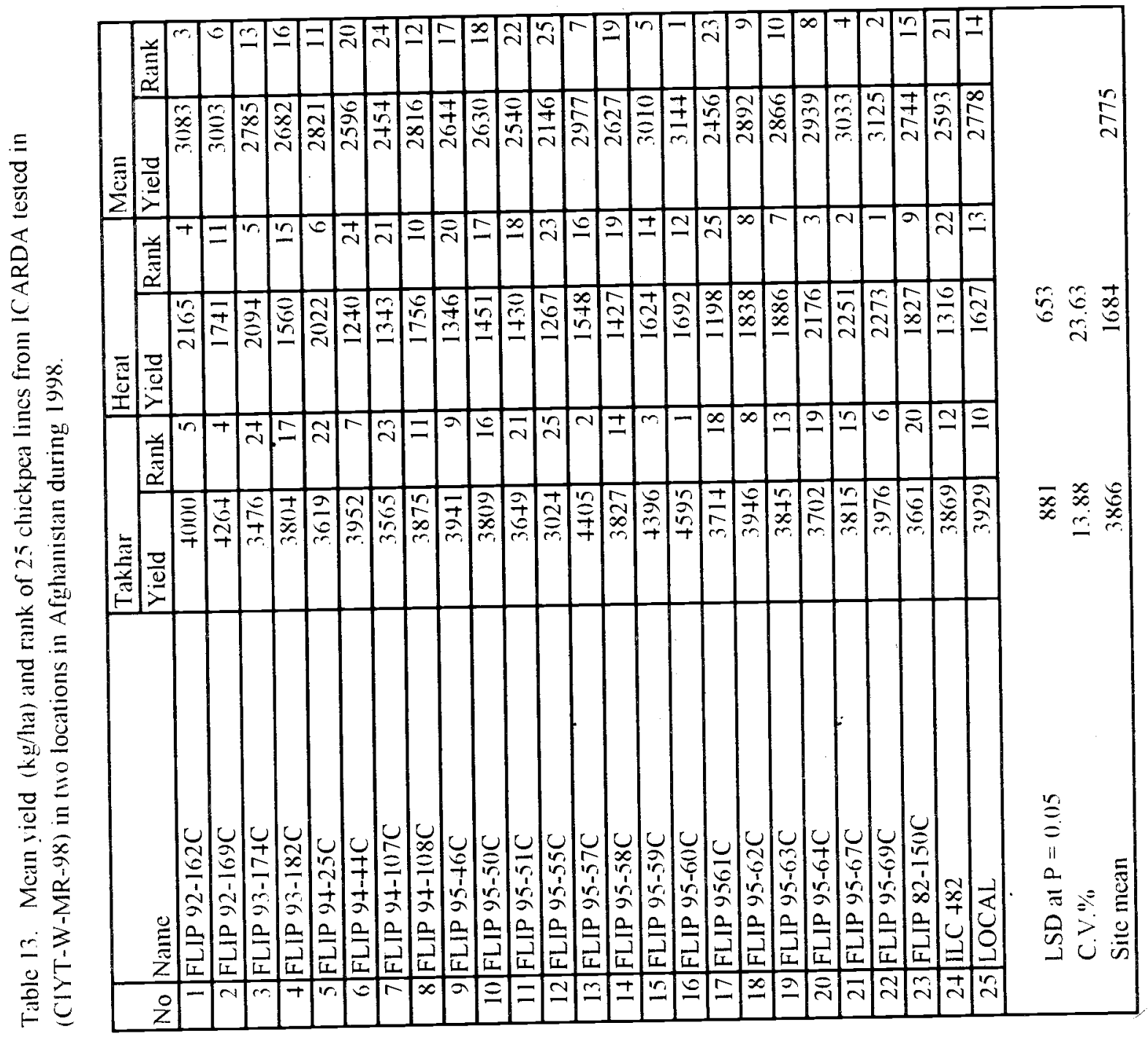


Table 14. Mean yicld ( $\mathrm{kg} / \mathrm{ha})$ and rank of 76 chickpea lines from ICARDA tested in (CICTN-)8) in Takhar. Afghanistan during 1998.

\begin{tabular}{|c|c|c|c|c|c|c|c|}
\hline \multirow[b]{2}{*}{ No } & \multirow[b]{2}{*}{ Name } & \multicolumn{2}{|l|}{ Takhar } & \multirow[b]{2}{*}{ No } & \multirow[b]{2}{*}{ Name } & \multicolumn{2}{|l|}{ Takhar } \\
\hline & & Yield & Rank & & & Yield & Rank \\
\hline 1 & ILC 8262 & 4055 & 12 & 39 & Sel 96TH11484 & 1778 & 53 \\
\hline 2 & ILC8568 & 2139 & 39 & 40) & Sel 96TH11485 & 2555 & 29 \\
\hline 3 & ILC8617 & 2111 & 41 & 41 & Sel 96THI I488 & 1005 & 68 \\
\hline 4 & FLIP93-252C & 3667 & 21 & 42 & Sel 96TH11507 & 3417 & 24 \\
\hline 5 & FLIP93-253C & $4(028$ & 13 & 43 & Sel 96TH11515 & 3972 & 15 \\
\hline 6 & FLIP93-254C & 1667 & 55 & 44 & Sel 96TH11516 & 3444 & 23 \\
\hline 7 & FLIP) $3-255 \mathrm{C}$ & 3983 & 14 & 45 & Sel 96TH11518 & 4333 & 10 \\
\hline 8 & FLIPY3-259C & 4067 & 11 & 46 & ILWC 81 & 305 & 72 \\
\hline 9 & FLIP93-260)C & 2833 & 26 & 47 & ILWC 106 & 39 & 74 \\
\hline 10 & FLIP93-261C & 1944 & 48 & 48 & ILWC 139 & 39 & 75 \\
\hline 11 & FLIP93-262C & 3917 & 17 & 49 & ILWC 181 & 22 & 76 \\
\hline 12 & FLIP 94-108C & 4417 & 7 & 50 & ILWC 235 & 128 & 73 \\
\hline 13 & FLIP 95-68C & 4667 & 3 & 51 & ILC 533 & 1361 & 65 \\
\hline 14 & 596037 & 1917 & 49 & 52 & ILC 533 & 2222 & 36 \\
\hline 15 & 596096 & 3722 & 20 & 53 & ILC 533 & 1639 & 57 \\
\hline 16 & S96097 & 1833 & 51 & 54 & ILC 533 & 1889 & 50 \\
\hline 17 & S96099 & 3611 & 22 & 55 & ILC 533 & 972 & 70 \\
\hline 18 & Sel 93TH 24405 & 2733 & 27 & 56 & ILC 533 & 1389 & 63 \\
\hline 19 & Sel 93TH $2+406$ & 4611 & 5 & 57 & ILC 533 & 1389 & 64 \\
\hline 20 & Sel 93TH 24411 & 2222 & 34 & 58 & ILC 533 & 2417 & 33 \\
\hline 21 & Sel 93TH 24416 & 1750 & 54 & 59 & ILC 533 & 2000 & 45 \\
\hline 22 & Sel 93TH 24460 & 4500 & 6 & 60 & ILC 533 & 1417 & 61 \\
\hline 23 & Sel 93TH 24464 & 4417 & 8 & 61 & ILC 533 & 2528 & 31 \\
\hline 24 & Sel 93TH 24467 & 3833 & 18 & 62 & ILC 533 & 2167 & 37 \\
\hline 25 & Sel 93TH $24+69$ & 3778 & 19 & 63 & ILC 533 & 1667 & 56 \\
\hline 26 & Sel 93TH $24+77$ & 4722 & 2 & 64 & ILC 533 & 2111 & +2 \\
\hline 27 & Sel 9.3TH 24479 & 3944 & 16 & 65 & ILC 533 & 2167 & 38 \\
\hline 28 & Scl $93 \mathrm{TH} 24483$ & 4389 & 9 & 66 & ILC 533 & 1983 & +7 \\
\hline 29 & Sel 93TH 24498 & 2222 & 35 & 67 & ILC 533 & $1+17$ & 62 \\
\hline 30 & Sel 95TH 1716 & 4944 & 1 & 68 & ILC 533 & 1000 & 69 \\
\hline 31 & Sel 95TH 1722 & 3278 & 25 & 69 & ILC 533 & 1055 & 67 \\
\hline 32 & Sel 95TH $17+4$ & 1778 & 52 & 70 & ILC 533 & 1583 & 59 \\
\hline 33 & Sel 95TH 1745 & 2528 & 30 & 71 & ILC 533 & 2000 & 46 \\
\hline 34 & Sel 96THII403 & 1611 & 58 & 72 & ILC 533 & 2639 & 28 \\
\hline 35 & Sel 96THII+04 & 539 & 71 & 73 & ILC 533 & 2139 & 40 \\
\hline 36 & Sel 96THII+(06 & 2501 & 32 & 74 & ILC 533 & 1500 & 60 \\
\hline 37 & Sel 96THI1409 & 2000 & 44 & 75 & ILC 533 & 2055 & +3 \\
\hline 38 & Sel 96TH11439 & 46.39 & 4 & 76 & ILC 533 & 1222 & 66 \\
\hline 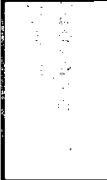 & $\begin{array}{l}\text { LSD at } \mathrm{P}=0.05 \\
\text { C.V.\% } \\
\text { Site mean }\end{array}$ & $\begin{array}{r}1496 \\
30.28 \\
2480 \\
\end{array}$ & & & & & \\
\hline
\end{tabular}




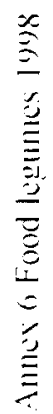

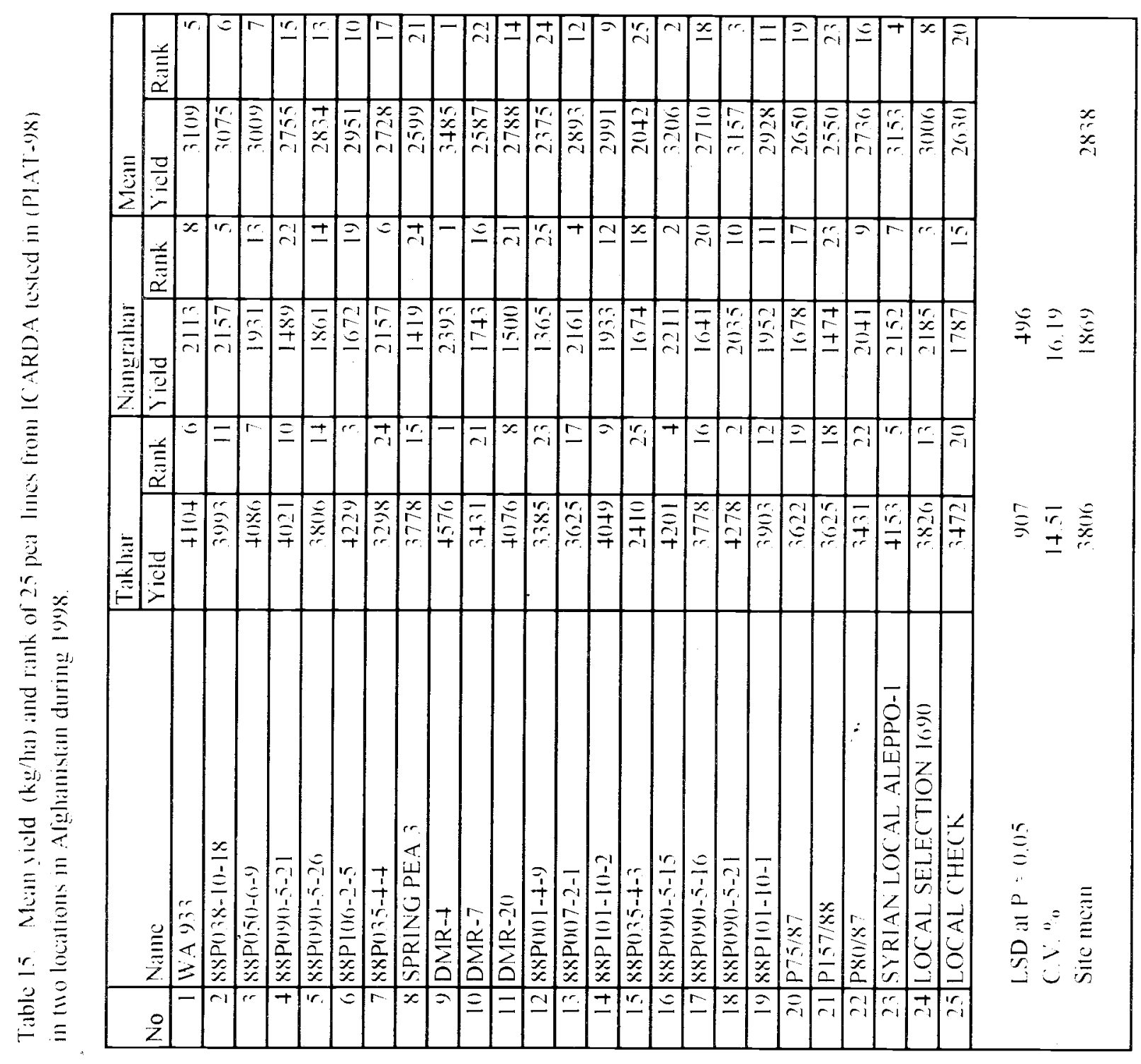




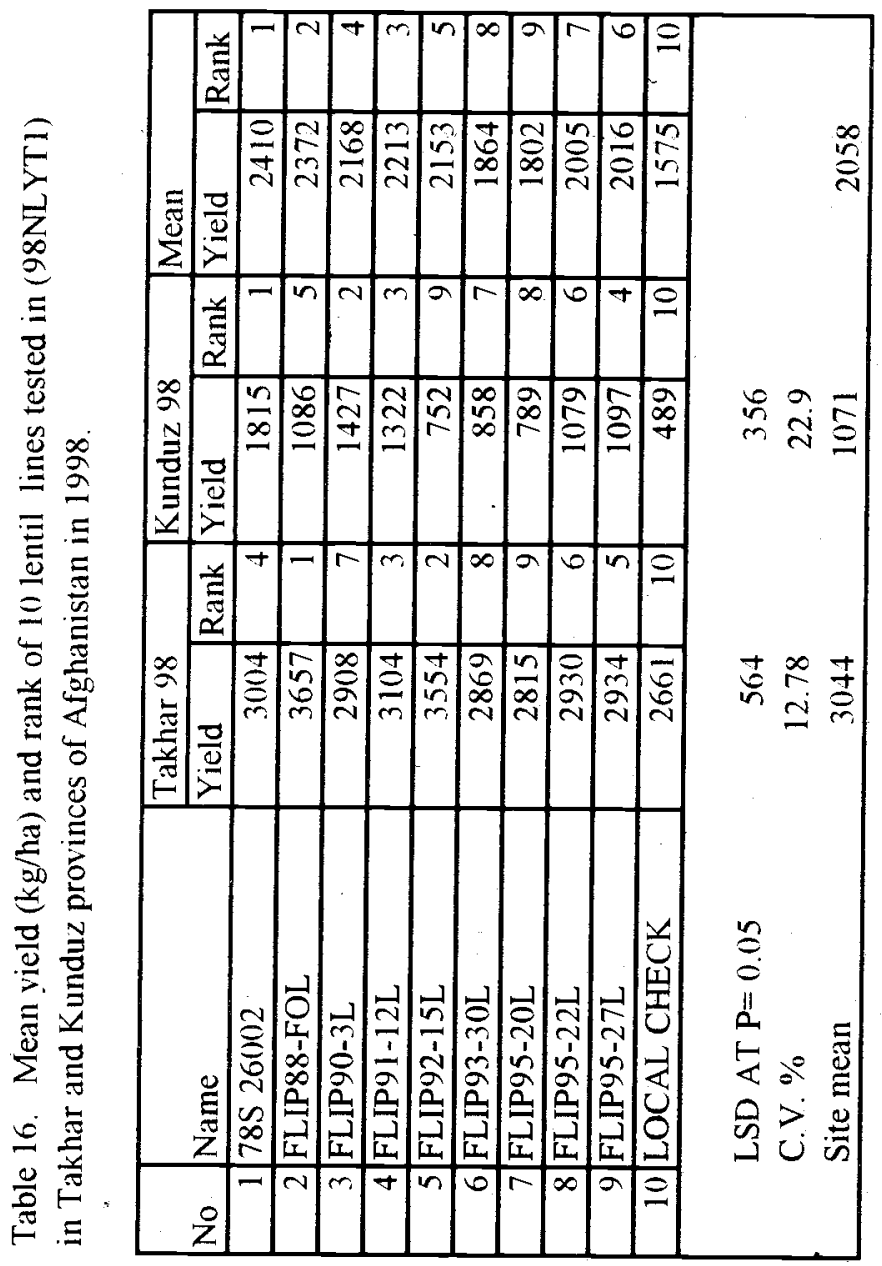


$\infty$
2
0
0
$\vdots$
0
0
0
8
0
0
0
0
0

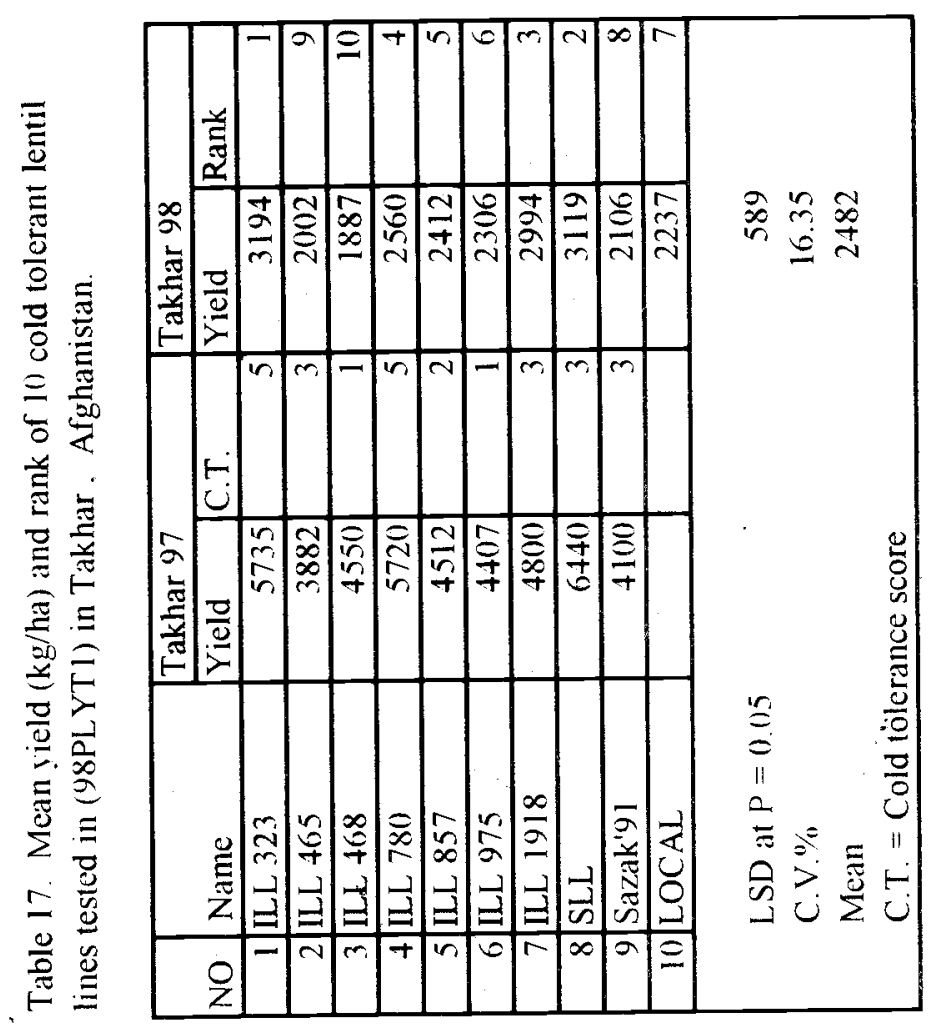




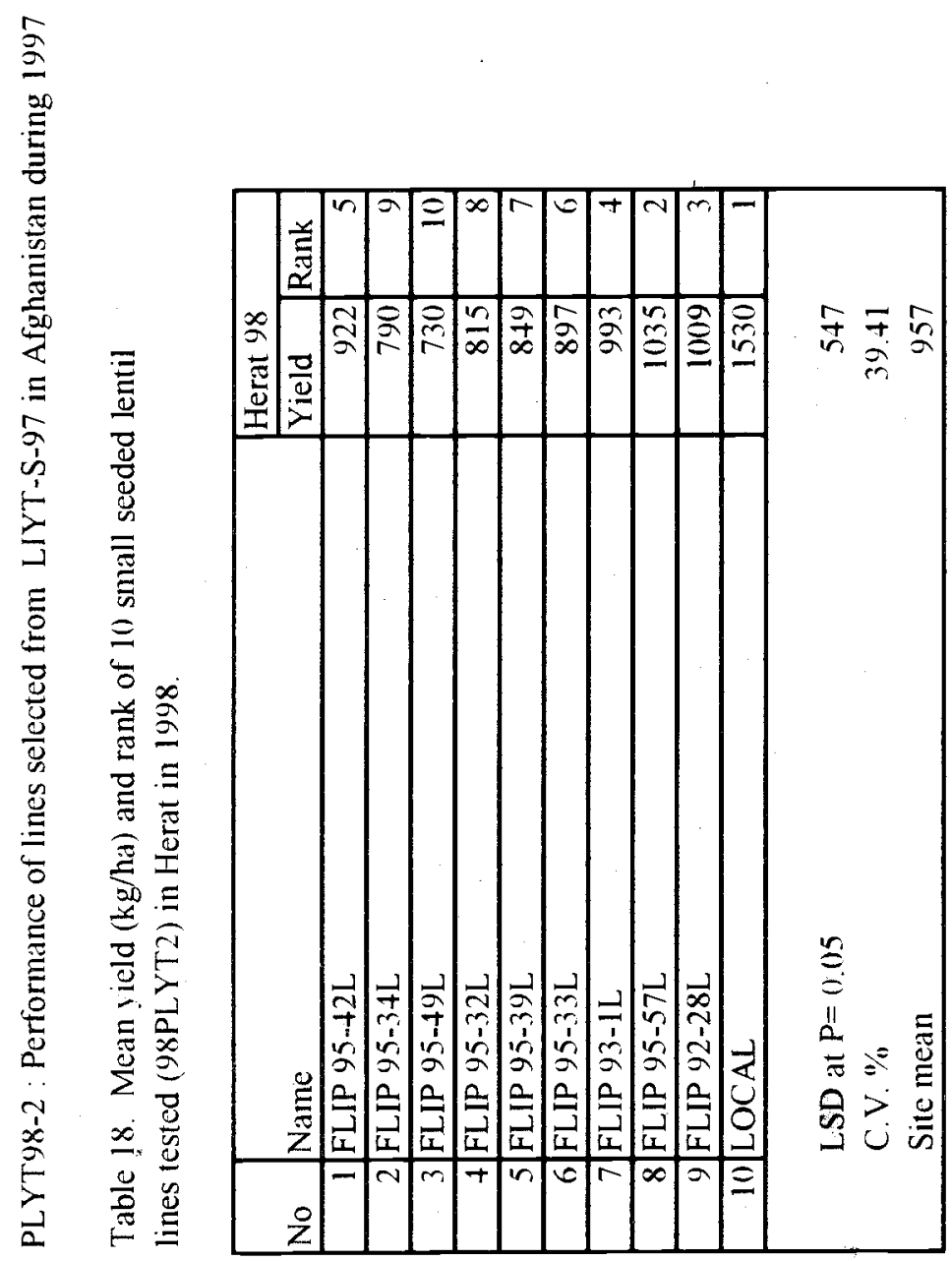




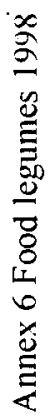

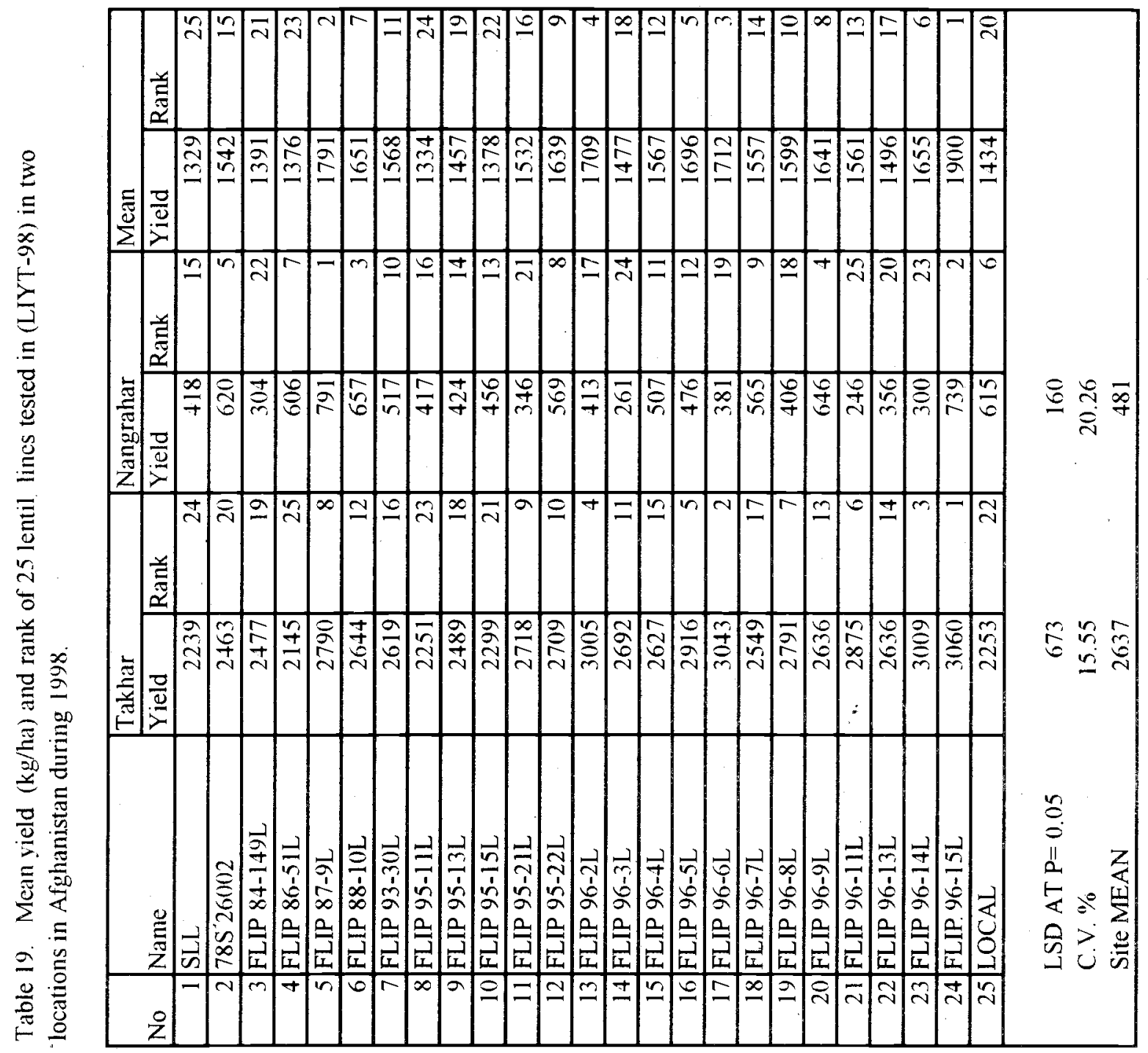




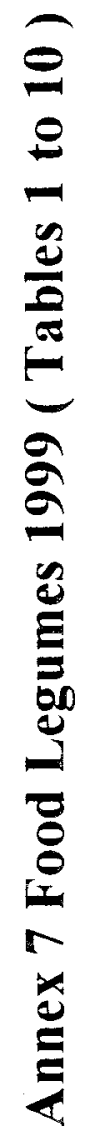




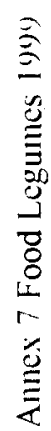

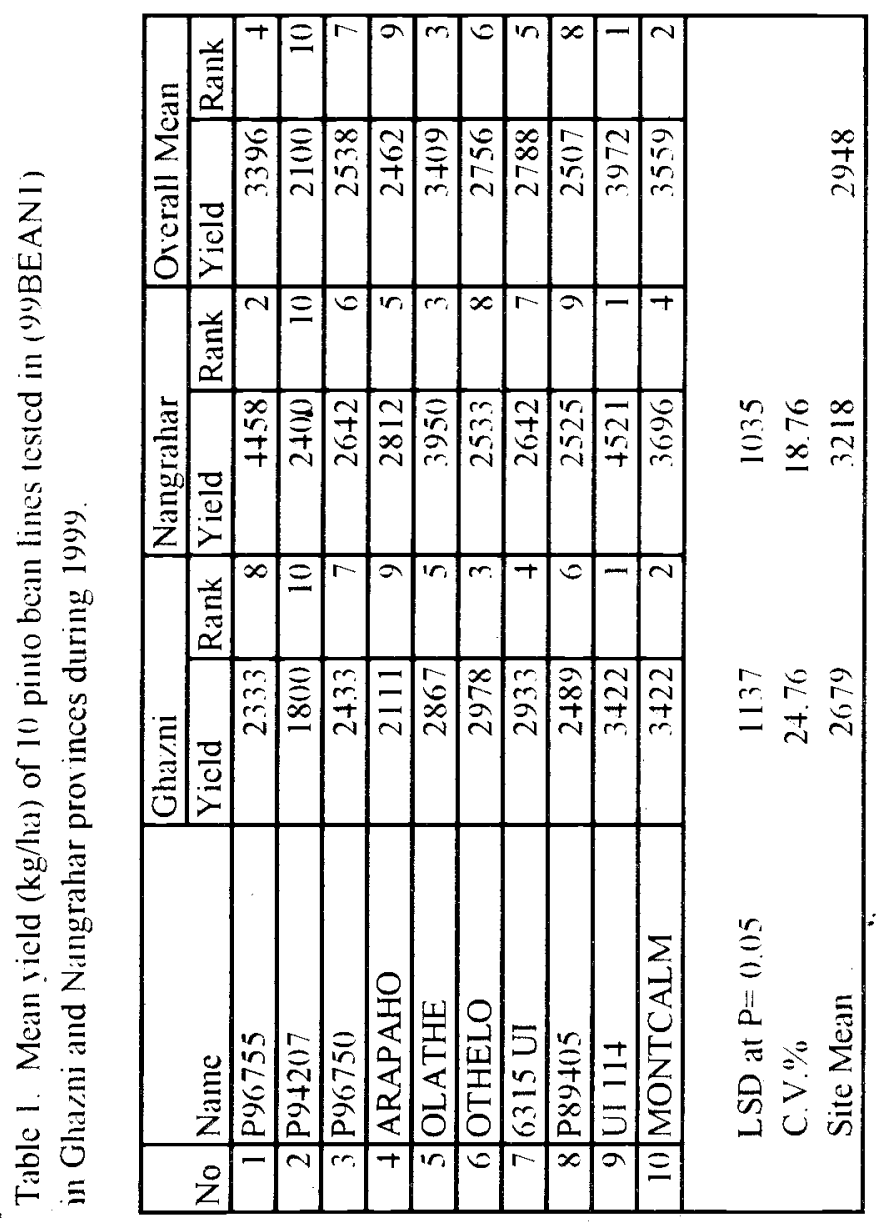




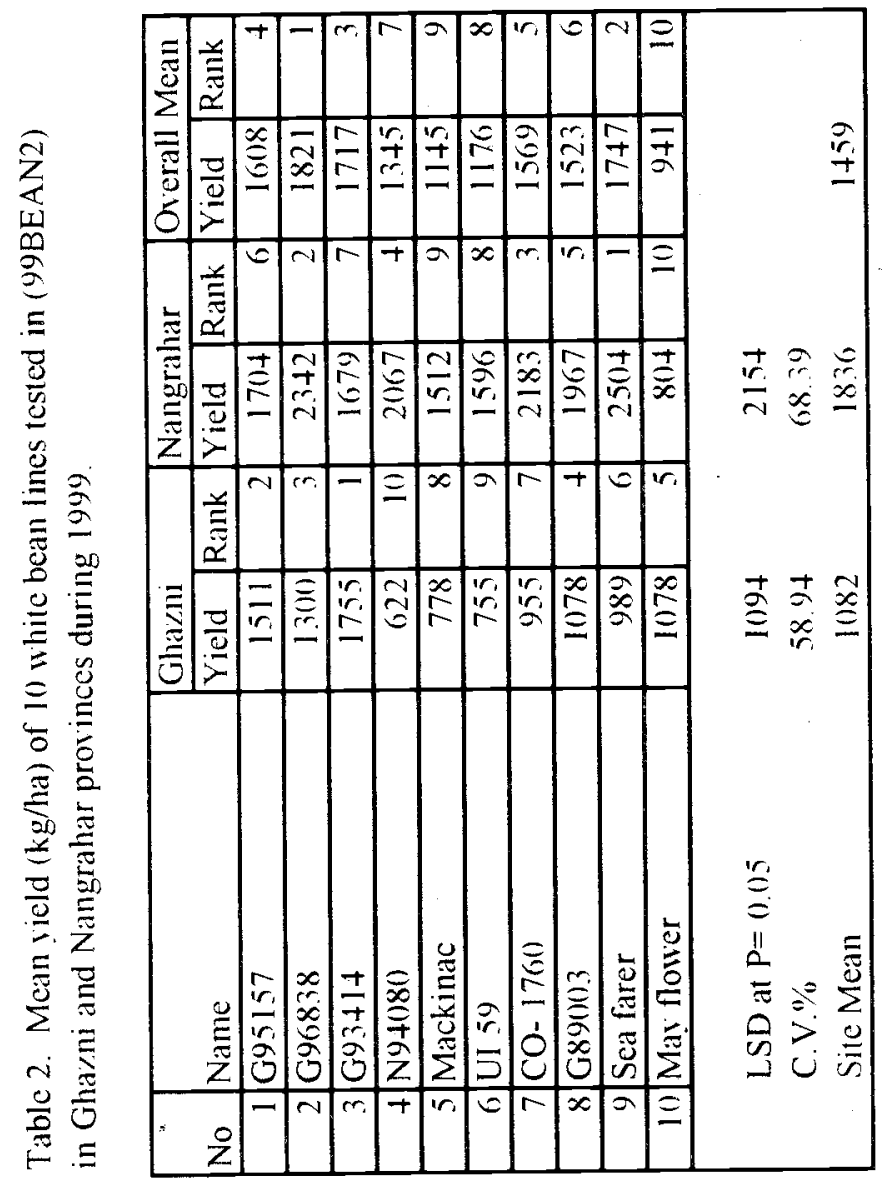




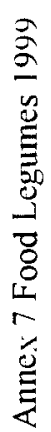

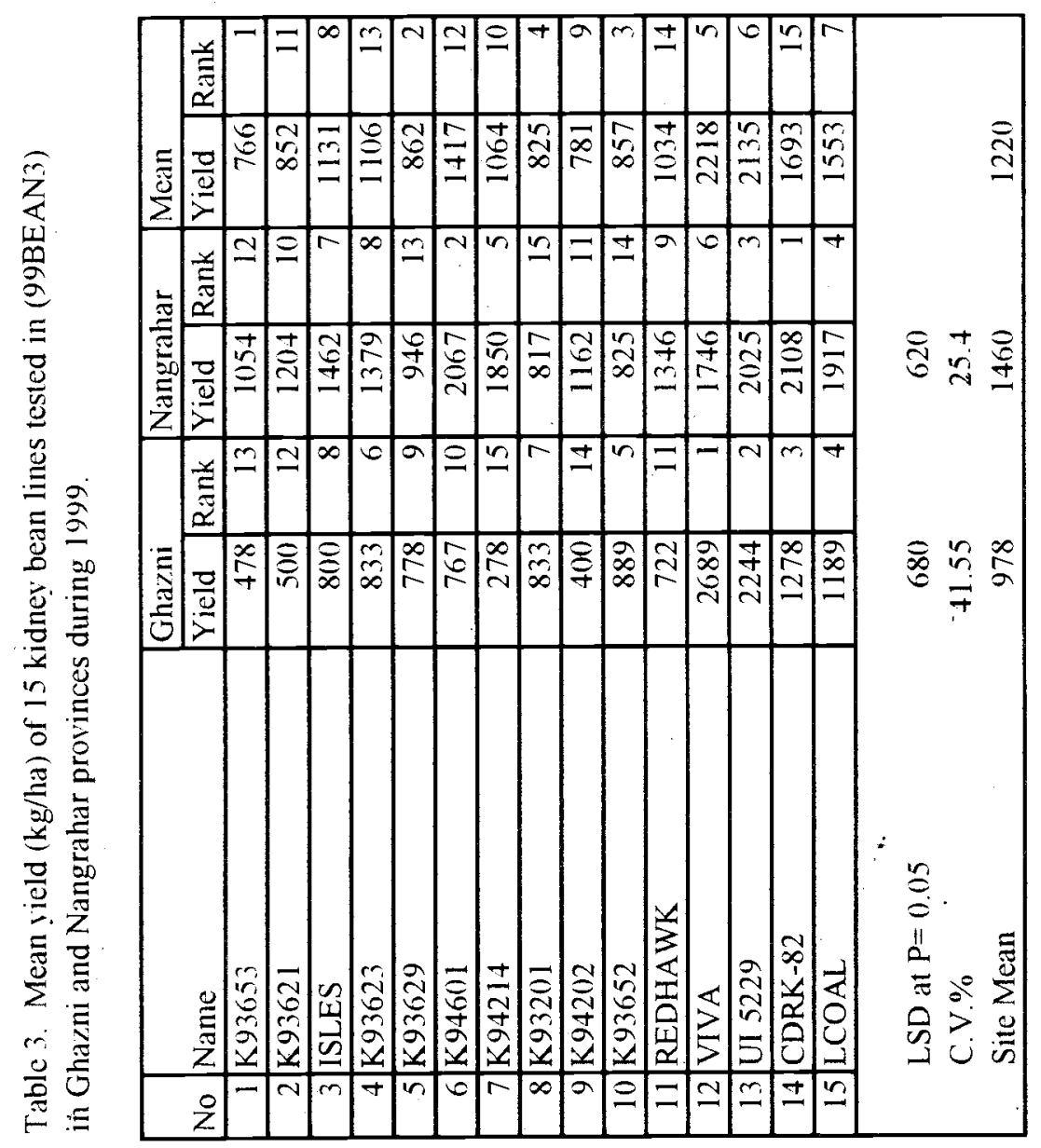




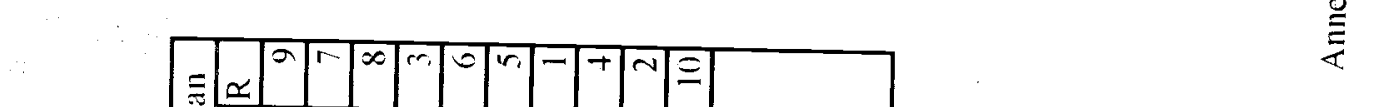

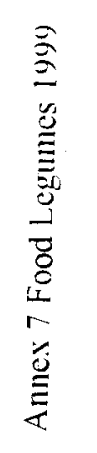

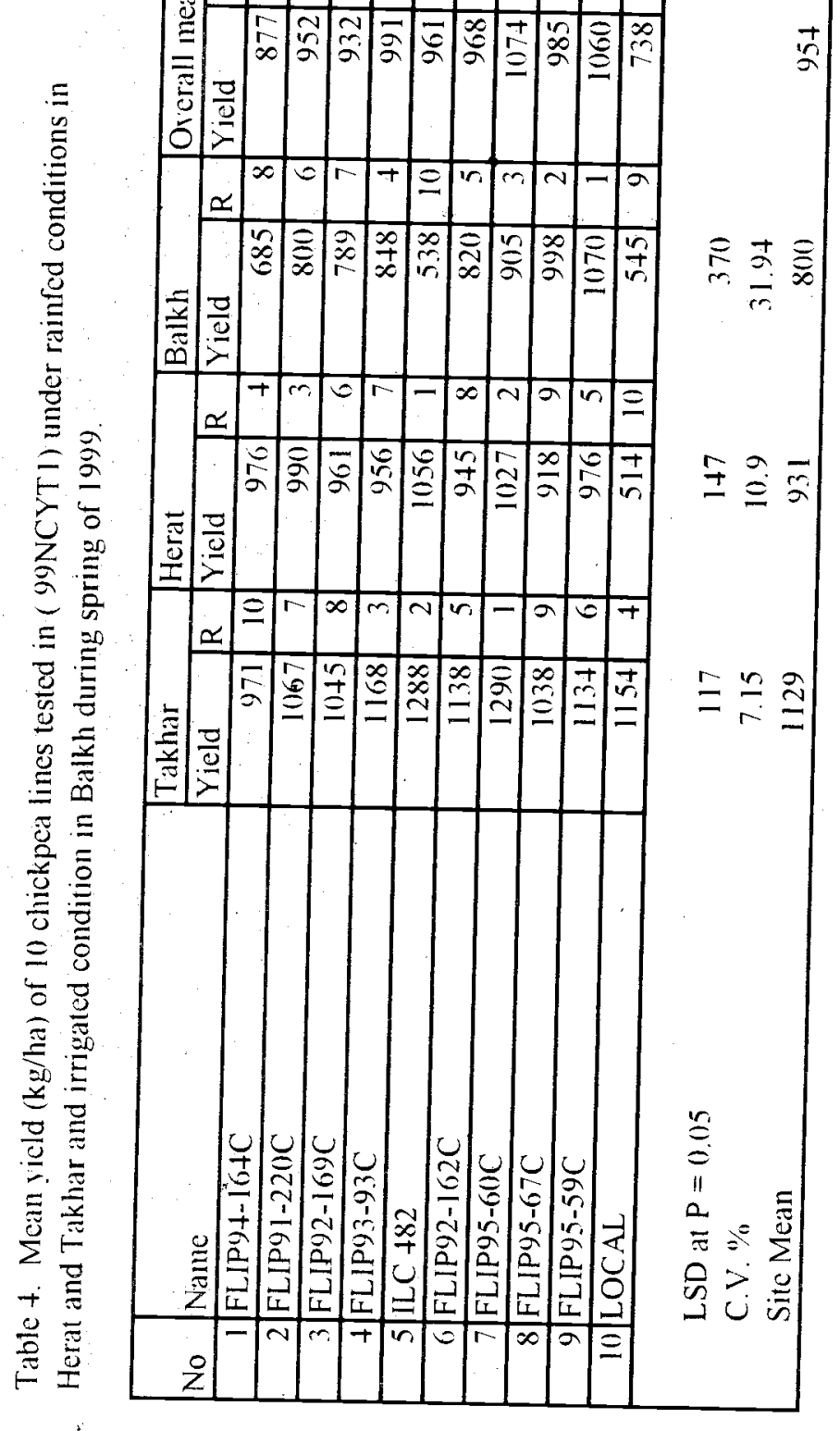




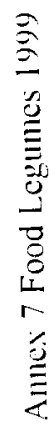

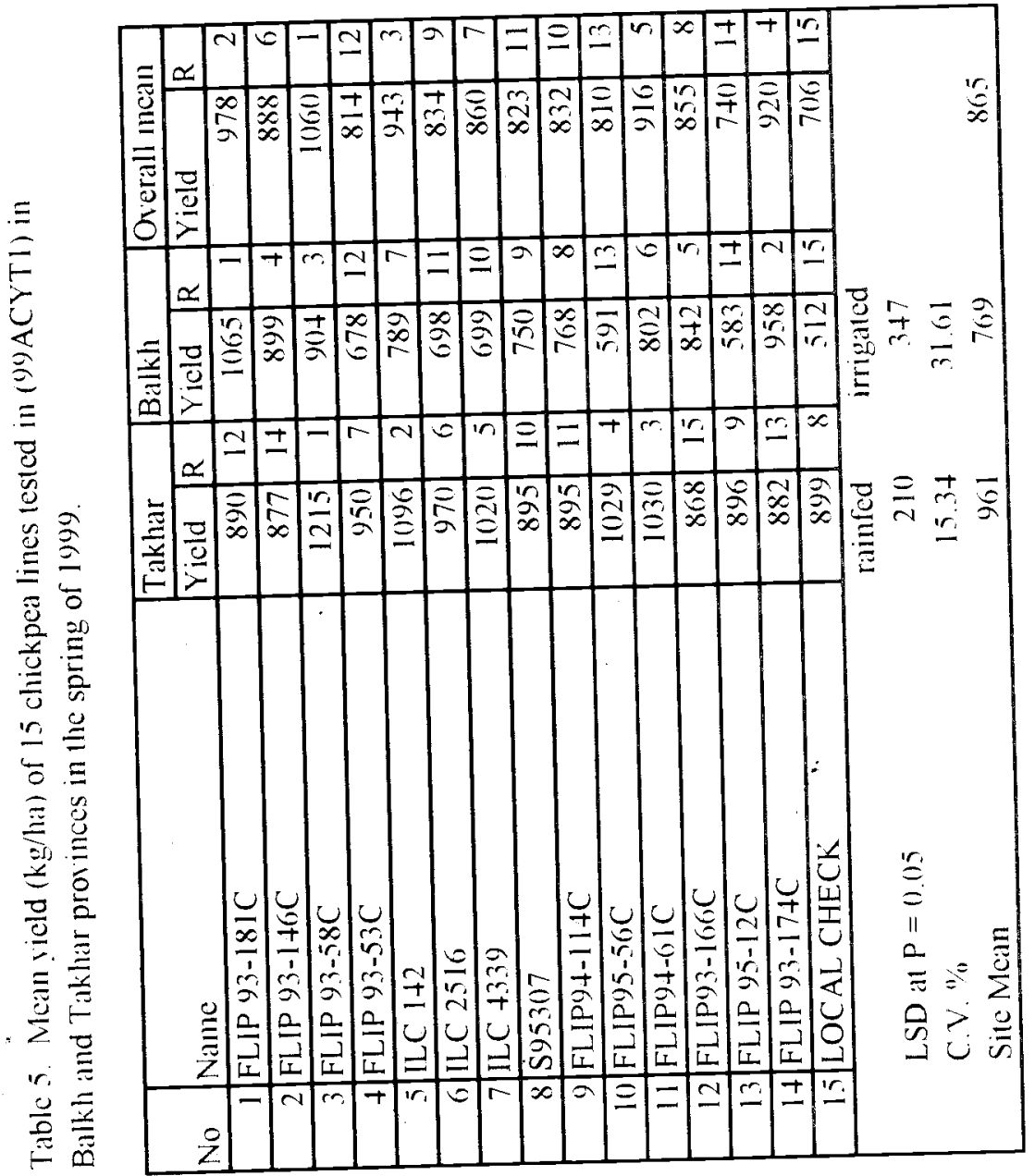




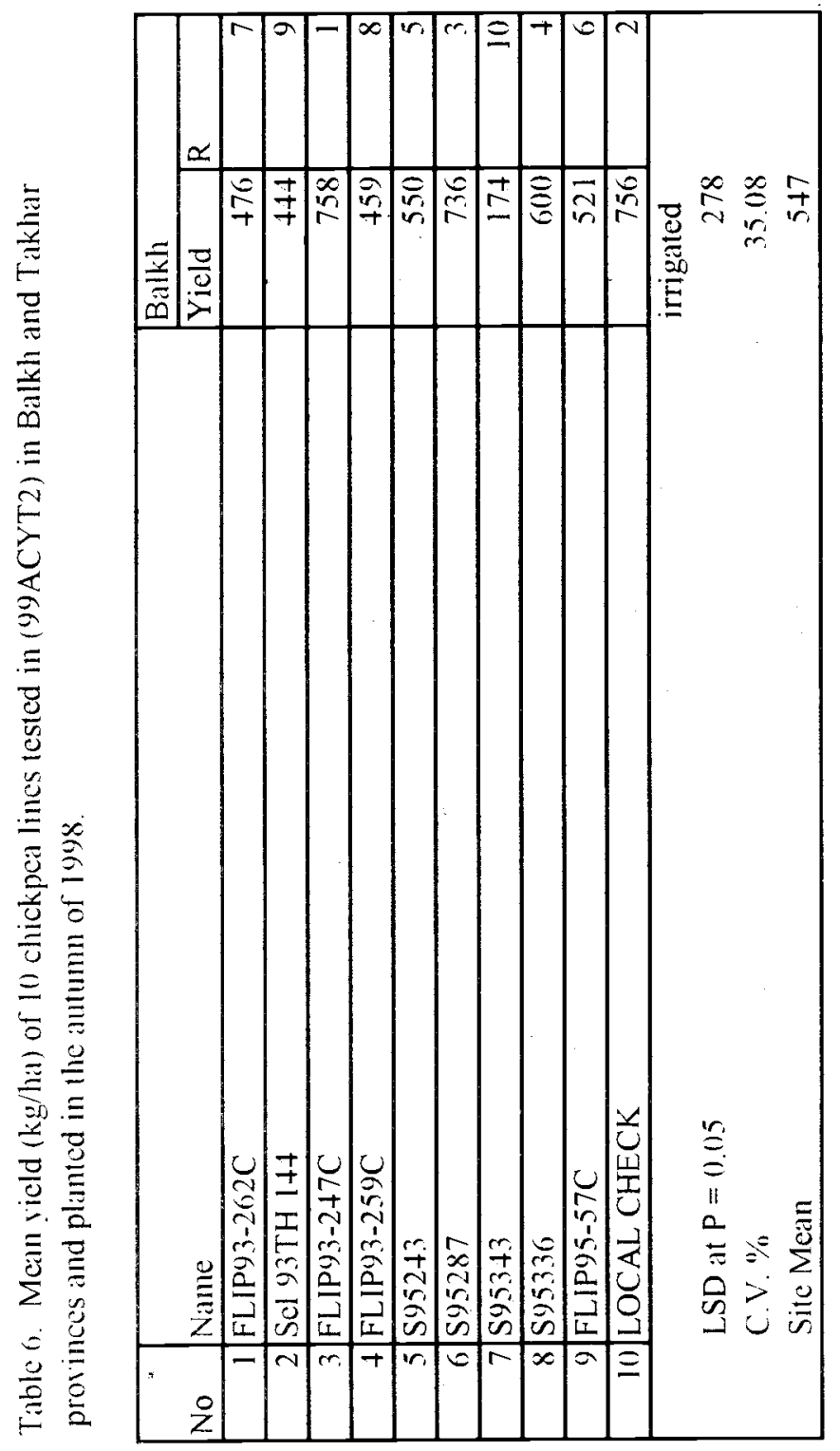




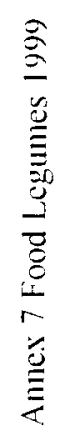

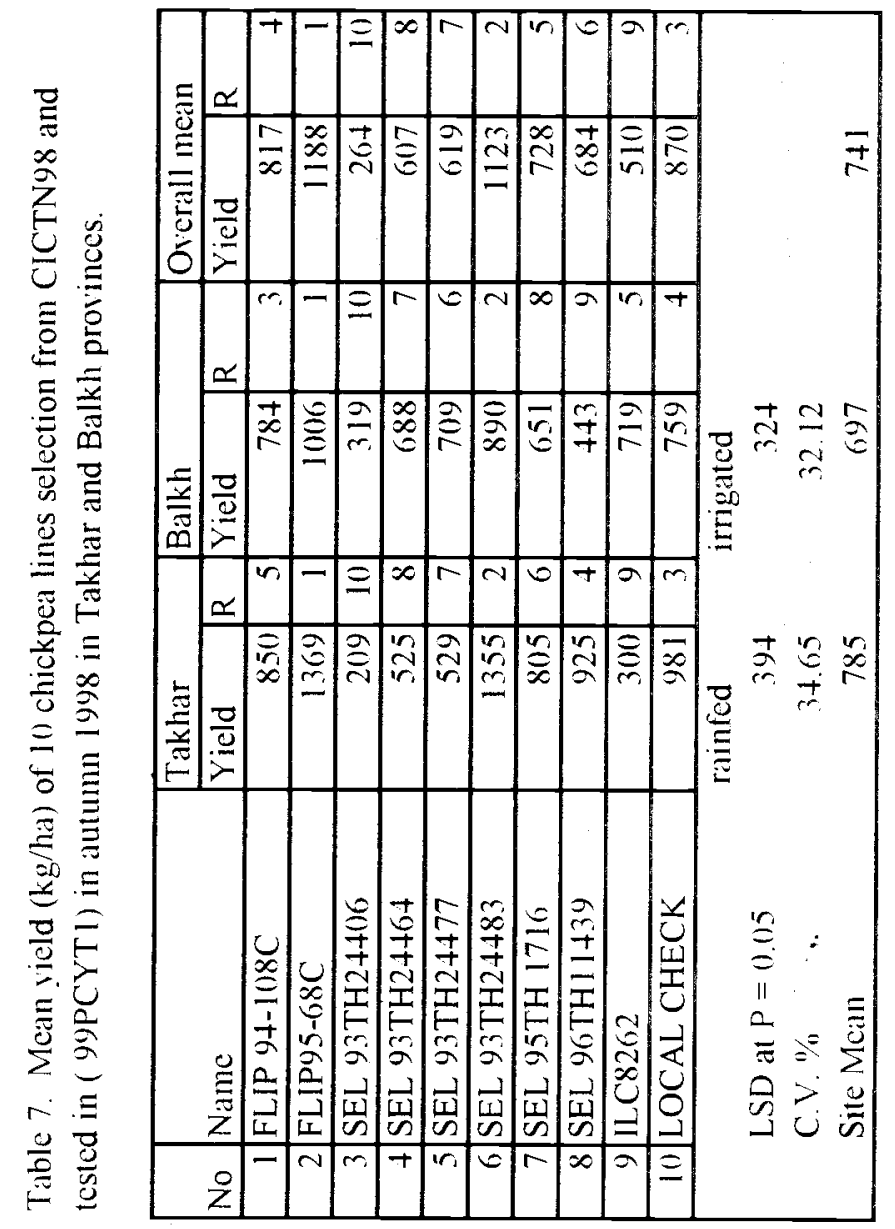




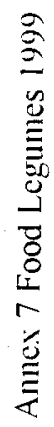

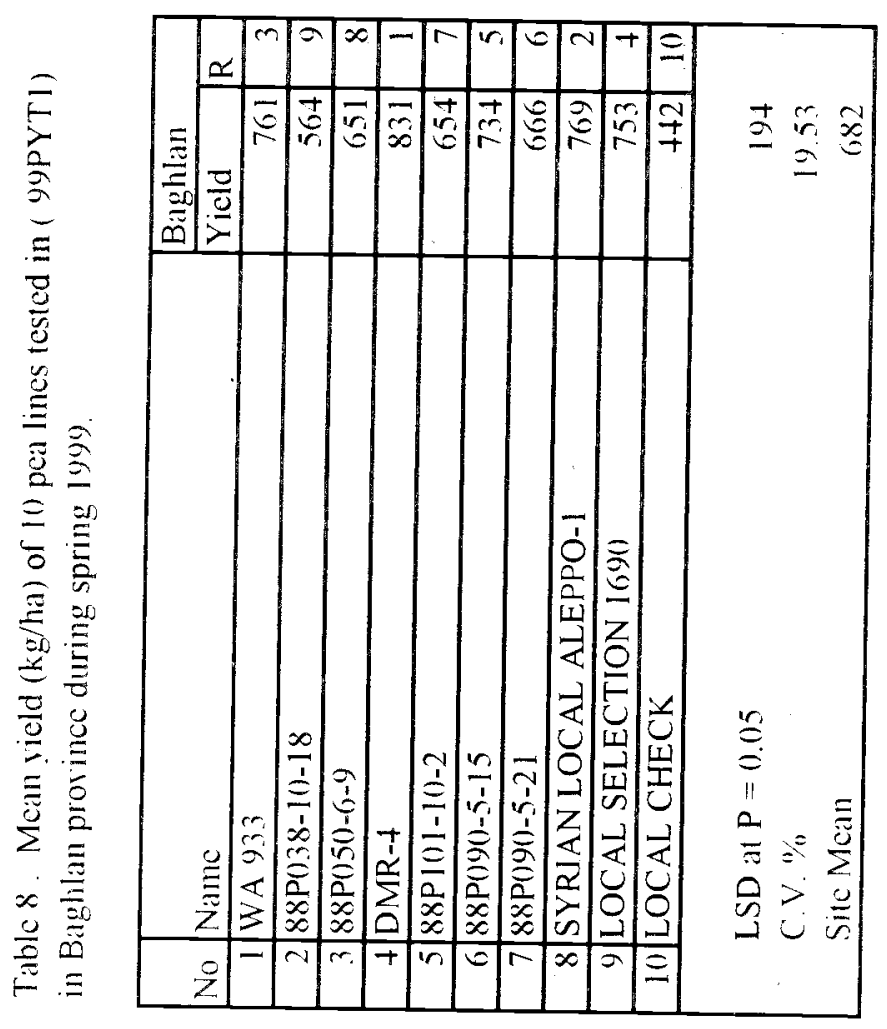




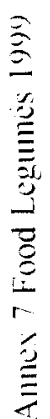

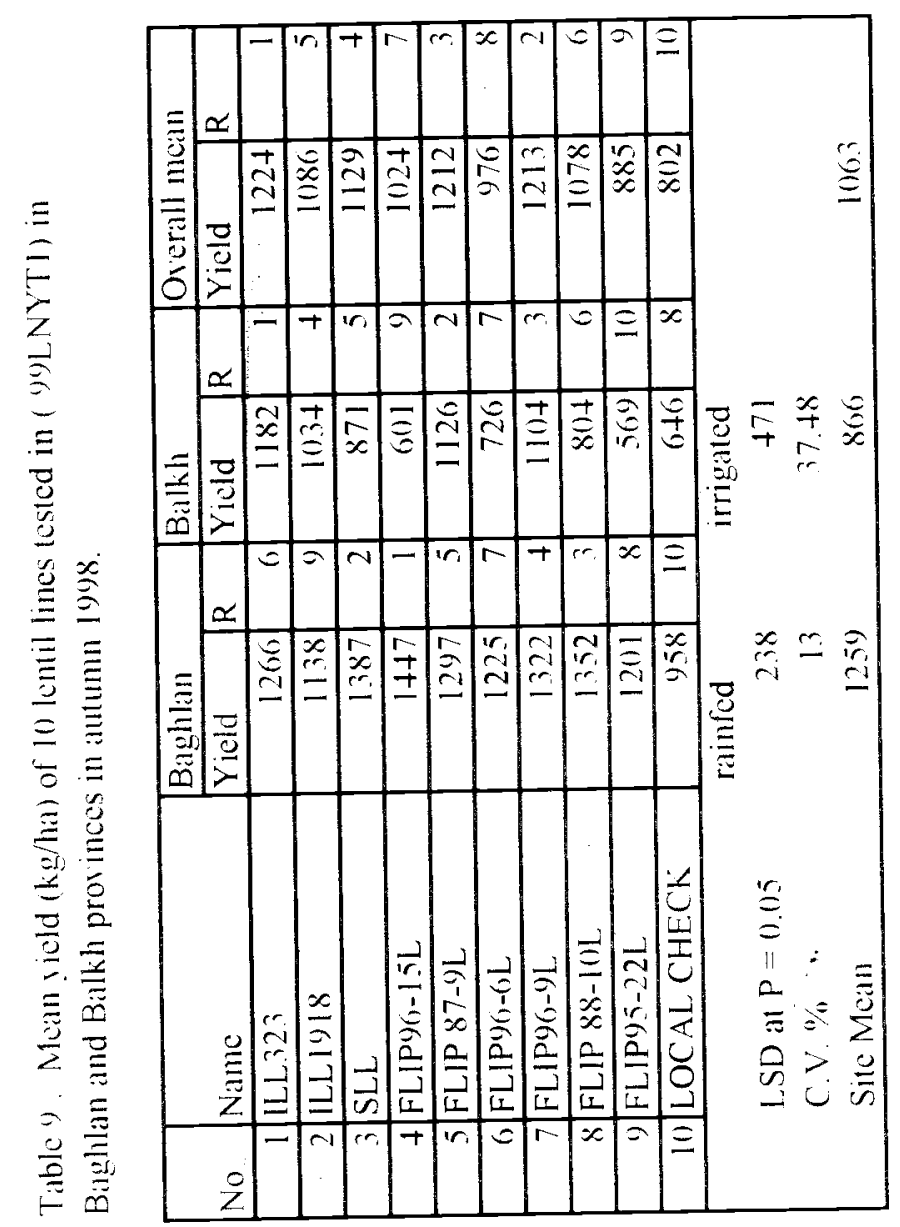




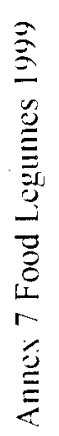

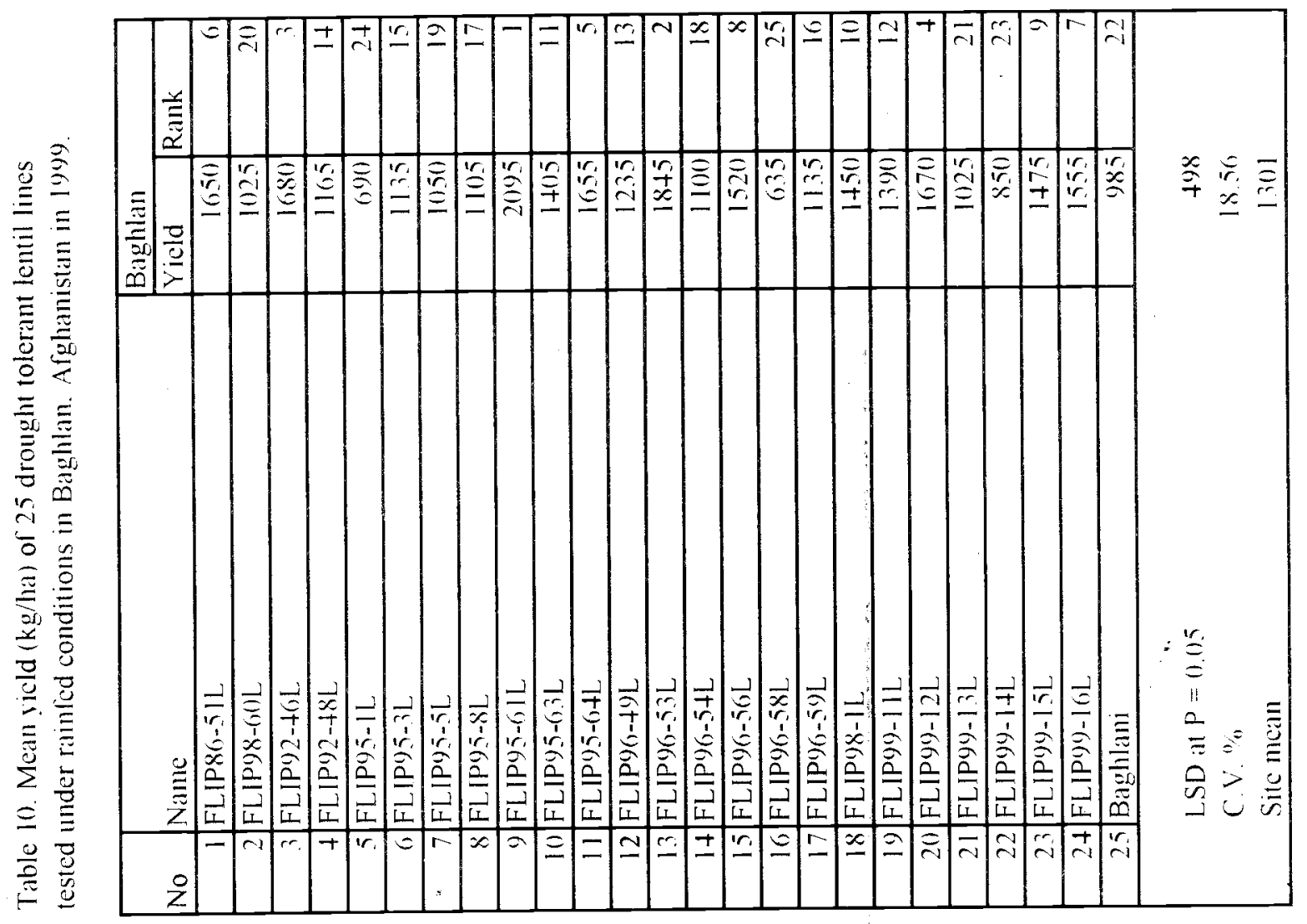




\section{Maize}

\section{Introduction}

Maize (Zea mays L.) is one of the most important cereal all over the world. Total areas covered in the world by maize is 129.8 million hectares (CIMMYT, 1990-1992). The areas covered by maize in Afghanistan reported 200,000 hectares with total production of 240,000 MT in 1998 (FAO production year book 1998). Maize is grown in Afghanistan for grain and forage production. The yield of maize in developed countries rapidly increased from 5 tons to almost 15 tons/ha. (grain yield) by using the hybrid seeds with advanced management practices. Under research and control conditions in Afghanistan the yield of maize was reported from 5-7 tons/ha.

Maize hybrid seed production is not practiced in Afghanistan, because hybrid seed production is expensive and also yearly replacement of seed is very difficult. Therefore the best varieties under Afghan conditions are open pollinating and synthetic varieties.

The old synthetic varieties released in Afghanistan were Synthetic-1, Synthetic-2 and Synthetic 551. Local varieties were also grown in each zone. The synthetic varieties were higher yielders than local, but due to genetic contamination and disease (smut) they lost their yield potential gradually and are replaced by new varieties recently introduced to Afghanistan.

In 1999 the FAO crop improvement project received 18 open pollinated lines from CMMYT. These lines were tested in Nangarhar and Kandahar provinces.

\section{Materials and Methods}

The trial was arranged in Randomized Complete Block Design (RCBD) with 4 replications. The distance between rows was $50 \mathrm{~cm}$ and between plants was $20 \mathrm{~cm}$. The depth of seeding was $5-6 \mathrm{~cm}$. The plot size was 6 rows, 6 meters long. Four central rows with 5 meters length were harvested for yeild determination, 0.5 meter was cut from both ends to avoid border effects. The fertilizer rates were 100 $\mathrm{Kg} /$ ha nitrogen in urea formulation and $60 \mathrm{Kg} / \mathrm{ha} \mathrm{P}_{2} \mathrm{O}_{5}$ Other cultural practices were applied uniformly on trials. In Kandahar the trial was planted in Dand district. During the growing season there was severe water shortage. In Nangarhar the trial was planted in Behsud district.

Statistical analysis of variance was computed for each trial and across years in multilocations testing and mean yield $\mathrm{kg} / \mathrm{plot}$ were changed to $\mathrm{kg} / \mathrm{ha}$. The yield, days to maturity and plant height data for each line and location is reported in tables 1 .

\section{Results and Discussion}

The Nangarhar data shows significant yield differences between genotypes. Lines 1, 4-6, 8, 9, 12, 13 and 15 are top yielding and significantly higher than the yield of the remaining lines. The yield differences between these lines are not significant. The five highest yielding lines are 12, 8, 4, 1, and 6 with mean yields of 5549,5061, 4983, 4676 and $4647 \mathrm{Kg} / \mathrm{ha}$. These lines have ranked 1, 2, 3, 4, and 5 respectively. The yields of these five lines exceed the nursery mean yield ( $4039 \mathrm{Kg} / \mathrm{ha}$ ) by 15 to $37 \%$ (Table 1). These line matured in 88 to 90 days. The plant height of these lines $225 \mathrm{~cm}$ to $305 \mathrm{~cm}$. 
In lines 5, 8-12, and 14 are the highest yielding. These lines are significantly higher yielding than the remaining lines. The five highest yielding lines are $8,5,14,11$ and 10 with mean yields of 7012,6600 , 6457,6114 , and $6107 \mathrm{Kg} / \mathrm{ha}$. These lines have ranked 1, 2, 3, 4, and 5 respectively. Their yield increase over the nursery mean yield is 10 to $27 \%$. In this location these line have matured in closed to 120 day and have heights raning from $205 \mathrm{~cm}$ to $260 \mathrm{~cm}$.

The two locations combined yield data shows that the top five yielding lines are $8,12,5,4$, and 6 with mean yields of $6037,5812,5611,5339$ and $5172 \mathrm{Kg} / \mathrm{ha}$. These lines have out yielded the nursery mean by 8 to $26 \%$ and include both flint and dent types of maize population. These populations can be carefully evaluated and selected for increase and distribution to farmers. 


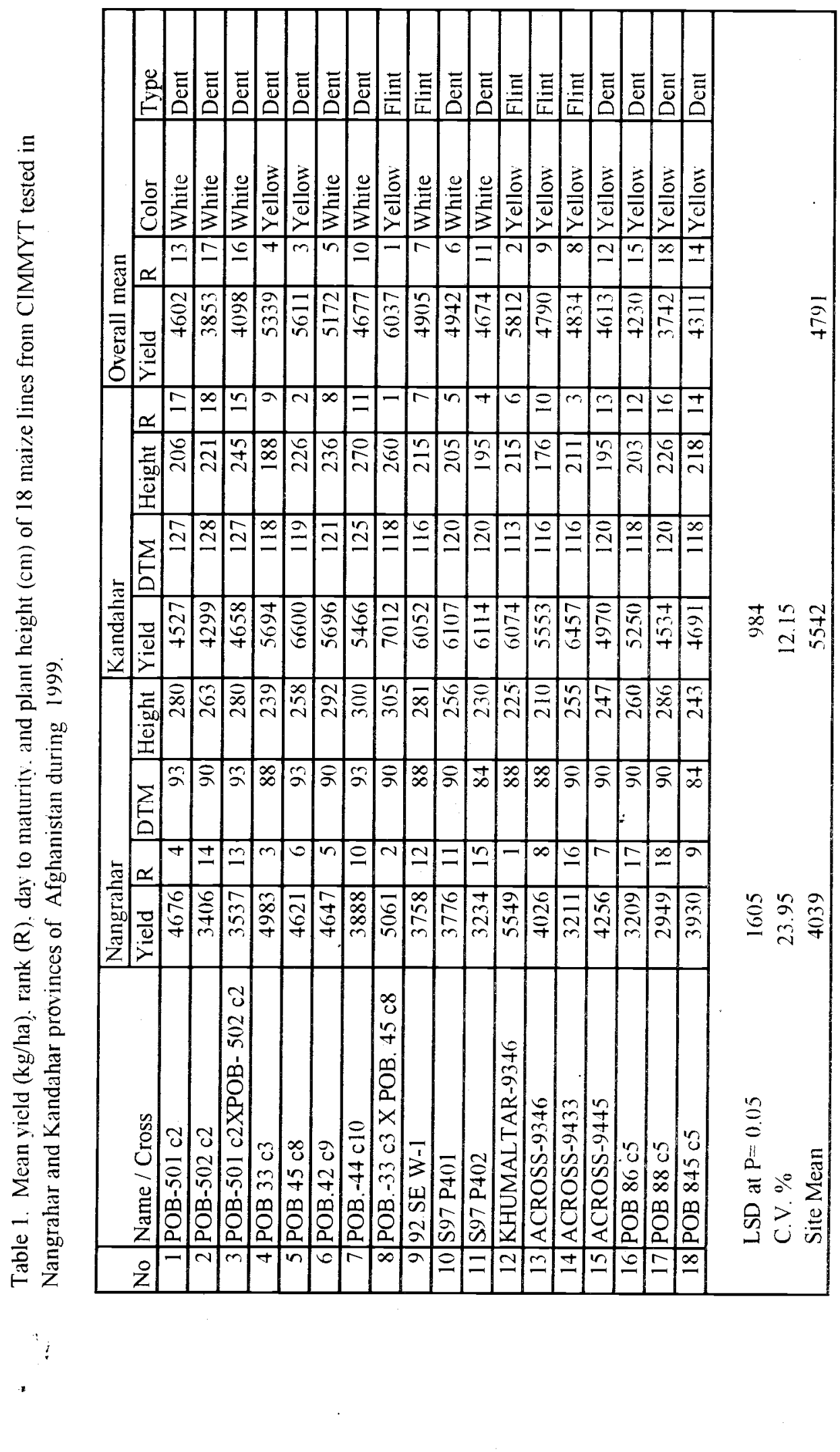




\section{Achievements of Crop Improvement Project}

\section{Introduction}

Crop Variety development, its multiplication and extension to farmers fields is a basic component of food security of a nation. The project AFG/94/A02 (UNO/AFG/001/DPS) with the financial support of SIDA was launched in 1996 in six locations ( Balkh, Takhar, Heart, Kandahar. Ghazni. and Nangarhar provinces ) representing six agro-climatic zones of Afghanistan. The objective of this crop improvement project is to achieve sustainable food security through increase in yield per unit area. This objective has been addressed by testing and selecting varieties of improved crops cereals ( wheat, rice, maize, barley), and pulses( bean, chickpeas, lentil. pea) that are high yielding pest and disease resistant and adaptable under Afghan conditions. This is a continuous process and the crop improvement component must do the technical work in order to meet the improved crop varieties seed requirements of farmers in all part of Afghanistan. This project has tested germplasm for evaluation from CIMMYT, ICARDA, IRRI. CIAT and NARC Pakistan in yield trials and observation nurseries under diverse agro climatic conditions.

The importance and significance of the achievement of this project can only be recognized by scientists and those decision makers who are familiar with the processes of crop varietal development, release and its impact on food security of Afghanistan. In both industrialized and less developed countries, there is a team of scientists ( plant breeders, plant pathologist, entomologist. agronomist) who are working to develop and release improved varieties in each crop. The time frame for crop variety release from hybridization to release is 8 to 12 years and for each crop there is a specialized team of core scientists. The maximum life span of a new improved variety is ten years. In this project a team of Afghan scientists and one senior technical adviser have worked on seven crops ( whet, rice, maize, barley, dry beans, chickpea and lentil) and their achievements are discussed as follow:

A. Wheat (Triticum aestivum L ): This project has been very successful in releasing new genotypes in wheat, rice and pulses. Ten new wheat varieties have been released and recommended for multiplication. Breeder nucleus, pre-basic and basic seed of these varieties has been produced and given to the seed component in all six zones of the country.

Wheat varieties released for irrigated conditions are Kauz, Rana-96, Roshan-96, Gul-96, Takhar96. Amu-99, Heart-99 and Mazar-99. For rainfed conditions the project has developed two wheat varieties Dayma-96 and Ghori -96. These improved varieties on the average under irrigated situation produce $3 \mathrm{MT} / \mathrm{ha}$, but in research plots and on progressive farmers field yields ranges from 6 to $7 \mathrm{MT} / \mathrm{ha}$. For dry land agriculture the yield average has been recorded as $1.5 \mathrm{MT} / \mathrm{ha}$. The salient attributes of these varieties are:

1. Kauz (JUP/BJY//URES) is a facultative bread wheat variety of Mexican origin with wide range of adaptability in lower elevations of Afghanistan. Its pedigree is CM7458-4y-1M-3YIM-3Y-08-OSY. Kauz has been tested from 1991-1997 in different trials. It was selected and tested in preliminary wheat trial in 1994. In 1995 it was tested in wheat trials in Takhar and Baghlan provinces. In 1996-97 It was tested in National Wheat Yield Trials in 6 zones (Ghazni, Herat, Kandahar, Nangrahar, Balkh, and Takhar). It has amber grain color and white chaff color. Its response to stem rust is zero, to stripe and leaf rust is MR and R 
respectively. The score to leaf blotch is 3 on (0-9) scale. It is resistant to lodging and has a height of $86 \mathrm{~cm}$. The average number of days to maturity was 284 days in Ghazni, 199 in Herat, 182 in Kandahar, 176 in Nangrahar, 197 in Balkh and 203 in Takhar. The thousand Kernel weight of Kauz is 38 grams. The mean yield from 1991-99 in 44 Location is 5.5 $\mathrm{Mt} / \mathrm{ha}$. In comparison to Pirsabak-85, the long term check it has produced $14 \%$ more yield.

2. Gul-96 (D8009994.W./VEE): It is a facultative bread wheat with prostrate growth habit. Its cross number is SWM 15134 and its pedigree is 2WM-OWM-OSE-1 YC-OYC. Its origin is Mexico/Turkey. Testing of this variety started in 1992 in $1^{\text {st }}$ FAWWON \#109, and $2^{\text {nd }}$ FAWWON \# 167, Logar, Wardak, Baghlan and Paktia by SCA and DACAAR under normal sowing date in the fall. It was included in ( $3^{\text {rd }}$ FAWWON\#75) 1993-94 and tested in Logar, Wardak, Gardez, Nangarhar and Kunduz provinces of Afghanistan which covers cold and mild winter areas. It has been selected and put in preliminary wheat yield trial in 1994-95 and in National Wheat yield trial in 1995-96 in Takhar, Baghlan and Balkh provinces. Also in 1996-97, it has been tested in national wheat yield trial in six zones (Ghazni, Herat, Kandahar, Nangarhar, Balkh and Takhar) provinces of Afghanistan. From 1992-99, its mean yield over 34 test sites is $5.78 \mathrm{Mt}$./ha which is $26 \%$ more than Pirsabak-85. The number of days to heading from January first in Baghlan was 142, 165 in Paktia, and the days to maturity from January first was 206 in Paktia. The dates of maturity was 287, 207, 191, 181, 208 and 213 respectively. The 1000 kernel weight is 44 grams, test weight of $75.3 \mathrm{~kg} / \mathrm{hl}$ and the number of grains/spike is $5 \mathrm{I}$. It is of medium maturity with average plant height of 98 $\mathrm{cm}$. It is resistant to stripe and leaf rusts with a score of O-MR. It has a high degree of winter hardiness. The grain color is amber with medium size of grain and white chaff color.

3. Takhar-96 (VEE \# 7/OPATA): This line was selected from 152 lines from CIMMTY, line \#50 in 199l. It is a bread wheat line with erect growth habit and good agronomic ratings. It has been tested from 1992-97; in national wheat yield trials in different parts of Afghanistan. In 1996-97, it was tested in Ghazni, Herat, Kandahar, Nangarhar, Balkh and Takhar provinces of Afghanistan. In national wheat yield trials, the number of days from planting to maturity was $281,195,172,201$ and 204 respectively. It has an average plant height of $99 \mathrm{~cm}$. The grain color is amber and its chaff color is white. Its 1000 Kernel weight is 41 grams and the number of grains/spike are 60. The response to stripe, leaf and stem rust is $\mathrm{R}$, and it is resistant to bunt and septoria. The yield potential is high, and its mean yield from 1992-99 in 34 test sites is $5.36 \mathrm{Mt}$./ha. In comparison to Pirsabak-85 it has given 14\% higher yield.

4. Roshan-96 ( Bloundan/3/Bb/7C*2//Y50E/Kal*3): It was introduced to Afghanistan in 1994 and 1995 in the Regional Bread Wheat Yield Trial for favorable environments from ICARDA. It was selected and included in National Wheat Yield Trials in 1995 in Baghlan and Takhar provinces and was an entry in the Elite Wheat Yield Trial of CIMMYT in Baghlan. In 1996-97 crop season this line was tested nation wide in six locations (Ghazni, Herat, Kandahar, Nangrahar, Balkh and Takhar provinces) and in 1998 and 1999 it was tested in 13 locations. This bread wheat line has white grain and chaff color. It has erect to semi-erect growth habit with a mean plant height of $94 \mathrm{~cm}$ and a 1000 kernel weight of 42 grams. The average number of days to maturity of this line are 286, 191, 179, 208, and 209 in the above provinces respectively. The stripe rust reaction of this line is $0-\mathrm{R}$ and with a score of 3 for leaf blotch (0-9 scale). It has shown resistance to bunt and smut diseases. Its mean yield (1994-1999) over 29 locations in Afghanistan is $5.55 \mathrm{Mt}$./ha which is $15 \%$ higher than the long term check of Pirsabak-85 (4.82 Mt./ha) in 40 locations. It is widely adapted and has superb bread making quality. 
5. Rana-96(CA8055 /6/ PATO®/ CAL /3/ 76 // BB /CN015 / CAL // CNO / SN64 /4/ CNO // NAD / CH ): It is a facultative bread wheat with prostrate to semi erect growth habit. The cross number is ICWIt 840431 and pedigree is 2AP-2AP-2AP-lAP-0AP. It was introduced in the $1^{\text {st }}$ FAWWON in 1991-92 to Afghanistan and planted in Logar, Baghlan, and Paktia (Jaji) by SCA. It has been tested in replicated trial from 1991-97. In 1996-99 it was tested in national wheat yield trials in Wardak, Herat, Balkh. Takhar, Ghazni, and Logar provinces of Afghanistan. Its days to maturity are 268, $199205,208,284$ and 269 respectively. The response to stripe rust is (O-R) and to leaf rust is MS. The average piant height is $95 \mathrm{~cm}$. The grain color is white and its agronomy rating is 4 . Its test weight is 75 $\mathrm{kg} / \mathrm{hl}$, and the average thousand grain weight is $43.5 \mathrm{~g}$. The average yield from 1991-99 in 33 locations is $5.02 \mathrm{Mt}$./lła Compared to Pirsabak-85, it has given $14 \%$ higher yield over years and locations. It is a soft white wheat with $16.5 \%$ protein.

6. Ghori-96 ( PRL"s"/PEW) : This is bread wheat lines that has performed well under rainfed conditions. This lines has been tested in Afghanistan since 1990-91 crop season when it was included in Regional Bread Wheat Yield Trial for Low rain fall areas (RBWYTLRA90-91\#15). Its pedigree is (CM59377-3AP-1AP-3AP-2AP-1AP-0AP) and its origin is Mex/Syria. Since that time it has been included in rainfed yield trials in Takhar, Baghlan and Balkh provinces. In 1996-97, 1997-98, 1998-99 crop seasons it has been tested in two districts in Herat, one district each in Balkh and Takhar provinces under rainfed conditions of Afghanistan. The stripe rust reaction of this line was recorded $0-\mathrm{MR}$, its leaf rust reaction is $R$. The average maturity of this line in two locations in Herat was 175 day, while in Takhar and Baghlan it was 113 days. It has amber grain color and yielded $1.38 \mathrm{Mt}$./ha in test plots (1992-1999) in 15 locations. It has a protein content of $13 \%$. This line is released for dry land production.

7. DAYMA-96 ( HD2206/HORK//BUC/BUL ): This is an other good lines that is suitable for rainfed conditions in Afghanistan. This line was sent by CIMMYT to SCA in 1990-91 as 152 lines for observation (line \# 27). It has been tested since 1992 in a number of trials both under rainfed and irrigated conditions. In 1995 and 1996 it was tested in rainfed wheat yield trials. The average yield of this line over years (1992-1999) and locations (15) has been 1.25 Mt./ha. It is resistant to stripe, stem and leaf rusts. The number of days to maturity varies from 175 days in Herat to 113 days in Baghlan and Takhar. It is an early variety and if planted earlier than other varieties, it will have $35-40 \%$ bird damage. It has amber color and weighs 35 gram per 1000 grains.

8. AMU- 99 (Bloyka) has been selected from 96 RBWYTFA\# 4 and the pedigree is ICW840008-013AP-300L-3AP-300L-0AP. The overall mean yield from 1997-99 in 21 trials in six zones was $5.8 \mathrm{MT} / \mathrm{ha}$. In warm winter such as Kandahar and Nangarhar it matures earlier as an average it takes 145 days to heading and 185 days to maturity. While in mild winter areas such as Herat, Balkh, and Takhar it takes about 162 days to head and 204 days to mature. In cool areas such as Ghazni the number of days to heading is 217 and to maturity it is 267 days. The growth habit is erect and the chaff color is white and the grain color is amber. The average plant height is $100 \mathrm{~cm}$. The response to yellow rust is MR-R and leaf rust it showed 0 -TR. reaction.

9. HEART-99 (MYNA/ VUL // PRL). The pedigree of Herat-99 is CM97958-0M-7YQ30M-030M-84-0M. The average yield in six zones is $5.4 \mathrm{MT} / \mathrm{ha}$ from $1977-99$ in 20 
replicated trials. The response to yellow rust is MR-R and the response to leaf rust is recorded $0-\mathrm{MR}$. The grain color is amber and the chaff color is white. The number of days to heading and maturity differs from regions to regions, but it takes 141 and 182 days from planting to Heading and maturity in warm areas such as Kandahar and Nangarhar. In mild winter areas in fall planting such as Takhar Balkh, and Herat it takes 163 and 205 days from planting to heading and maturity. In cool areas such as Ghazni it takes 228 days to head and 291 days to mature. The growth habit is erect and the average plant height is $96 \mathrm{~cm}$.

10. MAZAR-99 (Pasture) is selected from 15ESWYT\#18 and the pedigree is CM852950101 TOPY $-2 \mathrm{M}-0 \mathrm{Y}-0 \mathrm{M}-3 \mathrm{Y}-0 \mathrm{M}$. The chaff color is white and the grain color is amber. The average yield from $1997-99$ in 20 trials is $5.6 \mathrm{MT} / \mathrm{ha}$. The response to yellow rust is MR-R and the response to leaf rust showed 0 - MR. The chaff color is white and the grain color is amber. The number of days from planting to heading and maturity in normal time of planting during the fall in different zones differs. In warm winter areas such as Kandahar and Nangarhar the average number of days from planting to heading are 144 and days to maturity ranges from 175- 187 days. In mild winter zones such as Balkh, Takhar, and Herat the number of days to heading is 168 and to maturity it takes 206 days the average plant height is $94 \mathrm{~cm}$. It is taller than Kauz and Ps-85 and almost has the same days to heading and maturity.

B- Barley: Is an important crop for animal feed and under drought and famine condition it can be used for bread making. The project has successfully released two barley varieties Hewad-98 and Watan-98 in the barley growing areas of the country. Their distinctive features are:

1. Hewad-98.( GLORIA-BAR/ COMB-B // ORGE FICHEDETT 3270 / ROW 906.73 is the cross and the pedigree is CMB87. 643-E-11Y-lB-1M-OB-1M-OY. This line was planted in 18 IBYT \# 14 in 1995-96 which was sent from CIMMYT/ ICARDA and was planted in Baghlan province. It is a four row barley and was selected in put in 1996-97 in NBYT in six zones of Afghanistan for further testing under different agroclimatic conditions. The average days to heading is 117 and the number of days to maturity is 146 days. The average height is $79 \mathrm{~cm}$. It is resistant to rusts and bunts. The growth habit is semi- erect and the grain texture is medium. Thousand grain weight is 37 grams. This line produced in six zones of the country $35 \%$ more yield than the local variety.

2. Watan-98: The cross is LIBRA/UNA 8271// GLORIA-BAR/COM-B/3/ SEN. The pedigree is CMB89A.291-2M-1Y-1M-OY. This line was number 17 in $18^{\text {th }} 1 \mathrm{BYT}$ trial which was sent by CIMMYT and planted in Baghlan on 29/12/95 and harvested on 10/6/95 and selected as atop yielding line and resistant to rusts and bunt. From 1996-99 it was put in ( NBYT ) national barley yield trials in six zones of Afghanistan for further testing. The average plant height is $81 \mathrm{~cm}$ and the average number of days to heading and maturity is 1.18 and 150 respectively. The average thousand-grain weight is 38 grams. The agronomy rating is very good. The grain texture is hard and size is short. Compare to Hewad 98 is taller and matures a few days later. In comparison to the local variety this line produced $31 \%$ more yield in six zones.

C- Rice: Both loing grain or fine (Indica type) and short or coarse grain (Japonica type) are grown in Afghanistan in Balkh, Baghlan, Kunduz and Takhar (Northern provinces) and Nangrahar, Laghman and Kunar (Eastern provinces) of Afghanistan. On small scale rice is grown in Herat, Khost and Wardak provinces of Afghanistan. 
Afghan local rice varieties especially fine types have good "Pilaf" making quality with special aroma which is the preferred characteristic along with good jumping quality of cooked rice. Unfortunately they are tall, have weak stem and lodge severely in response to nitrogen resulting in lowest yield. Poor cultural practices, pests and diseases are other factors that contribute to low yield of rice in Afghanistan.

Fine grain local rice varieties such as Barah, Lawangai and improved rice varieties such as Saturn, Della and Kolo Australia had been also distributed to farmers by Agricultural Research Institute in North Eastern Afghanistan. In eastern provinces ( Nangrahar, Laghman and Kunar) fine grain local varieties (Lawangai, Barah and Pashadai) and improved old varieties such as Saturn, KC-14, KC-15 and CR44-11, old exotic improved coarse grain rice varieties (Tyching Native-1 and Padma) were also distributed. These varieties are used for cooking "Shola" a typical dish of short grain rice in the country.

From a number of rice lines tested in the rice growing areas of the country, 3 varieties Swat- 2 . Afghan-98 and Baghlan-98 have been released and recommended to the rice production zones of the country. Seed of all three varieties are given to farmers.

1. Afghan-98 (RP1670-7613-3-2): It is a medium grain rice line from IRRI that can be used for both "pilaf" and "shola" cooking. It was tested in 1994 and 1995 in preliminary yield trials in long grain rice in Baghlan province. In 1996, it was tested in national short grain rice yield trials in Nangrahar, Laghman, Kunar, Balkh, and Takhar provinces of Afghanistan. In 1997, it was tested in both long and short grain rice national yield trials in Nangrahar, Takhar, and Balkh provinces. In 1998 it was tested in 8 locations and in 1999 it was tested in 6 locations The three years and 23 locations mean yield of this rice variety is $6127 \mathrm{Kg} / \mathrm{ha}$. Because of its high yield, good cooking quality, and medium grain size, its economic return is higher than the local short grain rice variety. In the long grain rice variety yield trial conducted from 1994 to 1999, this line (RP1670-7613-3-2) is the top yielding and has produced 1.5 MT/ha more yield than Basmati-385 (the current long grain ) rice variety in Afghanistan. It has an average height of $82 \mathrm{~cm}$ and matures 5-10 days earlier than Swat-2 and one week earlier than Basmati-385. It is $5-10 \mathrm{~cm}$ shorter than Basmsti-385. Farmers in Baghlan. Kunduz and Taloqan are interested in this rice line. In 1997, the crop improvement project distributed 5.5 MT seed of Afghan-98 to farmers in Baghlan, Kunduz and Takhar provinces. During 1998 a total of $668 \mathrm{~kg}$ rice was distributed to 31 farmers in 11 districts of Nangarhar. In Herat $700 \mathrm{~kg}$ rice seed was distributed to 40 farmers in Enjil and Gozara districts. In Balkh province, $519 \mathrm{~kg}$ seed of this variety was distributed to ten farmers. In Takhar the project has distributed $3000 \mathrm{~kg}$ seed of this variety to 100 farmers.

2. Swat-2: It is a short grain rice variety tested in short grain rice yield trials from 1990 to 1995 by SCA (Swedish Committee for Afghanistan) and from 1996 to 1999 it is tested by FAO in different zones of Afghanistan. It is widely adapted and is top yielding in multilocation tests every year ( $6963 \mathrm{~kg} / \mathrm{ha}$ ). It matures in 147 days and has an average height is $103 \mathrm{~cm}$. It is resistant to lodging. It matures earlier than the local varieties in Nangrahar and in Takhar provinces. The two years combined yield advantage of Swat- 2 over local check is $16 \%$.

3. Baghlan-98 ( IR62871-166-2-2): It is a long grain rice line selected from IRRI international yield trial. It was tested in 1993 in long rice yield trials in Nangrahar, Laghman and Kunar provinces. It was also tested in 1994 and 1995 in long grain rice yield trial in 
Baghlan, Nangrahar, and Kunar provinces by SCA. In 1996, it was tested by FAO in long grain rice yield trials in Takhar, Balkh, Nangrahar, Laghman and Kunar provinces of Afghanistan. From 1997 to 1999 , it is tested in national long rice yield trials in Nangrahar. Balkh, and Takhar, Laghman, Kunar, and Nooristan provinces. It is a bout $5-10 \mathrm{~cm}$ shorter than Basmati-385 (the current improved long grain) rice and 3-5 days earlier maturing than Basmati-385. The overall mean yield of IR62871-166-2-2 over years (1993-1999) and 31 locations is $5524 \mathrm{~kg}$ /ha and has out yielded Basmati-385 by over $0.5 \mathrm{Mt}$./ha. In Balkh 1014 $\mathrm{kg}$ seed of Baghlan-98 was distributed to 14 farmers in Sholgara district. In 1999, $2000 \mathrm{~kg}$ of Baghlan-98 was distributed to farmers in Kunduz and Takhar provinces.

D. Maize ( Zea mays ): Maize is an import food and feed crop in Afghanistan. It cultivation is decreasing gradually because of lack of water. Among the maize lines tested for 3-4 years in multi locations in low and high elevation zones in Afghanistan the following varieties have been recommended for different altitudes in Afghanistan.

1. SHAHEEN: is the earliest-maturing white-grain variety. Developed from a cross between 'Zia' and the very early-maturing varieties 'Nodak' and 'Mandan' from the USA, and Payette' from Canada. Because of its special characteristics of cold tolerance in addition to early maturity, it is being cultivated in the high-elevation zones of NWFP and Afghanistan, where the growing seasons are short. It was released in 1974 and is recommended for cultivation at high elevation in the mountains. It is susceptible to leaf blights and rust. Its yield is about $4000 \mathrm{~kg} / \mathrm{ha}$.

2. AZAM: White, semi-flint, mid-season variety, maturing in about 90 days. Developed from the cross ('Pirsabak 7930'x Zia) x 'Pirsabak 9730', it is of medium height with good resistance to lodging. Moderate resistance to leaf blights. Grains are bold and pearly white. Yield 5000-5500 $\mathrm{kg} /$ ha. Released in 1983. Considerably improved through half-sib family selection for disease resistance, uniformity. and plant type. It is a very good variety for the irrigated plains and is moderately drought tolerant.

3. KISSAN 90: Another good, short to medium-duration, white-grain variety recommended for irrigated as well as good rainfed areas. Derived from a cross between a well-known experimental variety, 'Pirsabak 7930', and a leading local germplasm, using a full-sib family selection scheme. Has short plant type, with low ear placement, and can tolerate high plant densities. Matures in about 85 days and can be grown late in some parts of NWFP, after Virginia tobacco is harvested. Moderately resistant to Helminthosporium maydis. Yield potential higher than that of 'Azam'. Approved for general cultivation in 1990. Also planted in the lowlands of Afghanistan.

4. SARHAD YELLOW: Full-season (110-115 days), yellow-grain variety, developed from a cross between 'Vikram' x ('B57' x 'B37') x 'Akbar'. Height 2.3-2.5 m. Plant type resembles US temperate germplasm. Ears long, kernels dent-flint, arranged in 14-18 rows on the ear. Released in 1971. An excellent yellow variety in the full-season group. Also popular in the low-land, warmer areas of Afghanistan. Yield about $7000-8000 \mathrm{~kg} / \mathrm{ha}$. 'Sarhad Yellow' is moderately resistant to leaf blights.

5. SARHAD WHITE: White version of 'Sarhad Yellow'. White grains were selected from 'Sarhad Yellow', increased and tested for yield adaptation and maturity. Sarhad White is comparable to 'Sarhad Yellow' in yield, maturity, and adaptation, but is susceptible to leaf blights. Released for general cultivation in 1974. 
6. EHSAN: Mid-season, white flint variety. Developed from the cross between 'Sarhad White' and lot 81 of CIMMYT material. Matures in 100 days. An outstanding variety in this maturity group. Ears of medium size, compact with 14-16 kernel rows. Even after the ears are harvested, the plant stays green and its stalks remain sweet. It has much better resistance to stalk rots and leaf blights than any other varieties. Its yield is about $7000 \mathrm{~kg} / \mathrm{ha}$.

7. PAHARI (EV-II): A short-duration variety bred specially for production in the cool mountain environment. Developed at Kaghan through half-sib family selection from the cross of 'Shaheen' $x$ 'Pirsabak 7930'. 'Pahari' has the earliness and cold tolerance of 'Shaheen' and the disease resistance of 'Pirsabak 7930' it was released in 1992 for mid-elevation zones from 1000-1800m above sea level. But it can also be recommended for late planting following Virginia tobacco. Its yield on mid elevations is about $5000-7000 \mathrm{~kg} / \mathrm{ha}$.

8. SUNEHRI: Midseason June/early July planting 110 days at low altitude and 120 days at mid altitude up to $1300 \mathrm{~m}$.

9. POPULATION-31: Midseason June/early July planting 110 days at low altitude and 120 days at mid altitude up to $1300 \mathrm{~m}$.

E. Food legumes : In food legumes the project has identified 4 bean lines Viva (Barakat-99, Slamati99( 5229 UI ) Arzo ( CO-1760) and Bara -99 (Arapaho). Two chickpea lines Madad-99 ( Flip93-53C) and Sehat-99 ( Flip93-58C) have also been released to farmers, their description is as follows:

1. Beans ( Phaseolus vulgaris ): Since 1992 (IBYAN) International Bean Yield and Adaptation Nursery from CIAT and (MSU) Michigan State University at United States were tested in different locations of Afghanistan. From these trials 9 top yielding lines were selected and put in National bean trials in Logar. Wardak, Baghlan and Nangarhar provinces of the country for further testing during 1996-1997. During 1998 these lines were separated into 3 trials pinto, white and red types which was composed of 10,10 and 15 lines respectively in Nangarhar and Ghazni provinces. The results of the experiments from $1992-$ 1999 was summarized and showed that the following lines are the top yielding lines and should be multiplied in bean growing areas of the country.

1. The name Barakat-99 is given to (VIVA). This line was sent to FAO from MSU. This is kidney bean line and was tested in Baghlan, Logar and Wardak from 1992-1995 in dry bean trials. The seed color is light red or pink. The average number of seeds per pot is 4 . This line is an early maturing and the average number of days to flowering is 38 and to maturity it takes 90 days. The plant height is $28 \mathrm{~cm}$. Its growth habit is bush type. This line produced $75 \%$ more yield than the local line.

2. Salamati-99 is the name given to ( U1 5229). This is a bush type kidney bean and has dark red color. It was tested from 1993-1999 in different locations of the country. The average number of days to flowering and maturity is 49 and 97 respectively. The plant height is $35 \mathrm{~cm}$ and the number of seed/pod is 4 . This line was sent to FAO from MSU. It produced $56 \%$ more yield than the local line in 11 locations and 5 years.

3. ARAPAHO : This is a climbing and pinto type bean. The plant height is $45 \mathrm{~cm}$ and the average number of days to flowering and maturity is 46 and 91 . The number of seeds/pod is 4 . This line produced in 12 locations and 5 years $50 \%$ higher yield in compare to the local. This line was sent to the project from MSU. It has been named Bari-99. 
4. CO-1760 : This bush type beans and has white color. This line was introduced from MSU and tested in different locations of Afghanistan from 1992-1999. The average number of days to flowering and maturity is 38 and 96 . The number of the seeds /pod is 3 and the average plant height is $43 \mathrm{~cm}$. It produced in 13 locations and 5 years the amount of $41 \%$ more yield than the local line. It has been named Arzo 99.

2. Chickpea ( Cicer arietinum ): Chickpeas is an important pulse crop in Afghanistan. It is consumed both as cooked and roasted. Its production is mainly in cooler areas of the country. The project has tested germplasm of chickpea from ICARDA and has selected lines that are high yielding and stress tolerant. A brief discussion of the two lines that are released as new varieties follows:

1. FLIP 93-58C : The pedigree is X90TH249/( ILC5342x FlIP $84-78 \mathrm{C}$ ) x ILC 1272. The origin is ICARDA/ ICISAT. It was included in Chickpea international yield trial spring in 1998 and planted in Kunduz, Takhar and Herat provinces and during 1999 it was tested in 1999 ACYT ( advance chickpea yield trial in Takhar and Balkh provinces. The number of days to flowering is 64 and to maturity it takes 103 days. The plant height is $55 \mathrm{~cm}$ and the plant type is semi erect. The weight of 100 grain is 31 grams. The agronomy rating is very good and there is no lodging. This line produced in two years $12 \%$ more yield than the local line. The name Sehat-99 has been assigned to this lines.

2. FLIP 93-53C: It was tested in 99ACYT for spring planting in Takhar and Balkh provinces. The average number of days to flowering and maturity is 71 and 103 respectively. The plant height is $41 \mathrm{~cm}$ and the growth habit is erect. The weight of 100 seed is 32 grams and the seed quality is desirable to the farmers. It has produced $15 \%$ more yield than the local. It was selected in Takhar province for multiplication. The growers liked its seed and selected. This line was distributed to the farmers of Takhar, Kunduz Badakhshan for further multiplication and the name Madad-99 has been assigned to this line. 


\section{Project Staff}

The following is the staff who has worked very hard in the crop improvement project AFG/94/A02 (UNO/AFG/001/DPS) that was funded by SIDA from 1996 to 1999.

1. Mr. Abdul Ahad Ahad, Farm Foreman. Takhar, Afghanistan.*

2. Mr. Abdul Rahman Manan, NPPP. Peshawar, Pakistan.

3. Mr. Abdul Wahid, Farm Technician, Mazar-i-Sharif, Afghanistan.

4. Mr. Ahmad.Zia Aria, NPPP, Herat, Afghanistan.

5. Mr. Asadullah Habibi, Farm Foreman, Kandahar, Afghanistan.

6. Mr. Gul Aqa, store keeper, Takhar, Afghanistan.*

7. Mr. Hafizullah shinwari, Administration Assistant, Nangarhar, Afghanistan.

8. Mr. Hedayatullah. Fam Technician, Ghazni, Afghanistan.

9. Mr. Khalilurahman, Farm Foreman, Herat, Afghanistan.

10. Mr. Mohammad Ayoub, NPPP, Ghazni, Afghanistan.

11. Mr. Mohammad Essa, Farm Foreman, Nangarhar, Afghanistan.

12. Mr. Mohammad Sarwar, Farm Foreman, Mazar-i-Sharif, Afghanistan.

13. Mr. Mohebullah Numan, store keeper, Nangarhar, Afghanistan.

14. Mr. Noorulhaq Hakimi, Farm Technician, Nangarhar, Afghanistan.

15. Mr. Shah Mohammad Mohaqiq, NPPP, Taloqan, Afghanistan.

16. Mr. Shah Sayed Aalimi, NPPP, Mazar-i-Sharif, Afghanistan.

17. Mr. Shamsuddin Siddiqi, NPPP, Kandahar, Afghanistan.*

18. Mr. Sultan Hamid, Farm foreman, Ghazni, Afghanistan.

$*=$ Left project in 1999. 

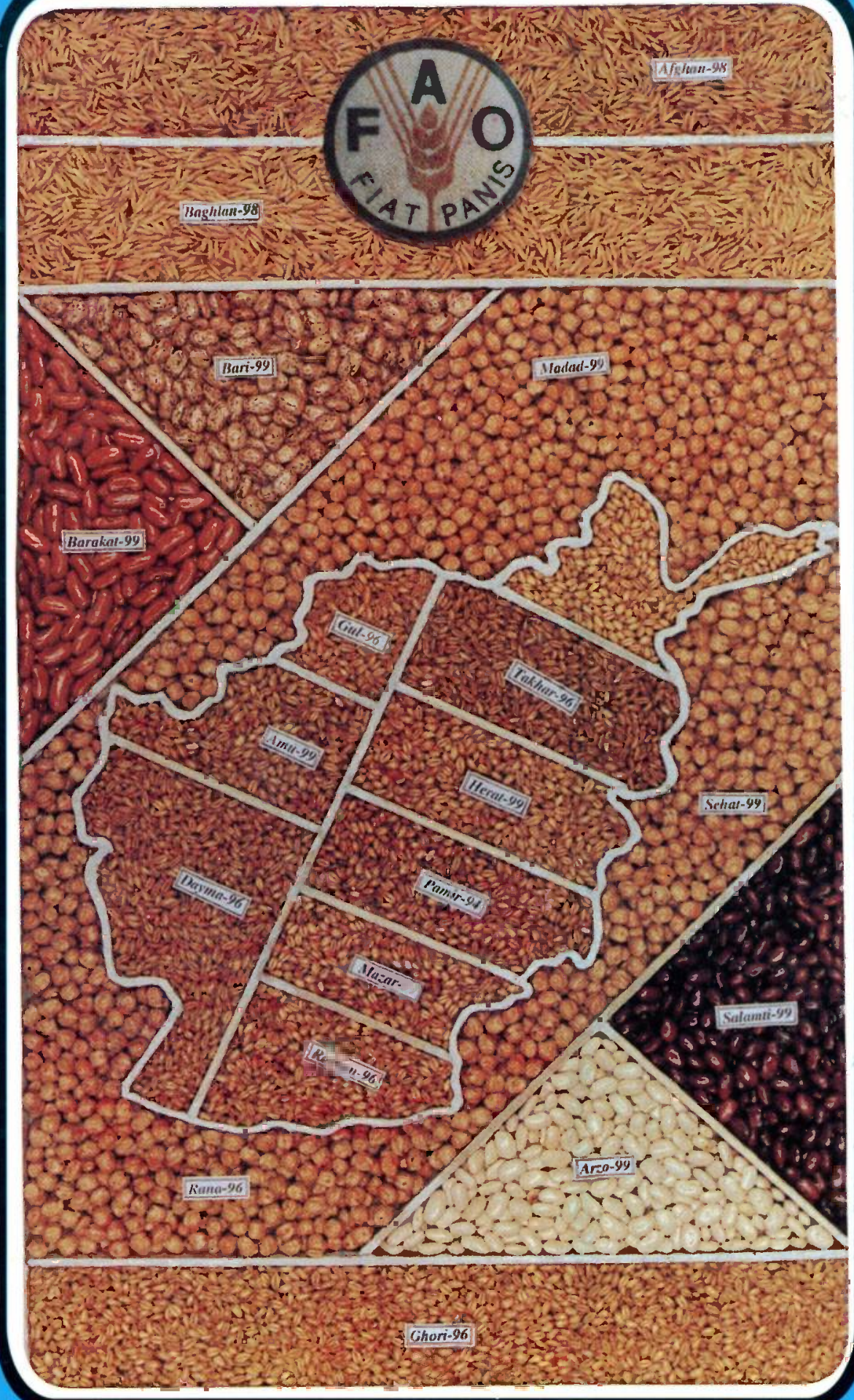

Achievements of SIDA/UNDP Funded Project AFG/94/A02(UNO/AFG/001/DPS) January 1996 to December 1999 